
Integral Fast Reactor Integral Fast Reactor Integral Fast Reactor Integral Fast Reactor Integral Fast Reactor Integral Fast Reactor

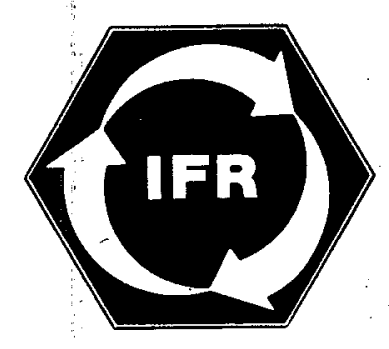

\title{
Inherency Control Strategies
}

Integral Fast Reactor Integral Fast Reactor Integral Fas: Reactor Integral Fast Reactor Integral Fast Reactor Integral Fast Reactor Integral Fast Reactor Integral Fast Reactor Integral Fast Reactor Integral Fast Reactor Integral Fast Reactor Integral Fast Reactor Integral Fast Reactor Integral Fast Reactor Integral Fast Reactor Integral Fast Reactor Integral Fast, Reactor Integral Fast Reactor Integral Fast Reactor

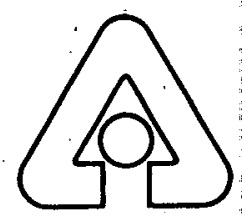

Argonne National Laboratory, Argonne, Illinois 60439 operated by The University of Chicago

for the United States Department of Energy under Contract W-31-109-Eng-38

IFR Technical-Memorandum

Prestis in IFP TM sorios of memoranda frequently are preliminary and stbject to revion. Gonsequently they should

not be queted of referenced.

Any further sistribution by an holder of thi third parties representing foreign interests, for panies, and foreign susidiaries or foreign div be approved by the Associate Deputy Assist tems, Development and Technology, U. S. I foreign party release may require DOE appro tion 10 CFR Part 810 , and/or max be s Atomic Energy Act.

NO ACCESS RESTRICTIONS
This document is not considered OUO-Applied Technology. It was
reviewed for Export Controlled Information and found to be suitable for
unlimited access and reproduction.
This label reflects Applied Technology instructions issued April 13,
2006, by the the Department of Energy Office of Nuclear Energy.
Additional guidance has also been provided by DOE in 2016 and 2018
memos, as well as from NNSA.
Paul Betten, ANL

Pelegsad fer antementh fn ATF. Distributing to

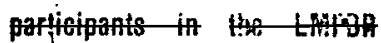
frogram. Others request iroth RSAT, BOE. 
Argonne National Laboratory, with facilities in the states of Illinois and Idaho, is owned by the United States government, and operated by The University of Chicago under the provisions of a contract with the Department of Energy.

\section{DISCLAIMER}

This report was prepared as an account of work sponsored by an agency of the United States Government. Neither the United States Government nor any agency thereof, nor any of their employees, makes any warranty, express or implied, or assumes any legal liability or responsibility for the accuracy, completeness, or usefulness of any information, apparatus, product, or process disclosed, or represents that its use would not infringe privately owned rights. Reference herein to any specific commercial product, process, or service by trade name, trademark, manufacturer, or otherwise, does not necessarily constitute or imply its endorsement, recommendation, or favoring by the United States Government or any agency thereof. The views and opinions of authors expressed herein do not necessarily state or reflect those of the United States Government or any agency thereof. 
INHERENCY CONTROL STRATEGIES

by

T. Y. C. Wei

Reactor Analysis and Safety Division

Argonne National Laboratory

9700 South Cass Avenue

Argonne, Illino is 60439

IFR TECHNICAL MEMORANDUM NO. 88

Results reported in the IFR-TM series of memoranda frequently are preliminary and subjeet to revision. Consequent iy they should not be quoted or referenced.

\section{APPLIED TECHNOLOGY}

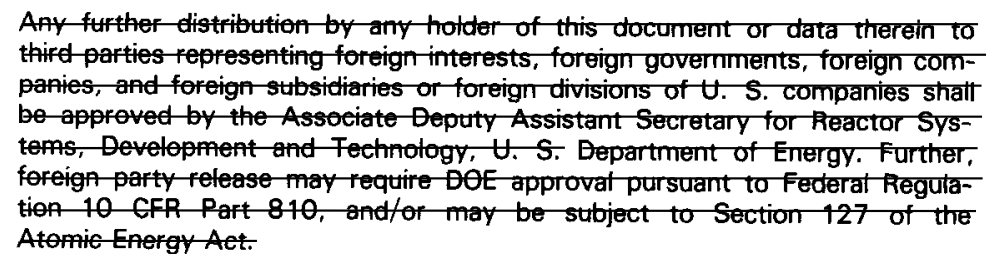




\section{DISCLAIMER}

Portions of this document may be illegible in electronic image products. Images are produced from the best available original document. 


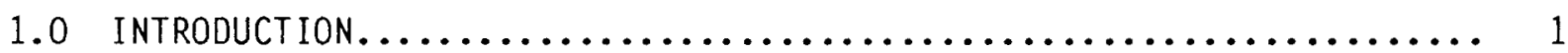

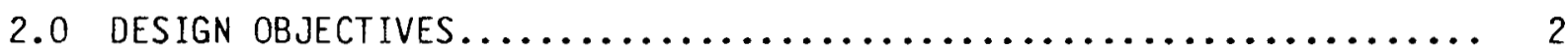

3.0 PLANT DUTY CYCLE............................... 5

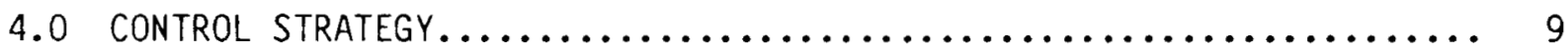

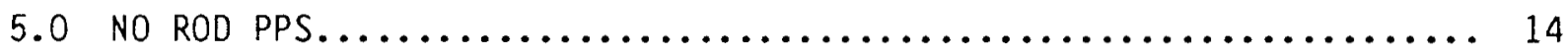

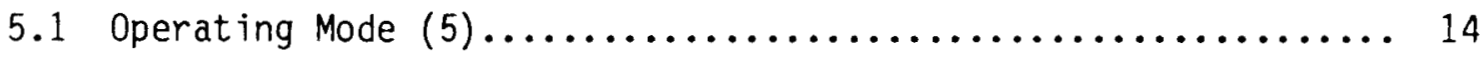

5.1 .1 Reactivity Events......................... 14

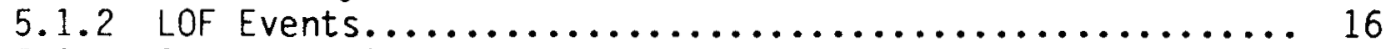

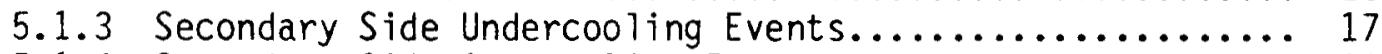

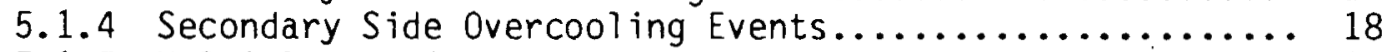

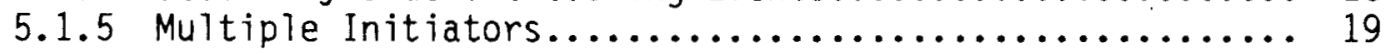

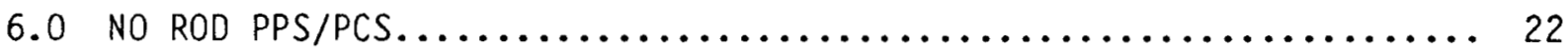

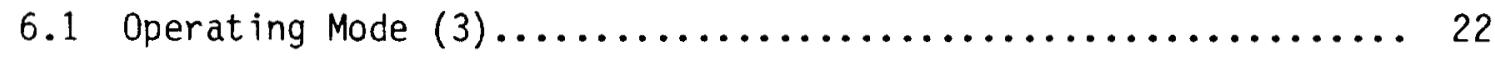

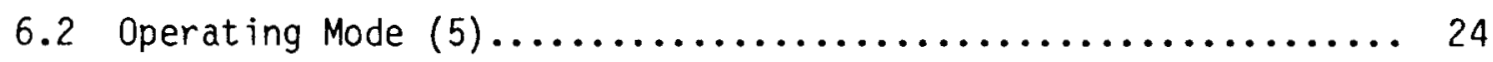

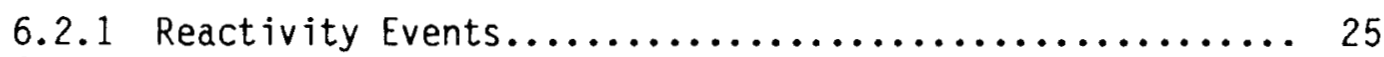

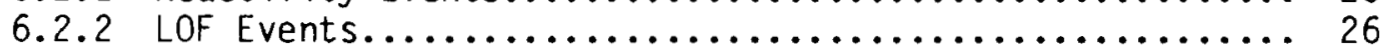

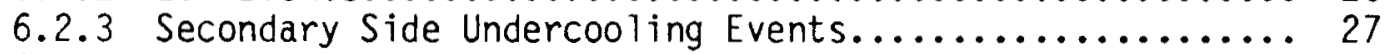

6.2 .4 Secondary Side Overcooling Events................. 29

6.2 .5 Multiple Initiators........................ 30

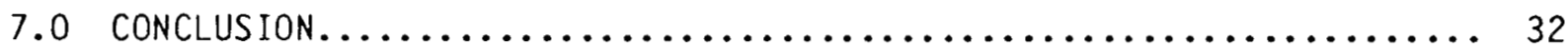

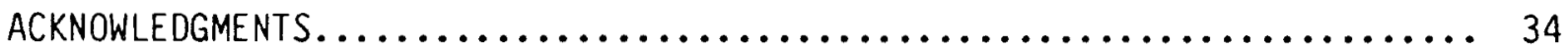

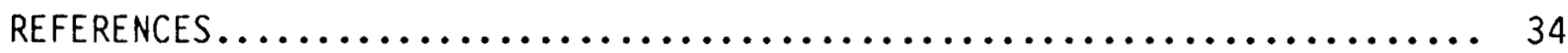




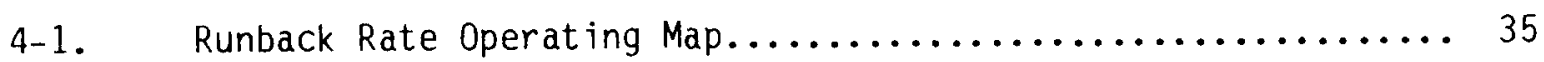

4-2. No Rod PPS. Runback with Pumps Trip - Reactor Core

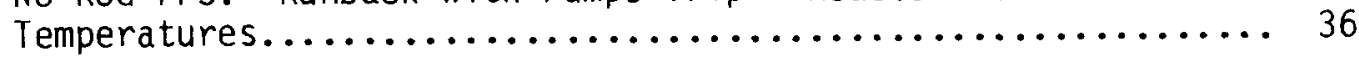

5.1-1. No Rod PPS. 2\$/sec Control Rod Withdrawal - Reactor Power... 37

5.1-2. No Rod PPS. 2\$/sec Control Rod Withdrawal - Channe 1 Peak Temperatures............................ 37

5.1-3. No Rod PPS. 2\$/sec Control Rod Withdrawal - Reactor Core Temperatures................................ 38

5.1-4. No Rod PPS. 2\$/sec Control Rod Withdrawa 1 - IHX Primary Side Temperatures............................ 38

5.1-5. No Rod PPS. 20 /sec Control Rod Withdrawal - Channel 1 Peak Temperatures.............................. 39

5.1-6. No Rod PPS. 20\$/sec Control Rod Withdrawal - Reactor Core Temperatures............................... 39

5.1-7. No Rod PPS. 20\$/sec Control Rod Withdrawal - IHX Primary Side Temperatures............................ 40

5.1-8. No Rod PPS. 20\$/sec Control Rod Withdrawal/No Sensor Reactor Power............................... 40

5.1-9. No Rod PPS. 20\$/sec Control Rod Withdrawa1/No Sensor Channel 1 Peak Temperatures....................... 41

5.1-10. No Rod PPS. 20\$/sec Control Rod Withdrawal/No Sensor Reactor Core Temperatures....................... 41

5.1-11. No Rod PPS. 20 $\$ / \mathrm{sec}$ Control Rod Withdrawal/No Sensor IHX Primary Side Temperatures..................... 42

5.1-12. No Rod PPS. 20 $\$ / \mathrm{sec}$ Control Rod Withdrawal/No Sensor SG Sodium Temperatures.......................... 42

5.1-13. No Rod PPS. 20\$/sec Control Rod Withdrawal/No Sensor SG Water Temperatures.......................... 43

5.1-14. No Rod PPS. 1 PHTS Pump Trip - Loop Flows............. 43

5.1-15. No Rod PPS. 1 PHTS Pump Trip - Channel Peak Temperatures.... 44

5.1-16. No Rod PPS. 1 PHTS Pump Trip - Reactor Core Temperatures.... 44 
LIST OF FIGURES (Contd.)

Page

5.1-17. No Rod PPS. 1 PHTS Pump Trip - IHX 1 Intermediate Side

Temperatures..................................... 45

5.1-18. No Rod PPS. 2 PHTS Pump Trip - Channel 1 Peak Temperatures... 45

5.1-19. No Rod PPS. 2 PHTS Pump Trip - Reactor Core Temperatures..... 46

5.1-20. No Rod PPS. 2 PHTS Pump Trip - IHX Intermediate Side Temperatures...................................... 46

5.1-21. No Rod PPS. 2 PHTS Pump Trip - SG Sodium Temperatures....... 47

5.1-22. No Rod PPS. 2 PHTS Pump Trip - SG Water Temperatures........ 47

5.1-23. No Rod PPS. 1 Seized PHTS Pump - Loop Flows.............. 48

5.1-24. No Rod PPS. 1 Seized PHTS Pump - Channel 1 Peak

Temperatures.................................... 48

5.1-25. No Rod PPS. 1 Seized PHTS Pump - Reactor Core Temperatures... 49

5.1-26. No Rod PPS. 1 Seized PHTS Pump - IHX1 Intermediate Side

Temperatures...................................... 49

5.1-27. No Rod PPS. 1 Seized PHTS Pump - SG Sodium Temperatures..... 50

5.1-28. No Rod PPS. 1 IHTS Pump Trip - Reactor Power.............. 50

5.1-29. No Rod PPS. 1 IHTS Pump Trip - Loop Flows.............. 51

5.1-30. No Rod PPS. 1 IHTS Pump Trip - Channe1 1 Peak Temperatures... 51

5.1-31. No Rod PPS. 1 IHTS Pump Trip - Reactor Core Temperatures.... 52

5.1-32. No Rod PPS. 1 IHTS Pump Trip - IHX1 Primary Side Temperatures..................................... 52

5.1-33. No Rod PPS. 1 IHTS Pump Trip - SG Sodium Temperatures....... 53

5.1-34. No Rod PPS. 1 IHTS Pump Trip - SG Water Temperatures....... 53

5.1-35. No Rod PPS. 2 SG FW Valve Closure - Reactor Power.......... 54

5.1-36. No Rod PPS. 2 SG FW Valve Closure - Loop Flows............. 54

5.1-37. No Rod PPS. 2 SG FW Valve Closure - Channel 1 Peak

Temperatures..................................... 55 
LIST OF FIGURES (Contd.)

Page

5.1-38. No Rod PPS. 2 SG FW Valve Closure - Reactor Core

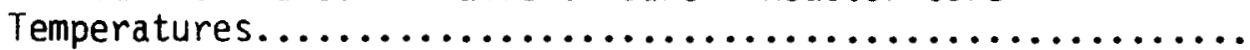

5.1-39. No Rod PPS. 2 SG FW Valve Closure - IHX Intermediate Side Temperatures................................. 56

5.1-40. No Rod PPS. 2 SG FW Valve Closure - SG Sodium Temperatures... 56

5.1-41. No Rod PPS. 2 SG FW Valve Closure - SG Water Temperatures.... 57

5.1-42. No Rod PPS. 2 SG MFW Overfeed/No Sensor - Reactor Power..... 57

5.1-43. No Rod PPS. 2 SG MFW Overfeed/No Sensor - Channel 1 Peak

Temperatures.................................. 58

5.1-44. No Rod PPS. 2 SG MFW Overfeed/No Sensor - Reactor Core Temperatures................................. 58

5.1-45. No Rod PPS. 2 SG MFW Overfeed/No Sensor - IHX Intermediate Side Temperatures............................... 59

5.1-46. No Rod PPS. 2 SG MFW Overfeed/No Sensor - SG Sodium Temperatures................................. 59

5.1-47. No Rod PPS. 2 SG MFW Overfeed/No Sensor - SG Water Temperatures................................... 60

5.1-48. No Rod PPS. SSE - Reactor Power.................. 60

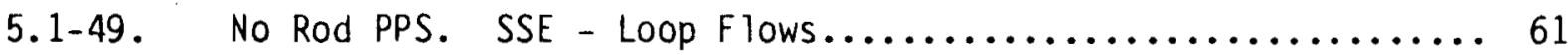

5.1-50. No Rod PPS. SSE - Channe 11 Peak Temperatures............ 61

5.1-51. No Rod PPS. SSE - Reactor Core Temperatures.............. 62

5.1-52. No Rod PPS. SSE - IHX Primary Side Temperatures.......... 62

5.1-53. No Rod PPS. SSE - SG Sodium Temperatures............. 63

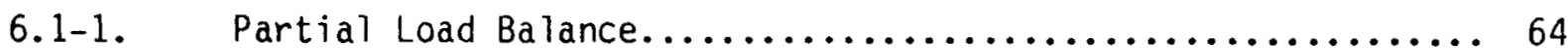

6.1-2. No Rod PPS/PCS. Power Ramp 3\%/min. - Reactor Power........ 65

6.1-3. No Rod PPS/PCS. Power Ramp 3\%/min. - Loop Flows........... 65

6.1-4. No Rod PPS/PCS. Power Ramp 3\%/min. - Channel 1 Peak

Temperatures................................. 66 


\section{LIST OF FIGURES (Contd.)}

$\underline{\text { Page }}$

6.1-5. No Rod PPS/PCS. Power Ramp 3\%/min. - Reactor Core

Temperatures................................. 66

6.1-6. No Rod PPS/PCS. Power Ramp 3\%/min. - SG Water Temperatures... 67

6.1-7. No Rod PPS/PCS. Power Ramp 3\%/min. - SG Water Flows........ 67

6.2-1. No Rod PPS/PCS. 2\$/sec Control Rod Withdrawal - Reactor

Power..................................... 68

6.2-2. No Rod PPS/PCS. 2\$/sec Control Rod Withdrawal - Loop Flows... 68

6.2-3. No Rod PPS/PCS. 2థ/sec Control Rod Withdrawal - Channel 1

Peak Temperatures.............................. 69

6.2-4. No Rod PPS/PCS. 2\$/sec Control Rod Withdrawal - Reactor Core Temperatures............................ 69

6.2-5. No Rod PPS/PCS. 20\$/sec Control Rod Withdrawal/No Sensor -

SG Water Temperatures........................ 70

6.2-6. No Rod PPS/PCS. 20\$/sec Control Rod Withdrawal/No Sensor -

Reactor Power............................... 70

6.2-7. No Rod PPS/PCS. 20\$/sec Control Rod Withdrawal/No Sensor Loop Flows................................... 71

6.2-8. No Rod PPS/PCS. 20\$/sec Control Rod Withdrawal/No Sensor -

Channel 1 Peak Temperatures........................ 71

6.2-9. No Rod PPS/PCS. 20\$/sec Control Rod Withdrawal/No Sensor Reactor Core Temperatures........................ 72

6.2-10. No Rod PPS/PCS. 1 PHTS Pump Trip - Loop Flows........... 72

6.2-11. No Rod PPS/PCS. 1 PHTS Pump Trip - Channel 1 Peak

Temperatures................................ 73

6.2-12. No Rod PPS/PCS. 1 PHTS Pump Trip - Reactor Core

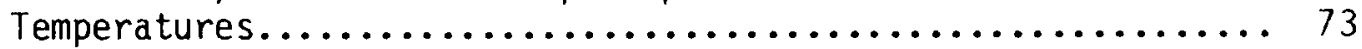

6.2-13. No Rod PPS/PCS. 2 PHTS Pump Trip - Channel 1 Peak

Temperatures................................. 74

6.2-14. No Rod PPS/PCS. 2 PHTS Pump Trip - Reactor Core

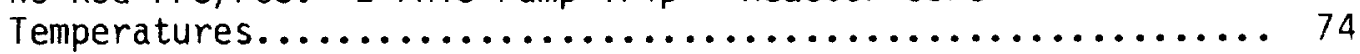

6.2-15. No Rod PPS/PCS. 2 IHTS Pump Trip - Reactor Power......... 75 
LIST OF FIGURES (Contd.)

$\underline{\text { Page }}$

6.2-16. No Rod PPS/PCS. 2 IHTS Pump Trip - Loop Flows........... 75

6.2-17. No Rod PPS/PCS. 2 IHTS Pump Trip - Channel 1 Peak

Temperatures................................ 76

6.2-18. No Rod PPS/PCS. 2 IHTS Pump Trip - Reactor Core

Temperatures............................... 76

6.2-19. No Rod PPS/PCS. 2 IHTS Pump Trip - IHX Primary Side

Temperatures................................ 77

6.2-20. No Rod PPS/PCS. 2 IHTS Pump Trip - SG Sodium Temperatures.... 77

6.2-21. No Rod PPS/PCS. 2 IHTS Pump Trip - SG Water Temperatures.... 78

6.2-22. No Rod PPS/PCS. 2 SG FW Valve Closure - Reactor Power....... 78

6.2-23. No Rod PPS/PCS. 2 SG FW Valve Closure - Loop Flows......... 79

6.2-24. No Rod PPS/PCS. 2 SG FW Valve Closure - Channel 1 Peak

Temperatures................................... 79

6.2-25. No Rod PPS/PCS. 2 SG FW Valve Closure - Reactor Core

Temperatures................................. 80

6.2-26. No Rod PPS/PCS. 2 SG FW Valve Closure - IHX Intermediate

Side Temperatures.............................. 80

6.2-27. No Rod PPS/PCS. 2 SG FW Valve Closure - SG Sodium

Temperatures................................ 81

6.2-28. No Rod PPS/PCS. 2 SG FW Valve Closure - SG Water

Temperatures................................ 81

6.2-29. No Rod PPS/PCS. 2 SG MFW Overfeed/No Sensor - Reactor

Power...................................... 82

6.2-30. No Rod PPS/PCS. 2 SG MFW Overfeed/No Sensor - Channel 1

Peak Temperatures.............................. 82

6.2-31. No Rod PPS/PCS. 2 SG MFW Overfeed/No Sensor - Reactor

Core Temperatures............................. 83

6.2-32. No Rod PPS/PCS. 2 SG MFW Overfeed/No Sensor - IHX Inter-

mediate Side Temperatures........................ 83

6.2-33. No Rod PPS/PCS. 2 SG MFW Overfeed/No Sensor - SG Sodium

Temperatures................................. 84 


\section{LIST OF FIGURES (Contd.)}

Page

6.2-34. No Rod PPS/PCS. 2 SG MFW Overfeed/No Sensor - SG Water

Temperatures................................ 84

6.2-35. No Rod PPS/PCS. SSE - Reactor Power............... 85

6.2-36. No Rod PPS/PCS. SSE - Loop Flows $\ldots \ldots \ldots \ldots \ldots \ldots \ldots \ldots \ldots$

6.2-37. No Rod PPS/PCS. SSE - Channel 1 Peak Temperatures......... 86

6.2-38. No Rod PPS/PCS. SSE - Reactor Core Temperatures.......... 86

6.2-39. No Rod PPS/PCS. SSE - IHX Primary Side Temperatures....... 87

6.2-40. No Rod PPS/PCS. SSE - SG Sodium Temperatures............ 87 


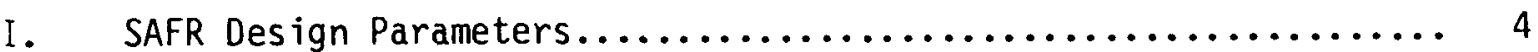

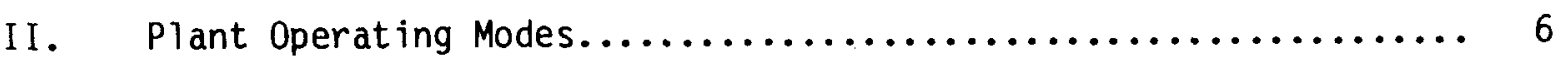

III. Plant Duty Cycle............................... 6

IV. Design Criteria................................. 8

v. Sensor Channels................................... 11

VI. PCS Process Controllers................................. 11

VII. Reactivity Coefficients......................... 23 


\section{ABSTRACT}

This study makes an examination of exploiting the IFR characteristics for the operational/anticipated transients in terms of simplifications in the plant control system/plant protection system design. Results obtained with the SASSYS plant system code are presented for a number of alternative control strategies. These control strategies are essentially based upon the minimization of active control rod motion relying instead on pump swings and balance of plant maneuvers for reactivity adjustments. 

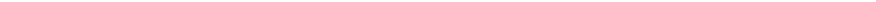


\subsection{INTRODUCTION}

The advantages of the IFR innovative reactor concept [1] utilizing sodium cooling (improved heat transfer characteristics), metal fuel (improved reactivity feedback response) and a pool configuration (improved inherent safety capability) has been amply demonstrated for the beyond design basis transients (BDBAs). It then becomes of interest to determine whether or not improvements oriented towards beyond design basis transients, such as the Anticipated Transient Without Scram (ATWS) 12,3], can also lead to improvements in design margins and/or event frequencies for the operational transients (or DBAs), encountered during normal operating circumstances.

Inherent operability, the scheme proposed by Planchon and Sackett [4], where reactor power control is effected through the usage of primary pumps and BOP (balance of plant) swings rather than through the active motion of control rods, is a proposal to utilize the enhanced inherent feedback response of the IFR to improve the operating characteristics of LMRs. The scheme has associated with it potential advantages in the areas of plant control and design simplification. Design simplifications would ensue through the reduction in the number of control rod drive mechanisms which would clear the deck and possibly the upper internal structure. This would lead not only to economic benefits but could also reduce the number of transient initiators. Similarly enhancement in plant operation could result from implementation of a simplified control scheme which utilized inherency effects for control purposes and reduced the possibility of specific plant control system failures which would generaliy negate or actively defeat inherency feedbacks. Such a development could clear the path for the next logical step, complete automation. Even if ultimately it is decided not to implement these specific control schemes, variations such as replacing Plant Protection System (PPS) scram with a rapid plant runback controlled by the Plant Control System (PCS) could be feasible. There certainly are other alternatives possible based on combinations of these schemes. Current intentions are to analytically explore possibilities of applying such schemes to modular sized LMR plants with the aid of the SASSYS system code and then to test viable alternatives in the EBR-2 plant under the auspices of the ISOT program.

For the purposes of this study the modular sized SAFR plant is selected as the reference plant. 


\subsection{DESIGN OBJECTIVES}

The unique features of the IFR concept consists of two salient characteristics:

(A) Pool configuration: As opposed to loop plants the IFR concept would immerse the core and the components of the PHTS in a large sodium pool contained by a reactor vessel. This pool configuration manifests itself during upset transient conditions through its large thermal inertia and a large time constant. While it is clear that this would render the thermal/hydraulic response during a transient slower, it is not evident whether or not this is undesirable from a control strategy point of view. Put in other terms, it is not clear how this "sluggishness" can be best utilized to manage transients. It is perhaps clearer that it should not affect steady state operating conditions as it is a dynamic trait.

(B) Metal fuel: As is well documented, the use of metal fuel in the reactor core leads to feedback coefficients very different from those derived by the use of oxide fuel in the core. The power coefficient a-1a Sevy [5] is significantly lower for metal fuel. The two other coefficients necessary for the reactivity balance, the flow coefficient and the core inlet temperature coefficient [6] are roughly comparable for the two fuel types. This implies that much smaller changes in reactivity are sufficient for the same change in power in the metal system. This is a characteristic which could influence both steady state operating conditions and the dynamic response of the plant to upset transient conditions. It is also clear that this trait could be exploited in the choice of reactivity control.

What this report documents is an effort to examine what operating or control strategy could best make use of these two features of the IFR concept as applied to modular LMR plants under both upset and steady state conditions. We chose to actively focus on trait (B) for reactivity control and regard trait $(A)$ as a tag along.

Reactor plants consist of many components and systems selected and configured to reflect a number of constraints such as economics, safety, etc. The ground rule for this study is that with the exception of the plant control system (PCS) and the plant protection system (PPS) no other plant component or system will be modified or reconfigured to optimize the control strategy. For 
example, parameters such as the primary system adiabatic heat up rate, which would be affected by the pool size and power level, will be accepted as given by the satisfaction of the other design constraints. There is a possibility that the choice of a steam cycle, whether superheated or saturated, and the concomittant choice of a steam generator (SG), whether once through or recirculation, may affect the strategy. It is a question of degrees of control freedom and will be answered by a sequel report. This report concentrates on the strategy for the choice of the superheated steam cycle and the once through steam generator (OTSG) for the waterside of the balance of plant $(B O P)$. Even with these restrictions on the choice of systems and components there exists potential simplifications in the PCS/PPS algorithms and hardware which could lead to reductions in spurious scrams and event frequencies. Reductions in scram demand given an initiator would increase plant availability and reduce the rate of component cycling. Furthermore, there is the possibility of reducing the requirements for control rod action, thereby raising the possibility of decreasing the number of control rod drives and clearing the deck which also has economic implications. It should therefore be understood that the remainder of this report is oriented towards making major design changes only in the PPS/PCS to accommodate an optimum control strategy. The one exception is the choice of core duct/load pad material which will be discussed later in Section 6.0 .

Table I summarizes a number of the SAFR design parameters important for the transient response of the plant. It essentially consists of the $100 \% 10$ ad plant thermal/hydraulic conditions and physical constants which affect the thermal/hydraulic behavior of the system. Reactivity coefficients are affected by the choice of the core materials listed in the table. 316 SS has a larger coefficient of thermal expansion than HT9 so replacement of HT9 load pads with 316 load pads would appear to have the potential to enhance the radial expansion reactivity coefficients. The core outlet temperature, in conjunction with the limits compiled in Table IV in Section 3.0, determine the vessel structural temperature margins. The core inlet temperature determines the margin to sodium impurities precipitation. The IHX and SG temperatures shown in Table I are factors which influence the limits on temperature rates at the IHX/SG nozzles. The choice of the system pressure drops listed in Table I affect the various loop coastdown times upon pump trip. The various loop cycle times influence the degree of coupling between the core and the BOP 
in the removal of heat produced. The various pool capacities affect the various loop time constants. With the exception of the load pad material, as will be discussed later, none of these design parameters have been optimized for the purposes of this study.

Table I. SAFR Design Parameters

\begin{tabular}{|c|c|}
\hline $\begin{array}{l}\text { Core Power MWt } \\
\text { Core Inlet Temperature, }{ }^{\circ} \mathrm{F} \\
\text { Core Outlet Temperature, }{ }^{\circ} \mathrm{F}\end{array}$ & $\begin{array}{l}900 \\
675 \\
950\end{array}$ \\
\hline $\begin{array}{l}\text { IHX Intermediate Inlet Temperature, }{ }^{\circ} \mathrm{F} \\
\text { IHX Intermediate Out let Temperature, }{ }^{\circ} \mathrm{F} \\
\text { SG Steam Outlet Nozzle Temperature, }{ }^{\circ} \mathrm{F} \\
\text { SG Feedwater Temperature, }{ }^{\circ} \mathrm{F}\end{array}$ & $\begin{array}{l}620 \\
900 \\
855 \\
495\end{array}$ \\
\hline $\begin{array}{l}{ }^{+} \text {Primary Pump } \Delta p, p s i \\
+ \text { Intermediate Pump } \Delta p \text {, psi } \\
{ }^{+} \text {SG } \Delta p, p s i \\
\text { Steam Cycle/Steam Generator }\end{array}$ & $\begin{array}{l}70 \\
50 \\
100 \\
\text { Benson/OTSG }\end{array}$ \\
\hline 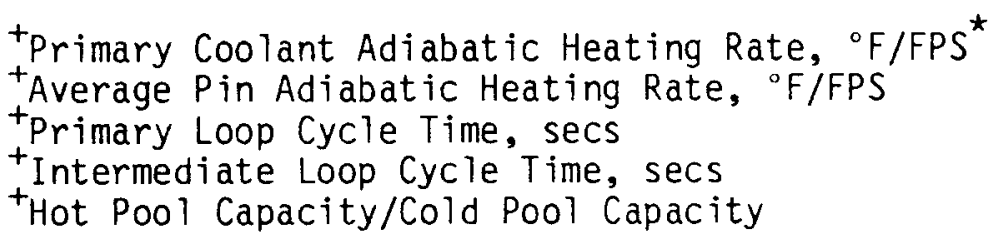 & $\begin{array}{r}1.5 \\
900 \\
200 \\
40 \\
1: 4\end{array}$ \\
\hline $\begin{array}{l}\text { Fuel } \\
\text { Clad } \\
\text { Duct/Load Pads } \\
\text { Grid Plate }\end{array}$ & $\begin{array}{l}\text { Metal } \\
\text { HT9 } \\
\text { HT9 } \\
316 \text { SS }\end{array}$ \\
\hline
\end{tabular}

${ }^{+}$Approximate value.

${ }^{\star}$ FPS $=$ full power seconds. 


\subsection{PLANT DUTY CYCLE}

Reactor plants are subject to several different operating modes. Table II comprehensively lists the possible operating modes. For the purposes of this study, attention will be restricted to modes (3) and (5). It is realized that modes (1) and (2), startup and shutdown, may dictate more stringent requirements for certain control strategies than modes (3) and (5), but there is always the alternative of mixed approaches. Mode (5) forms the category of transients which are commonly analyzed for compliance with NRC licensing criterion and are referred to as FSAR Chapter 15 events. In the terms of the plant duty cycle, they are the service Conditions $B, C$ and $D$ events, and in terms of event frequencies are mostly the NUREG-800 (SRP) 17] anticipated operational occurrences class of transients which approximately corresponds to the ANSI 18.2 (1973) standard Condition II (incidents of moderate frequency) and. Condition III (infrequent incidents) transients. Some Condition IV limiting faults transients are considered. All these events can be categorized by event initiator type which in the standard FSAR format is as shown in Table III. It should be noted that with the exception of the "Multiple Initiators" category, these are a 11 single initiator event categories. The categorization is by broadly similar physical response. As can be imagined there are several events which fall into these categories. For the purposes of this study, a mild transient and a severe transient for each of these categories will be selected for analyzing the effects of different control strategies. The selection process, as can be seen from Table III, also encompasses the frequency range from Class $B$ (anticipated) to Class D (limiting). In this manner, the entire spectrum of probable initiators and plant responses can be bracketed. Table III shows the list of selected transients and includes operating mode (3). It is acknowledged that this is a preliminary envelope. Further work may be necessary depending upon the acceptability of the conclusions drawn in this report.

The transients selected for the reactivity category can be variously interpreted as the withdrawal of a maximum worth rod at either nominal or breakaway speed. The selection of the two PHTS pump trip event in conjunction with the one PHTS pump seizure event as the "severe" transient in the loss of coolant flow category is more a matter of bounding the core response of the LOEP event. The two events have similar core response as the trip of the PHTS 
Table II. Plant Operating Modes

1) Startup

2) Shutdown

3) Steady State/Load Adjustment

a) $\pm 5 \%$ step

b) $\pm 3 \% / \mathrm{min}$ ramp

4) (N-1) Loop Operation

5) Scram Transients/Duty Cycle Events

6) ATWS and Severe Accidents

Table III. Plant Duty Cycle

\begin{tabular}{|c|c|c|c|}
\hline $\begin{array}{l}\text { Operating } \\
\text { Mode }\end{array}$ & $\begin{array}{c}\text { FSAR } \\
\text { Chapter } 15 \\
\text { Category }\end{array}$ & $\begin{array}{l}\text { Service } \\
\text { Condition }\end{array}$ & Transient \\
\hline \multirow[t]{2}{*}{3} & & A & $10 \%$ load step setpoint change \\
\hline & & A & $\begin{array}{l}3 \% / \mathrm{min} \text { load change from } 100 \% \text { to } \\
40 \% \text { power }\end{array}$ \\
\hline \multirow[t]{10}{*}{5} & $\begin{array}{l}\text { Reactivity } \\
\text { Insertion }\end{array}$ & B & $\begin{array}{l}\text { Uncontrolled control rod with- } \\
\text { drawal } 2 \phi / \mathrm{sec}\end{array}$ \\
\hline & & ? & $\begin{array}{l}\text { Uncontrol led control rod with- } \\
\text { drawal } 20 \$ / \mathrm{sec}\end{array}$ \\
\hline & Loss of Flow (LOF) & B & 1 PHTS pump trip \\
\hline & & C & 1 PHTS pump seizure \\
\hline & & $C / D$ & 2 PHTS pump trip \\
\hline & Secondary Side & B & 1 IHTS pump trip \\
\hline & & $B / C$ & $\begin{array}{l}2 \text { steam generator } \mathrm{FW} \text { valve } \\
\text { closure }\end{array}$ \\
\hline & $\begin{array}{l}\text { Secondary Side } \\
\text { Overcooling }\end{array}$ & $B / C$ & $\begin{array}{l}2 \text { steam generator } \mathrm{FW} \text { valve } \\
\text { overfeed }\end{array}$ \\
\hline & ${ }^{\star}$ Multiple Initiators & B & $\begin{array}{l}\text { LOSS of Offsite Electric Power } \\
\text { (LOEP) }\end{array}$ \\
\hline & & D & Safe Shutdown Earthquake (SSE) \\
\hline
\end{tabular}

*While not totally consistent with the FSAR format, this category represents combination events. 
(Primary Heat Transport System) Pumps in the LOEP event dominates the transient. The LOEP event will therefore not be explicitly simulated. In the case of the secondary side induced undercooling events, the one IHTS (Intermediate Heat Transport System) pump trip event should be a milder transient than the corresponding seized pump event and was therefore selected as the "mild" event in this category. The steam generator FW (Feedwater) valve closure event allows the behavior of the waterside to be examined as the driving function.

While, in general, event initiators which were not control system malfunction driven, were selected in order to avoid the question of control system parameters, it proved difficult to do so in the case of the secondary side induced overcooling category. The choice of the once through steam generator (OTSG) with the superheated cycle strictly limits the severity of the driving cooldown which can be induced by "breaks" on the waterside. This is due to the fact that the OTSG has a small liquid inventory and therefore limited cooldown potential in the event of stuck open valves or leaks. Steam line breaks very quickly ( couple seconds) become overheating events instead of overcooling events. The enveloping cooldown event selected, as included in Table II, is the MFW (main feedwater) overfeed event. This is also an anticipated event which makes it important from a frequency perspective. Finally, it should be noted that the SSE is a combination event which was specifically chosen as an example of a service class $D$ event with multiple initiators.

An added complication to the determination of the optimum control strategy is the fact that the four classes of transient service conditions $A-D$ have associated with them the spectrum of frequencies ranging from anticipated ( $1 /$ reactor year) to limiting (much less than $1 /$ reactor year). This leads to a range of acceptable design consequences with the mild consequences corresponding to the most frequent class, and the more severe consequences associated with the least expected class. Table IV shows typical frequency/ consequence event acceptability criteria. These are the criteria which will be used in this study to establish the optimum control strategy. Essentially, the acceptability criteria are criteria for core integrity and vessel structure integrity. In the context of the SASSYS plant transient calculations which are presented in Sections 5.0 and 6.0, the vessel structure criteria should be interpreted as determiny the maximum temperature increase permitted 
Table IV. Design Criteria

\begin{tabular}{|c|c|c|c|}
\hline $\begin{array}{l}\text { Frequency } \\
\text { Group }\end{array}$ & $\begin{array}{l}\text { Moderate } \\
\text { Frequency } \\
\text { Events }\end{array}$ & $\begin{array}{l}\text { Infrequent } \\
\text { Events }\end{array}$ & $\begin{array}{c}\text { Limiting Fault } \\
\text { Events }\end{array}$ \\
\hline $\begin{array}{l}\text { Primary } \\
\text { Structural } \\
\text { Components }\end{array}$ & $\begin{array}{l}\text { ASME Leve } \mathrm{B} \\
\left(\sim 1050^{\circ} \mathrm{F}\right)\end{array}$ & $\begin{array}{l}\text { ASME Leve] C } \\
\left(\sim 1250^{\circ} \mathrm{F}\right)\end{array}$ & $\begin{array}{l}\text { ASME Leve } 1 \text { D } \\
\frac{\left(\sim 1450^{\circ} \mathrm{F}\right)}{\uparrow}\end{array}$ \\
\hline Coolant & $\begin{array}{l}\text { No Boiling } \\
\left(1650^{\circ} \mathrm{F}\right)\end{array}$ & $\begin{array}{l}\text { No Boiling } \\
\left(1650^{\circ} \mathrm{F}\right)\end{array}$ & $\begin{array}{l}\text { Mainta in Coolable } \\
\text { Geometry }\end{array}$ \\
\hline Clad & $\begin{array}{l}1325^{\circ} \mathrm{F}^{\star} \\
\quad \text { (No Clad Damage) }\end{array}$ & $1600^{\circ} \mathrm{F}$ & \\
\hline Fuel & $\begin{array}{l}\text { No Fue } 1 \text { Melting }{ }^{+} \\
\left(\sim 2200^{\circ} \mathrm{F}\right)\end{array}$ & $\begin{array}{l}\text { No Fue } 1 \text { Melting } \\
\left(\sim 2200^{\circ} \mathrm{F}\right)\end{array}$ & $\begin{array}{l}\text { Offsite Dose Within } \\
\text { 10CFR100 } \\
+\end{array}$ \\
\hline
\end{tabular}

* No more than 60 second duration.

the consequences and implications of fuel melting in metal fuel are substantially different from those for oxide fuel.

in core outlet flow temperature. An additional criterion which is not listed in Table IV is an acceptability criterion for thermal shocking component nozzles such as those on the steam generator. As none have yet been specified, the discussion in Sections 5.0 and 6.0 on the SASSYS transient simulation results will indicate the thermal transient rate at each component for each transient for future evaluation. 


\subsection{CONTROL STRATEGY}

With this list of bracketing events and the restriction to modifications only in the PPS/PCS, it is proposed to investigate the possibility of making optimum use of traits (A) and (B) of the IFR through alterations in the operating strategy. In general, the principal theme will be one of utilizing trait (B) to minimize the use of active control rod motion under any plant operating circumstances to operate the plant. This theme can be explored in two consecutive steps:

(a) Use the control rods only in the PCS circuit. In other words, there should be no use of the rods in the PPS for scram.

(b) Remove the control rods entirely from the PPS/PCS circuits. Operate the plant only through other components such as the PHTS pumps and BOP swings.

Strategy (a) does not, per se, directly decrease the usage of control rods in the operation of the plant. What it does is attempt to use trait (a) of the IFR to reduce the severe thermal stresses forced upon the plant components during a scram. Indirectly the reduction in scram circuitry would reduce the probability of spurious scrams and thereby indirectly decrease rod usage. It is envisioned that as a possible backup procedure the scram alternative would still be incorporated but with higher setpoints so if the PCS runback is for some reason insufficient to mitigate the initiator fast shutdown would still be available. Strategy (b) is an extrapolation of strategy (a). It would use the PHTS pump flow and the BOP temperature swings to control the reactivity in the core. No active control rod motion would be used for all the duty cycle events ranging from mild load changes to class $D$ seismic events.

Control strategies for operating mode (3) will not be discussed in this general section as there are significant differences between the response of strategy (a) and strategy (b) to design load adjustments. Attention will be focused on operating mode (5).

It should be stressed that this report is a preliminary study. It may well be that the most acceptable strategy is neither strategy (a) nor strategy (b) but a combination of stratecies. There may be a need for a PPS with 
active control rod usage, dictated by licensing constraints, together with modifications of strategies (a) and (b). In which case the results of this study can be utilized to determine the degree to which setpoints can be raised to take advantage of inherency effects. This would decrease the number of spurious scrams and perhaps simplify plant design and operation. Strategies (a) and (b) are being proposed and examined as they clearly constitute the simplest independent alternatives.

Upon receipt of sensor information that would indicate certain abnormal behavior, the plant supervisory control system (SCS) would direct the PCS to runback the plant to "standby" conditions, making active use of the control rods in the PCS circuit. This would replace the conventional response where the PCS would maintain load conditions and the responsibility of securing the plant through shutdown would belong to the PPS. In order to establish this strategy the following details have to be determined:

(i) sensor signals and timing,

(ii) specific runback actions of the individual controllers, including ramp rate. Bringing the plant down requires action not only by the rod controller but also by the other process controllers.

(iii) "Standby" condition.

Table $V$ shows the list of sensor signals and delays for initiation of PCS action. This list is derived from the list of PPS safety channels [8] as these channels would be a logical starting point. The timing information given is a preliminary estimate. It approximately divides the sensor instrumentation into "slow" flow and thermal measurement and "fast" neutronic measurement. The slow PCS response dominates over the sensor delays. The results of this study with the timing information of Table $V$ will allow the determination of the "final" sensor setpoints for the appropriate PCS response.

Table VI lists the individual process controllers which the SCS controls. In the interest of simplification, it is best to have the same response by all the individual process controllers to the entire set of upset conditions. This approach would then obviate the need for a SCS diagnostician which would have to differentiate between different initiators. This should not only simplify the design of the SCS and reduce its probability of failure, 
Table V. Sensor Channels

\begin{tabular}{lcccc}
\hline $\begin{array}{c}\text { Transient } \\
\text { Category }\end{array}$ & $\begin{array}{c}\text { Sensor } \\
\text { Signal }\end{array}$ & Threshold & $\begin{array}{c}\text { Sensor } \\
\text { Delay }\end{array}$ & $\begin{array}{c}\text { SCS Delay } \\
\text { secs }\end{array}$ \\
\hline Reactivity & High Flux & $+15 \%$ & Negligible & 2.0 \\
& Flux-delay & & & 2.0 \\
Loss of Flow Flux & P/F & $\pm 15 \%$ & 0.5 & 2.5 \\
& & & & 3.5 \\
Secondary Side & Flow & $-15 \%$ & 0.5 & 3.58 \\
$\begin{array}{l}\text { Undercooling } \\
\text { Secondary Side }\end{array}$ & & & & 2.5 \\
Overcooling & & & \\
\hline
\end{tabular}

Table VI. PCS Process Controllers

\begin{tabular}{l} 
Process Controller \\
\hline Rod \\
PHTS Pump \\
IHTS Pump \\
FW Valve \\
FW Pump Speed \\
SG Pressure (Turbine Throttle Valve) \\
\hline
\end{tabular}

but would also remove the possibility of an incorrect diagnosis. It is not evident that this common response of the controllers to all the initiators is feasible. In bringing the plant down the PHTS pump runback cannot exceed a maximum rate. If the rate is faster than the natural coastdown rate upon pump trip, then the PHTS pump would essentially be acting as a dynamometer instead of a pump and the braking action would cause more pump stress than a pump trip. In which case, as far as component cycling is concerned, this would be no better than a PPS induced plant scram. Furthermore, a fast PHTS pump runback rate could leave the power runback lagging the flow rundown. Trait (B) of the IFR has several time constants associated with the inherent reactivity feedbacks. These, together with the limited (1 $\$ / \mathrm{sec})$ runback capability of the rod controller, restrict the runback rate of the power. Large discrepancies in $P / F$ could lead to violations of the core and vessel 
structural design acceptability criteria listed in Table IV. However, too slow a PHTS pump runback rate could aggravate thermal stress transients for components such as the IHX nozzles when a IHTS pump trip occurs. Analogously too slow a runback rate for the IHTS pump controller or the FW valve controller could lead to unacceptable IHX or steam generator nozzle thermal shock rates when the corresponding PHTS, IHTS or steam generator loop is disabled for whatever reasons. Figure 4-1 is an attempt at delineating in a qualitative way the constraints on the runback rates for the various controllers. The establishment of quantitative design limits will certainly have to be left to the results of the SASSYS plant simulation calculations performed for the transients listed previously in Table III.

Figure 4.2 is the result of a SASSYS calculation where a 11 PHTS/IHTS pumps are tripped simultaneously with the PCS initiated rod insertion from $100 \%$ operating conditions. It is a duplication of the conventional PPS action upon scram. The figure shows that the class $B$ vessel structural 1 imits are violated in the hot pool. This means that not only strategy (a), but also strategy (b), since the situation with strategy (b) would be aggravated by the absence of control rod action, cannot respond to operating mode (5) transients with a common response of an all pump trip/PCS rod insertion algorithm. A controlled rundown of the entire system would be required. Initially, a few $\% / \mathrm{sec}$ rapid runback of the plant will be investigated as a common response. Further delineation is discussed in Sections 5.0 and 6.0 where transient specific SASSYS plant results are presented.

"Standby" conditions will be initially defined as the flow conditions corresponding to $40 \%$ load for the PHTS, IHTS and the waterside with the neutron power taken down to essentially zero. Decay heat is given by the appropriate previous operating history. While this may not be the final and exact version of "standby" conditions for runback of the plant, it is an operating condition encountered during plant startup. Further delineation of "standby" conditions will be left to the following sections which present the results of transient plant calculations performed with SAFR SASSYS plant mode 1 .

The following sections discuss the results and implications of applying the two strategies to the enveloping events identified previously and listed in Table III. Calculations have been performed with the EOC 1986/1987 metal 
core design SASSYS plant model [9]. For each transient combinations of the following set of figures is presented, total and decay power, channel 1 peak temperatures, the reactor core temperatures, the IHX tube sheet primary and intermediate side temperatures, PHTS and IHTS loop flows, the steam generator sodium side and waterside nozzle temperatures, and the steam generator waterside flows both steam and feedwater. The channel 1 peak temperature figure shows the time behavior of the maximum coolant, clad and fuel temperatures within the peak subassembly which is represented in the SASSYS simulation by core channel 1. These results determine the fuel design margins to fuel melting and clad eutectic formation and delineate the limits of local sodium boiling. Reference should be made to the design acceptability criteria listed previously in Table IV. The reactor core temperatures are presented mainly for establishing vessel structural margins relative to the criteria tabulated in Table IV. The IHX temperature histories and the steam generator temperature histories present the thermal shock histories to the IHX and steam generator inlets and outlets which are defined to be around the tube sheet regions. As of yet no equivalent of Table IV has been made available for this stress problem so the results presented in this report will have to be further evaluated. Only comparative conclusions can be currently drawn. 


\subsection{NO ROD PPS}

Strategy (a) retains the PCS design established for the SAFR plant in the recent past utilizing "conventional" control algorithms [9]. Operating mode (3) is therefore not discussed here as load adjustment with rods in the "conventional" PCS circuit is a traditional and well examined transient. The focus is on operating mode (5). Strategy (a) has been explored with the EOC 1986/1987 metal core design SASSYS plant model [9]. This particular model represents the reactor core with three core channels; one channel each for the peak fuel assembly, the average driver subassembly and the average internal blanket subassembly. The entire plant is modeled from the reactor core to the steam generator feedwater valve and steam exit nozzle.

\subsection{Operating Mode (5)}

The PCS sensor signals and delays used for the SASSYS results presented in this section are those of Table IV. Initially an entire plant runback with a rate of $5 \% / \mathrm{sec}$ is examined as the common PCS response to the various initiators. Reactor scram by the PPS with trip of the PHTS/IHTS pumps would result in a flow rundown rate of $\sim 10 \% / \mathrm{sec}$. The $5 \% / \mathrm{sec}$ controlled runback rate should therefore be below the PHTS/IHTS pump coastdown rate. The results should be interpreted as being valid for runback rates in the range of a few $\% / \mathrm{sec}$. The "standby" conditions are taken to be $40 \%$ flow/"0"\% power. Each category of initiators is discussed separately and modifications are made to strategy (a) accordingly. With the exception of one transient, all the event simulations include an initial 15 second null transient.

\subsubsection{Reactivity Events}

Results for the mild reactivity transient, $2 \$ / \mathrm{sec}$ control rod withdrawa1, are shown in Figs. 5.1-1 to 5.1-4. Corresponding results for the $20 \$ / \mathrm{sec}$ uncontrolled control rod withdrawal are shown in Figs. 5.1-5 to 5.1-7. The striking point of the results for the two transients is that it appears that PHTS pump runback due to plant runback is an aggravating rather than a mitigating factor initially. Particularly in the $20 \$ / \mathrm{sec}$ case it can be seen that the coolant and cladding temperatures continue to rise even after the insertion of the entire rod reactivity (20ф). The fuel temperature rise 
essentially stops after the rod reactivity insertion stops. The rod worth designed for mild burnup swings is small enough that at least initially pump rundown is not a mitigating factor. The power lags the flow significantly for the $5 \% / \mathrm{sec}$ runback rate. However, none of the core acceptability criteria of Table III have been violated. Figures 5.1-3 and 5.1-6 show that this is not true for vessel structural design limits. Some fine tuning of the runback rate would be necessary if strategy (a) is to become the reference design strategy. Any attempt at decreasing the runback rate significantly will lead to the situation where the SCS would have to decide on different rates for different classes of transients, thus increasing the complexity of the SCS design. This will be apparent from the results presented later for the other transient categories.

For reasons which will be evident later, strategy (a) will be modified to respond to reactivity initiators with no power runback. In this way, the rod controller will continue to insert negative reactivity ${ }^{\star}$ without aggravation of the transient by PHTS flow reduction. No sensor channel will be required so this modification should retain the goal of PCS simplicity. Figures 5.1-8 to 5.1-13 present results with this strategy for the $20 \$ / \mathrm{sec}$ ramp rate case. These results should bound the $2 \$ / \mathrm{sec}$ case. Figures 5.1-9 and 5.1-10 show that no core or vessel structural class B limits are violated. Figure 5.1-11 shows that the IHX thermal transient is mild. The steam generator results also show a mild thermal transient but some tuning of the individual controllers may be required for better turbine temperature control. In general, the waterside transient is a mild one with the steam generator remaining wet.

In summary, the strategy of a $5 \% / \mathrm{sec}$ plant runback requires modifications for these reactivity transients. A possible alternative is to have the SCS not change setpoints during these transients. Significant margins were obtained with this modification. It should be realized that this is to a large extent attributable to the low total rod worth.

\footnotetext{
*At various stages in the SAFR design process this alternative of negative insertion during inadvertent rod runout was considered. It will be retained for the purposes of this study.
} 


\subsubsection{LOF Events}

The loss of coolant flow category is a category where the initiators are severe enough and the time scales are long enough that the passive reactivity feedbacks play a significant role in the mitigation of the consequences.

The class $B$ event for this category is the one primary pump trip initiator. Figures 5.1-14 to 5.1-17 present results for this event. Figure 5.1-15 shows that the class B core limits are not violated. Uncertainties in the reversed flow pump response around the 40 second mark are responsible for the second temperature peak. Nevertheless, the temperatures throughout the transient are still marginally around the class B core limits. However, Fig. 5.1-16 shows that the class $B$ vessel structural limits are violated within the first 25 seconds. Modifications to strategy (a) which would not run back the unaffected PHTS pump as the rest of the plant is runback, would mitigate this difficulty. It would also reduce the thermal transient on the components which from Figs. 5.1-17 is $\sim 2^{\circ} \mathrm{F} / \mathrm{sec}$. This event may necessitate a multi-tier response for strategy (a). There is, however, no point in pursuing this any further as a reactor scram on flow reduction would be required for another class B event discussed next.

Results are presented in Figs. 5.1-18 - 5.1-22 for the two primary pump trip event which also provides useful data for the LOEP. The core response of the LOEP, a combination class $B$ event further discussed in Section 5.1.5, is dominated by the PHTS flow behavior so the results of this two PHTS pump trip event can be extrapolated to the LOEP. Figure 5.1-18 shows that no class $B / C / D$ limits are violated for the core. The PCS rod runback and the passive feedbacks lead to large margins. However Fig. 5.1-19 shows that there is a significant violation of the class $B$ vessel structural limit. The IHX outlet and the steam generator inlet nozzle experience a thermal transient of $2-3^{\circ} \mathrm{F} / \mathrm{second}$. Some adjustment to the waterside algorithm is required as the calculations show that the steam generators fill up. The results for the class $C$ event, one PHTS seized pump, are presented in Figs. 5.1-23 to 5.1-27. Figure 5.1-24 shows that class $C$ limits for the core are not violated. As with the two pump trip event the passive reactivity feedbacks play a significant role in reducing the consequences. Figure 5.1-25 shows that the runback of the unseized PHTS pump still leads to acceptable margins 
with respect to class $C$ vessel structural limits. There is still some margin, albeit small, to the cavitation limit for the SAFR PHTS pumps. As with the two PHTS pump trip event, the IHX outlet and the steam generator in let nozzle undergo a thermal transient of $\sim 2^{\circ} \mathrm{F} / \mathrm{sec}$. This is shown in Fig. 5.1-26.

In summary; it can be seen that, in general, if a $2-5^{\circ} \mathrm{F} / \mathrm{sec}$ thermal transient at the IHXs and the steam generators is acceptable, than the strategy of a 5\%/sec load runback as the PCS response for this category of loss of coolant flow events is adequate for the thermal stress question. Some adjustment will have to be made to the waterside algorithm to prevent steam generator overfill but that is a relatively minor change. However at least one class $B$ event has been identified which would require strategy (a) to have a two tier response. Core margins are adequate but class $B$ vessel structural limits are violated, and asides from a significantly higher PCS rod insertion rate, there will be a need for a flow initiated reactor scram. A two tier response which relied soley on the PCS would require a diagnostician to differentiate between various LOF events. A PPS flow initiated scram would avoid this need.

\subsubsection{Secondary Side Undercooling Events}

Figures 5.1-28 to 5.1-41 show the results for the next category of transients. This is the secondary side undercooling category. Figures 5.1-28 - 5.1-34 are for the one IHTS pump trip event while Figs. 5.1-35 - 5.1-41 are for the two steam generator feedwater valve closure transient. The one IHTS pump trip event vividly illustrates the tradeoffs required in the design strategy. Figure 5.1-32 shows the thermal shock problem in the affected IHX, IHX1. With the differing flow matches in the PHTS and IHTS the primary side outlet nozzle undergoes a thermal transient which is affected by the runback of the PHTS pump. The faster the runback the milder the transient. However, Figs. 5.1-30 and 5.1-31 show that violations of the core and vessel structural design limits are driven by faster coastdown PHTS pump runback rates. The power lags the flow. For the $5 \% / \mathrm{sec}$ rate selected for this study these core and vessel structural class $B$ limits are not violated. The resulting $2-3^{\circ} \mathrm{F} / \mathrm{sec}$ thermal transient on the IHX outlet nozzle is probably not a severe one, but that question will have to be further examined by the individual component designer. On the waterside the FW valves respond quickly enough 
that thermal stresses in the steam generator should be inconsequential. As with the reactivity events examined earlier, some additional tuning of the waterside controllers and the "standby" condition may be required to reduce the turbine steam inlet temperatures. The steam generator does not dry out. The spurious water flows at the end of the transient calculation are numerical in nature and should be ignored. The two steam generator feedwater valve closure initiator further illustrates these tradeoff issues. In this event the thermal transient is driven by the waterside with the steam generator drying out at $\sim 60$ seconds. It should be noted that there is an initial 15 second null transient. The SG sodium outlet nozzle experiences a thermal transient of $\sim 4-5^{\circ} \mathrm{F} / \mathrm{sec}$. This propagates back through the IHTS loops and is seen in somewhat milder form at the IHX inlet which is also ultimately transmitted to the primary side. Without the pump runbacks the transient would be more severe. However, as with the one IHTS pump trip transient, the power lags the flow with the selected runback rate. This manifests itself in the reactor and fuel temperatures presented in Figs. 5.1-37 and 5.1-38. The selected runback rate, however, does not violate the corresponding design limits. An interesting feature of the results both from this event and the previous one IHTS pump trip event is the slow increase in the core inlet temperature. The reactivity feedback from this mechanism comes in too slowly to influence the power decrease during the critical part of the transient. The implication is that core reactivity control with the BOP will only be possible with "slow transients".

In summary, it appears that for the transients selected from the category of secondary side undercooling events the $5 \% / \mathrm{sec}$ power runback strategy would be acceptable if the $4-5^{\circ} \mathrm{F} / \mathrm{sec}$ thermal transients are within the thermal stress design limits of the individual components.

\subsubsection{Secondary Side Overcooling Events}

Figures 5.1-42 to 5.1-47 present the results for the secondary side induced overcooling category of transients. The single event analyzed is the two steam generator $F W$ valve overfeed. It can be seen that the plant response should be similar to that for a step change in load setpoint. For representative values, the feedwater flow to the steam generators is ramped up to $115 \%$ in 1 second. This is a fast driving function but it is not 
untypical. In the case of this event, automatic runback of the plant would lead to an overfilled generator and liquid in the steam lines to the turbine. While design accommodations could possibly be made, such as a level sensor signal in the PCS, an alternative strategy was adopted where the SCS essentially ignored the initiator and maintained the individual process controller setpoints at their 100\% values. Figure 5.1-42 shows that the power rises to meet the increased cooling. No fuel or vessel structural limits are violated in Figs. 5.1-43 and 5.1-44. The IHXs and the steam generators undergo a very mild transient, as shown in Figs. 5.1-45-5.1-47. Due to the lack of design information, the steam generator inlet feedwater temperature was maintained at the $100 \%$ value, where in reality it probably should rise somewhat with the increasing steam flow rate which reaches $115 \%$ in about a second. This is depicted in Fig. 5.1-47. Figure 5.1-47 shows that with the constant feedwater temperature the turbine inlet steam temperature decreases by approximately $50^{\circ} \mathrm{F}$. While the data is not presented the steam generator water level increases by $\sim 10 \mathrm{ft}$ and stabilizes. The steam generator does not overfi11. What appears to happen is that the entire plant stabilizes well at a new power level without violations of any design limits.

In summary, overcooling initiators for this plant design are apparently ignorable by the SCS. No signals are needed for this category.

\subsubsection{Multiple Initiators}

The final category of transients represents the multiple combination events. The class $B$ event for this category, loss of offsite electric power, is not explicitly simulated as the analysis of this event can be separated into two parts. The primary system response can be extrapolated from the results of the two primary pump trip event discussed in Section 5.1.2. This is due to the dominance of the primary pump flow behavior with the large pool thermal inertia. To reiterate, those results show that no core class B limits are violated. There is a violation of the class B vessel structural limits. The ramifications of this violation have been previously discussed in Section 5.1.2. The thermal shock margins which are determined by the secondary side response should be similar to those for the class 0 event, the SSE in this category. 
Figures 5.1-48 to 5.1-53 present the results for the final event, the multiple initiator transient, the safe shutdown earthquake (SSE). In the case of this event, the earthquake is assumed to cause a step reactivity insertion of $50 \notin$ due to the inward radial motion of the subassemblies. The subsequent oscillating behavior will not be treated. The earthquake also causes a loss of offsite electric power which trips the PHTS and IHTS pumps. In reality the FW pumps would also coastdown but for the purposes of this study it will be assumed that the automatic runback of the FW valves will suffice to represent the behavior of the feedwater flow. Certainly the FW pump coastdown would be faster, but for a class D event the "failure" criteria are set considerably higher so the steam generator should not be the focus of evaluating transient consequences. The final assumption is that with the power runback the rod insertion rate (emergency power) equivalent to a negative ramp of $1 \$ / \mathrm{sec}$, is slow enough to accommodate misalignments in control rod drives as the core configuration flexes. This should be a good assumption when compared to the CRBR licensing assumption of 10 seconds to drive in the safety rods upon receipt of the PPS scram signal. Figures 5.1-50 and 5.1-51 shows that no class $D$ limits for core and vessel structural response are violated. To the contrary, there exists considerable margin for the fuel. The hot pool response may be marginal. In addition, the IHX and the steam generators undergo mild transients. While it is recognized that the steam generator thermal transient is artificially on the mild side, it appears that the $5 \% / \mathrm{sec}$ power runback by the PCS is a sufficient response for this multiple initiator event.

To summarize; while it is possible to respond to the class D SSE event with strategy (a), the class B event in this category, LOEP, will require modifications. Unless a significant increase is made in the PCS rod insertion rate, a flow reduction initiated plant scram will have to be included in the design.

In summary, an effort was made to investigate the design of a PCS algorithm which would substitute for the deletion of a PPS system by running the plant back according to some scheme involving control rods in the PCS circuit, PHTS/IHTS pump flows and BOP maneuvers. The simulation results using the SASSYS SAFR plant model show that: 
For the envelope of operating mode (5) plant duty cycle transients, ranging in frequency from class $B$ to class $D$ and driving initiators from mild to severe, it appears that for the secondary side induced undercooling transients a plant runback at a few $\% / \mathrm{sec}(\sim 5 \% / \mathrm{sec})$ to $40 \%$ standby flow conditions and " $0 \%$ " fission power leads to acceptable consequences if a thermal transient of a few ${ }^{\circ} \mathrm{F} / \mathrm{sec}$ at steam generator and IHX nozzles and tubesheets are proven to be "mild" from a thermal stress perspective. These rates are roughly comparable to previous results obtained for the traditional PCS design. Some adjustment will have to be made to the preliminary waterside controllers in order to prevent steam generator fillup.

It will not be possible to apply a uniform response to all the other transient categories. For the reactivity transients and the secondary side induced overcooling events the strategy would be to have the SCS take no action. This would also reduce the number of sensor channels required. The loss of coolant flow/combination event categories would require a significant increase in the PCS control rod insertion rate if the rapid power runback strategy (few \%/sec) is to succeed or a flow reduction initiated plant scram would be called for.

It should be emphasized that these conclusions are preliminary as it is acknowledged that the envelope of events analyzed is a preliminary one and may require augmentation. However, it should encompass the majority of events both in frequency and in consequences. 


\subsection{NO ROD PPS/PCS}

Strategy (b) envisions the deletion of control rods both from the PPS and PCS circuits. In essence, this means that the ground rules for strategy (a) will now have to be modified to compensate for the deletion of the rod controller. This has implications for normal operating procedure so while operating modes (1) and (2) will still not be discussed, operating mode (3) will be examined in this section. Operating modes (1) and (2) under this strategy will require significant testing at EBR-2 as it is difficult to analyze the operational aspects of operating procedures without significant operational experience. It should be emphasized that the results presented in this section on strategy (b) are derived for the 1986/1987 metal core design with 316 SS used instead of HT-9 for load pads/ducts. This was required in order to meet the restriction of meeting temperature limits with a minimum of reference design alterations.

\subsection{Operating Mode (3)}

Steady state operation requires the ability not only to deal with minor high frequency "noise" fluctuations, but also the ability to adjust to significant alterations in demand. The question of reactivity "noise" fluctuations will not be examined here but the issue of dispatcher demand change will be discussed. Without a rod controller, neutronic power changes to meet demand changes will have to be effected through temperature changes in the core. Core temperature changes can be controlled through either the PHTS pump controller or through the secondary side controllers which in essence control the core inlet temperature. Work performed previously [10] indicates that given the restriction of limiting design changes at this stage of the project, it would be most convenient to run the PHTS pump controller to maintain the core temperature drop constant. Opening up this temperature drop results in reduction of design margins at the core outlet while closing it leads to design difficulties with inlet piping and plenum structural stresses as load decreases. Furthermore, the previous work [10] shows that Fig. 6.1-1 would be a reasonable choice for the partial load balance with this PHTS pump strategy. The design load swing requirement is from $40 \%$ to $100 \%$ power. Table VII

lists the reactivity coefficients which correspond to the partial load balance of Fig. 6.1-1. Reference should be made to [5] for a further explanation of 
Table VII. Reactivity Coefficient

\begin{tabular}{l|l}
\hline Power Coefficient & $11.0 \$$ \\
Flow Coefficient & $42.0 \$$ \\
Inlet Temperature Coefficient & $0.33 \$ /{ }^{\circ} \mathrm{C}$ \\
\hline
\end{tabular}

the various reactivity coefficients (á-1a Sevy [5]). It should be noted that these specific coefficients correspond to a design where 316 SS load pads or ducts were utilized instead of HT-9. A deliberate decision was made in design of Fig. 6.1-1 to select a strategy which would not alter the BOP design. Apparentiy non regenerative feedwater heating at high temperatures bears a high economic disadvantage [10]. However, the flip side of that decision manifests itself in the mismatch of flows across the IHXs and the steam generators. Axial temperature profiles are fairly skewed and sensitive to inaccuracies in the flow control. These issues will have to be further explored if this version of strategy (b) is adopted. Figure 6.1-1 also shows that the upper temperature limits on HT-9 cladding may also have to be reexamined. With all these caveats it can be seen that the partial load balance depicted in Fig. 6.1-1 leads to reasonable temperature swings as far as component stress limits are concerned. Figures 6.1-2 - 6.1-7 present results for a power rampback of $3 \% / \mathrm{m}$ in from $100 \%$ to $60 \%$ power. The requirement for a $5 \%$ step load change will be discussed in conjunction with the secondary side overcooling event of operating mode (5) as those events are quire similar. The results for the $3 \%$ /minute power rampdown show good load following capability. At these slow rates the passive reactivity feedbacks are perfectly capable of a coherent in phase response. The initial 15 second null transient needs to be run further to settle out but that is an artifice of the calculation. Some additional tuning of the PHTS pump controllers gain constants will be required for finalizing the design.

To reiterate: the changes made to the SCS used for strategy (a) were to drop the rod controller, control the PHTS flow to maintain the core $\Delta T$ constant instead of following a flow/load schedule, and finally to drop the feedwater valve trim off the steam temperature so that the feedwater flow follows a flow/load schedule. In this manner the core power is made to passively follow the load through BOP maneuvers without changing the core 
temperature drop. The scheme appears adequate to meet the requirement of a $3 \% / m i n$ load change for strategy (b).

\subsection{Operating Mode (5)}

As with the case of strategy (a), upon receipt of a sensor signal the PCS would attempt to runback the plant to "standby" conditions without violating safety margins. Once again the plant function which traditionally is assigned to the PPS is now assigned to the PCS. However, in the case of strategy (b), the PCS will attempt to perform this function without the use of control rods which was not the case with strategy (a).

The same preliminary set of sensor signals and delays used to explore strategy (a) will also be used here. Reference should therefore be made to Table $V$. In essence, the sensor channels are grouped by the category of transients which need to be accommodated. The preliminary strategy will also be to runback the plant at $5 \% / \mathrm{sec}$ to "standby" conditions for a 17 the transients. A common response irrespective of transient will obviate the need for a SCS diagnostician at this level. As with strategy (a) there is a window for the runback rate. Reference should be made to Section 4.0 for details regarding the window as the same limitations apply. However, as a matter of partial interest, there is a difference in the control of the individual controllers. Since the steam temperature setpoint is kept constant during the runback on this preliminary waterside algorithm, the only process controller which is actually runback is the feedwater valve controller. The remainder of the plant follows. Reference should be made to section on operating mode (3) for further details on alterations to specific controllers for strategy (b). The "standby" condition for the runback used in examining strategy (a) has to be modified for strategy (b). It is now a $40 \%$ flow/40\% flux condition since the power is essentially set by the feedwater valve flow. Results are presented for the envelope of transients presented previously in Table III. It should be understood that the results presented in these sections would have associated with them larger uncertainties than those of Section 5.0. This is due to the domination of passive reactivity feedbacks with their associated uncertainties as opposed to the active feedback from the rod controller. 


\subsubsection{Reactivity Events}

In the category of reactivity transients, Figs. 6.2-1 to 6.2-4 shows results for a mild uncontrolled $2 \$ / \mathrm{sec}$ control rod withdrawal initiator. Strategy (b) responds by running back the plant at $5 \% / \mathrm{sec}$ entirely through the use of the feedwater valves which ramps back the feedwater flow to $40 \%$ nominal. This is the standby condition. The PHTS pump follows in order to keep the core $\Delta T$ constant. This is the algorithm discussed previously. The figures shows that some alteration will have to be made to the BOP algorithm if the neutron power is to be brought down to $40 \%$. Figure $6.2-3$ shows that class B limits for the fuel are not violated. However, Fig. 6.2-4 shows that vessel structural B limits in the hot pool would be violated if the power reduction to $40 \%$ power is to be achieved. In the case of strategy (b), the runback of the PHTS pumps does not aggravate the power transient. The core $\Delta T$ following scheme for controlling the PHTS pumps leads to essentially a constant PHTS flow. This can be demonstrated from Fig. 6.2-2 where the maximum motor torque limiter is reached. The transient can basically be divided into two parts; one where the core passively responds to the control rod withdrawal and two where the plant is being brought down from the $125 \%$ steady power level. Given the reactivity coefficients for the system listed in Table VII, it would violate the class B vessel structural limit to bring the power level down from $125 \%$ to $40 \%$ with passive feedback only. In essence, an extra $20 \notin$ of control rod reactivity has to be compensated for in addition to the $100 \%$ to $40 \%$ power defect. Figures $6.2-5$ to $6.2-9$ present results for the $20 \$ / \mathrm{sec}$ control rod withdrawal case. It can be seen that the differences between the two ramp rate cases are minor. Once again the passive response to the initiator and the plant runback can be separated. In this case the plant is not run back. Figure 6.2-8 shows that the fuel margins are similar even though the ramp rate is significantly higher than the $2 \phi / \mathrm{sec}$ case. Furthermore, Fig. 6.2-9 shows that the class B vessel structural margins in the hot pool are similar. It appears that strategy (b) will require at least a two tier response. For reactivity transients the plant may have to be runback at significantly slower rates than the $5 \% / \mathrm{sec}$ to a "standby" condition which is

significantly higher than the $40 \%$ flow/40\% power condition. For the $5 \% / \mathrm{sec}$ runback rate a thermal transient of $\sim$ several ${ }^{\circ} \mathrm{F} / \mathrm{sec}$ would be experienced at certain component nozzles. 


\section{2 .2 LOF Events}

For the category of loss of coolant flow transients SASSYS simulations expressly for the purpose of this study were not comprehensively performed. What was done was to examine the results of analyses performed for the beyond design basis ATWS events to complement this study. Substantial work in this ATWS area has been performed by Wigeland et a1. [11] for the two primary pump trip event and the one seized PHTS pump event.

Figures 6.2-10 - 6.2-12 present results for the one primary pump trip event which is the class $B$ selected for analyses in this category. Figures 6.2-11 and 6.2-12 show that both core class B limits and vessel structural class $B$ limits are violated. While there are significant uncertainties regarding the class $B$ margins for the core due to the uncertainty in reverse flow pump behavior, the conclusions regarding the structural margins are much more definite. Given the current SAFR hydraulic design, enough core flow is bypassed through the affected PHTS pump loop in a short enough time to create a substantial power/flow mismatch. This causes the core outlet temperature to increase by $\sim 200^{\circ} \mathrm{F}$ which is beyond the class $B$ limit. While there is some uncertainty regarding pump response in the various quadrants, extrapolations to the asymptotic flow limit around the ten second mark show a definite trend to the class B limits. Alterations in strategy (b) to minimize this difficulty would require design change as strategy (b) already drives the unaffected loop flow close to the pump cavitation limit. The results presented do not include a SAFR pump cavitation model as there is still some margin, albeit small, to cavitation. This would appear to be a transient which would require some control rod action unless design requirements are placed on the SAFR PHTS pump in the reverse flow regime.

Analyses of the class $C$ event, the one seized PHTS pump initiator, and the two primary pump trip event will be based in part on extrapolations from the ATWS work of Wigeland et a1. [11]. The two primary pump trip results will be discussed in this section as part of the LOEP, the class B combination event, since the a11 PHTS pump trip is the dominant feature of that event. Figures 6.2-13 to 6.2-14 present results for the two PHTS pump trip event. Figure 6.2-13 shows violation of the core class B limits. Figure 6.2-14 also shows a violation the class $B$ vessel structural limits. Strategy (b) will not be able to accommodate this event without some control rod action either by 
the PPS or the PCS. These results also show that it will not be possible to respond to all transients with the strategy of a simultaneous all pumps trip on both the primary and secondary system.

Results for the class $C$ event in this transient category, the one PHTS seized pump event are taken from the ATWS analysis work of Wigeland et a]. [11]. The ATWS analyses were performed with HT-9 ducts/load pads and no plant runback. While plant runback would be a small effect on the core response on the loss of flow time scale, as the large pool thermal inertia slows down the core inlet temperature response considerably, the influence of the ducts/load pads would be considerably more important. It can, however, be said that the HT-9 core temperature results should envelope the corresponding 316 SS results. The results of wigeland et al. [11] show that no class $C$ limits for both core and vessel structure are violated. The thermal shock issue should be a question of $\sim 2^{\circ} \mathrm{F} / \mathrm{sec}$ as with strategy (a). The large pool inertia renders the thermal shock issue more a question of flow mismatches rather than differences in primary pool temperatures between the two strategies. There is no need to rerun Wigeland's calculation with the core $\Delta T$ PHTS control algorithm since the flow of the unaffected pump reaches the cavitation limit within a few tenths of a second.

To summarize; it appears that for the category of loss of flow events there is a need to include some control rod action either by the PCS or the PPS.

\subsubsection{Secondary Side Undercooling Events}

In the category of secondary side induced undercooling events the two events analyzed for strategy (a), presented in Section 5.1.3, are the one IHTS pump trip and the two steam generator feedwater valve closure. For strategy (b), the two IHTS pump trip event will be substituted for the one IHTS pump trip. The maximum thermal shock rate for the components in each IHTS loop should be comparable for the two cases and it will be seen that useful conclusions can be drawn about the class B limits. Figures 6.2-15 to 6.2-21 show results for the two IHTS pump trip. It can be seen that the core class B limits are not violated in Fig. 6.2-17. Figure 6.2-16 shows that the PHTS loop flow responds slowly to the IHX flow coastdown with the core $\triangle T$ PHTS control algorithm. The consequences of this slow response are reflected in 
Fig. 6.2-19 where the thermal shock for the IHX on the PHTS side is $\sim 10^{\circ} \mathrm{F} / \mathrm{sec}$ at the tubesheet. The steam generator flows are better matched so the thermal shock on steam generator nozzles is $\sim 1^{\circ} \mathrm{F} / \mathrm{sec}$. However some alterations may have to be made to the $\mathrm{FW}$ valve shutdown algorithm in order to limit the steam temperature rise. Extrapolation from the results presented in Fig. 6.2-18 should lead to some margin to the class B structural limits in the hot pool for the one IHTS pump trip case. As the PHTS flow change is slow the core outlet temperature increase is essentially determined by the core inlet temperature increase. A one IHTS pump trip case would have a smaller core inlet temperature rise and therefore more margin to the class $B$ structural limits. The two IHTS pump trip results do show an anomaly at the 230 second mark. Figures 6.2-17 and 6.2-18 show nonmonotonic temperature behavior. Further examination of Fig. 6.2-16 show that the PHTS flow control is beginning to degrade. This is probably an indication of a need for adaptive control techniques. With the inherent control nature of strategy $(b)$, the variations in flow time constants from $100 \%$ to $10 \%$ flow are affecting the power to flow phase relationship. Additional work is required on this issue.

Results for the two steam generator feedwater valve closure transient using strategy (b) are presented in Figs. 6.2-22 to 6.2-28. The main issue with this event is the question of nozzle temperature shock. It has been amply demonstrated $[8,11]$ that the passive reactivity feedbacks are ample enough to mitigate a LOHS ATWS event. While a trip of all feedwater pumps may lead to a faster feedwater flowdown and consequently a larger thermal shock, the probability of such an event is much smaller. Attention will therefore only be focused on the two steam generator feedwater valve closure transient. Furthermore, the long term decay heat removal problem will not be simulated here. It will be presumed that the decay heat removal systems will begin to operate in the long term outside the window of this particular analysis. Figure 6.2-24 shows that in the first 250 second time frame no class $C$ core limits are violated. Figure 6.2-25 shows that in this window class $C$ vessel structural limits are not violated either. However, it would be prudent to initiate the startup of the standby decay heat removal systems. Figures $6.2-26$ and 6.2-27 show that the thermal shock problem is of the order of a few ${ }^{\circ} \mathrm{F} / \mathrm{sec}$ for both the IHX and the steam generator for this event. Further examination of absolute temperature limits for the steam generator will have to be made. This may define the startup window for the 
decay heat removal systems. As with the two IHTS pump trip there is some evidence that the inherent control strategy (b) may require some form of adaptive control for the complete flow range.

To summarize; it appears that for the category of secondary undercooling events no core $B / C / D$ limits are violated with strategy (b) at a plant runback rate of $5 \% / \mathrm{sec}$. However, faster thermal transient of a few ${ }^{\circ} \mathrm{F} / \mathrm{sec}$ to $10^{\circ} \mathrm{F} / \mathrm{sec}$ would be experienced by components. If these rates are unacceptable, there are alternative schemes which could run down the PHTS flow more rapidly. These schemes would essentially decouple the PHTS pump control from the core $\Delta T$ which would complicate the transfer from mode (3) operation to mode (5) operation. Absolute steam generator temperature limits would have to be explored. These limits and vessel structural limits would determine the window for the startup of the decay heat removal systems. Some modifications may have to be made to the waterside shutdown flow control scheme in order to limit these temperatures.

\subsubsection{Secondary Side Overcooling Events}

The results for the secondary side induced over cooling category of events are shown in Figs. 6.2-29 to 6.2-34. The single event chosen for this category is the two steam generator FW valve overfeed. A fast, but not untypical, ramp up of $\mathrm{FW}$ flow to $115 \%$ in one second is used as the driving function. It can be seen that the plant response should be similar to that for a stepchange in load setpoint. To avoid steam generator fillup with power runback when control of the feedwater valves is lost, the strategy (b) is modified to ignore this event. No sensor signal will be sent to the SCS. This is the same response used in strategy (a) for this category of events. Figures 6.2-30 - 6.2-34 show that this secondary side induced overcooling event, selected to maximize overcooling, is a mild transient. The feedwater temperature is run constant in Fig. 6.2-34 for lack of design information but that does not invalidate the conclusion that the steam generator cools down by $\sim 50^{\circ} \mathrm{F}$ to a new steady state with higher water levels. Loss of a feedwater heater would also result in $\sim 50^{\circ} \mathrm{F}$ overcooling of the steam generator. The entire plant stabilizes at a new steady state in $\sim 200$ seconds without violating any class B limits. Overcooling events appear to be ignorable by the SCS. Operating procedures may require a plant shutdown at some time, but that issue will not be addressed here. 


\subsubsection{Multiple Initiators}

Of the two combination events considered for this category the class $B$ event, LOEP, is not explicitly simulated for this study. This is due to the fact that with the large pool thermal inertia the core response is enveloped by the two pump trip event discussed in Section 6.2.2. The PHTS pump coastdown dominates that response. For a discussion of the class $B$ margins for both the core and the vessel structure reference should be made to Section 6.2.2. To summarize there is some margin to the class B core limits but the class $B$ vessel structural limits are violated. The question of thermal shock to components for this class $B$ event is enveloped by the class $D$ event, the SSE, presented next.

Figures 6.2-35 to 6.2-40 present results for the SSE. As noted in Section 5.1.5, where the response of this event under strategy (a) was discussed, it is assumed that a nonoscillating $50 \$$ step is the driving function. In addition, it is presumed that the runback of the FW valves will provide an adequate simulation substitute for the coastdown of the feedwater pumps. In contract to Section 5.1.5, however, for strategy (b) no control rod insertion will be initiated. Figures $6.2-37$ and $6.2-38$ show that no class 0 core or vessel structural vessel limits are violated in the first few tens of seconds. However, some provision will eventually have to be made for decay heat removal but that issue is not addressed here. Component thermal shocks are on the order of $1^{\circ} \mathrm{F} / \mathrm{sec}$. The preliminary judgement is therefore that strategy (b) will succeed with this class $D$ event.

To summarize the analyses of the transients in this combination event category, a need has been shown for the inclusion of control rod action either by the PPS or the PCS.

In summary, an attempt was made to examine the design of a PCS algorithm which not only substituted for the deletion of a PPS system by a rapid plant runback, but would also achieve this without the active use of control rods. The simulation results obtained with the SASSYS SAFR plant model show that utilization of sodium pump control and BOP maneuvers alone leads to the following conclusions. 
Good load following capability can be obtained in the range from $100 \%-40 \%$ power for the load change requirements of operating mode (3). The design requirements for these class $A$ events are slow enough that the core follows the BOP and the flows well. However, there is no common SCS response which will accommodate all the transient categories of operating mode (5), ranging from class $B$ to class $D$ events in the duty cycle. The strategy for the reactivity category and the secondary side induced overcooling category would be to have the SCS take no action. At some point operational procedure would require an orderly shutdown of the plant, but that issue will not be addressed here. For the secondary side induced undercooling events a rapid plant runback of a few $\% / \mathrm{sec}(\sim 5 \% / \mathrm{sec})$ leads to acceptable results if a thermal transient of a few to several ${ }^{\circ} \mathrm{F} / \mathrm{sec}$ at the steam generators or the IHXs can be tolerated. Modifications to the strategy to permit lower thermal rates are possible if these thermal stresses are unacceptable. These modifications would, however, imply PCS complications. For the loss of coolant flow/ combination event categories strategy (b) will not be feasible. Some control action either by the PCS or the PPS is required for these event categories. 


\subsection{CONCLUSION}

The objective of this study was to determine if control strategies for modular LMR plants existed which could allow simplifications in the "conventional" PCS/PPS design through the utilization of the passive traits of the innovative IFR concept. These modifications could not only have economic benefits through plant simplifications, but could perhaps also increase the reliability of plant operations and eventually lead to a high degree of plant automation. To this end, an examination was made of two control strategy alternatives for the SAFR plant. The first alternative is to replace the functions of the PPS with a controlled PCS response to various duty cycle initiators. This will be termed the "semi-innovative" alternative. The second alternative, denoted the "innovative" alternative, is to proceed an additional step and respond to all duty cycle events with a PCS which involved no active control rod action. The PCS response would be restricted to BOP maneuvers and sodium pump swings.

Results with the SAFR SASSYS plant model were obtained for these two alternative control strategies for a preliminary set of enveloping load adjustment duty cycle events and the FSAR chapter 15 duty cycle events. Other operating mode events, such as startup and shutdown, were not examined in this study. A preliminary set of sensor signal and delays were used to obtain the SASSYS transient results. While it is acknowledged that the preliminary set of parameters and transients could evolve in the future, the following conclusions for the SAFR plant can be drawn from this study.

For the semi-innovative strategy a plant runback of a few $\% / \mathrm{sec}$ is an acceptable response for the category of secondary side induced undercooling events if a thermal transient of a few ${ }^{\circ} \mathrm{F} / \mathrm{sec}$ at the heat transfer components is tolerable. The SCS response to the category of reactivity transients and to the category of secondary side induced overcooling transient should be one of no action. For the loss of coolant flow combination event categories if the PCS control rod ramp rate is not significantly increased, a flow initiated plant scram is required.

The innovative control strategy shows good load following capabilities for the required design load cycling with only BOP/sodium pump maneuvers. The

neutronic power follows the imposed load changes well for a core using 316 SS 
ducts/load pads. For the rest of the duty cycle conclusions similar to those drawn for the semi-innovative strategy can be inferred for the innovative control strategy with a few modifications; the thermal transient rates at the heat transfer components is of the order of several ${ }^{\circ} \mathrm{F} / \mathrm{sec}$ for the plant runback response to secondary side induced undercooling initiators; for the loss of coolant flow/combination event categories a flow initiated plant scram is required. If there is a need to reduce the thermal rates, alternative schemes can be examined with the implied possibility of PCS complications. The SCS response to the reactivity and secondary side overcooling events should be one of no action. Eventually operating procedures for these events will require the plant to be shutdown but the shutdown issue is not addressed in this report.

If either of these control strategies are pursued further, there will be a need to reexamine the waterside control algorithm to prevent steam generator overfill and a better definition of the "standby" conditions. In addition, if the innovative control strategy is to be considered as a long term alternative, some effort will have to be made to examine the possibilities of improved flow control techniques through the use of digital controllers and also to investigate the area of adaptive control.

In general it appears that without design modifications, except possibly for load pad material, a combination of strategies (a) and (b) may be in order. The results presented in this report show that design load changes without the active usage of control rods in the PCS is feasible; for the loss of flow event category a traditional PPS scram function with traditional settings may be required; for the reactivity events and secondary side overcooling events higher settings for the traditional PPS scram as a backup position can be tolerated; and that for the secondary side undercooling events a "fast" power runback by the PCS with or without the active use of control rods, in lieu of a PPS scram, could be acceptable depending upon component design rate limits. 


\section{ACKNOWLEDGMENTS}

R. H. Sevy of the RAS Division and J. I. Sackett of the EBR-2 Division are to be gratefully acknowledged for informative discussions regarding control strategies.

Ms. Karen Jenicek is to be thanked for her careful and painstaking typing of this report.

\section{REFERENCES}

1. Y. I. Chang, J. F. Marchaterre, R. H. Sevy, "The Integral Fast Reactor Concept," Trans. Am. Nucl. Soc., 47, 293 (1984).

2. J. E. Cahalan et al., "Preliminary Safety Assessment of the Integral Fast Reactor Concept," Argonne National Laboratory Report, ANL-IFR-3 (January 1985).

3. S. F. Su and R. H. Sevy, "Unprotected Loss of Flow Accidents - Performance of Metal Fuel," Argonne National Laboratory Report, ANL-IFR-5 (February 1985).

4. H. P. Planchon et a1., "Implications of the EBR-2 Inherent Safety Demonstration Test," Nuclear Engineering and Design, Vol. 101, pp. 75-90 (1987), North Holland-Amsterdam.

5. R. H. Sevy, "Quasi-Static Transient Analysis," Argonne National Laboratory Report, ANL-IFR-26 (October 1985).

6. R. H. Sevy, private communication (May 1986).

7. U.S. Nuclear Regulatory Commission, "Standard Review Plan," NUREG-0800 (Ju Ty 1981).

8. P. A. Pizzica and T. Y. C. Wei, "SAFR Plant Duty Cycle Events PSID NRC Review Analyses," Argonne National Laboratory Report, ANL-SAFR-23 (April 1986).

9. L. L. Briggs and T. Y. C. Wei, "SAFR Plant Control System 1987 Design Transients," Argonne National Laboratory Report, ANL-SAFR-43 (November 1987).

10. T. Y. C. Wei and R. H. Sevy, private communication (July 1987).

11. R. A. Wigeland et al., "SAFR Presentation to the NRC PSID Review (Chapter 15 and Appendix A)," Rockwell International Report BD 87-197 (October 15, 1987). 
dew 6u!zesədo әzеy yәеquny $\cdot[\cdot t \cdot 6 !\rfloor$

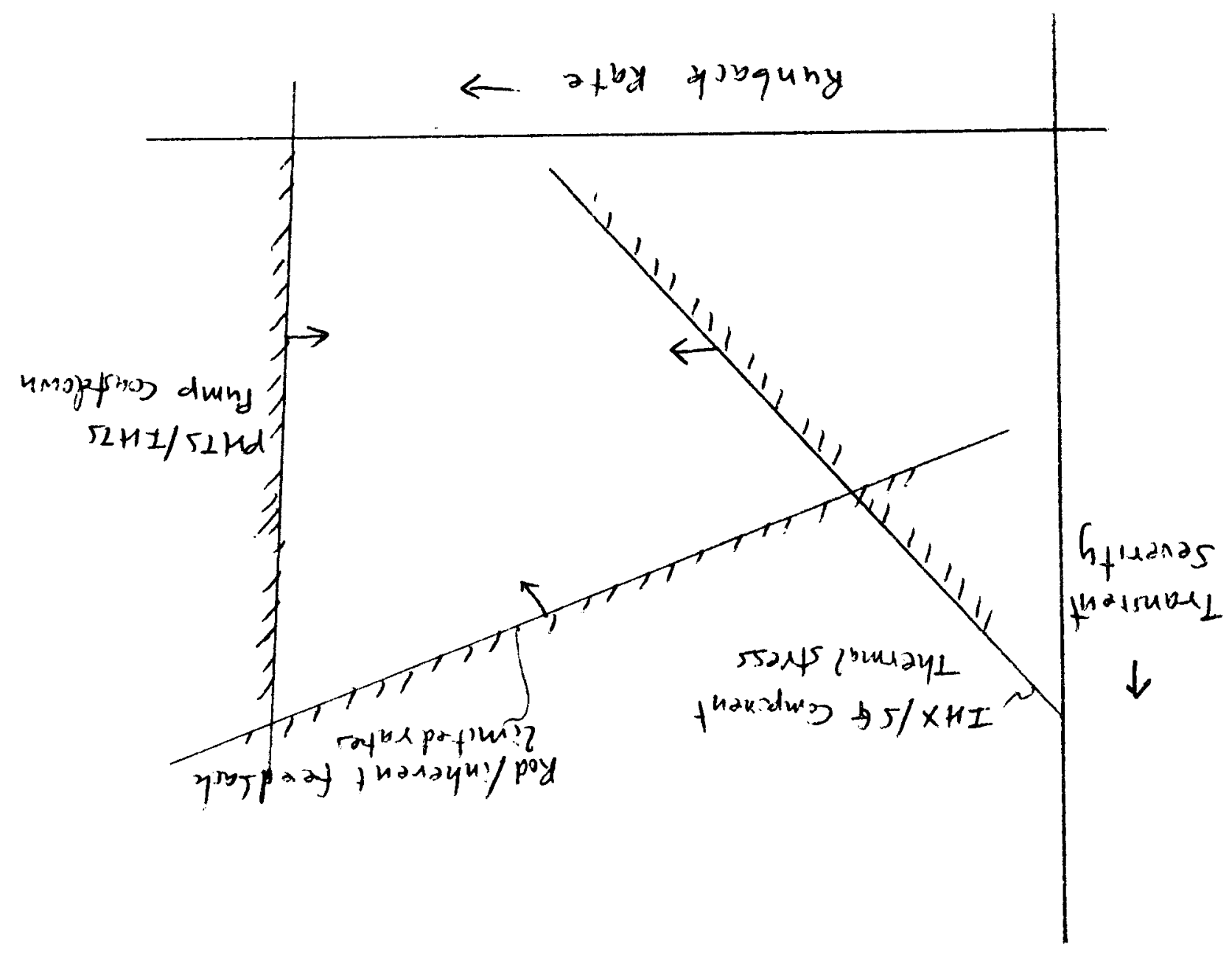




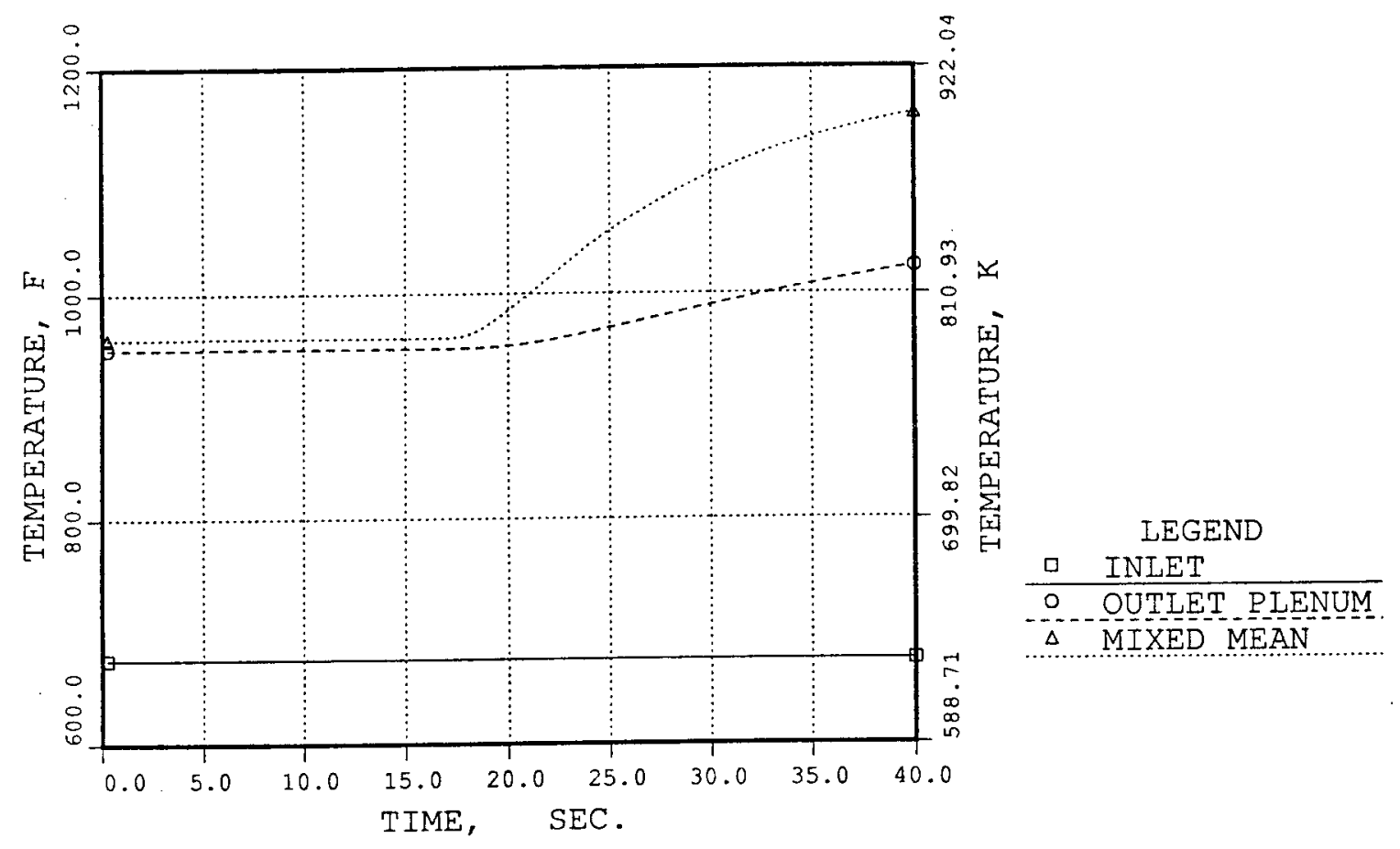

Fig. 4.2. No Rod PPS. Runback with Pumps Trip Reactor Core Temperatures 


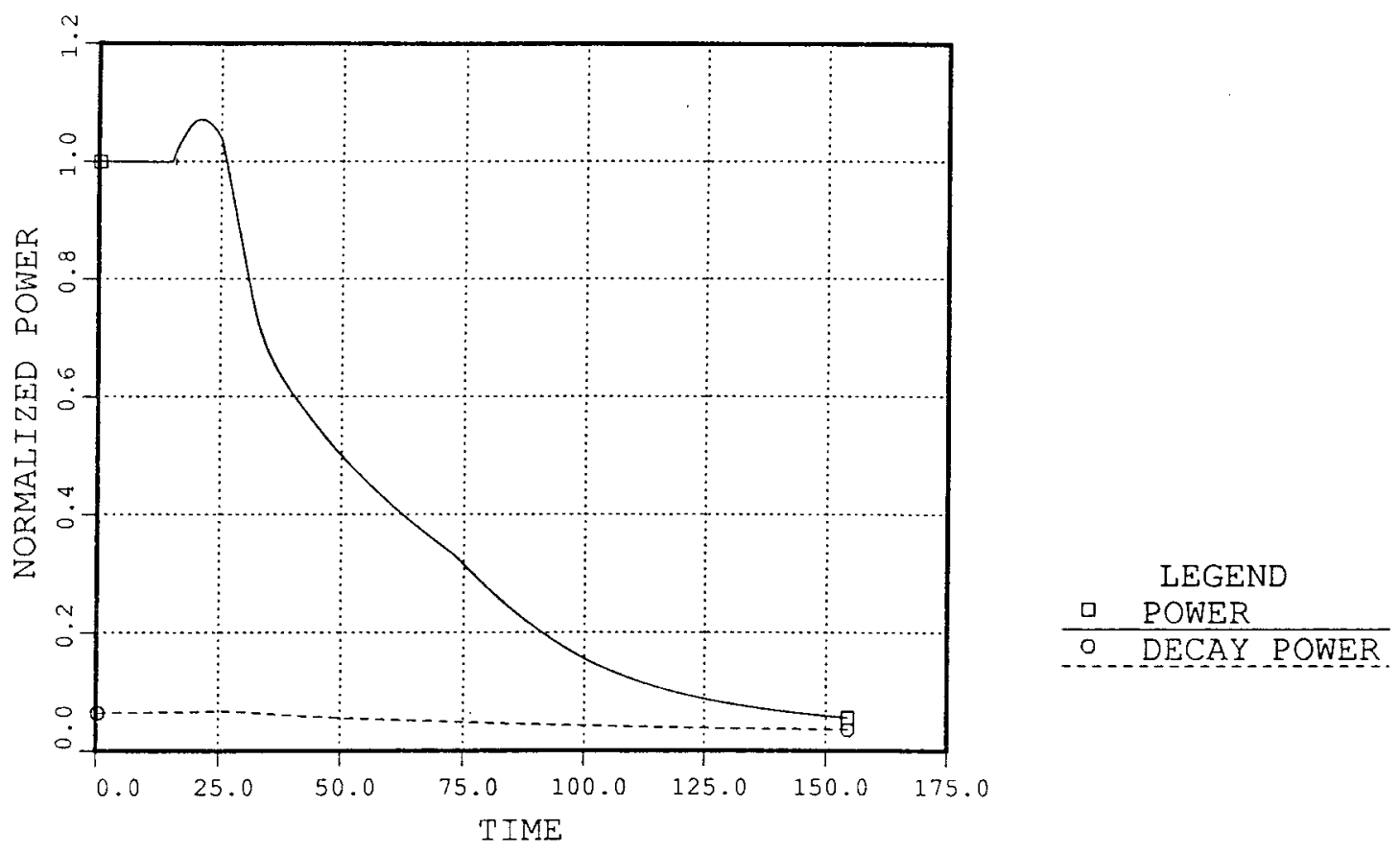

Fig. 5.1-1. No Rod PPS. 2\$/sec Control Rod Withdrawal Reactor Power

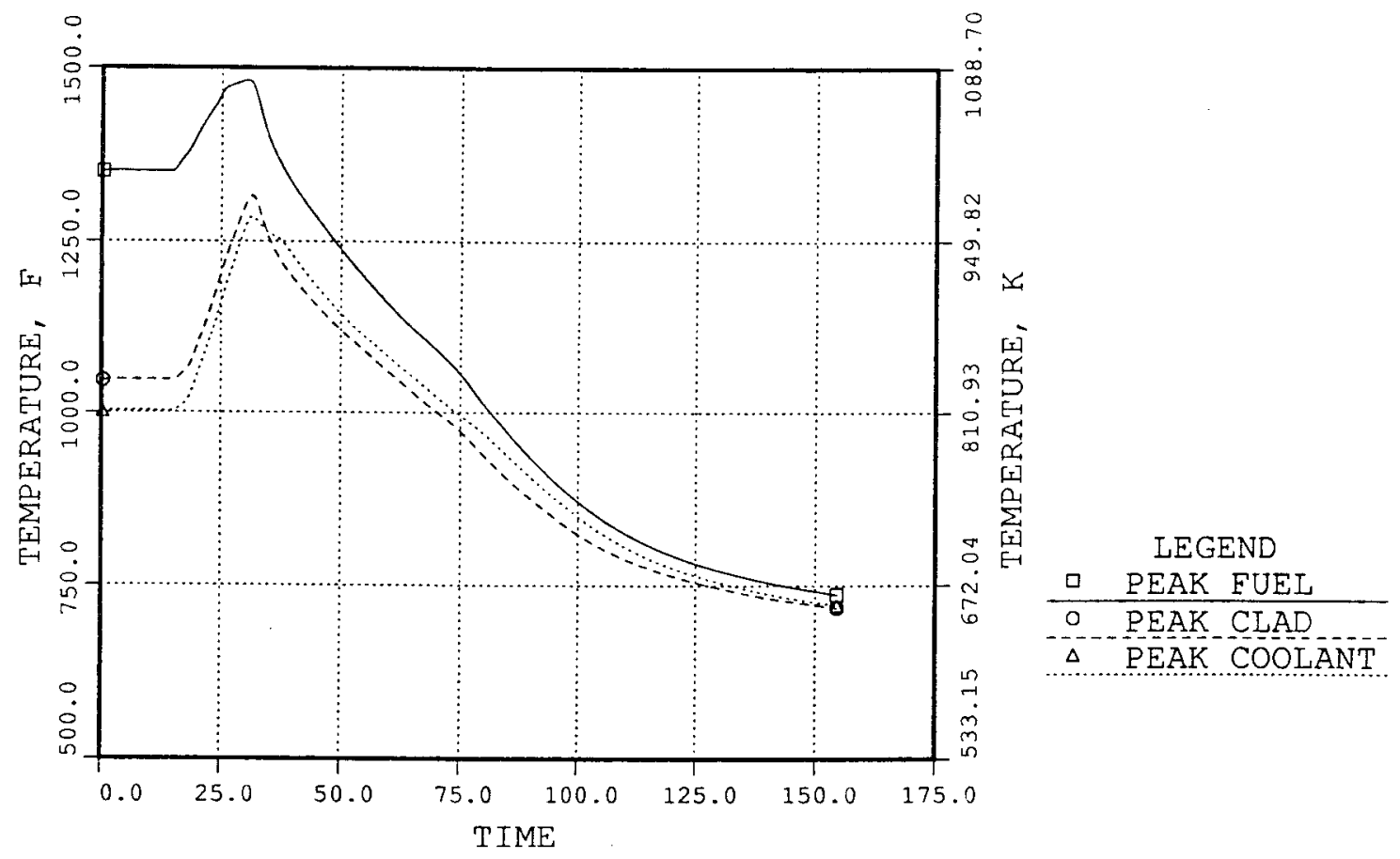

Fig. 5.1-2. No Rod PPS. 2\$/sec Control Rod Withdrawal Channel 1 Peak Temperatures 


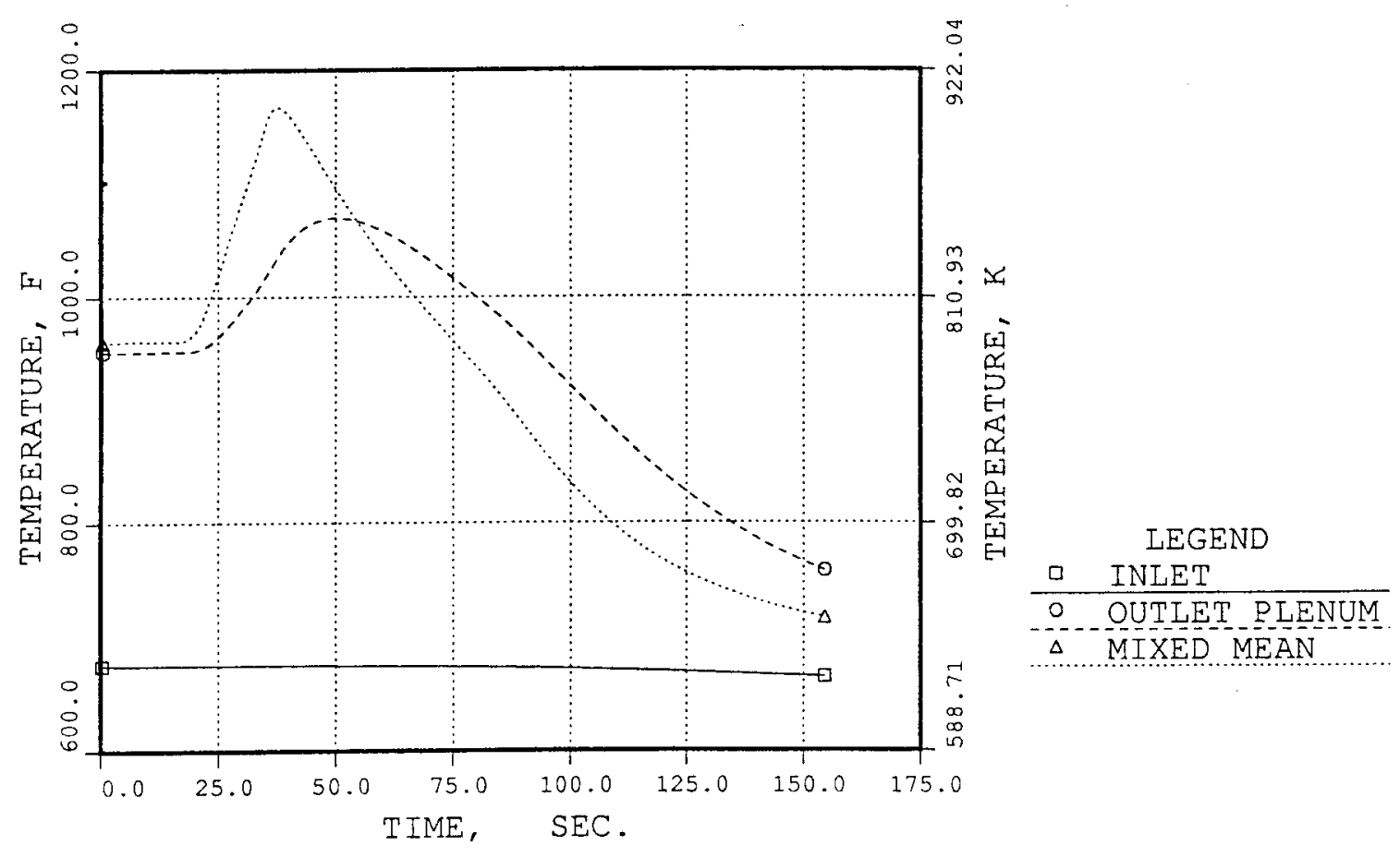

Fig. 5.1-3. No Rod PPS. 2\$/sec Control Rod Withdrawa 1 Reactor Core Temperatures

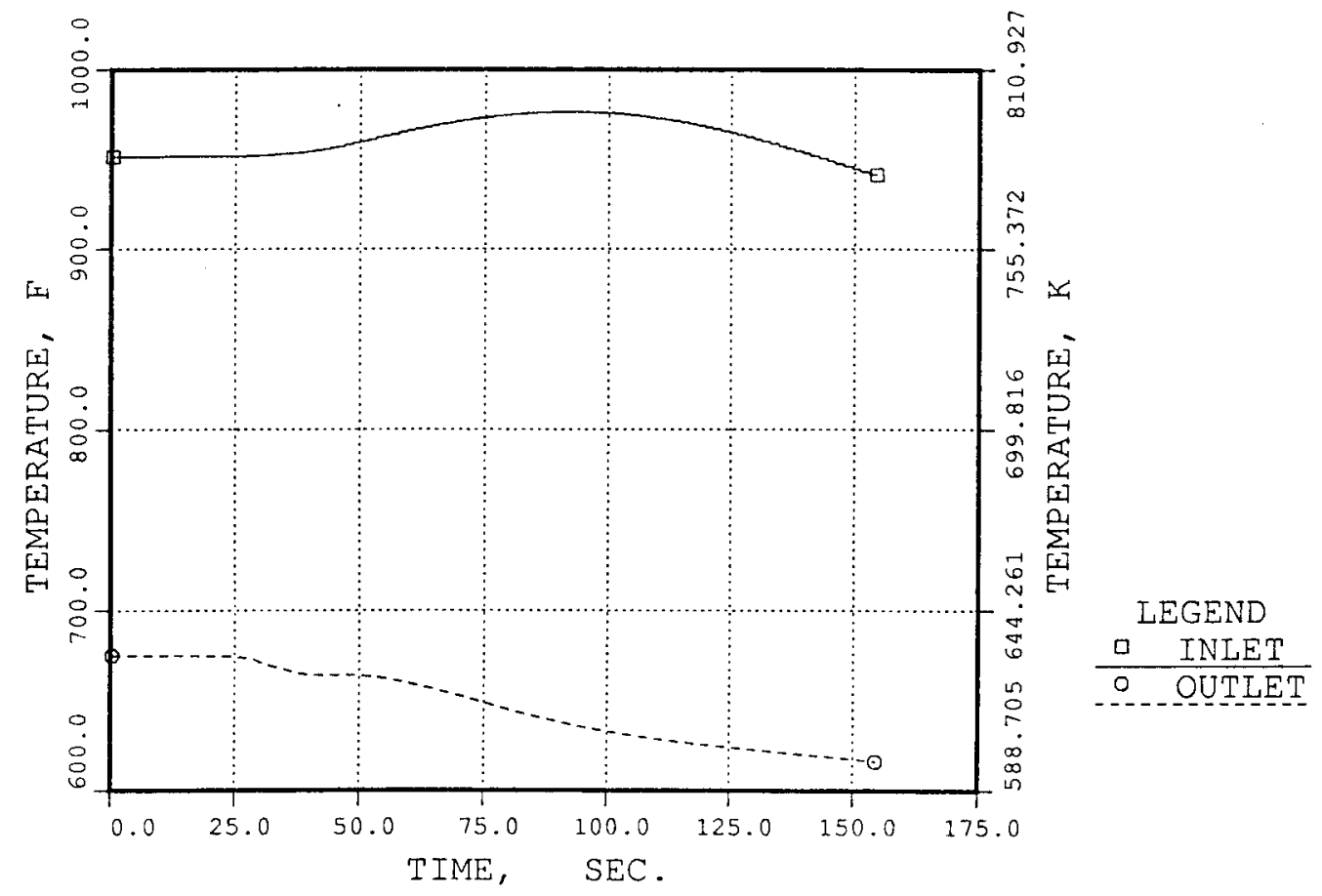

Fig. 5.1-4. No Rod PPS. 2\$/sec Control Rod Withdrawal IHX Primary Side Temperatures 


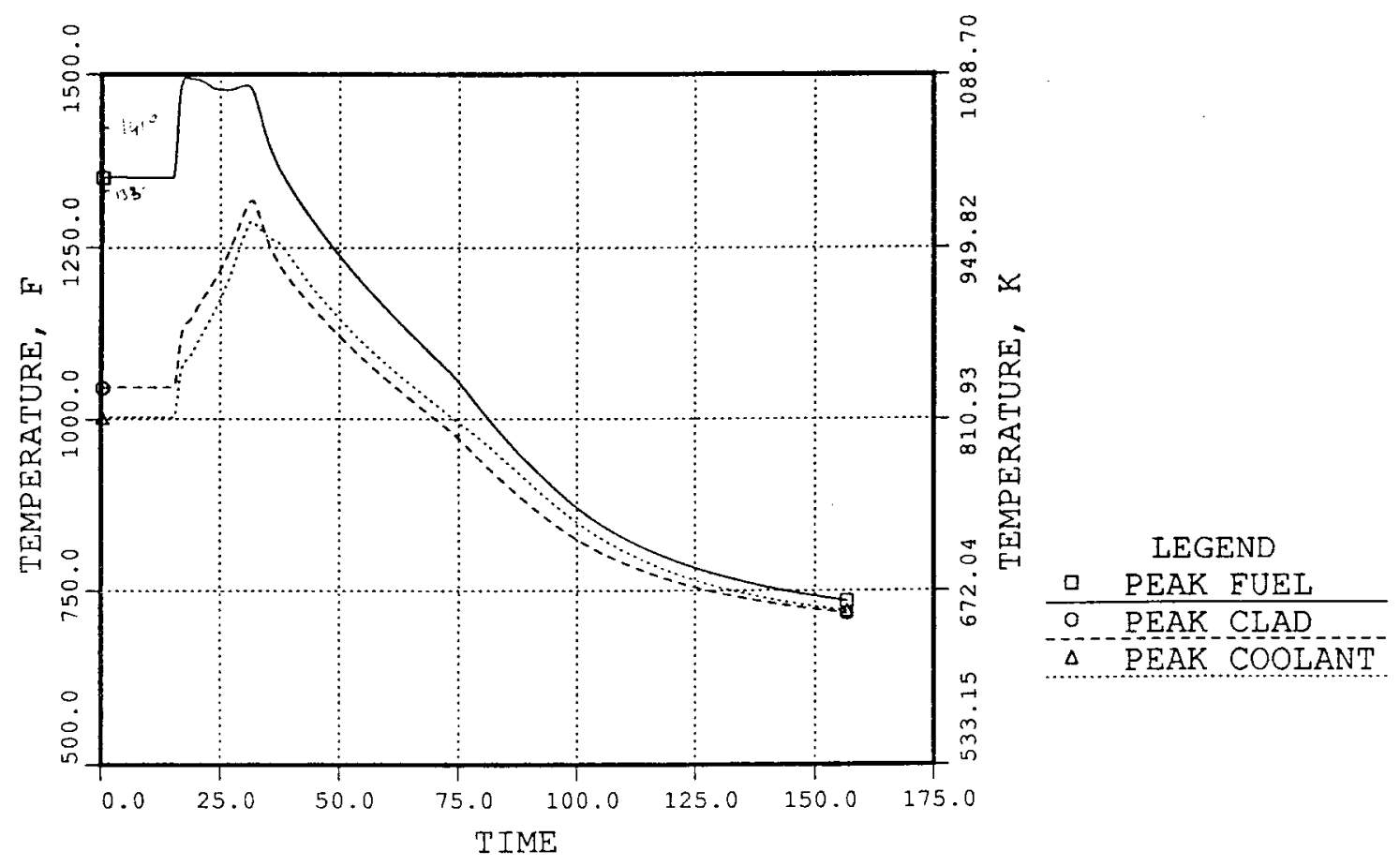

Fig. 5.1-5. No Rod PPS. 20\$/sec Control Rod Withdrawal Channe 11 Peak Temperatures

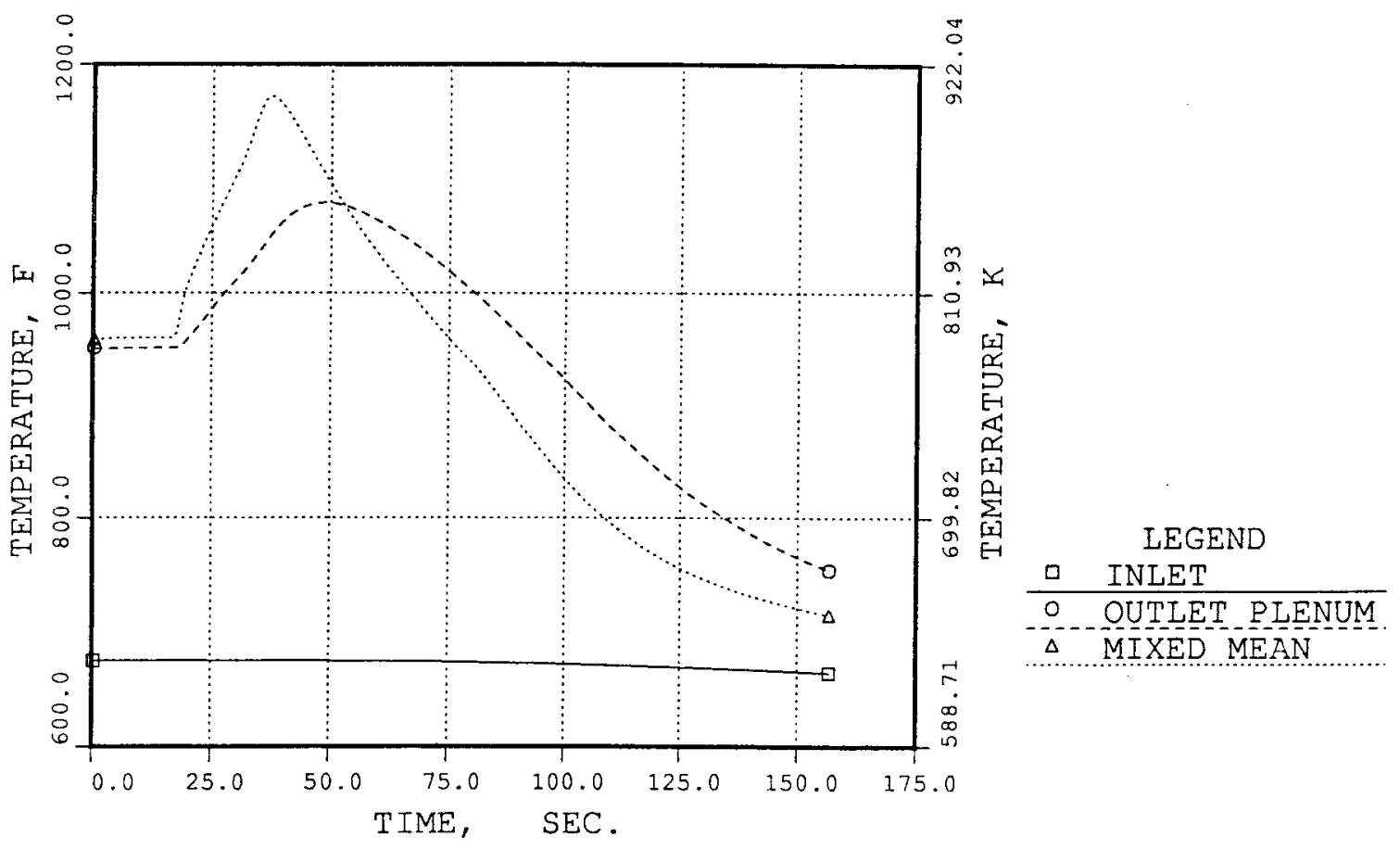

Fig. 5.1-6. No Rod PPS. 20\$/sec Control Rod Withdrawa1 Reactor Core Temperatures 


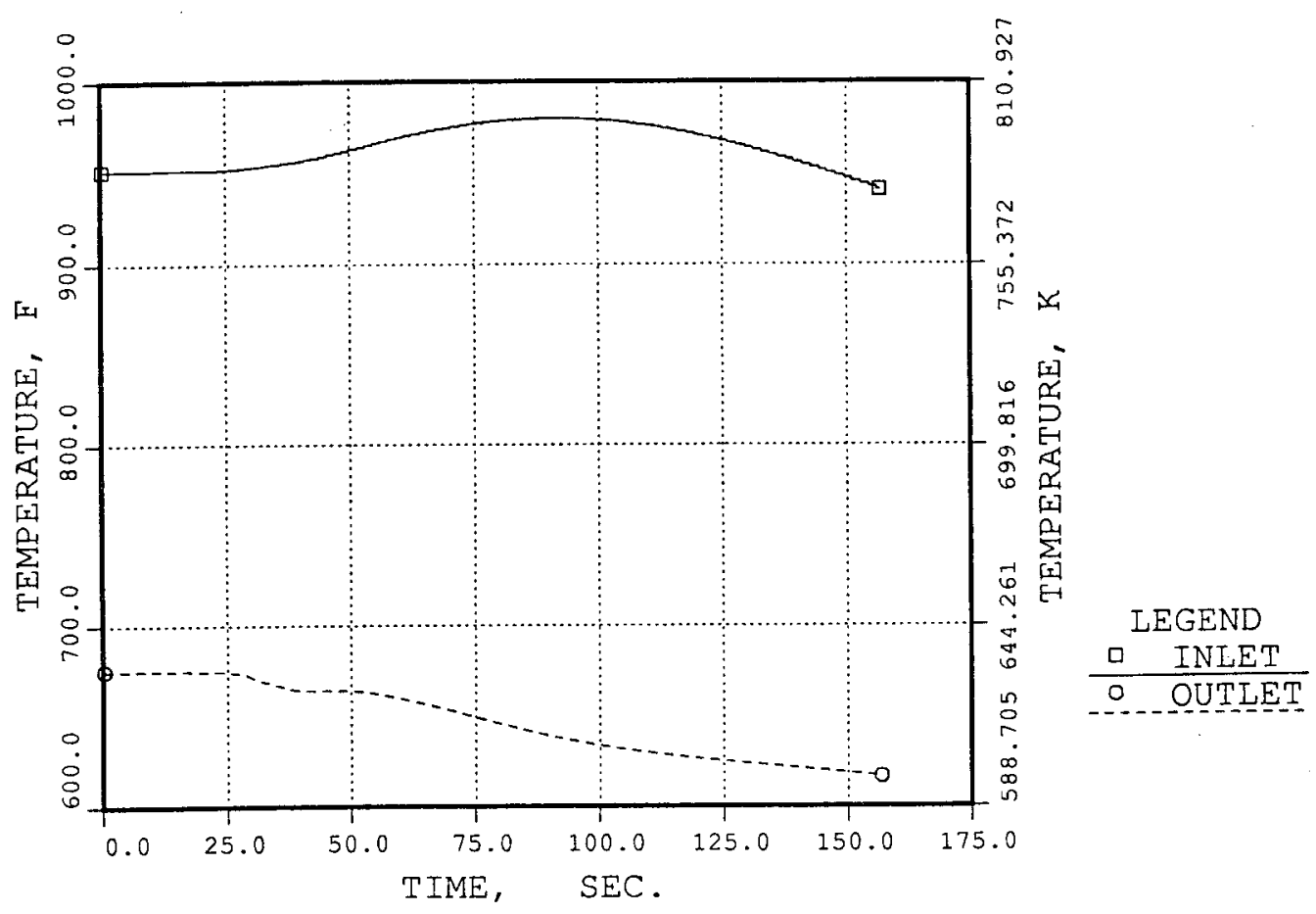

Fig. 5.1-7. No Rod PPS. 20ф/sec Control Rod Withdrawal IHX Primary Side Temperatures

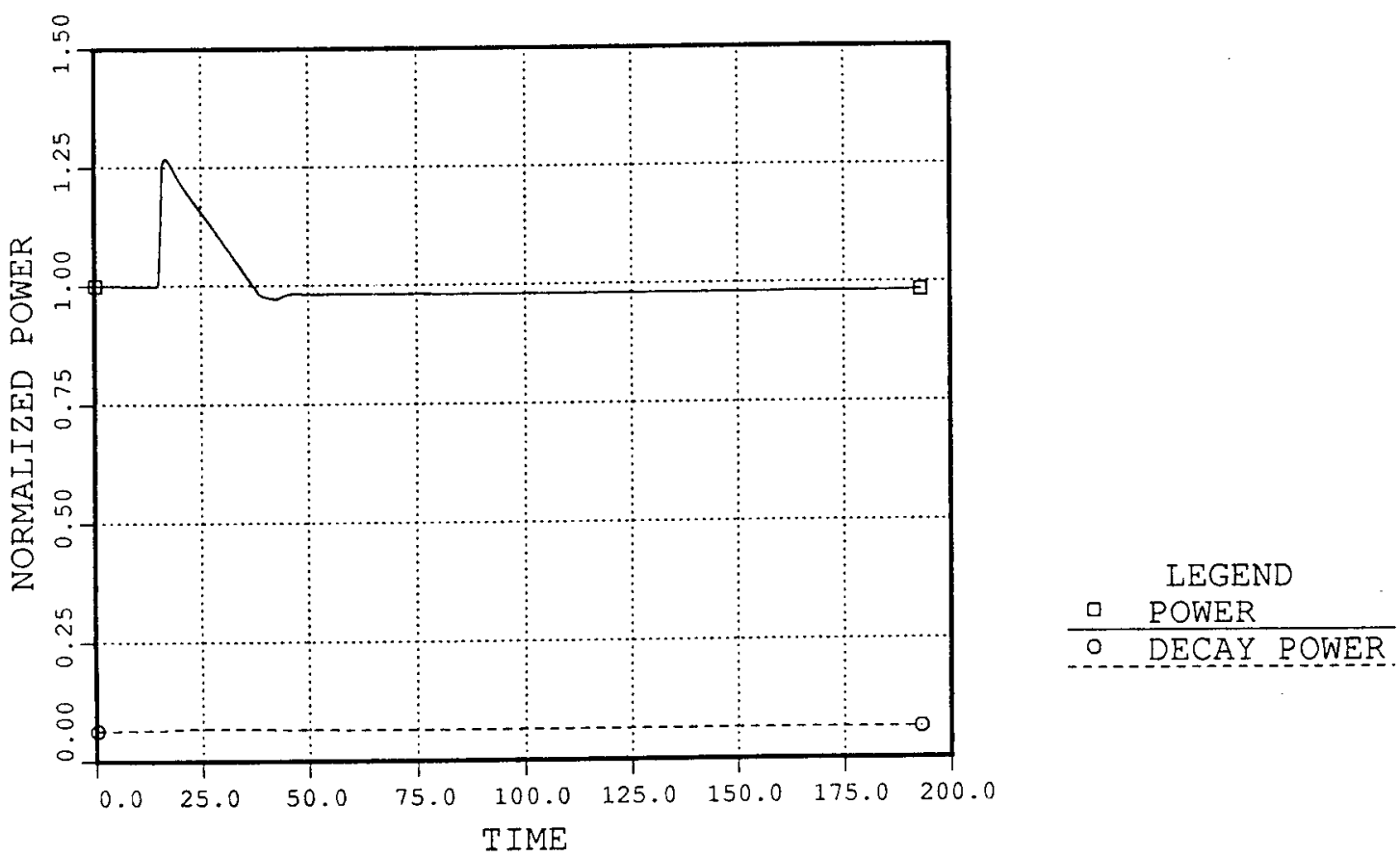

Fig. 5.1-8. No Rod PPS. 20\$/sec Control Rod Withdrawal/No Sensor Reactor Power 


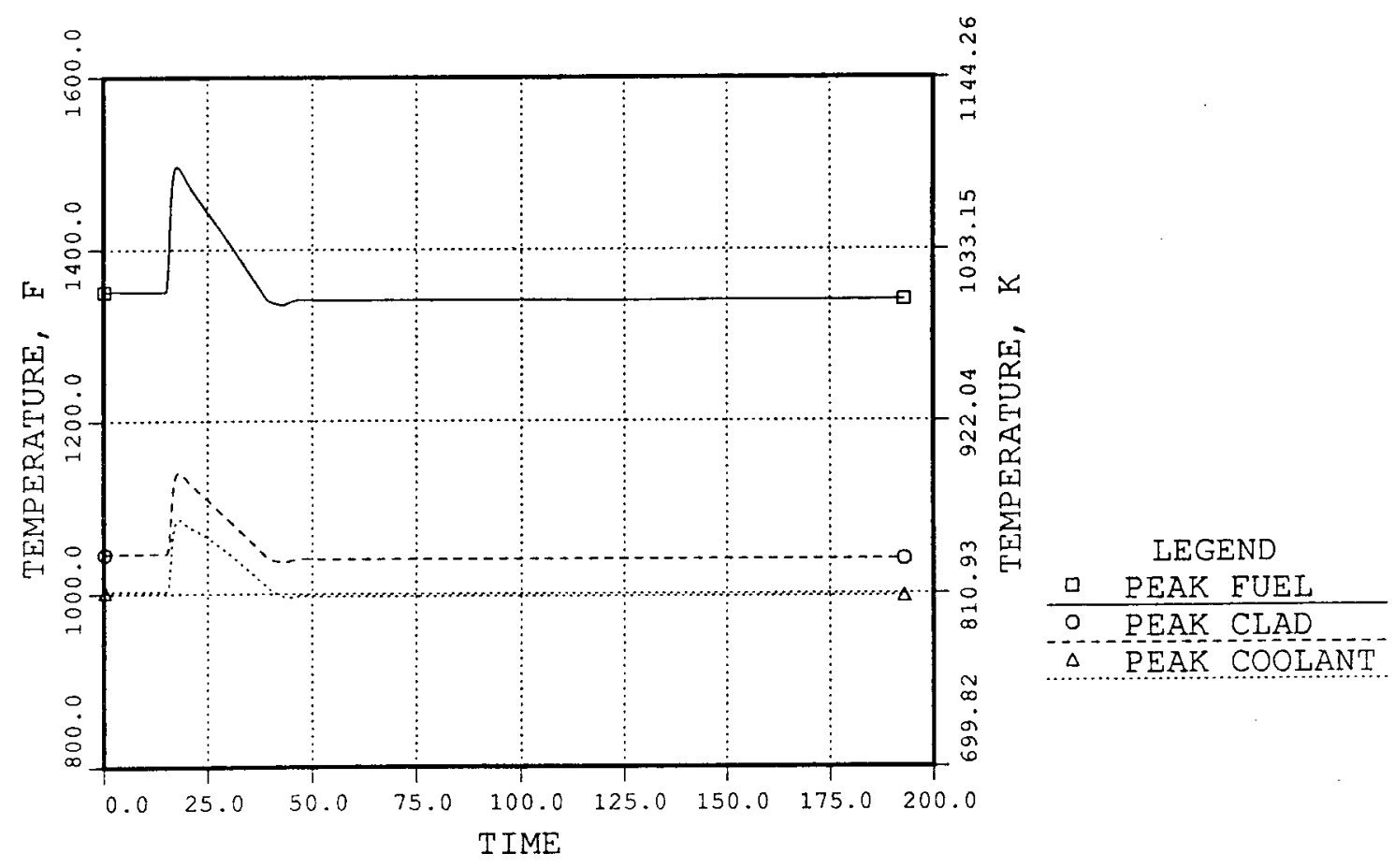

Fig. 5.1-9. No Rod PPS. 20\$/sec Control Rod Withdrawal/No Sensor Channe 11 Peak Temperatures

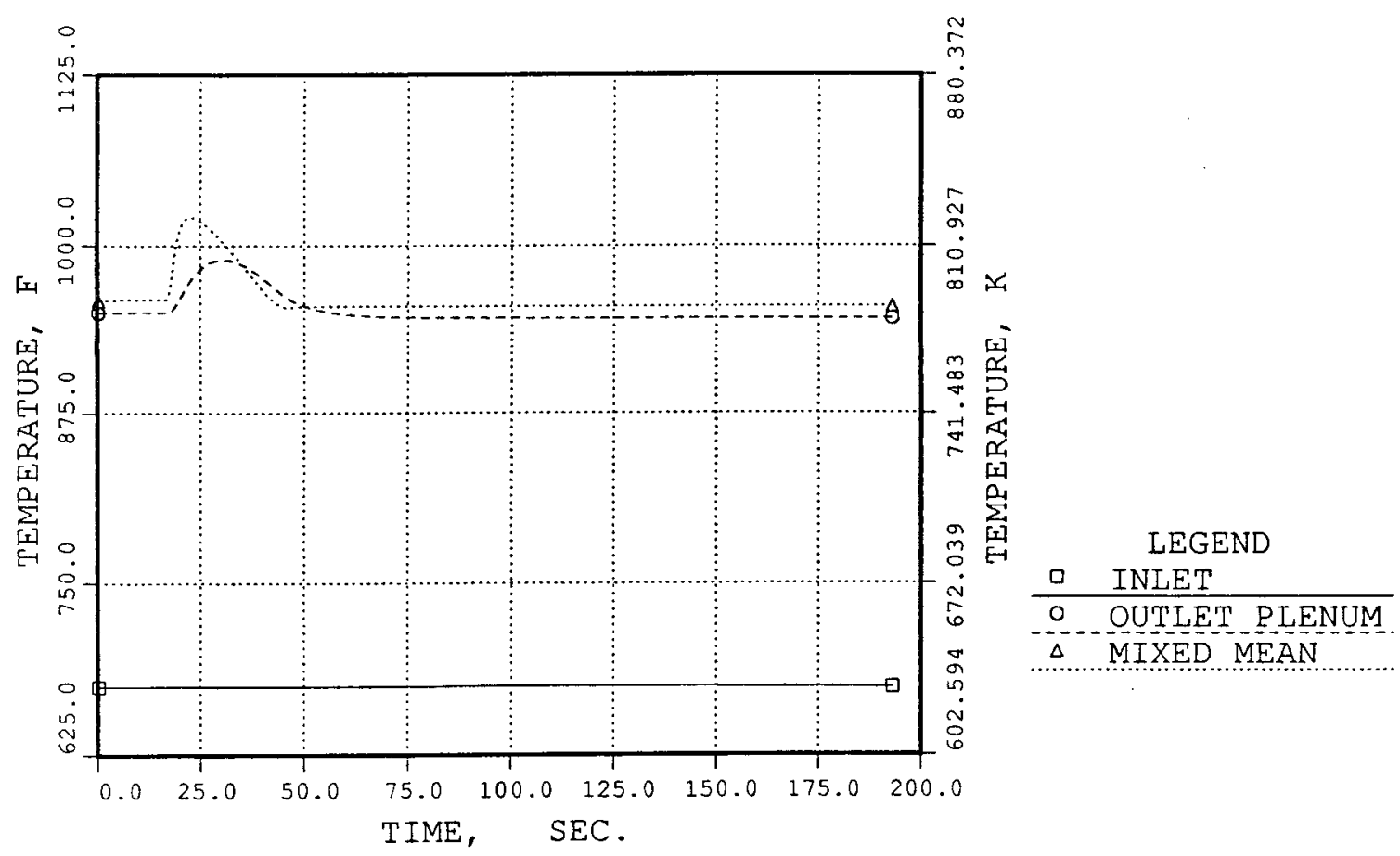

Fig. 5.1-10. No Rod PPS. 20\$/sec Control Rod Withdrawal/No Sensor Reactor Core Temperatures 


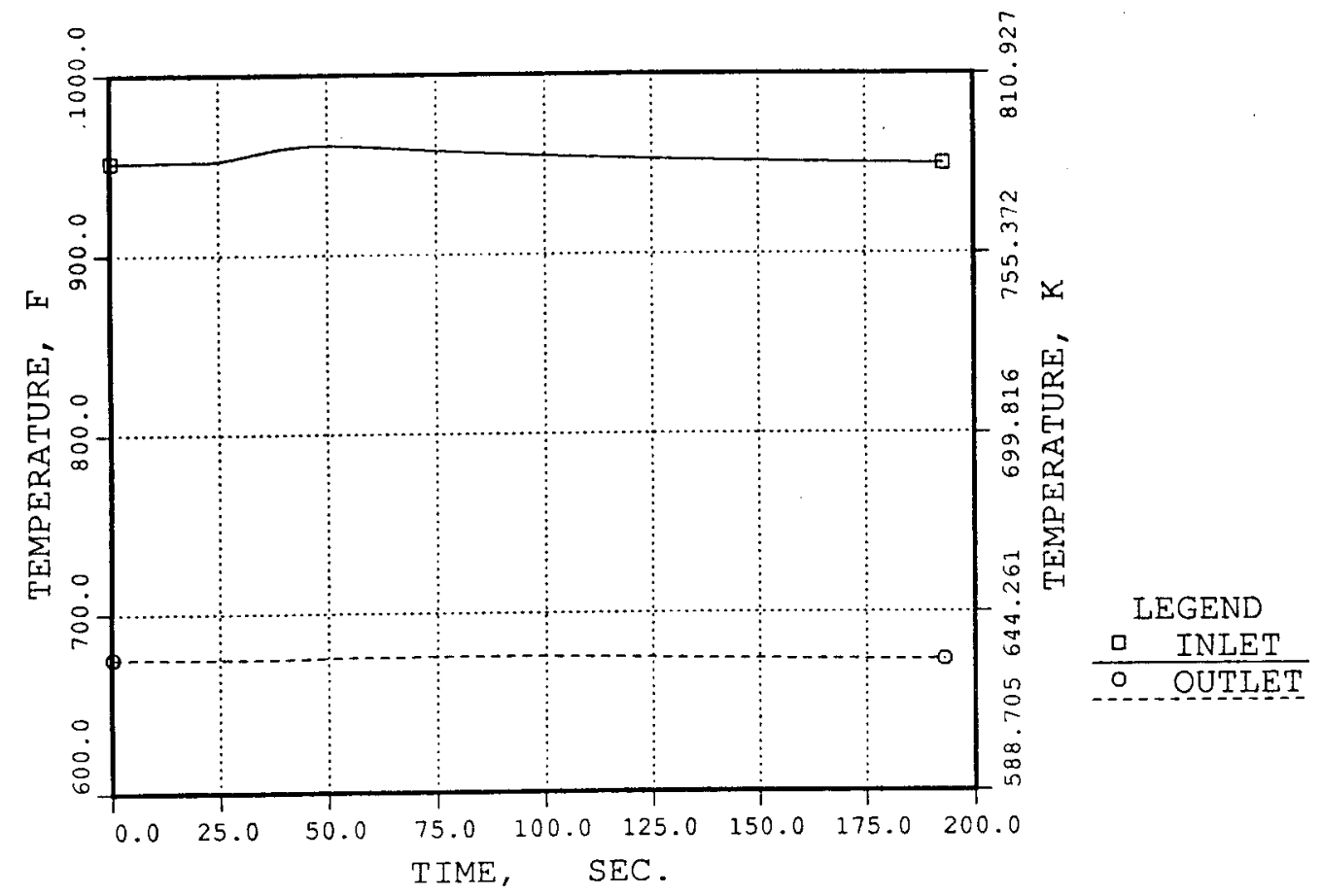

Fig. 5.1-11. No Rod PPS. 20\$/sec Control Rod Withdrawal/No Sensor IHX Primary Side Temperatures

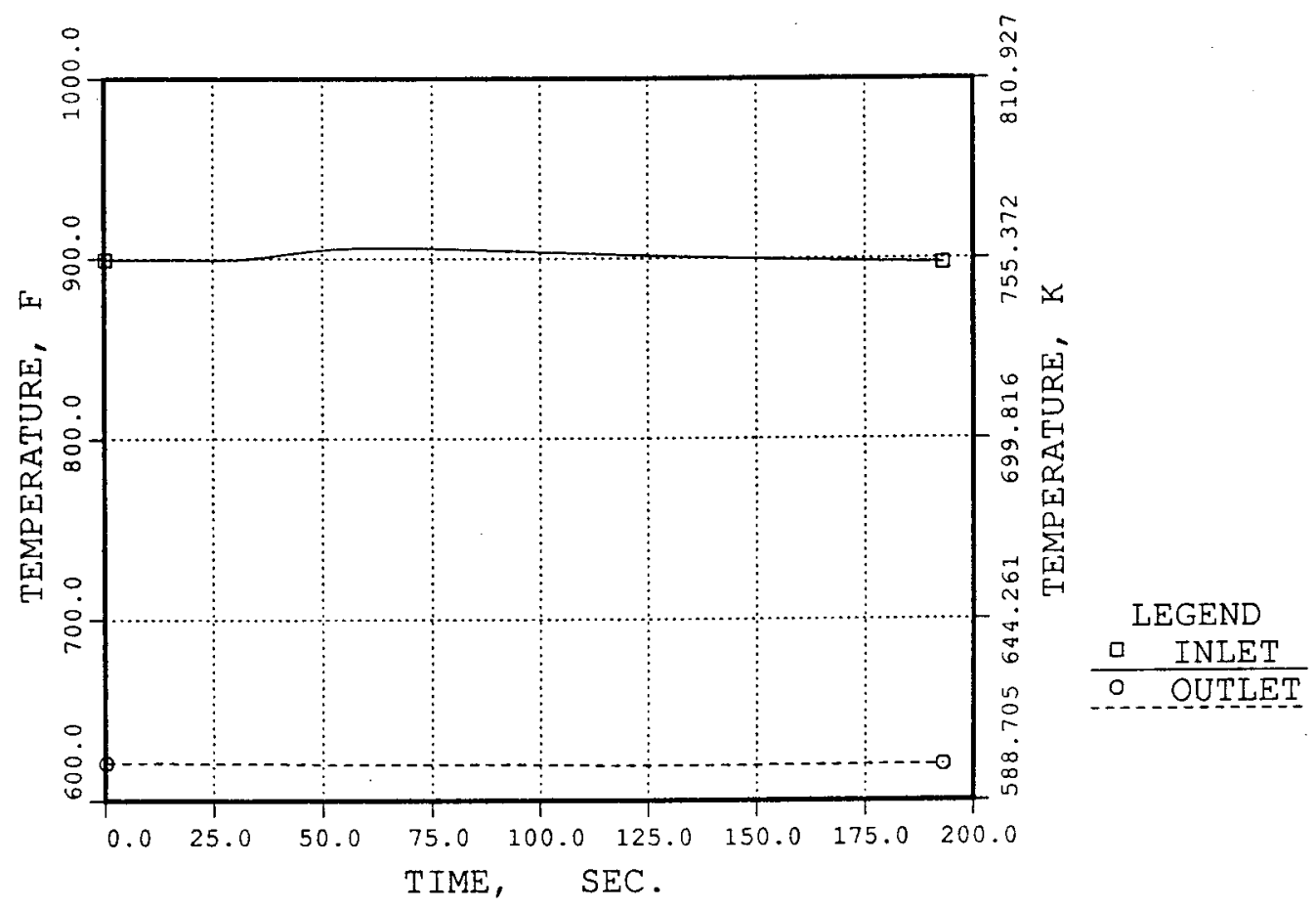

Fig. 5.1-12. No Rod PPS. 20ф/sec Control Rod Withdrawa1/No Sensor SG Sodium Temperatures 


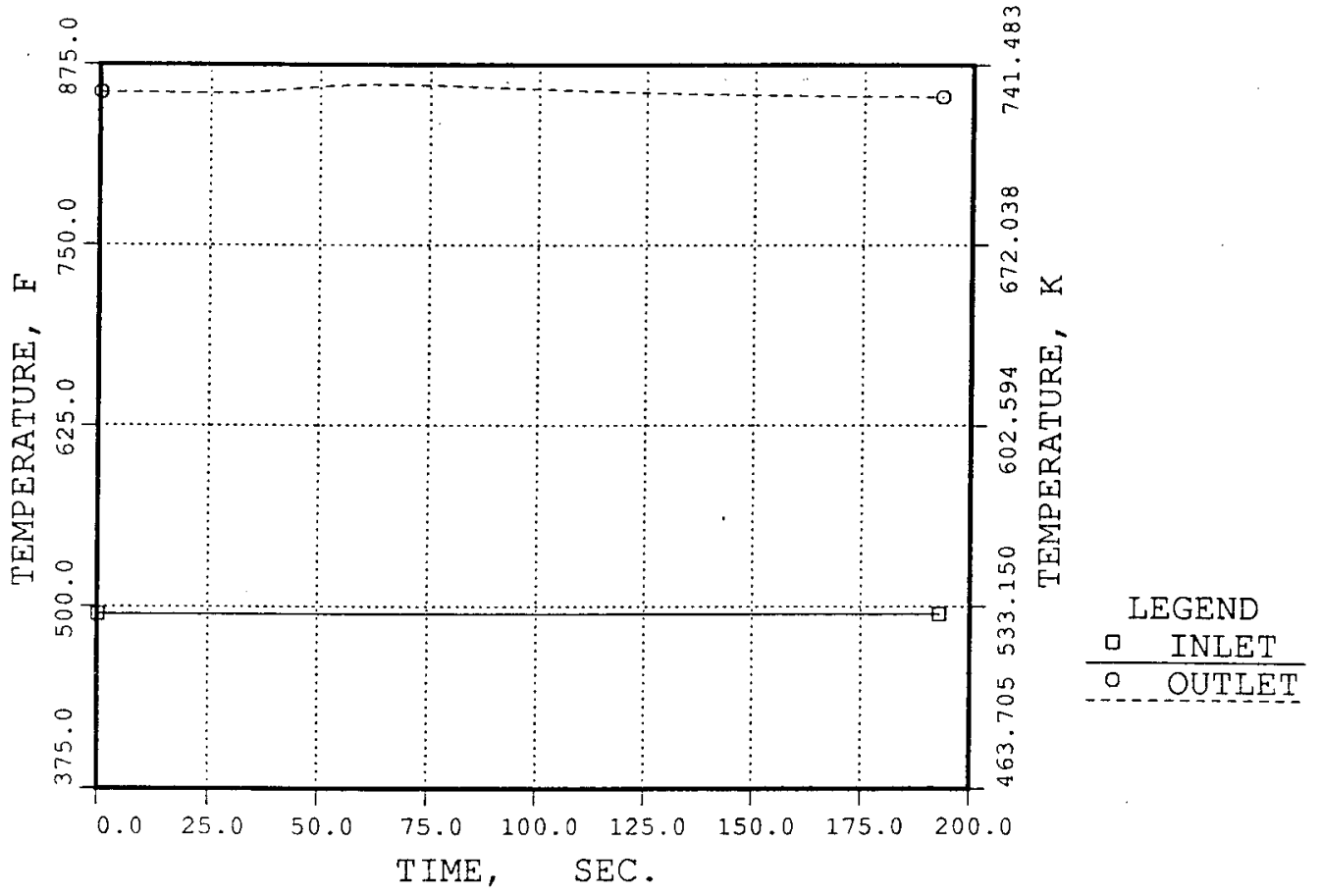

Fig. 5.1-13. No Rod PPS. 20\$/sec Control Rod Withdrawal/No Sensor SG Water Temperatures
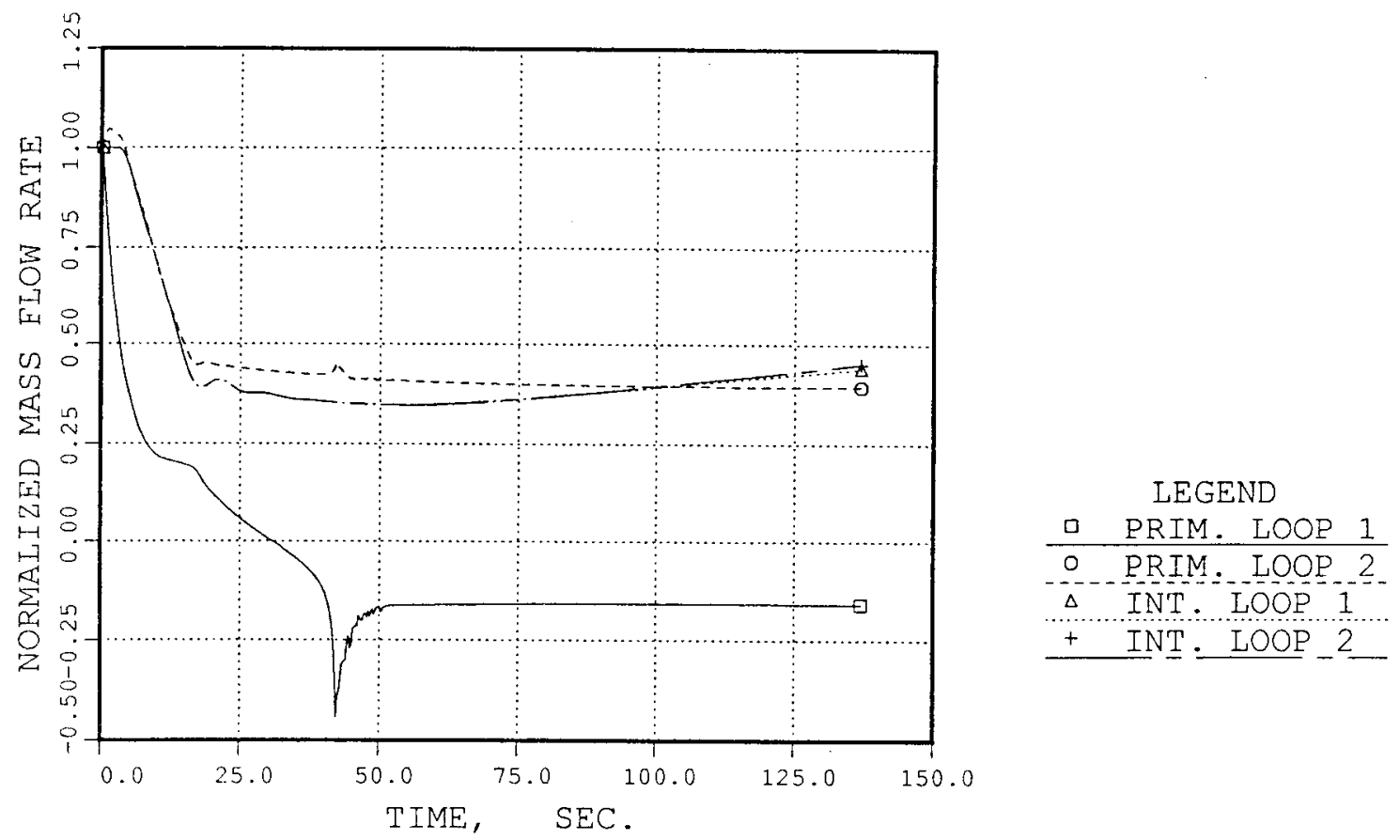

Fig. 5.1-14. No Rod PPS. 1 PHTS Pump Trip - Loop Flows 


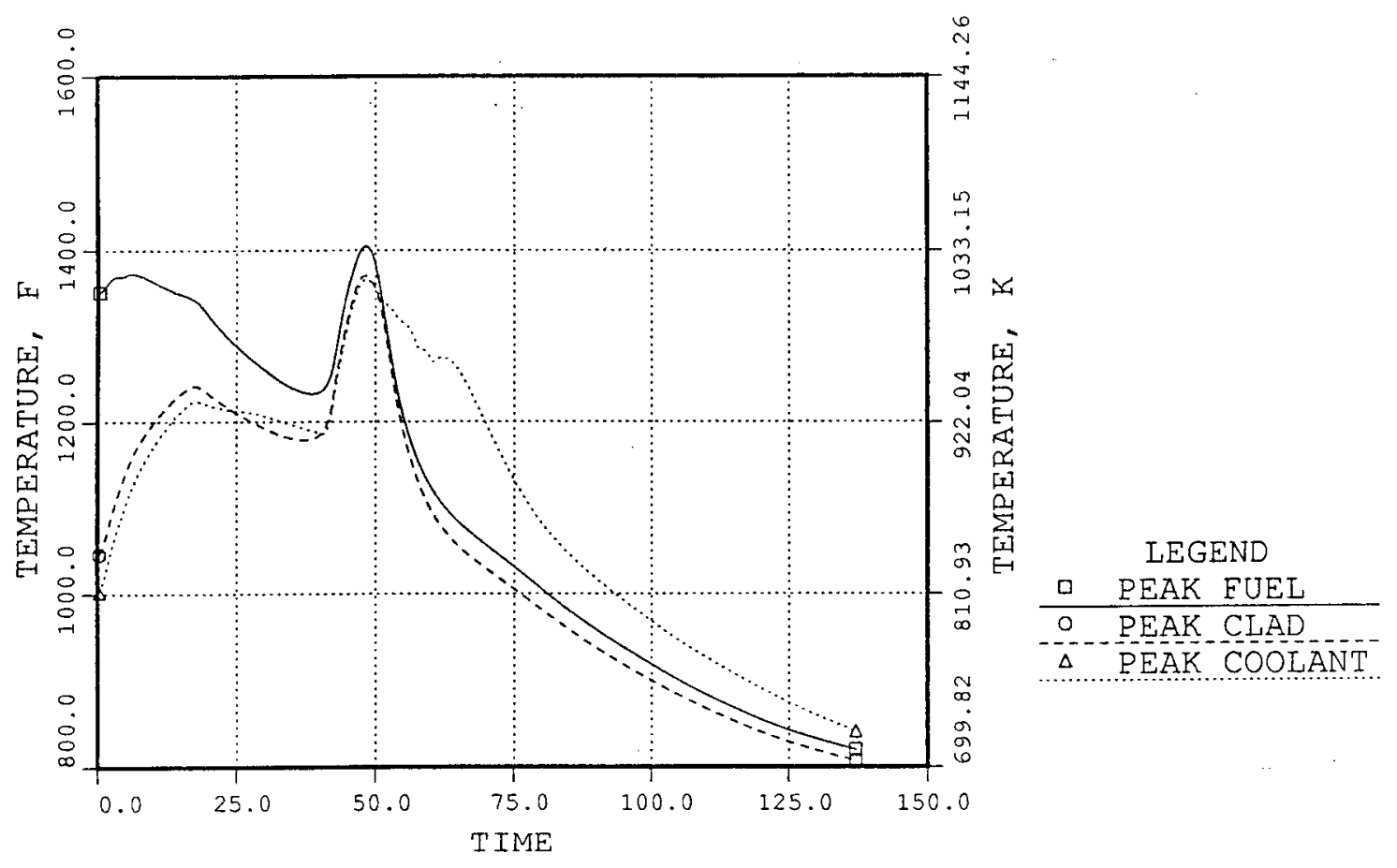

Fig. 5.1-15. No Rod PPS. 1 PHTS Pump Trip Channel Peak Temperatures

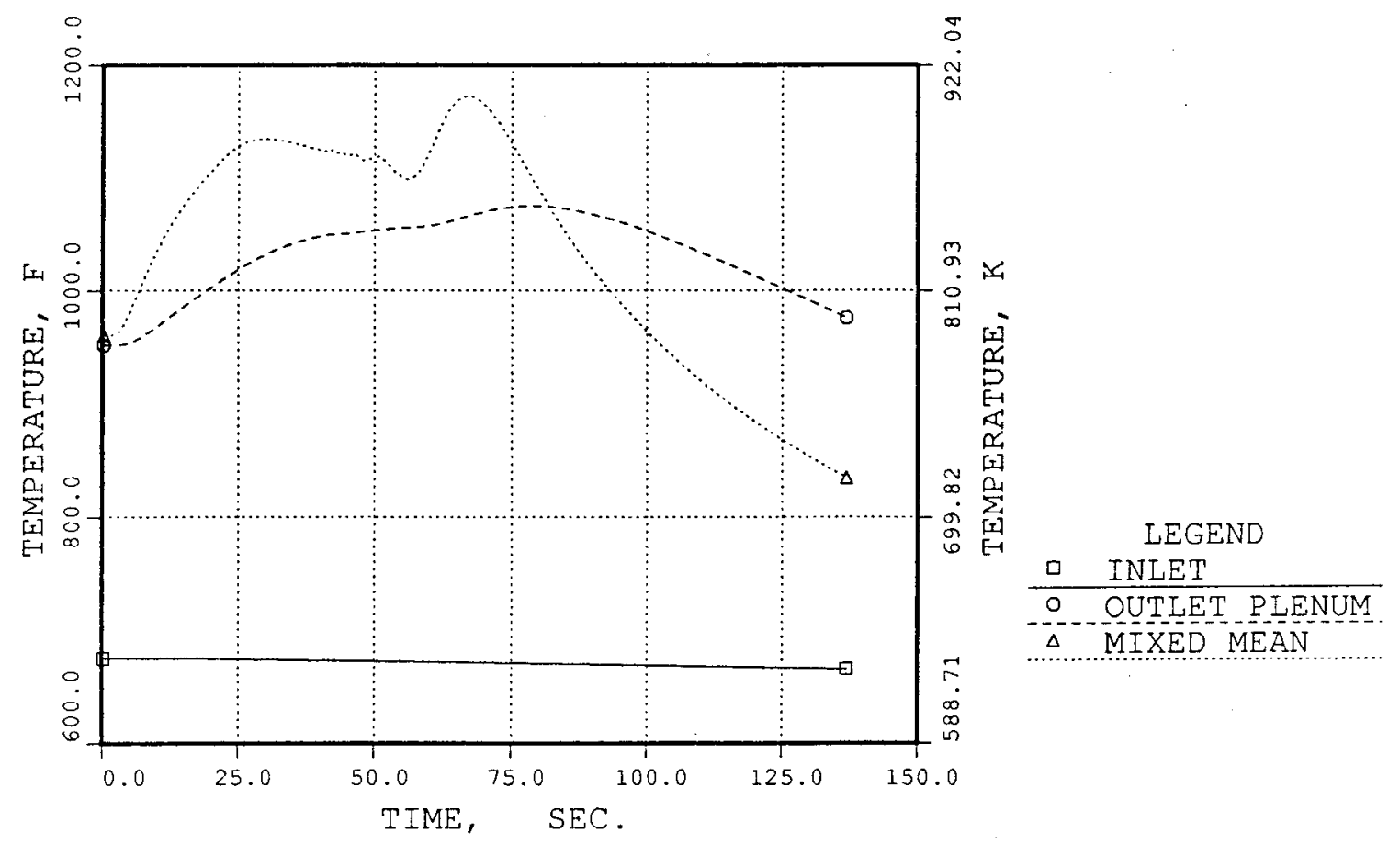

Fig. 5.1-16. No Rod PPS. 1 PHTS Pump Trip Reactor Core Temperatures 


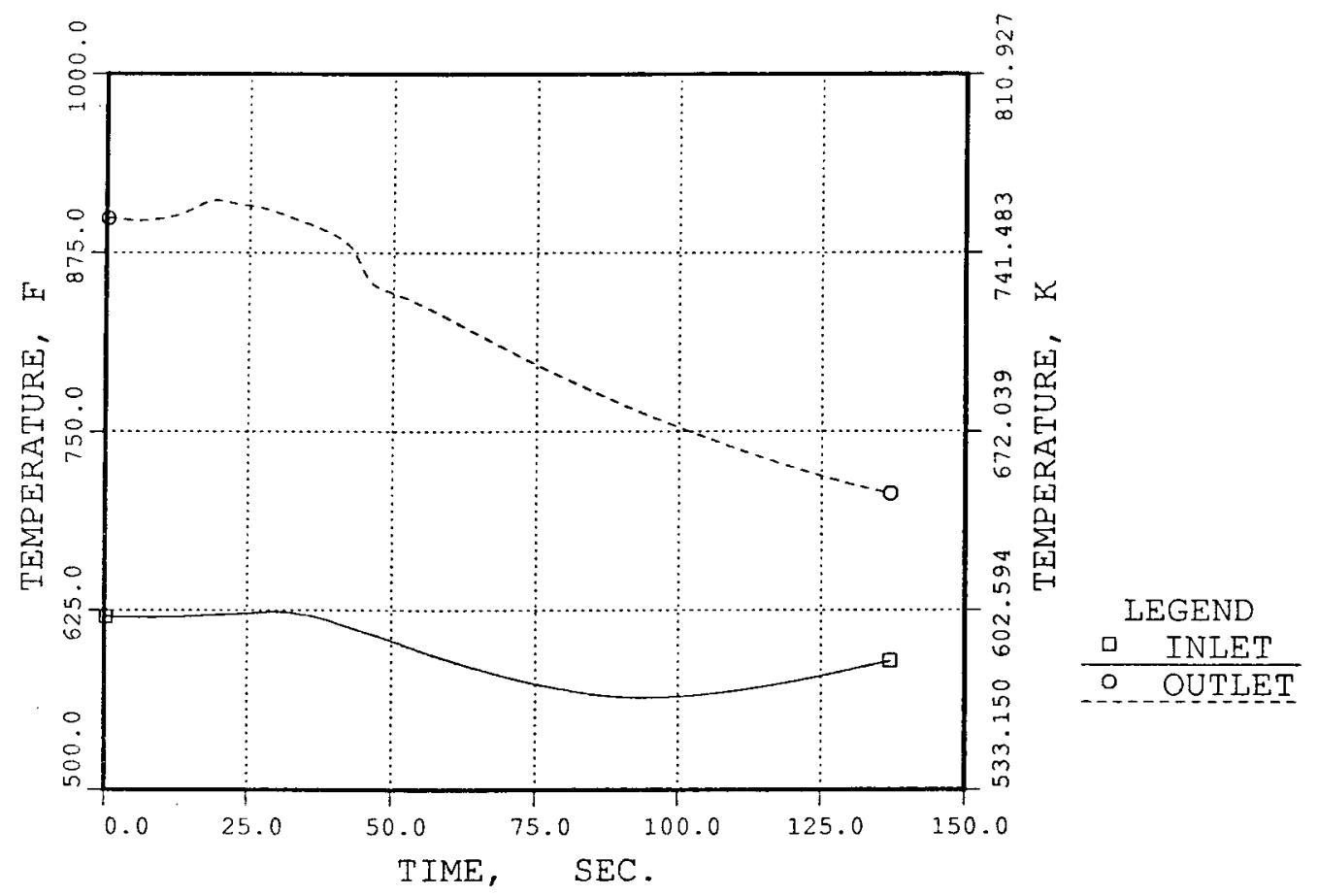

Fig. 5.1-17. No Rod PPS. 1 PHTS Pump Trip - IHX 1 Intermediate Side Temperatures

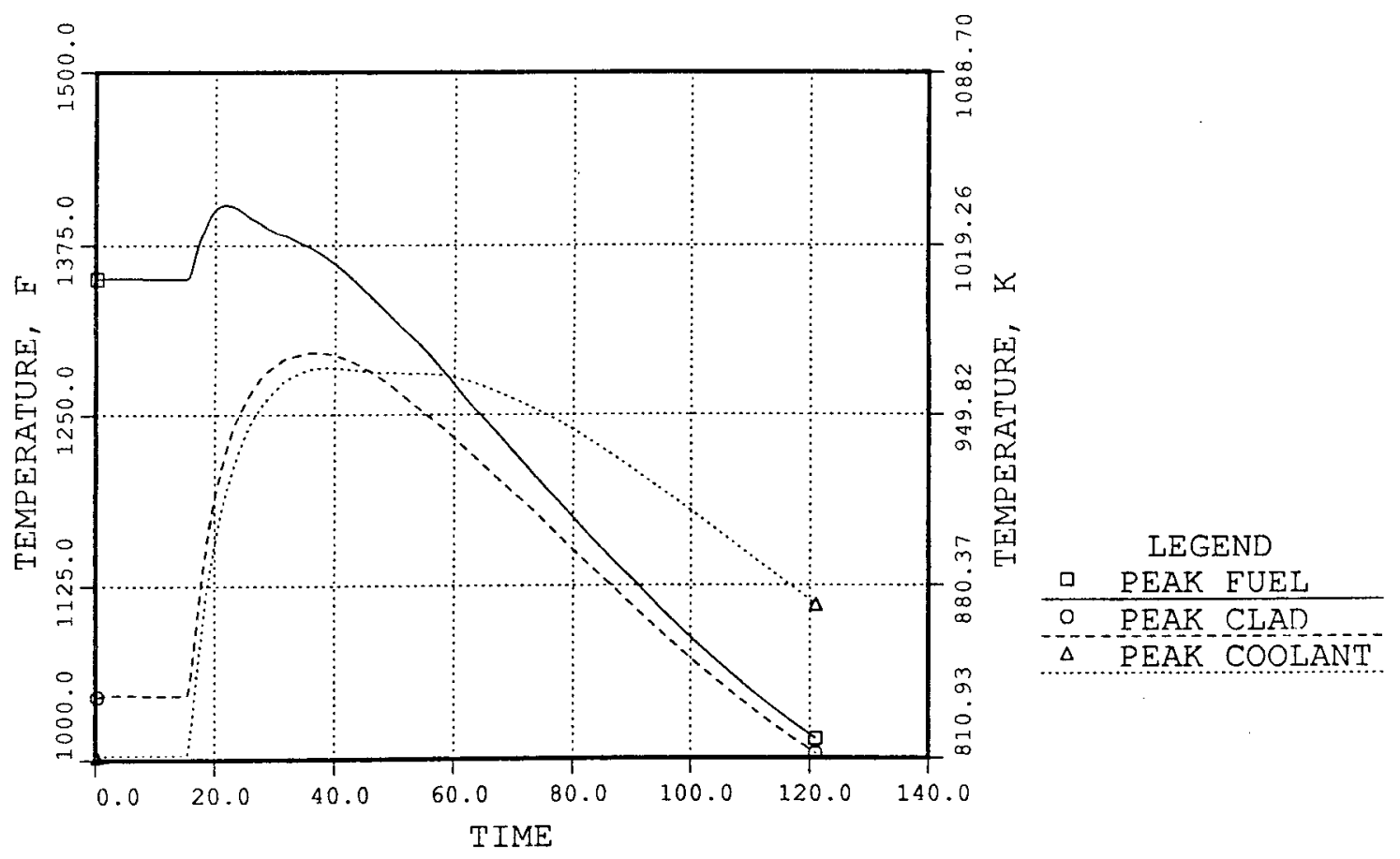

Fig. 5.1-18. No Rod PPS. 2 PHTS Pump Trip Channe 11 Peak Temperatures 


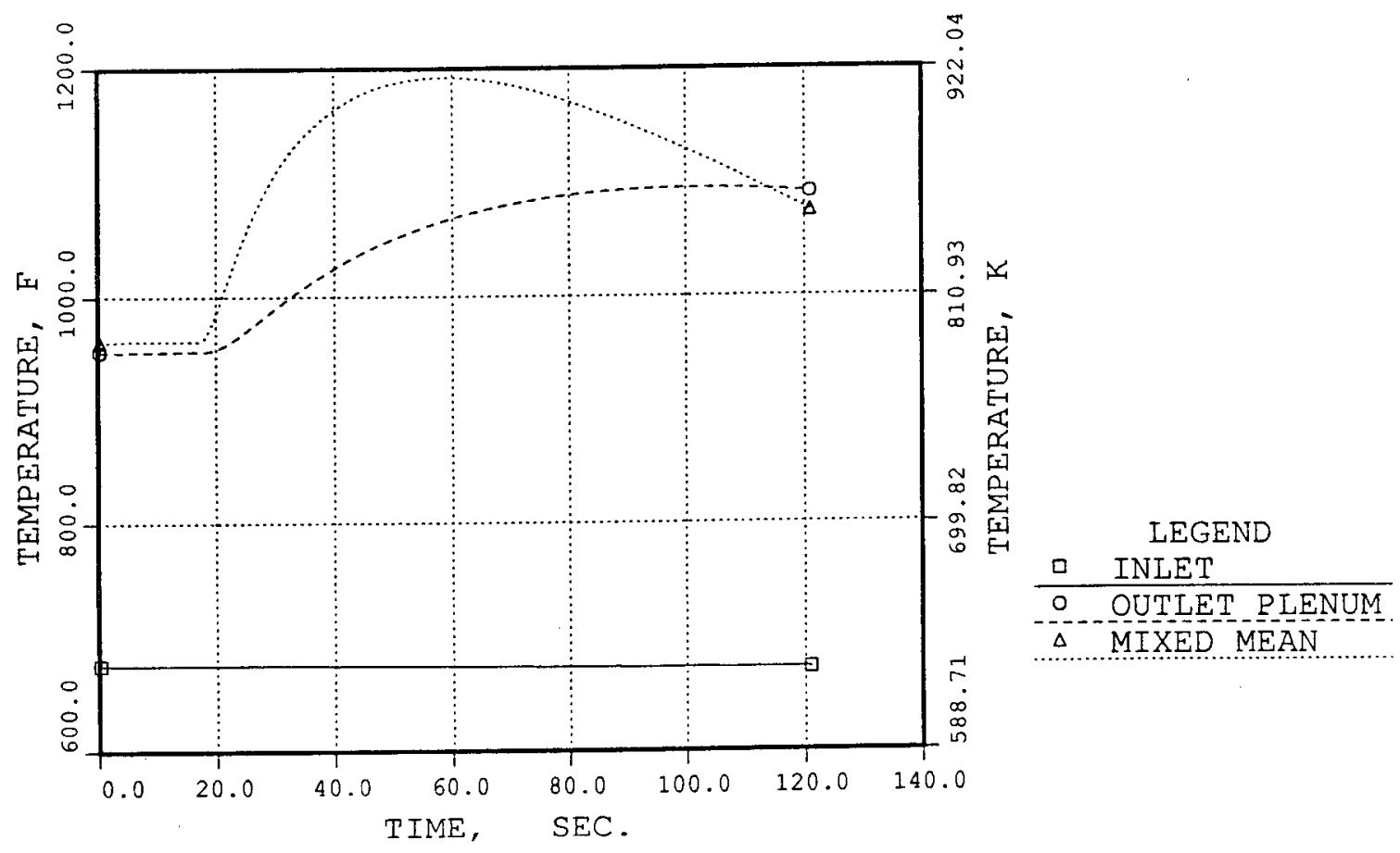

Fig. 5.1-19. No Rod PPS. 2 PHTS Pump Trip Reactor Core Temperatures

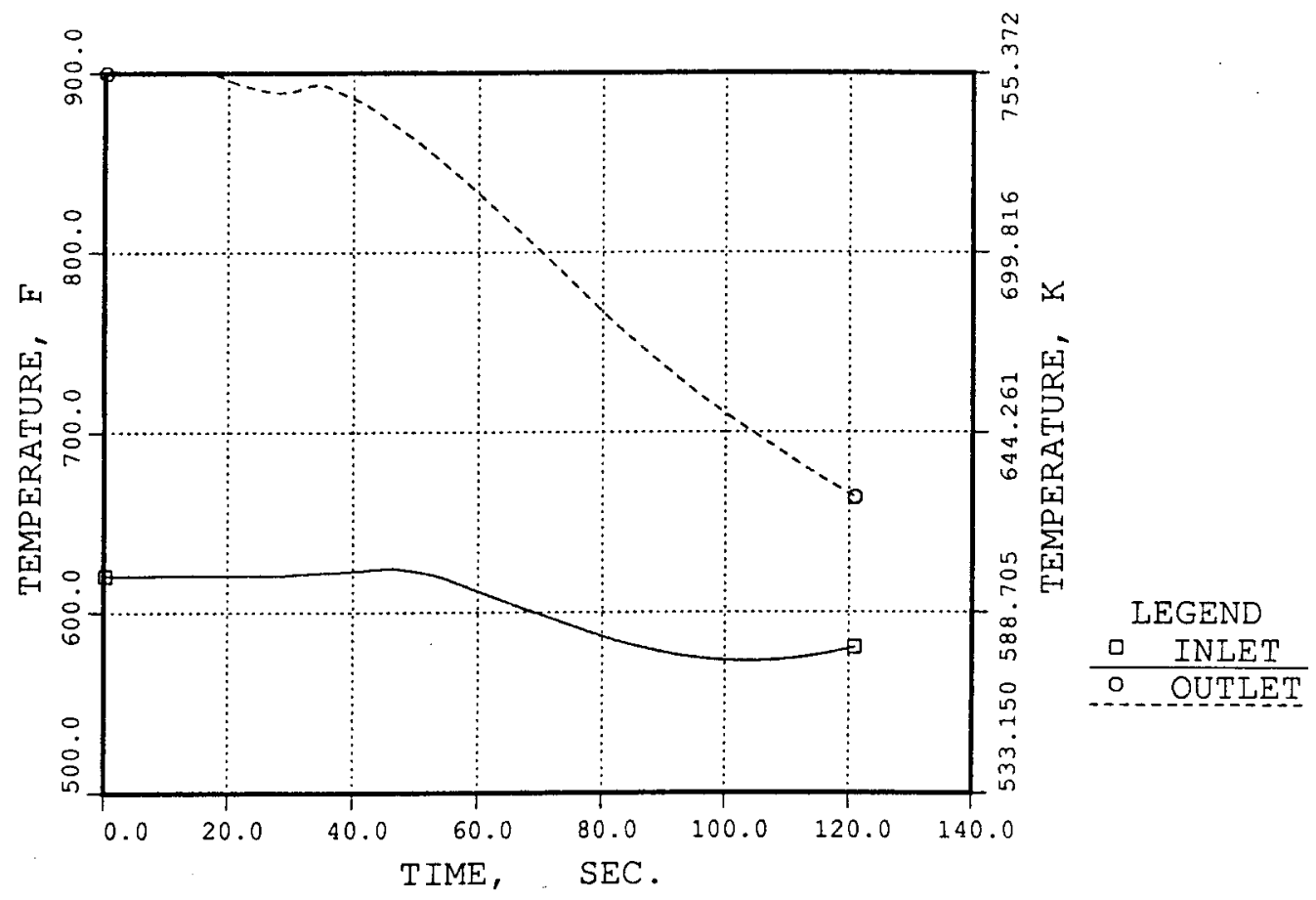

Fig. 5.1-20. No Rod PPS. 2 PHTS Pump Trip - IHX Intermediate Side Temperatures 


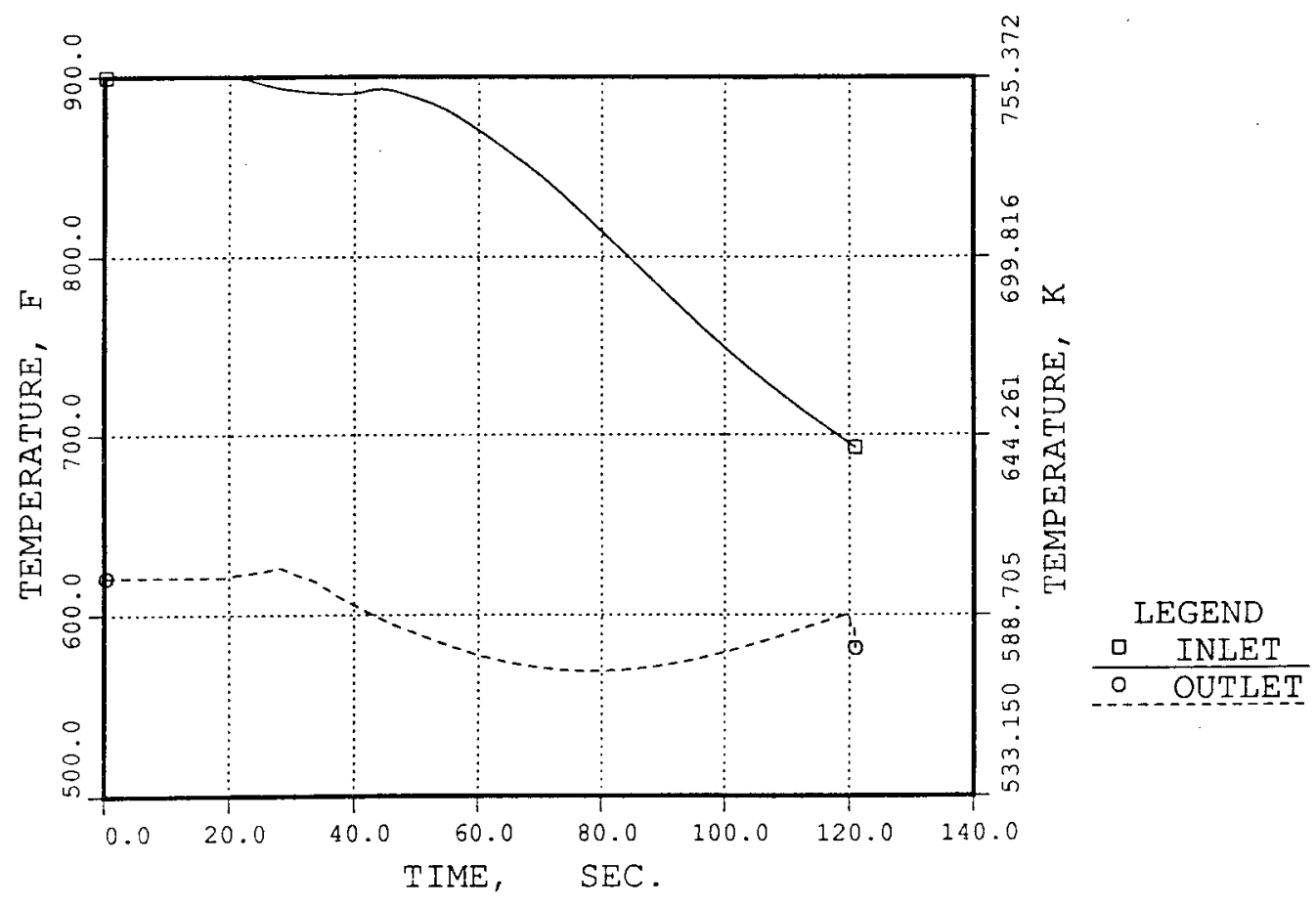

Fig. 5.1-21. No Rod PPS. 2 PHTS Pump Trip SG Sodium Temperatures

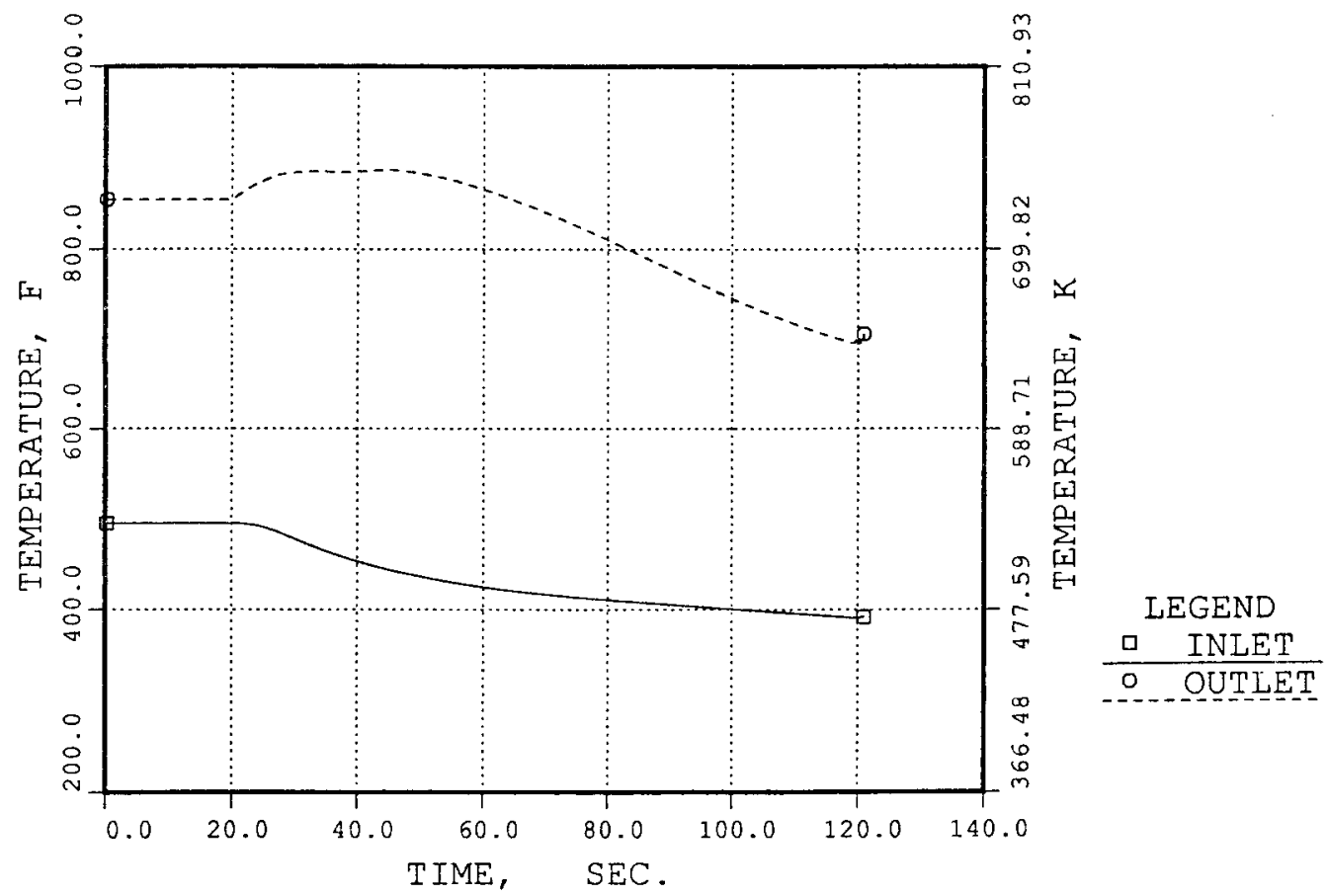

Fig. 5.1-22. No Rod PPS. 2 PHTS Pump Trip SG Water Temperatures 


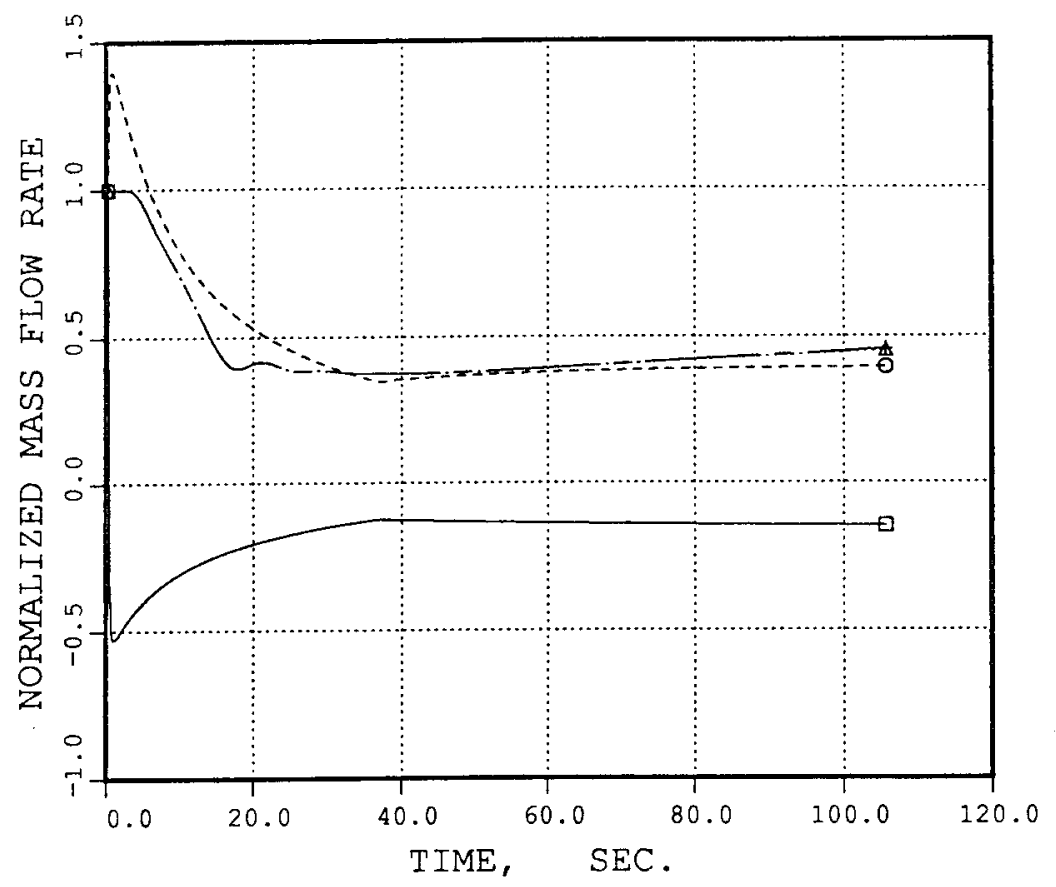

LEGEND

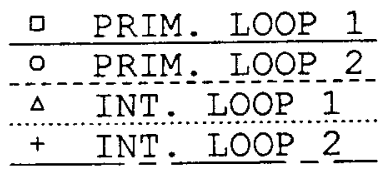

Fig. 5.1-23. No Rod PPS. 1 Seized PHTS Pump Loop Flows

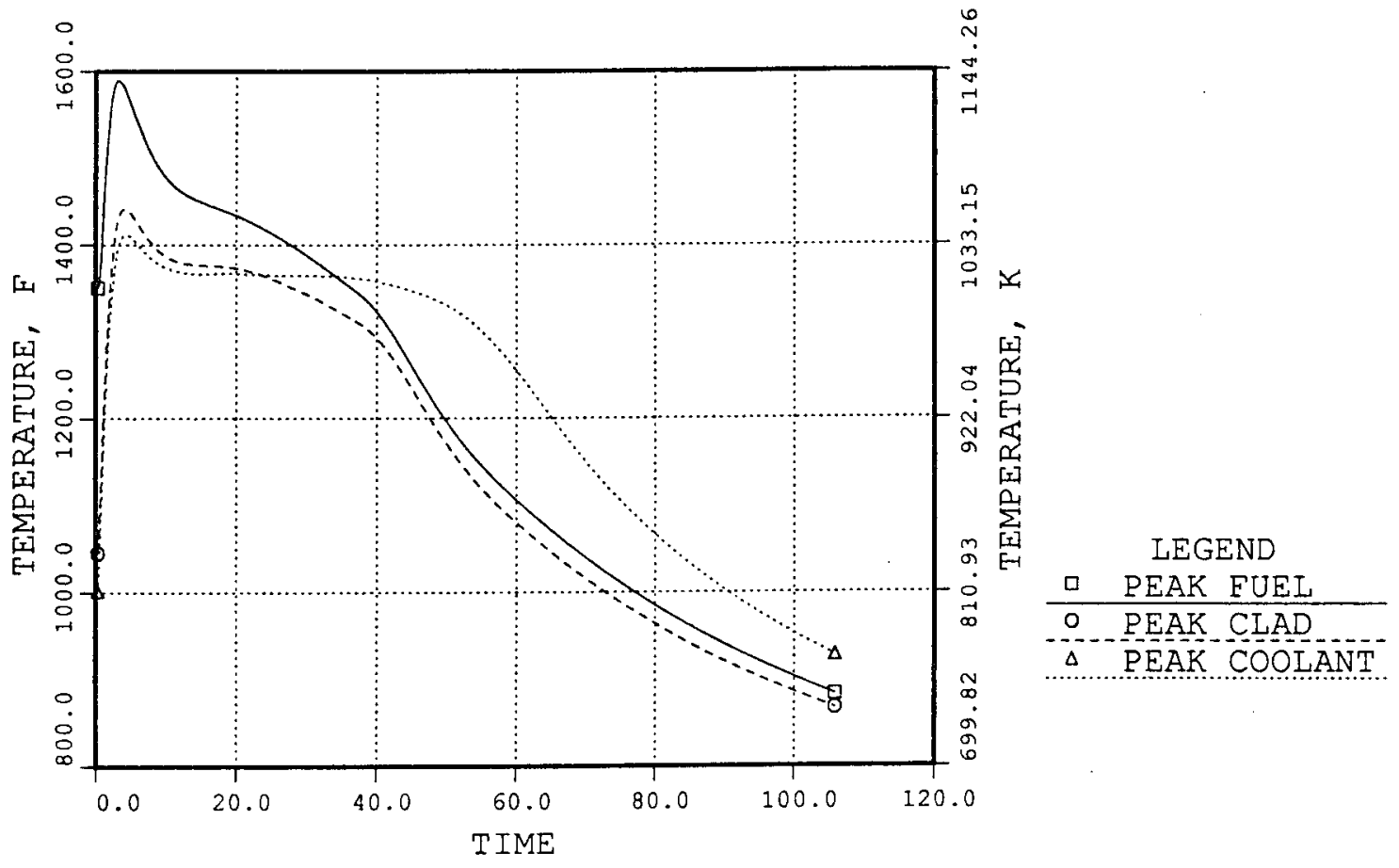

Fig. 5.1-24. No Rod PPS. 1 Seized PHTS Pump Channel 1 Peak Temperatures 


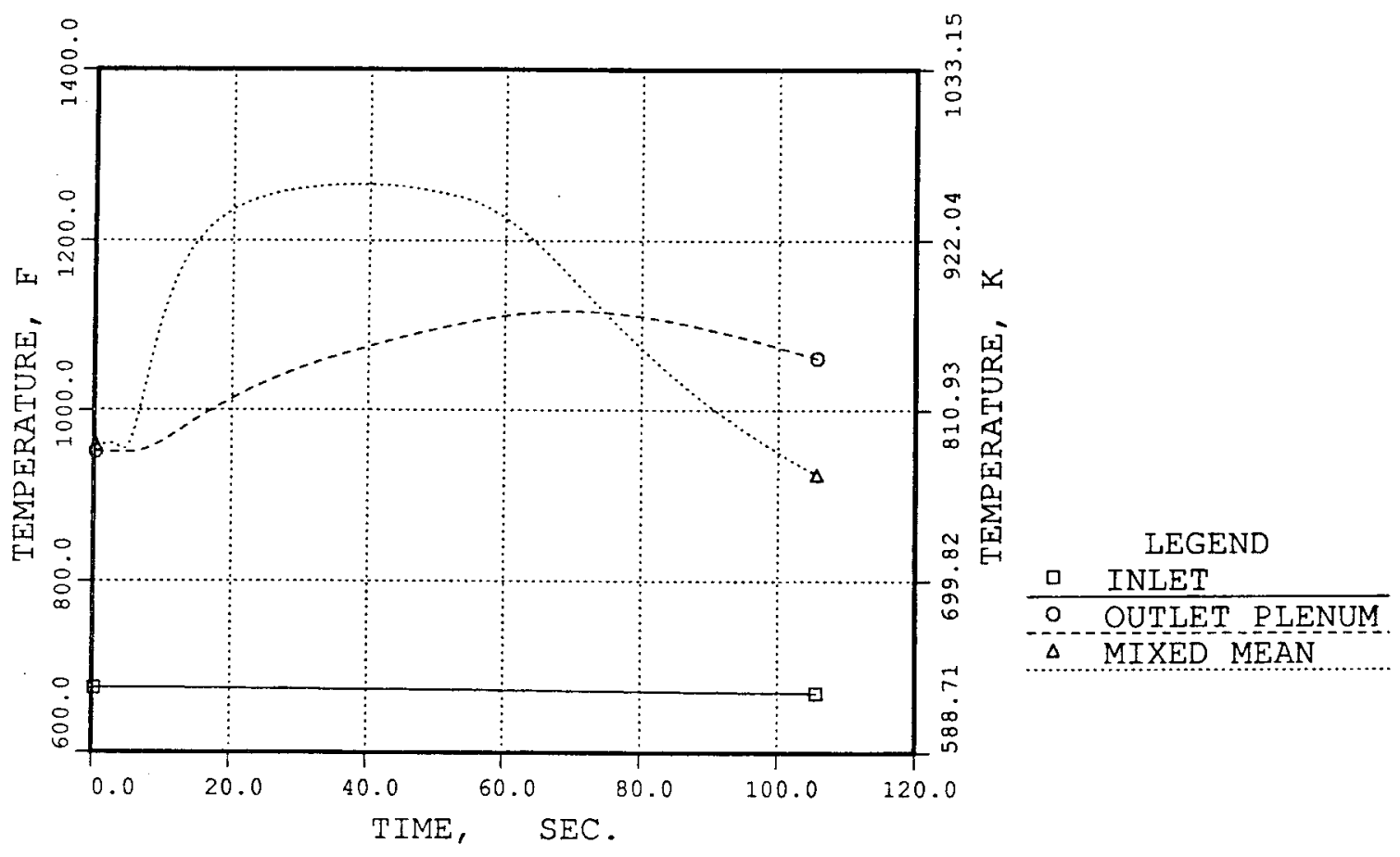

Fig. 5.1-25. No Rod PPS. 1 Seized PHTS Pump Reactor Core Temperatures

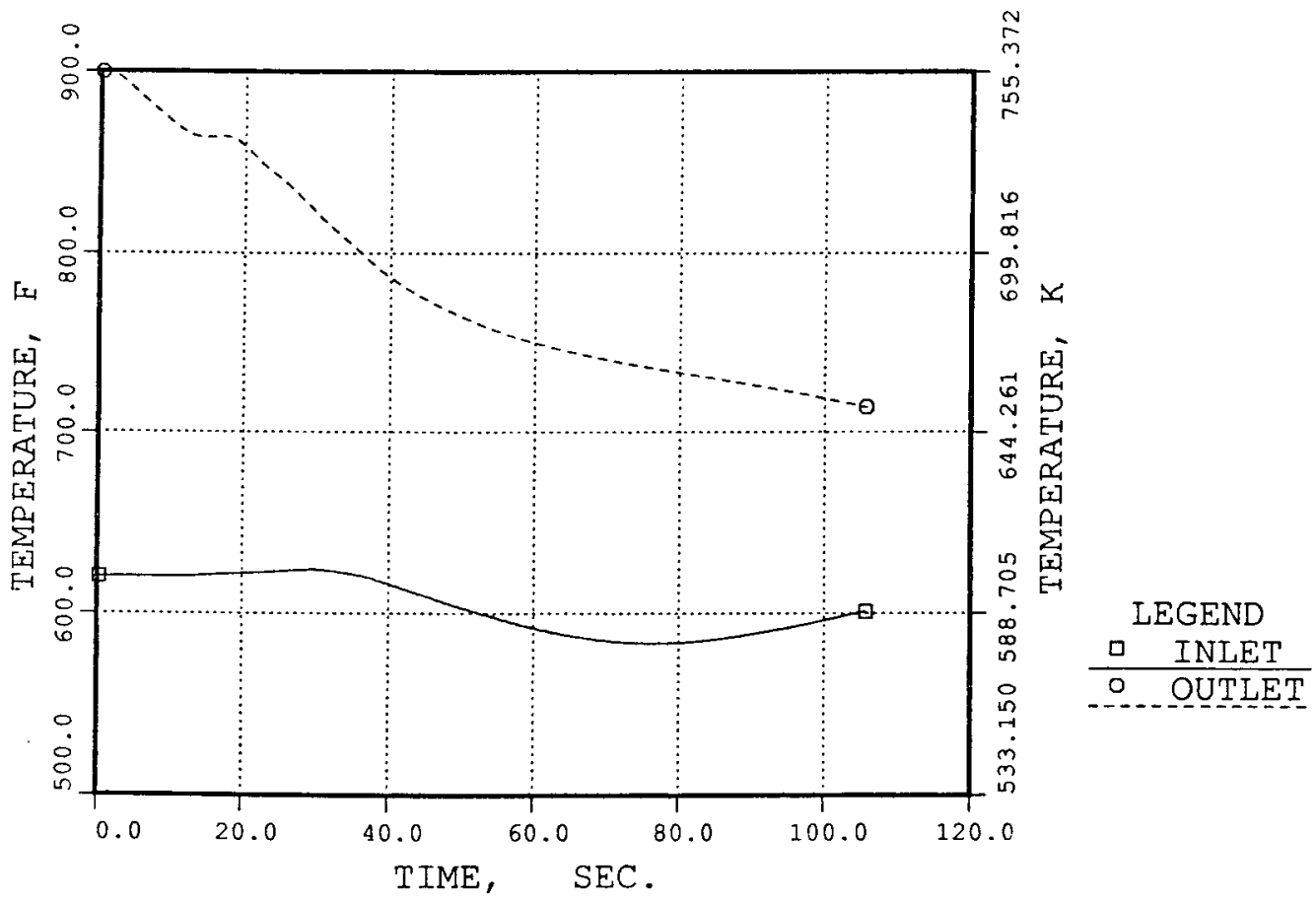

Fig. 5.1-26. No Rod PPS. 1 Seized PHTS Pump - IHXI Intermediate Side Temperatures 


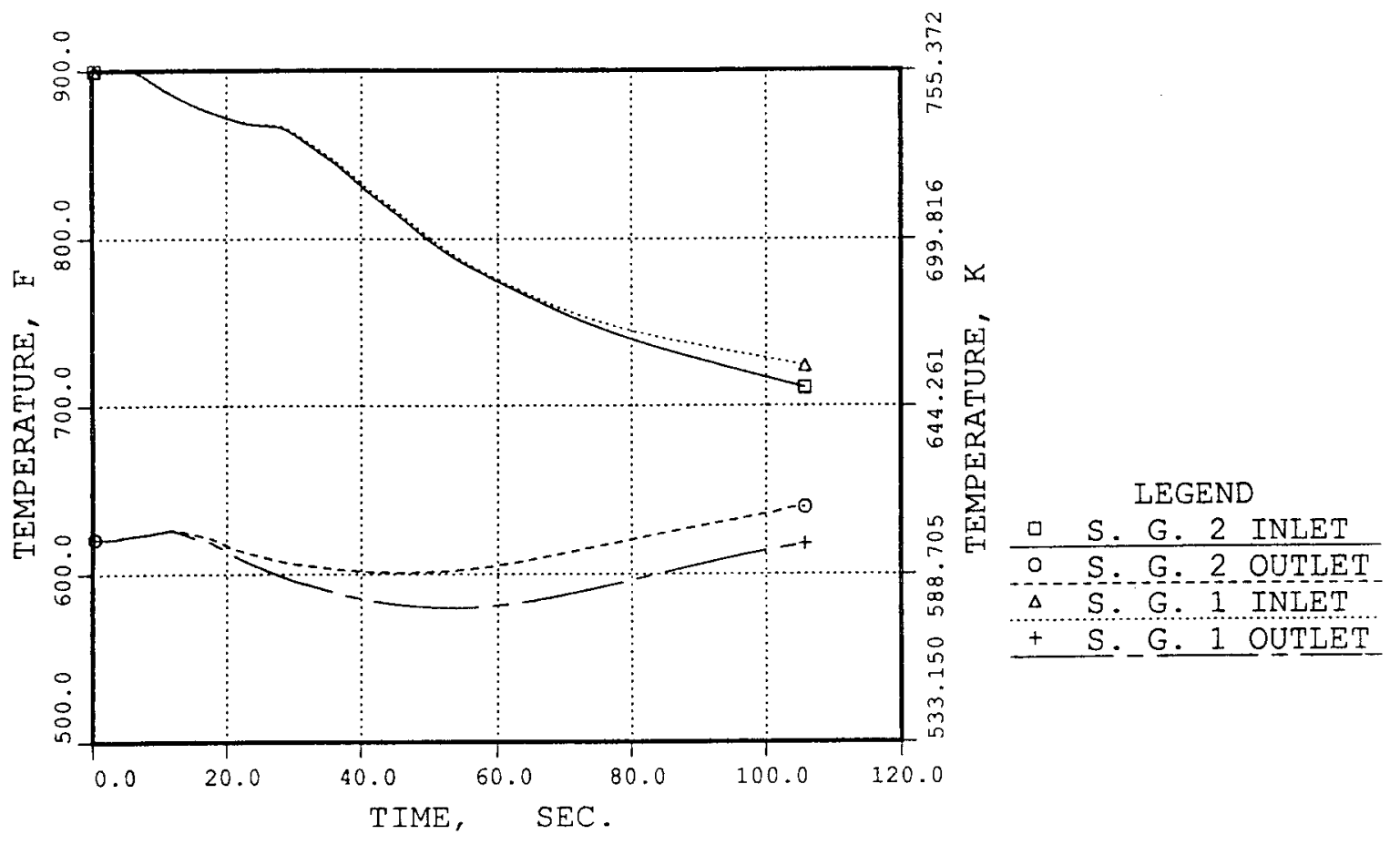

Fig. 5.1-27. No Rod PPS. 1 Seized PHTS Pump SG Sodium Temperatures
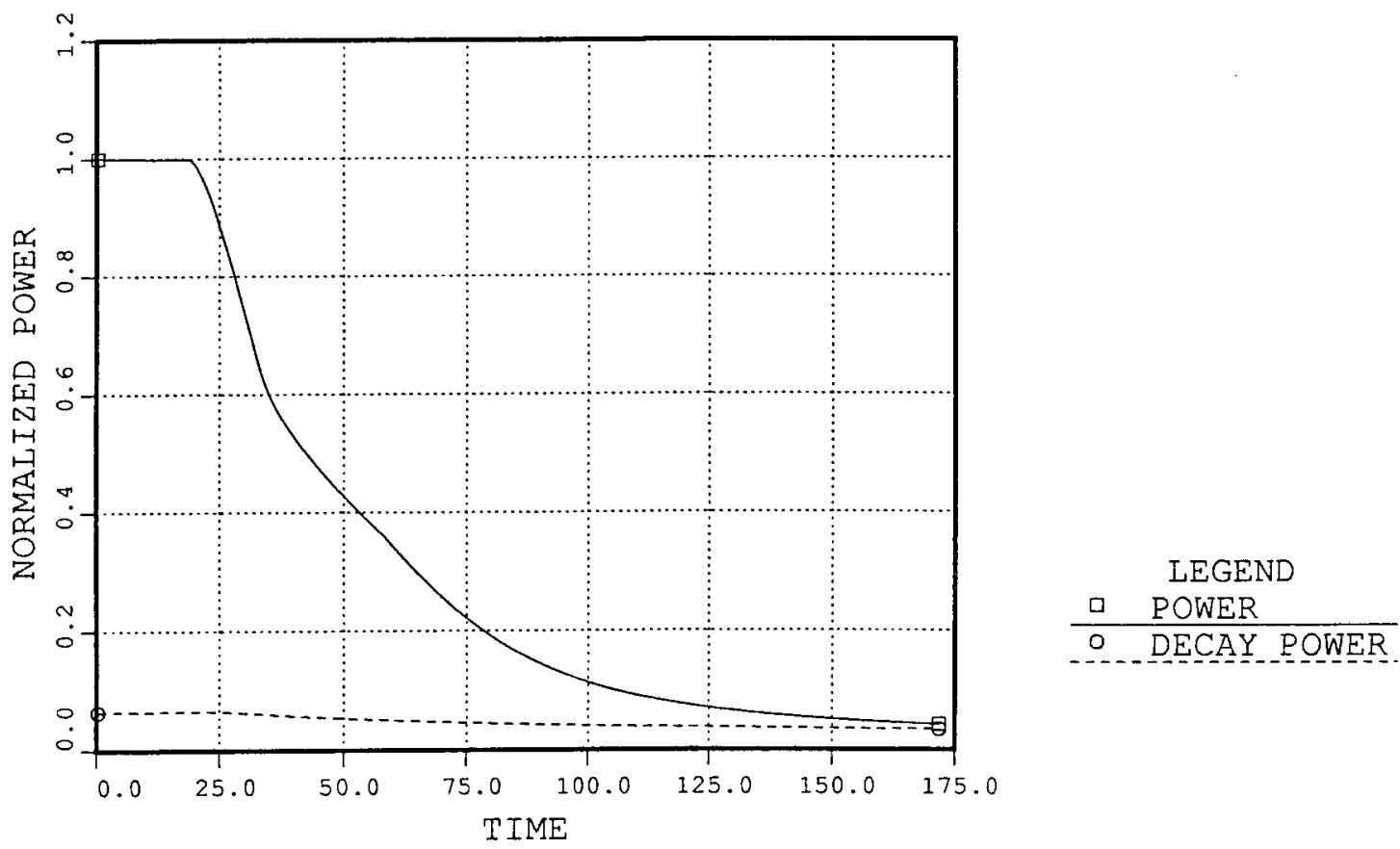

Fig. 5.1-28. No Rod PPS. 1 IHTS Pump Trip Reactor Power 

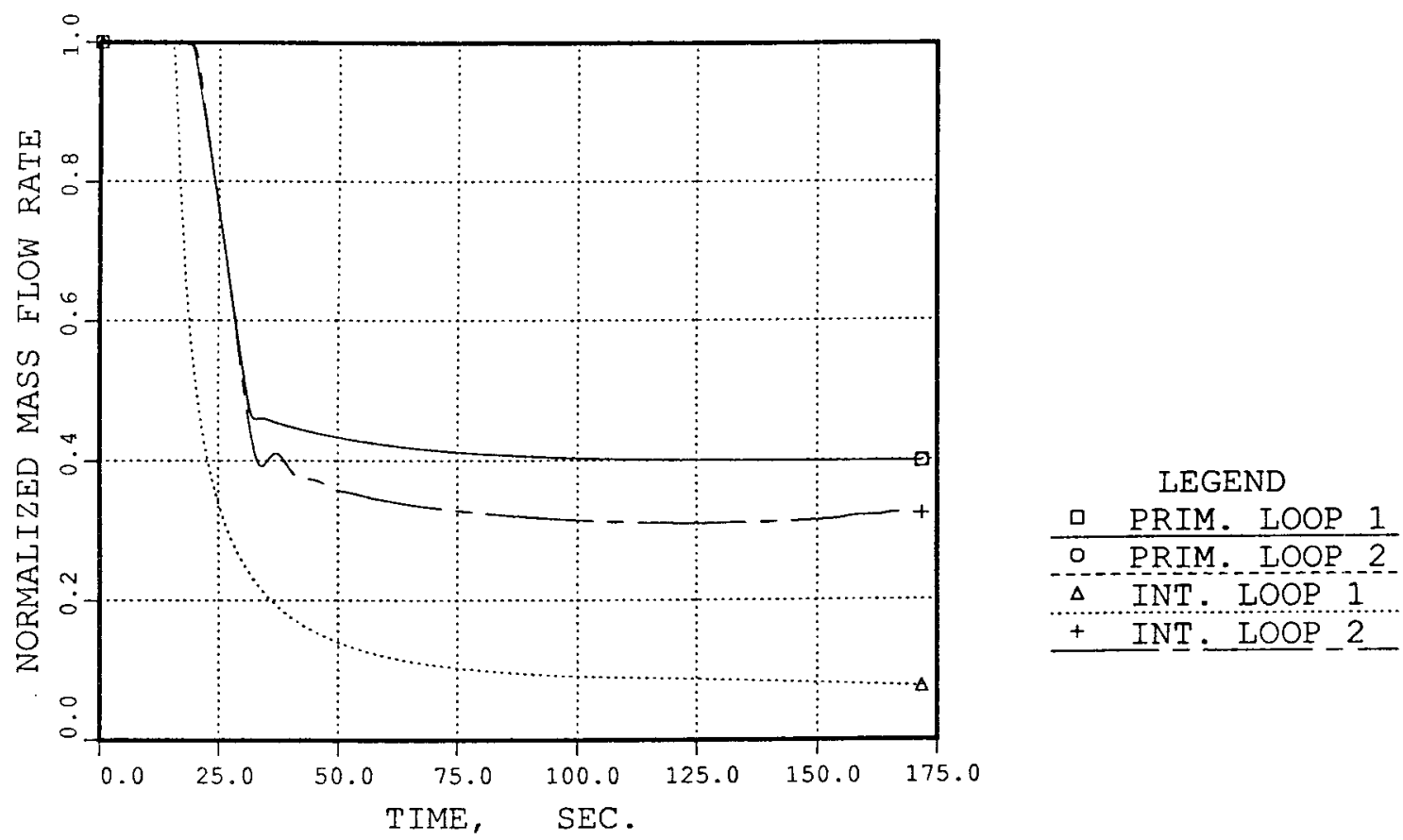

Fig. 5.1-29. No Rod PPS. 1 IHTS Pump Trip Loop Flows

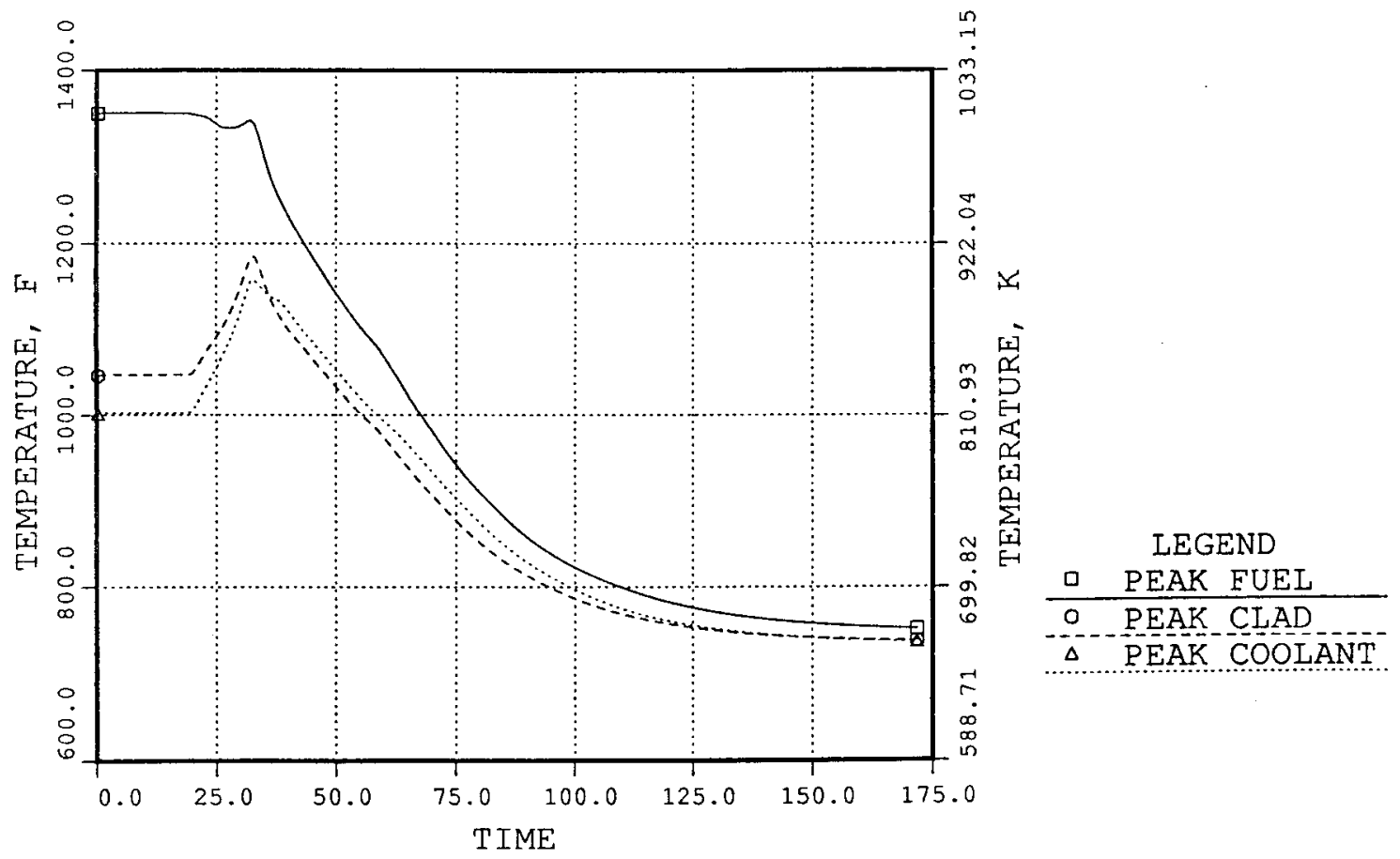

Fig. 5.1-30. No Rod PPS. 1 IHTS Pump Trip - Channel 1

Peak Temperatures 


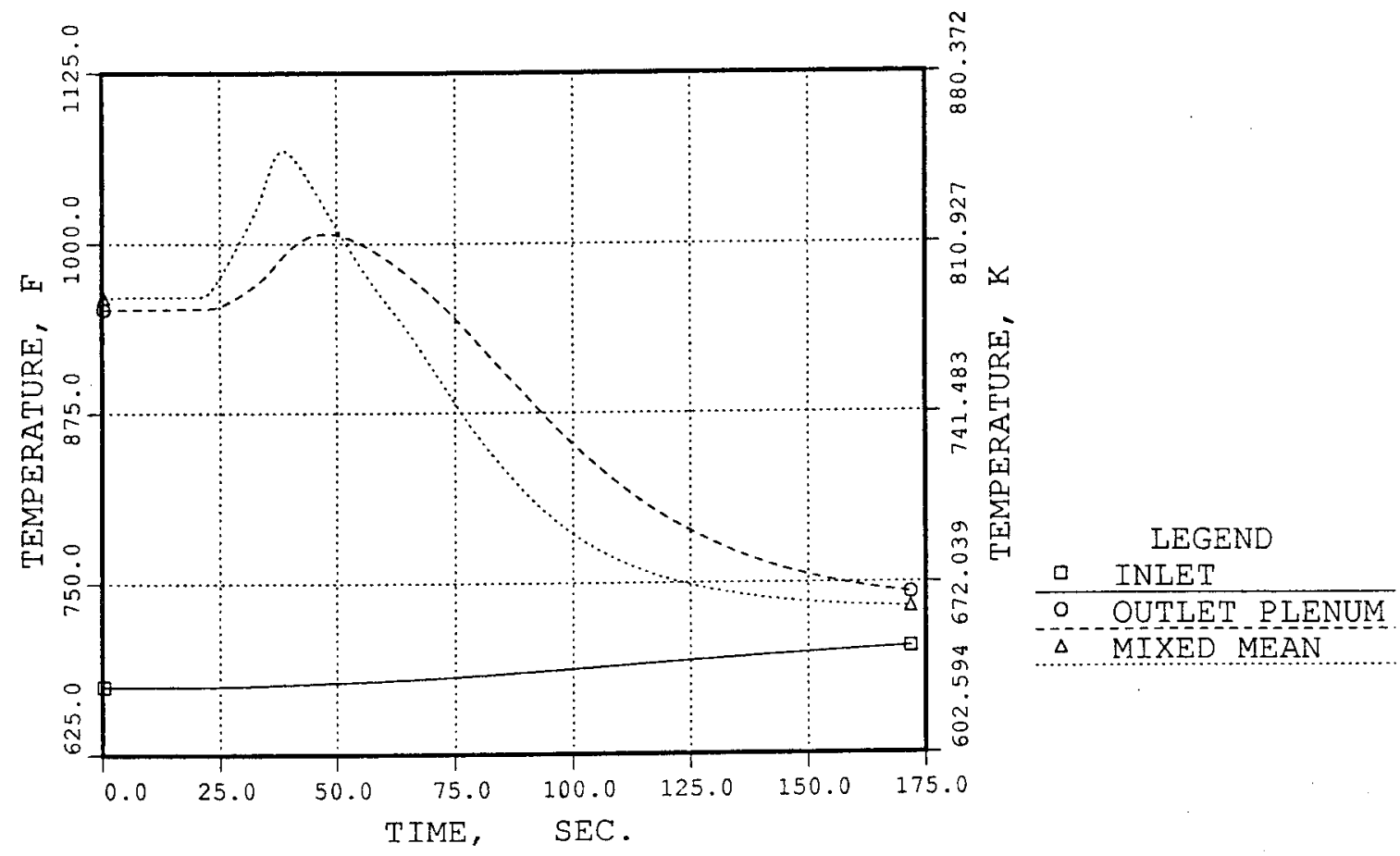

Fig. 5.1-31. No Rod PPS. 1 IHTS Pump Trip - Reactor Core Temperatures

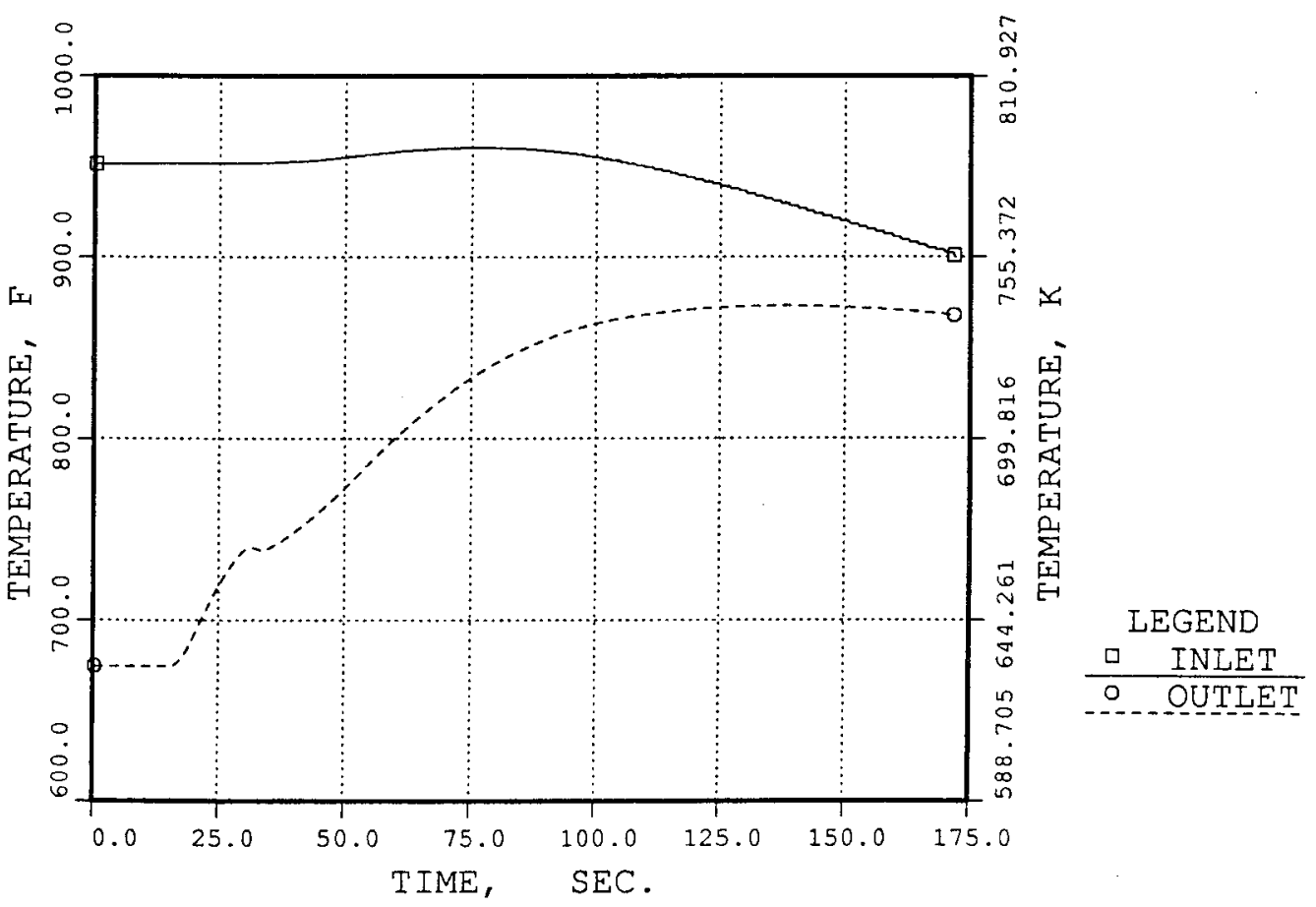

Fig. 5.1-32. No Rod PPS. 1 IHTS Pump Trip - IHXI Primary Side Temperatures 


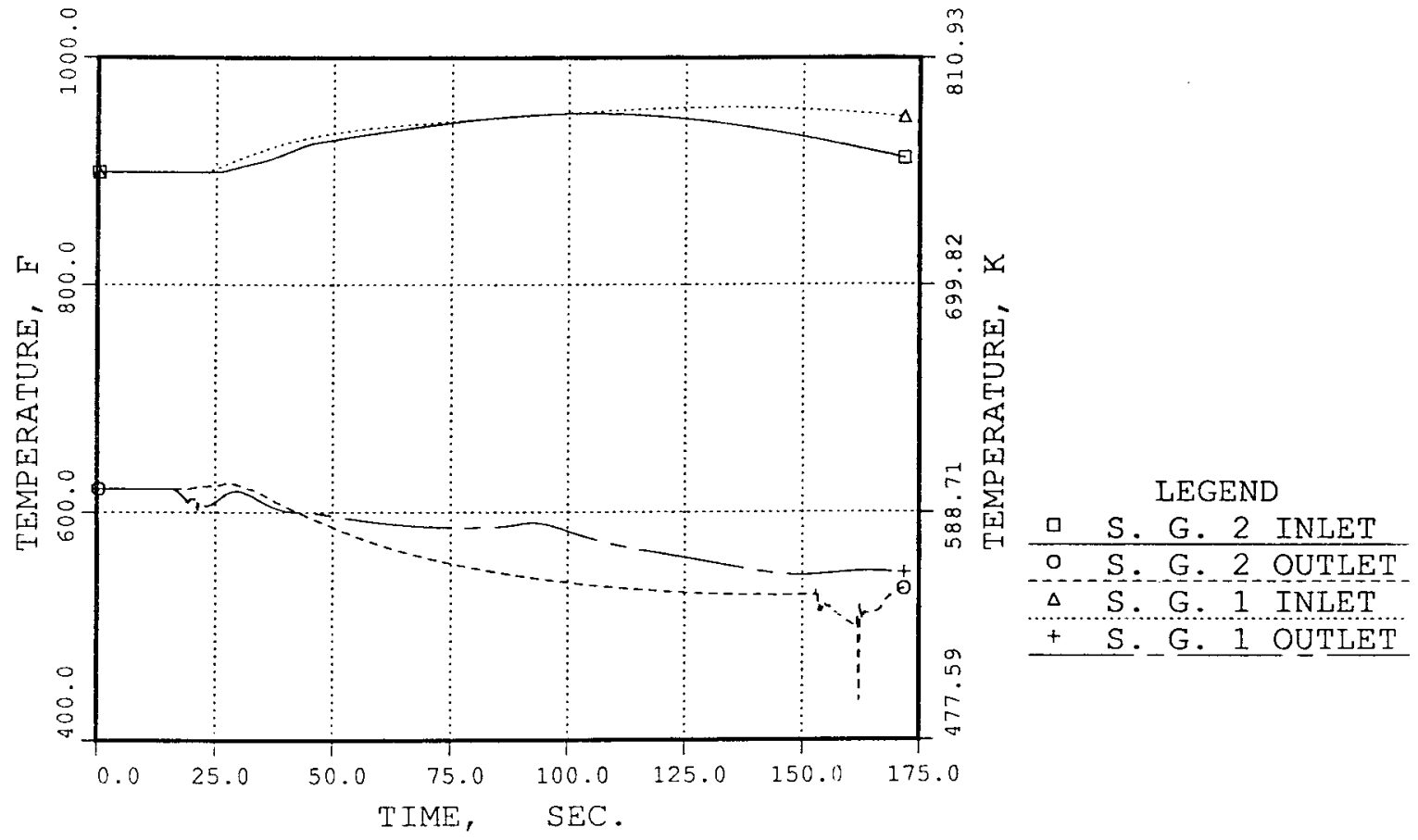

Fig. 5.1-33. No Rod PPS. 1 IHTS Pump Trip SG Sodium Temperatures

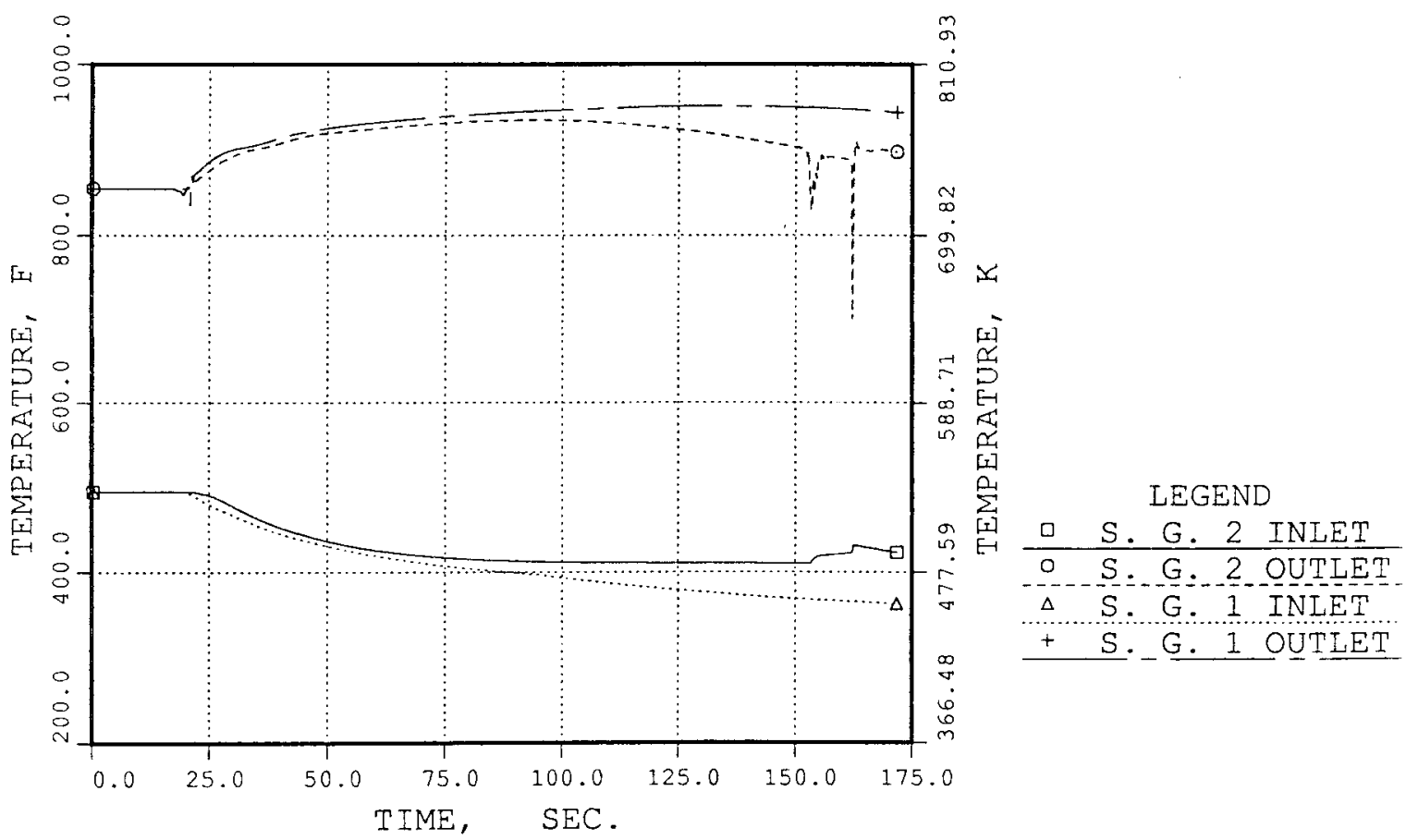

Fig. 5.1-34. No Rod PPS. 1 IHTS Pump Trip SG Water Temperatures 


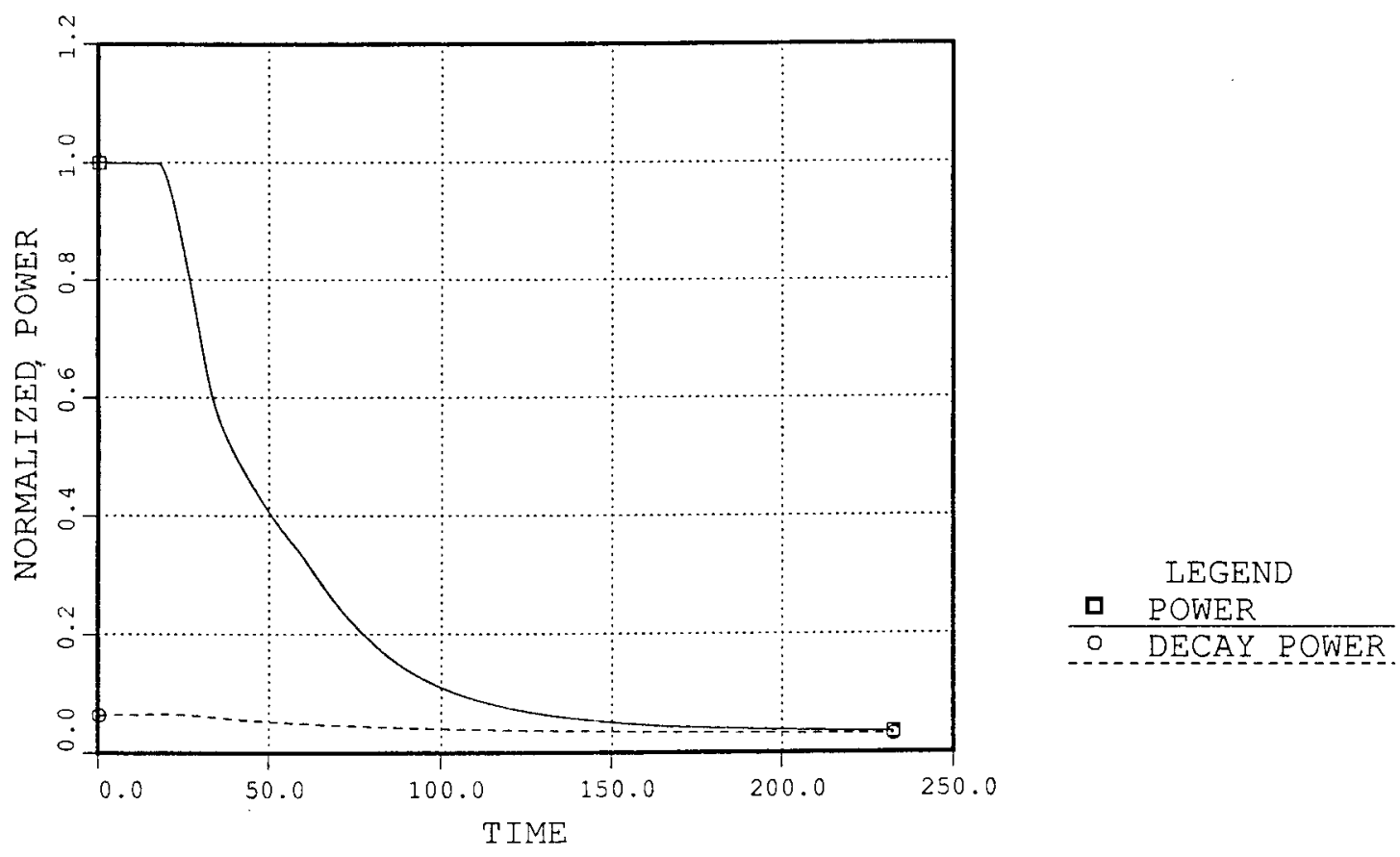
Fig. 5.1-35. No Rod PPS. 2 SG FW Valve Closure -
Reactor Power
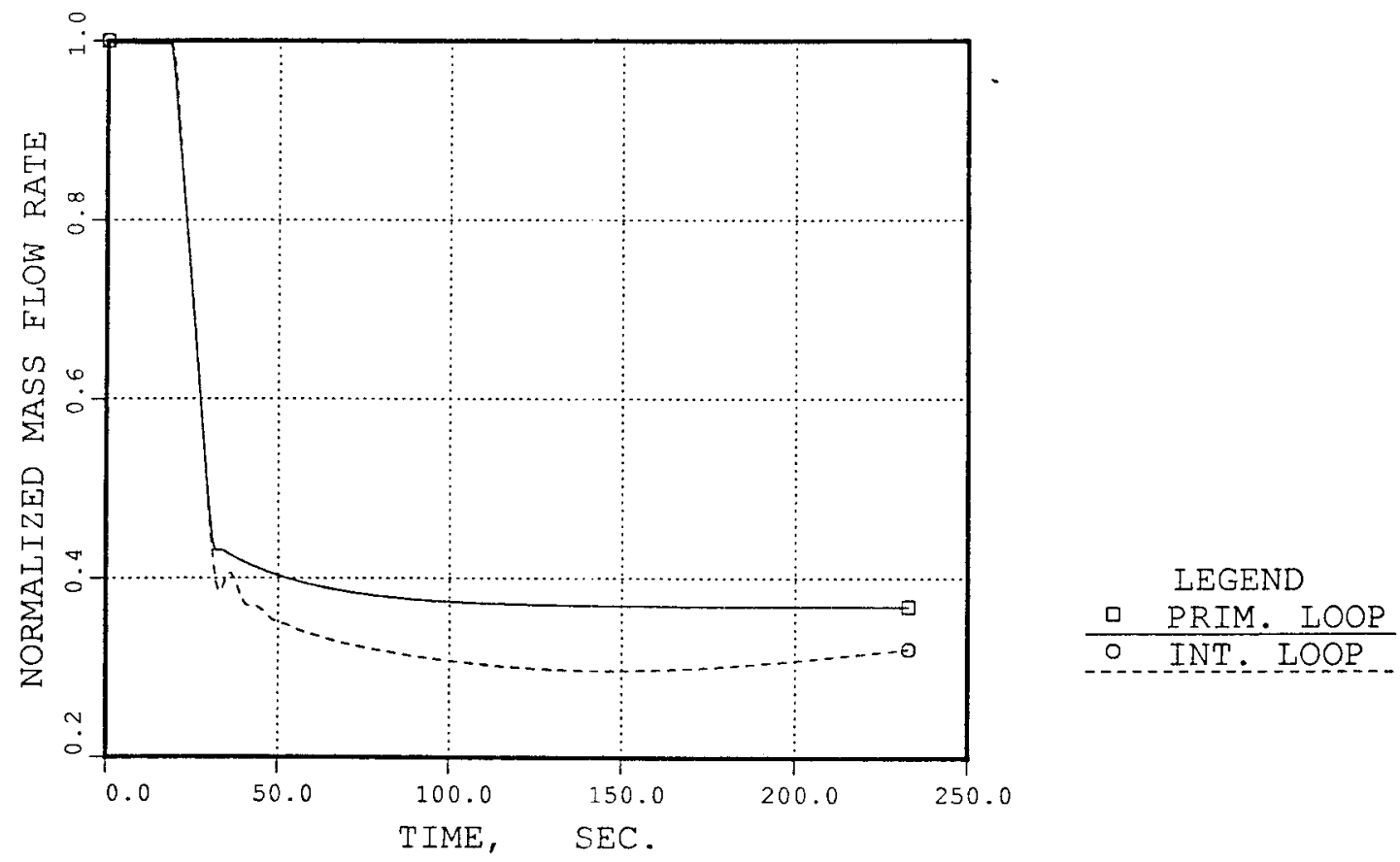

Fig. 5.1-36. No Rod PPS. 2 SG FW Valve Closure Loop Flows 


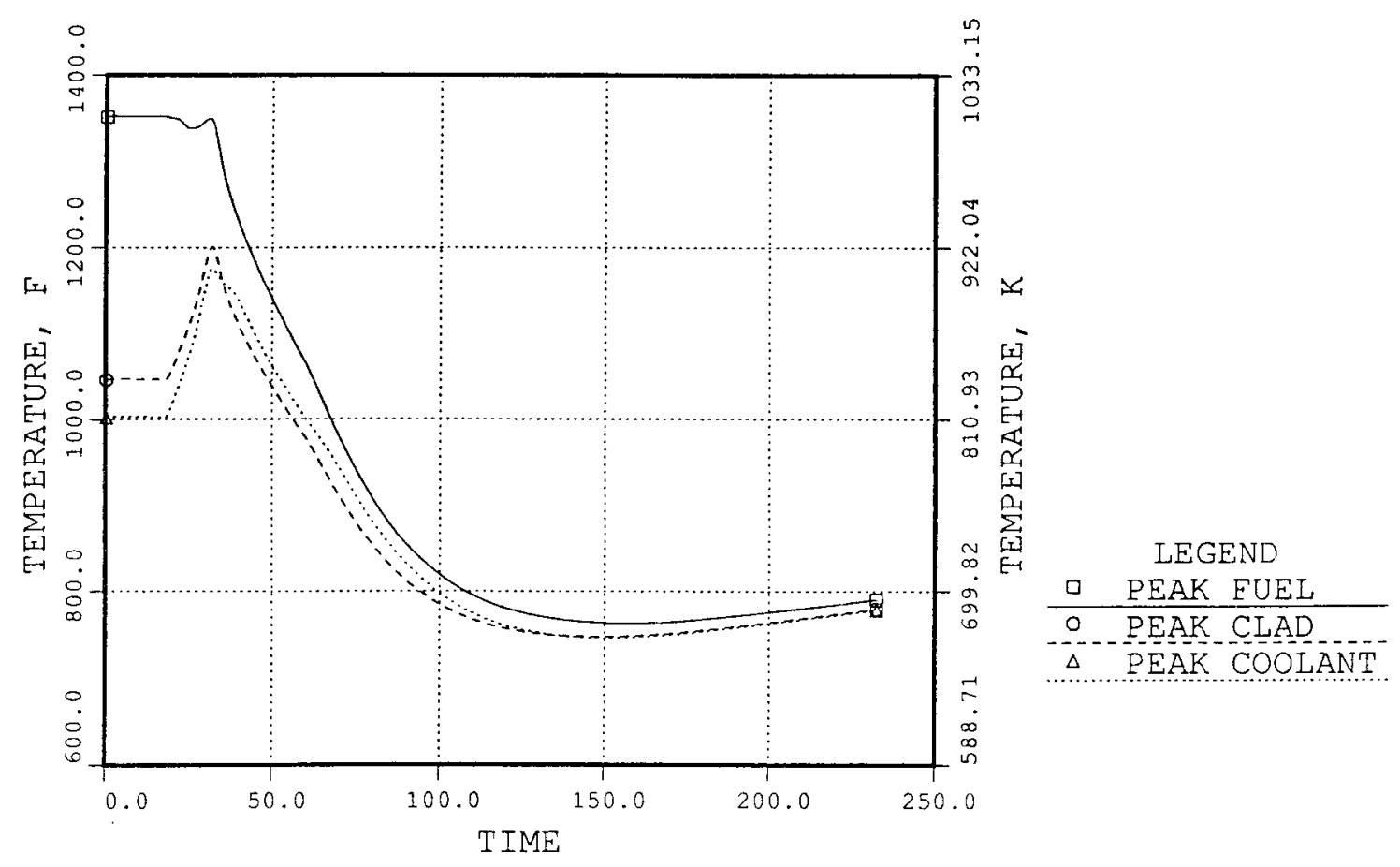

Fig. 5.1-37. No Rod PPS. 2 SG FW Valve Closure Channel 1 Peak Temperatures

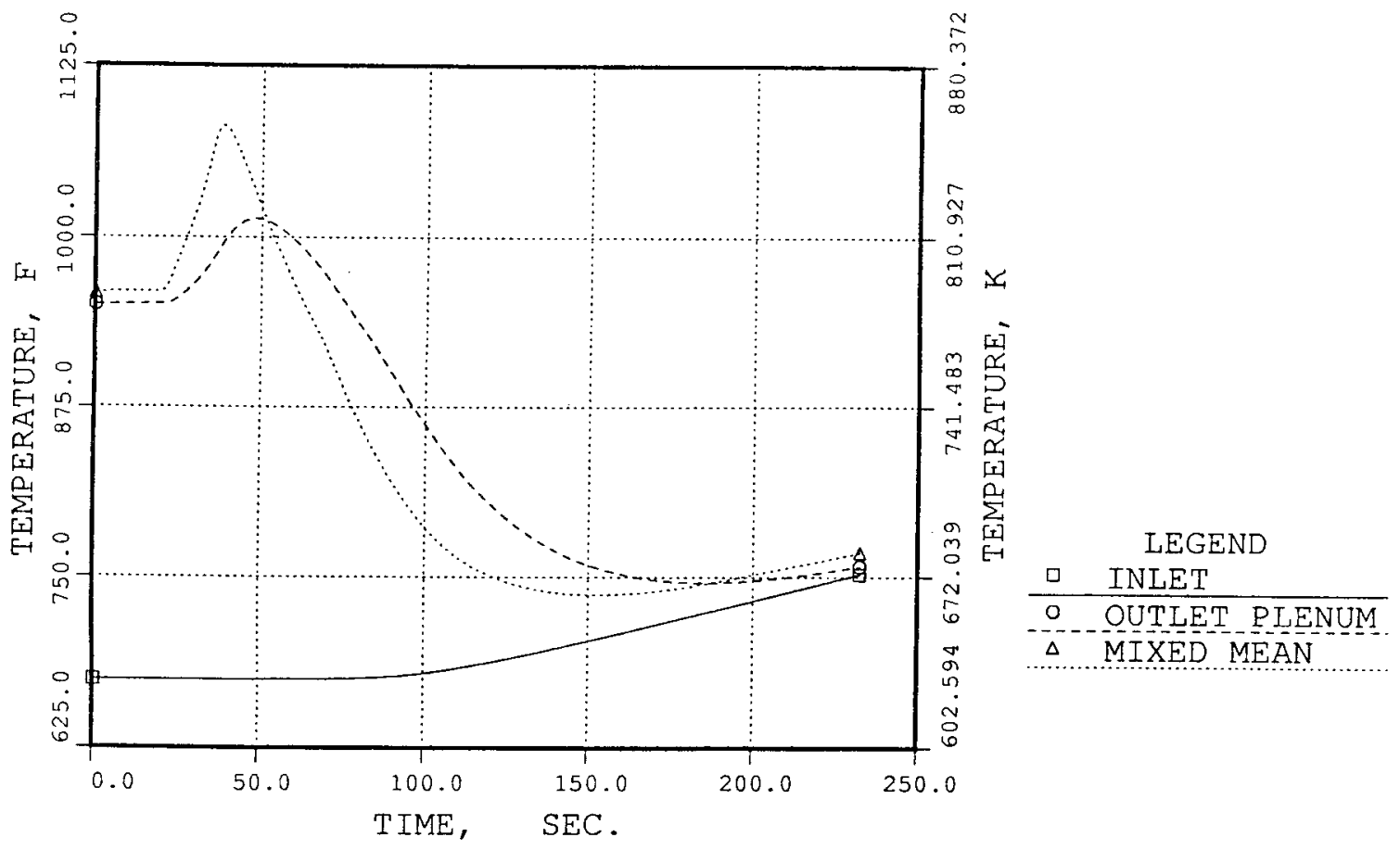

Fig. 5.1-38. No Rod PNS. 2 SG FW Valve Closure Reactor Core Temperatures 


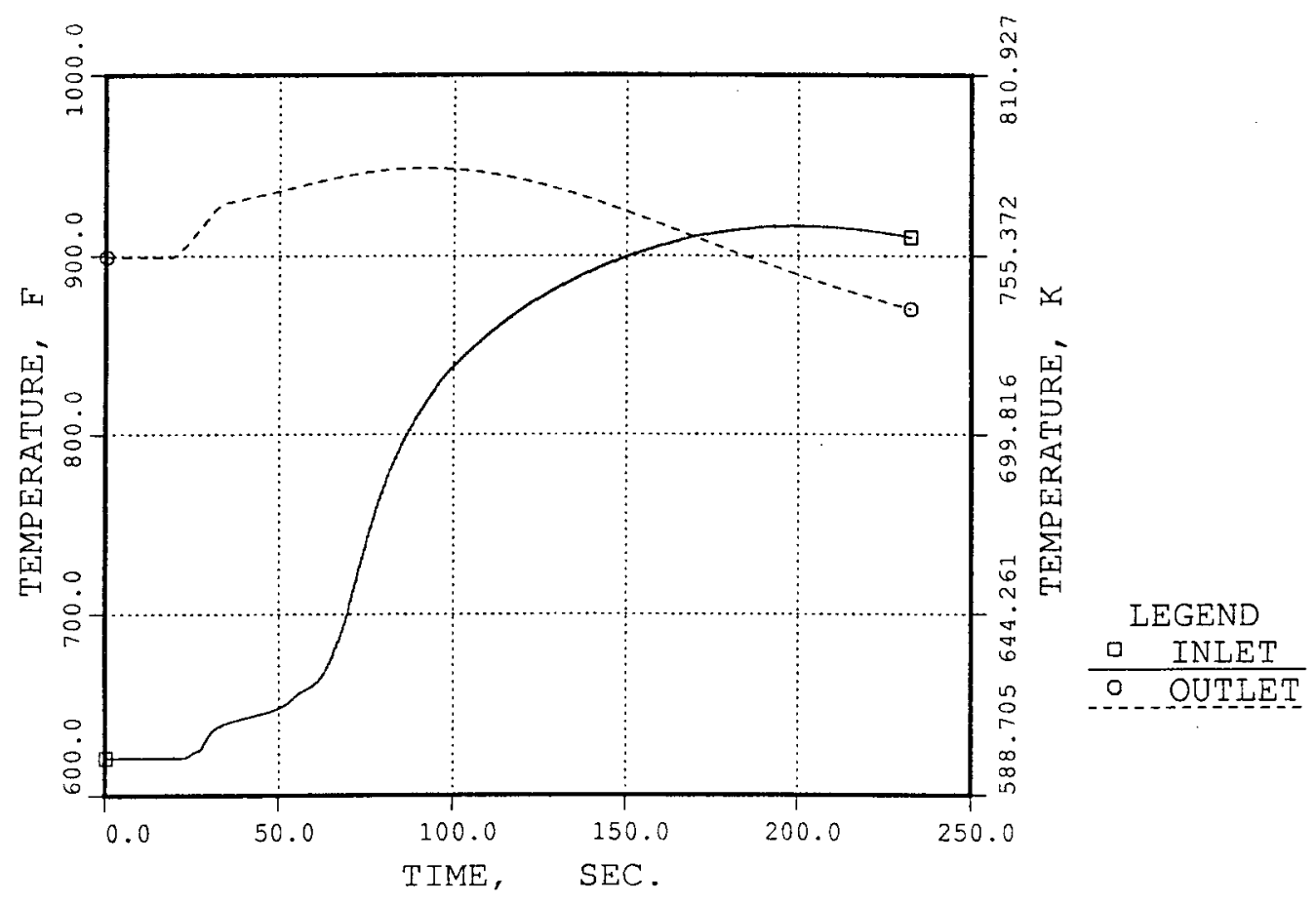

Fig. 5.1-39. No Rod PPS. 2 SG FW Valve Closure IHX Intermediate Side Temperatures

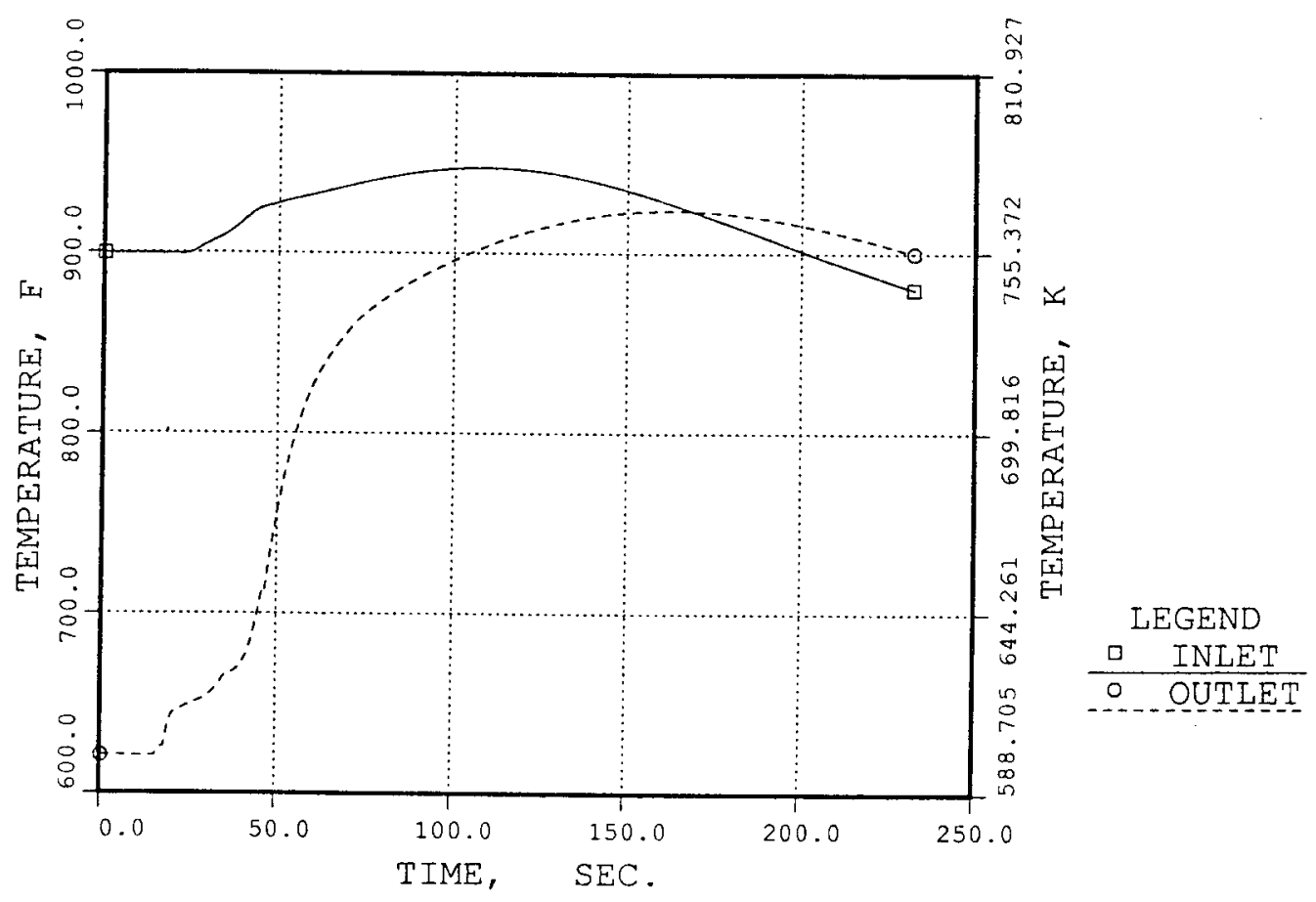

Fig. 5.1-40. No Rod PPS. 2 SG FW Valve Closure SG Sodium Temperatures 


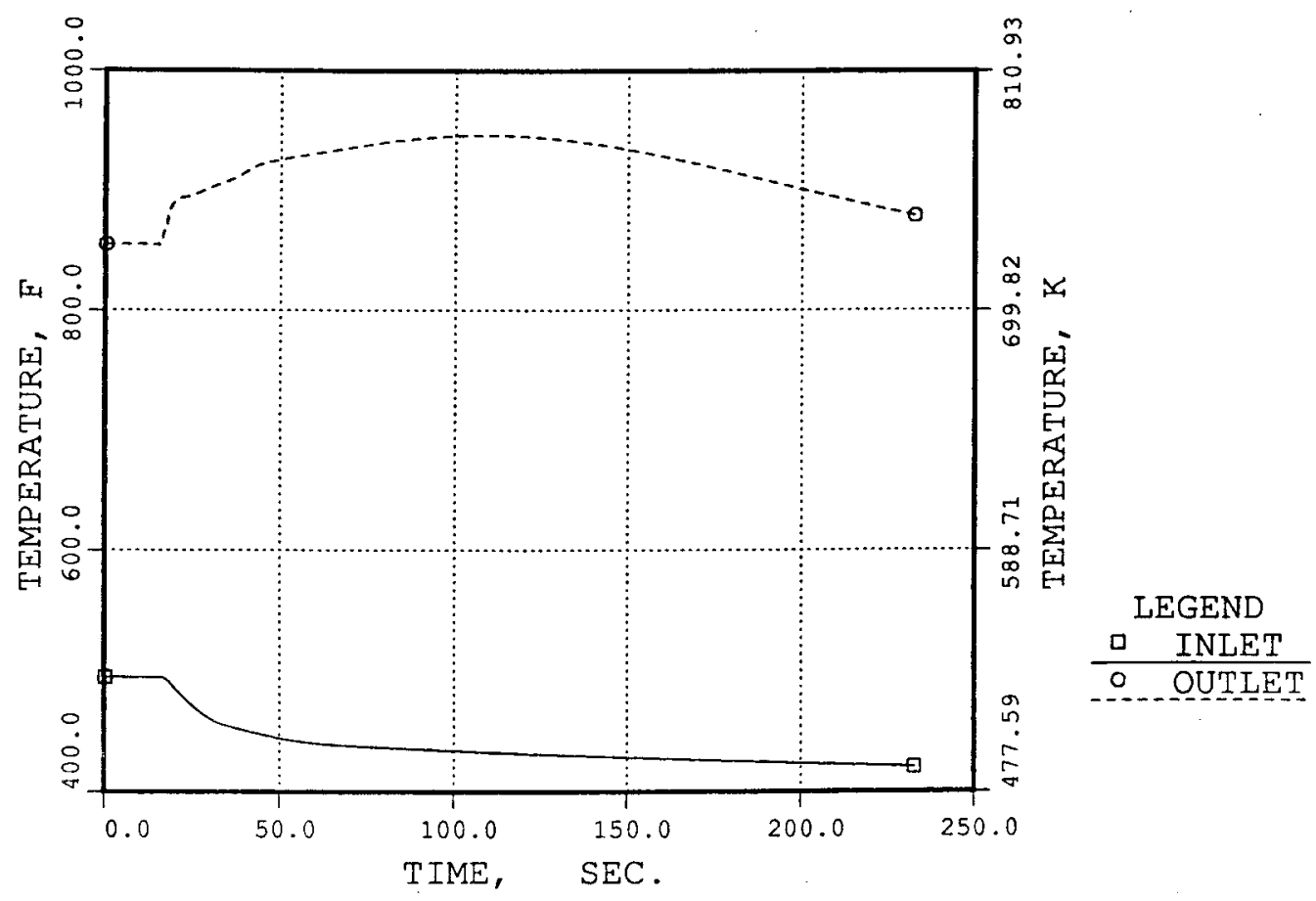

Fig. 5.1-41. No Rod PPS. 2 SG FW Valve Closure SG Water Temperatures
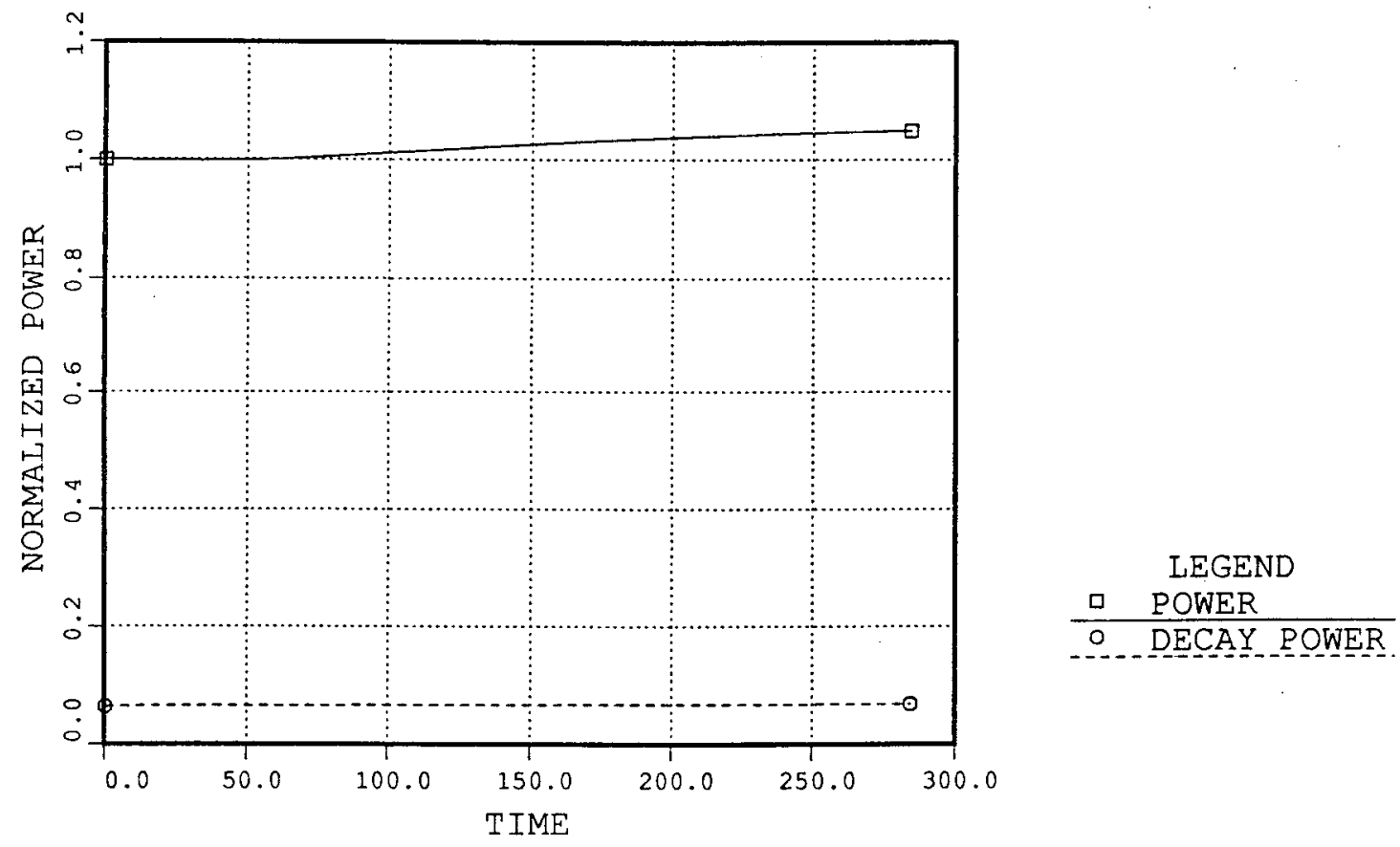

Fig. 5.1-42. No Rod PPS. 2 SG MFW Overfeed/No Sensor Reactor Power 


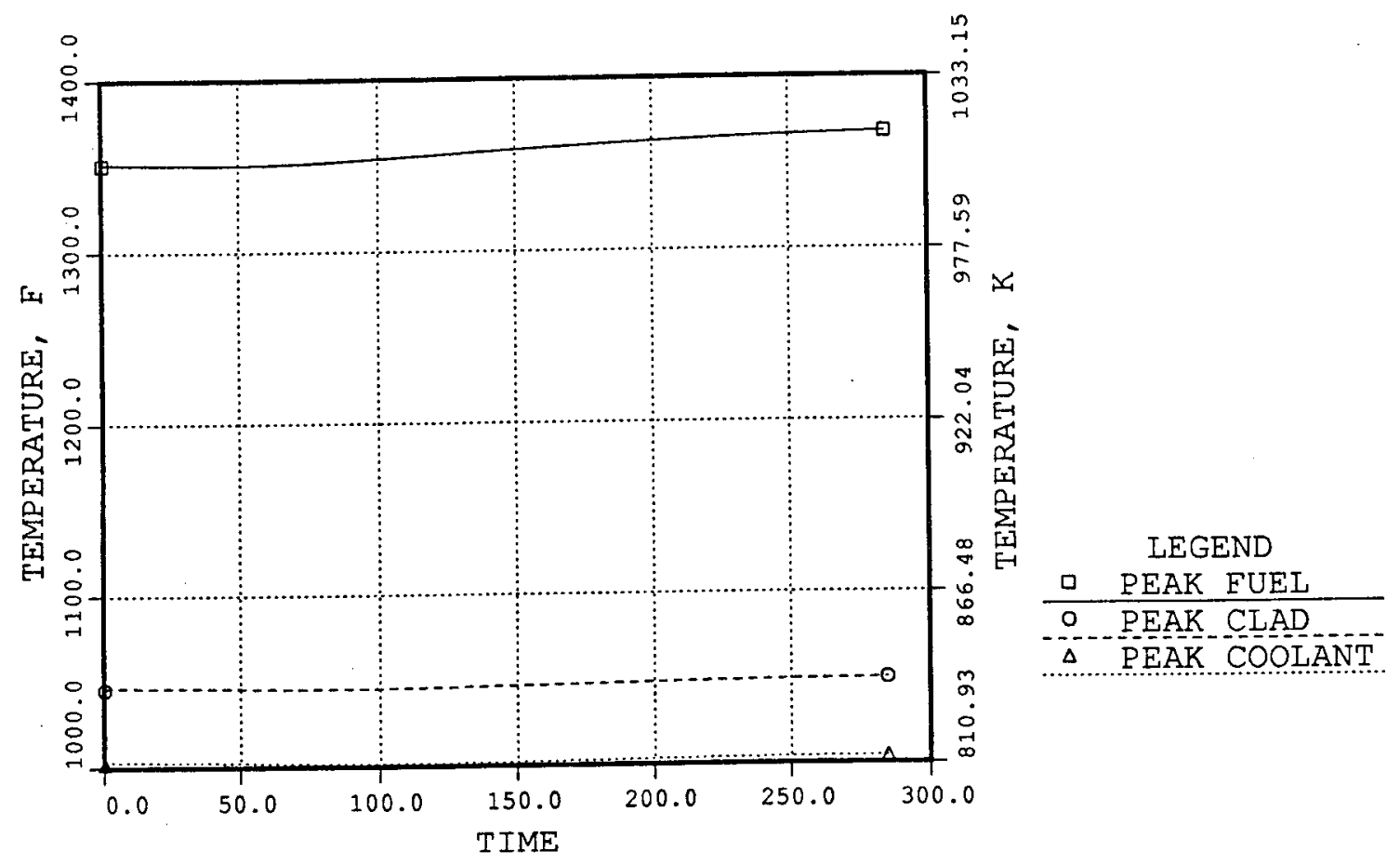

Fig. 5.1-43. No Rod PPS. 2 SG MFW Overfeed/No Sensor Channe 11 Peak Temperatures

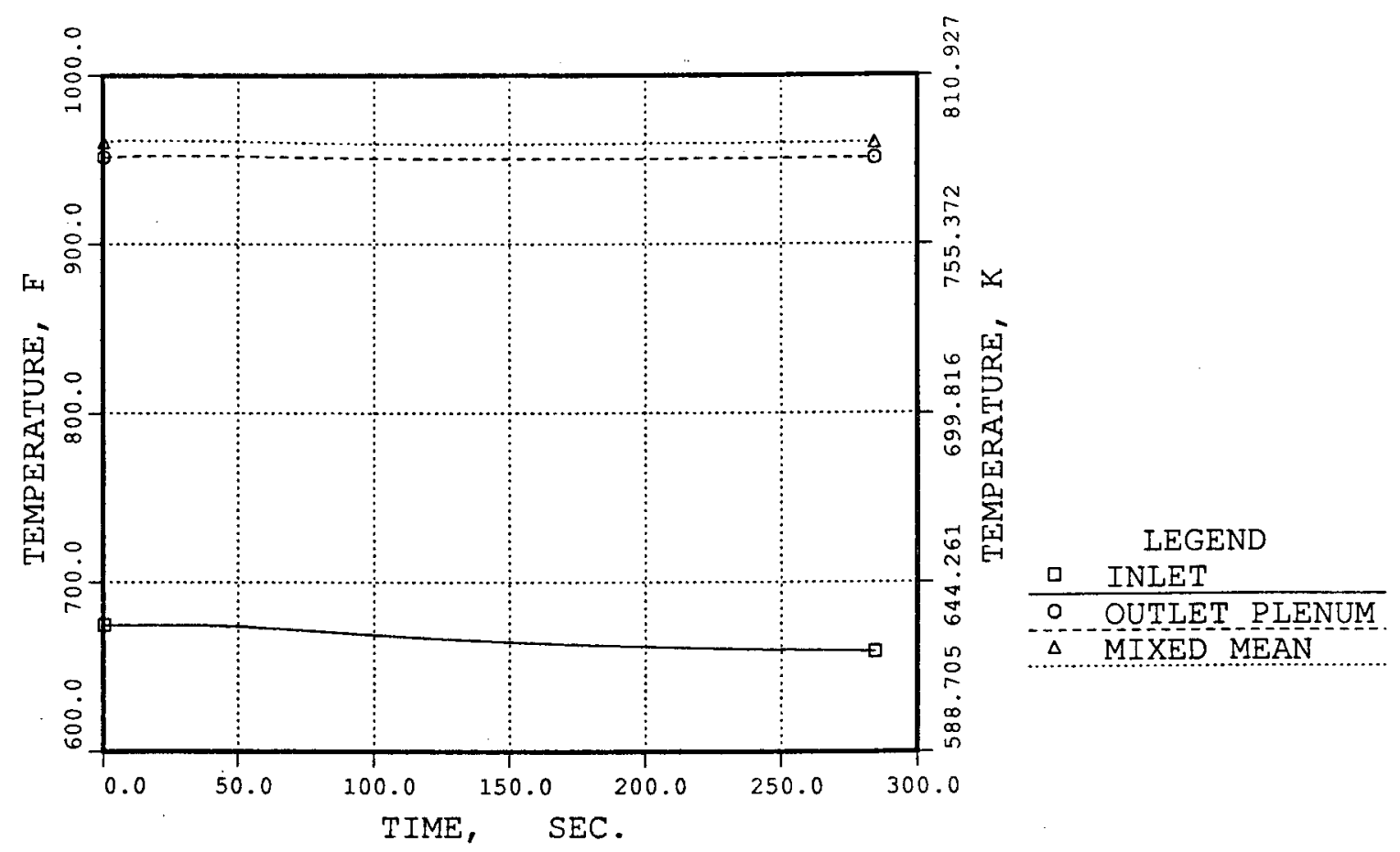

Fig. 5.1-44. No Rod PPS. 2 SG MFW Overfeed/No Sensor Reactor Core Temperatures 


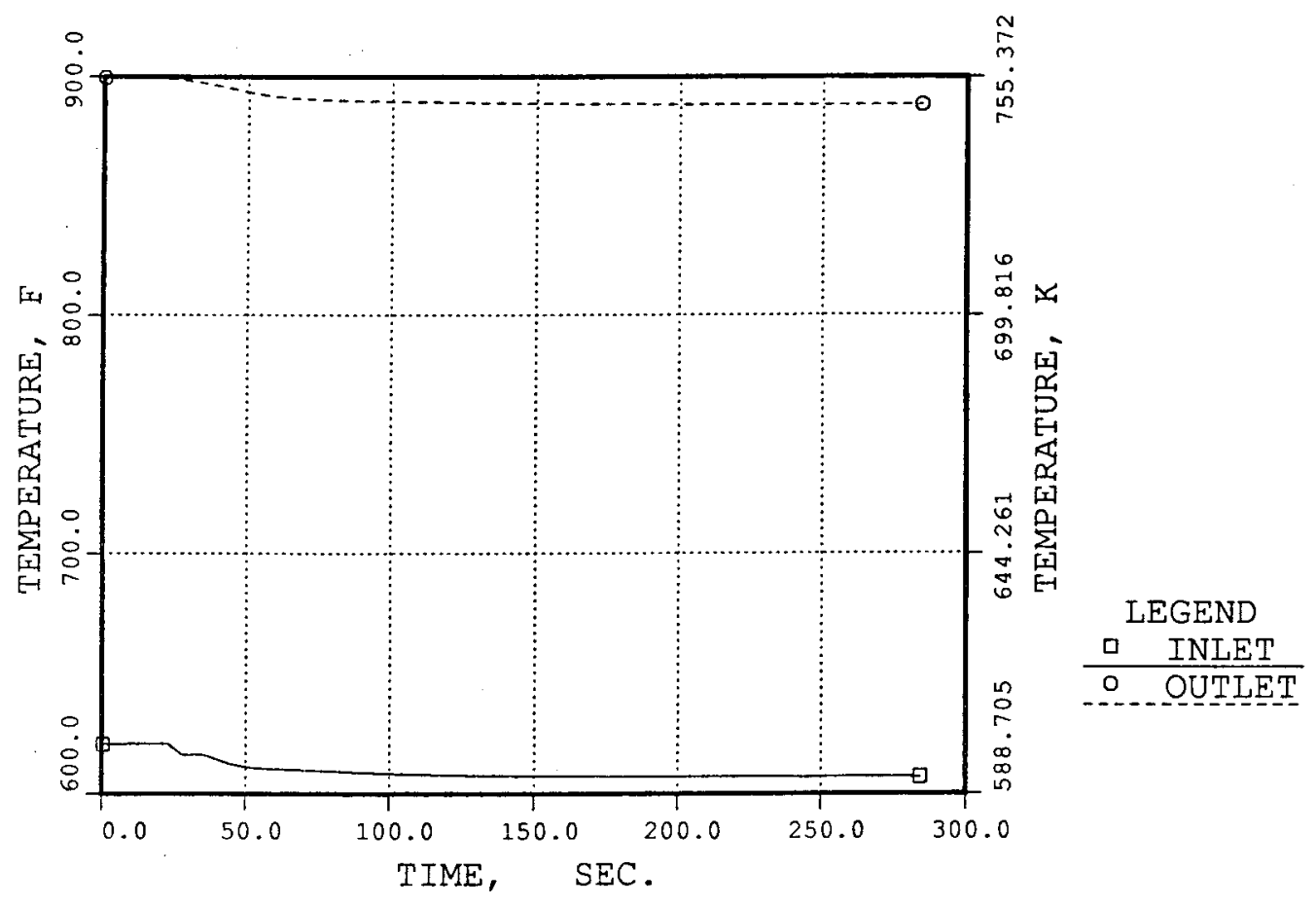

Fig. 5.1-45. No Rod PPS. 2 SG MFW Overfeed/No Sensor IHX Intermediate Side Temperatures

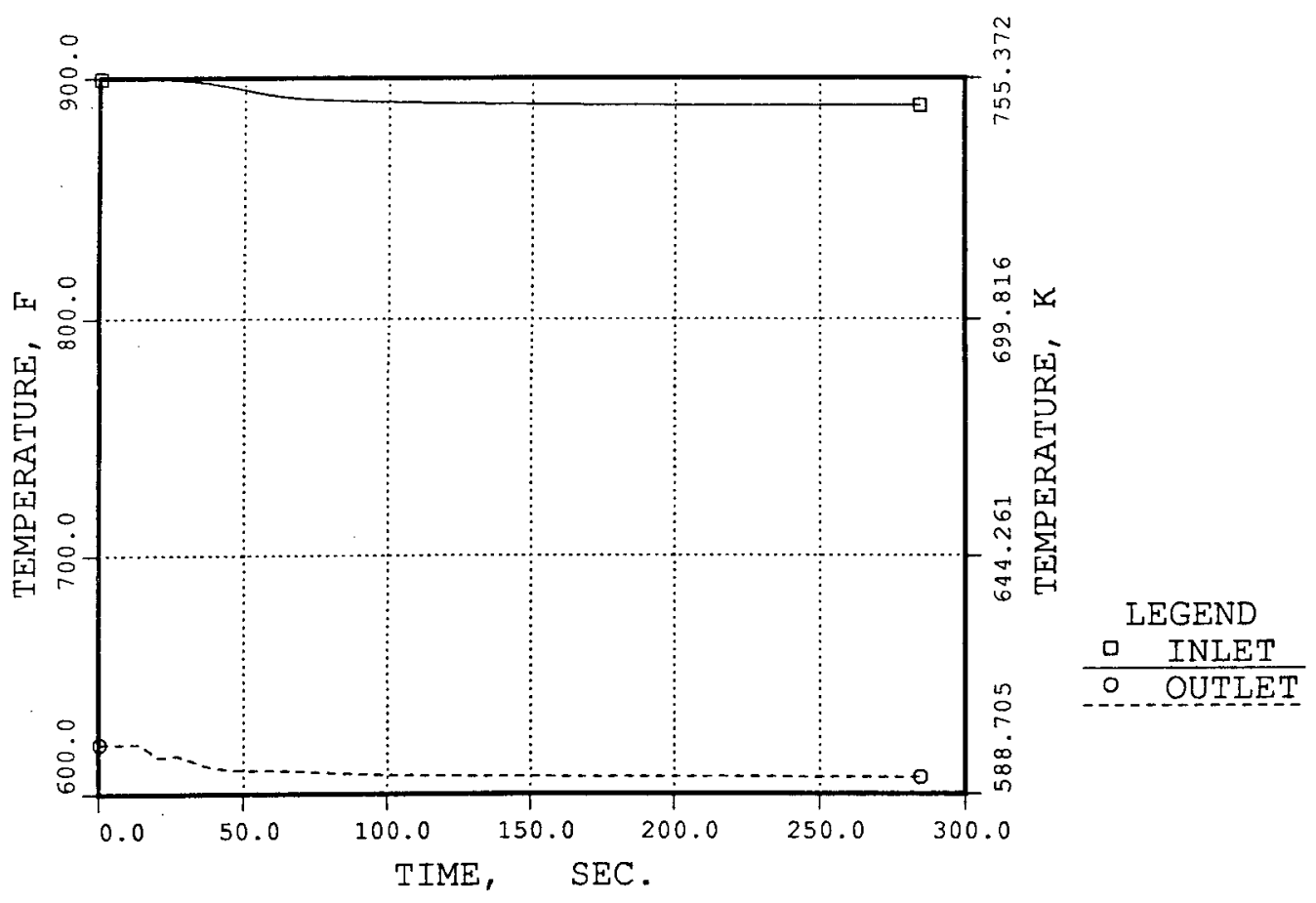

Fig. 5.1-46. No Rod PPS. 2 SG MFW Overfeed/No Sensor SG Sodium Temperatures 


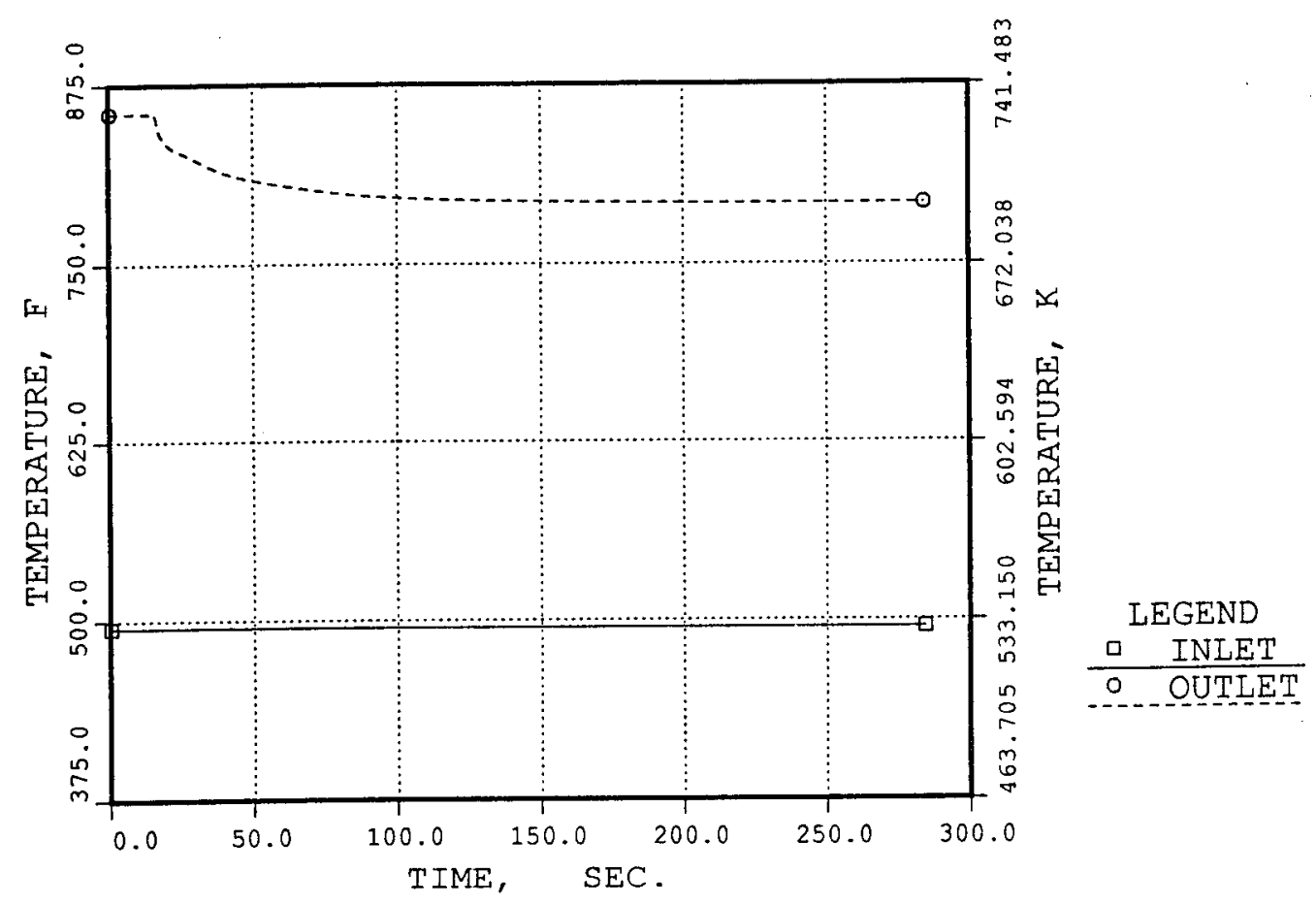

Fig. 5.1-47. No Rod PPS. 2 SG MFW Overfeed/No Sensor SG Water Temperatures
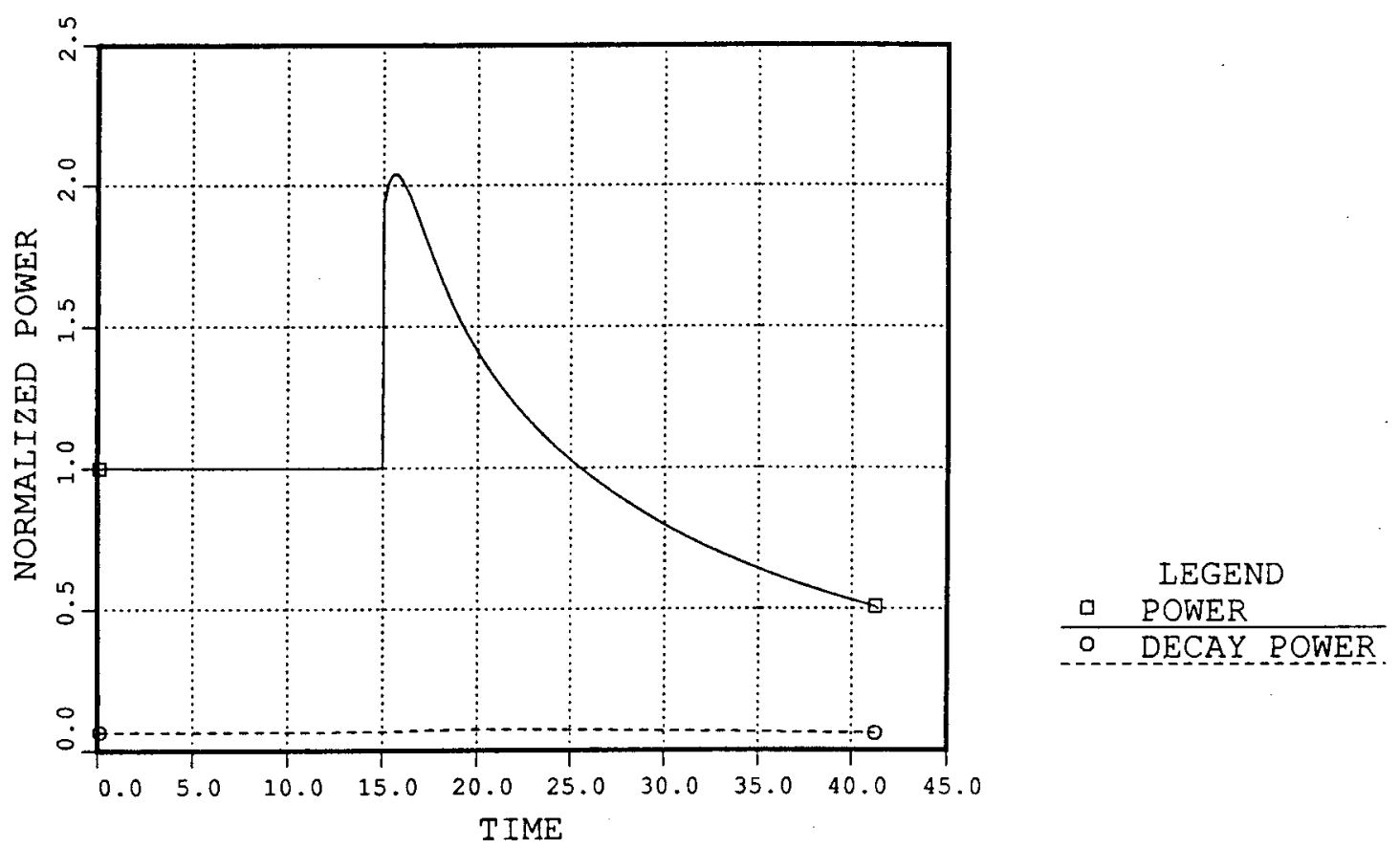

Fig. 5.1-48. No Rod PPS. SSE - Reactor Power 


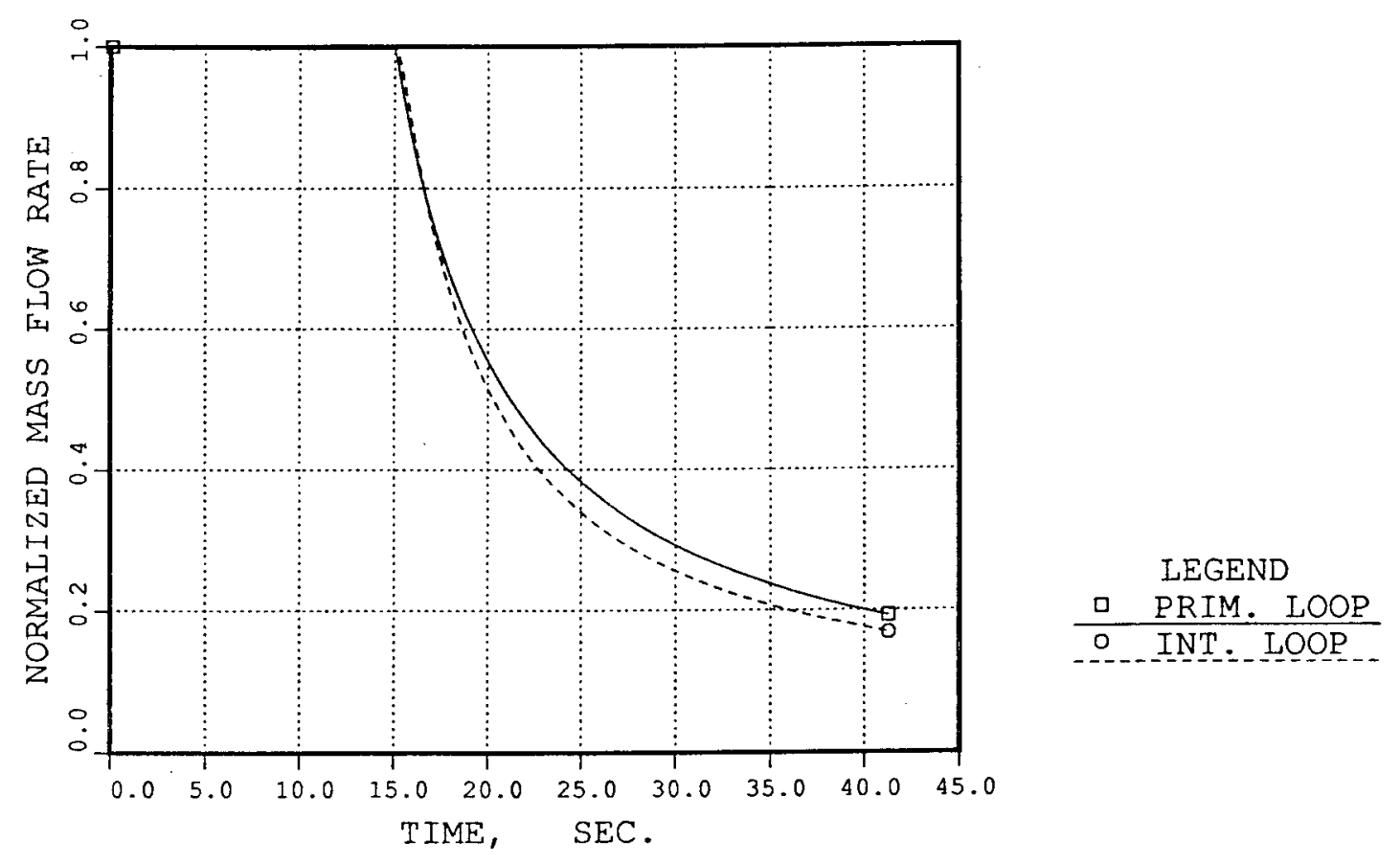

Fig. 5.1-49. No Rod PPS. SSE - Loop Flows

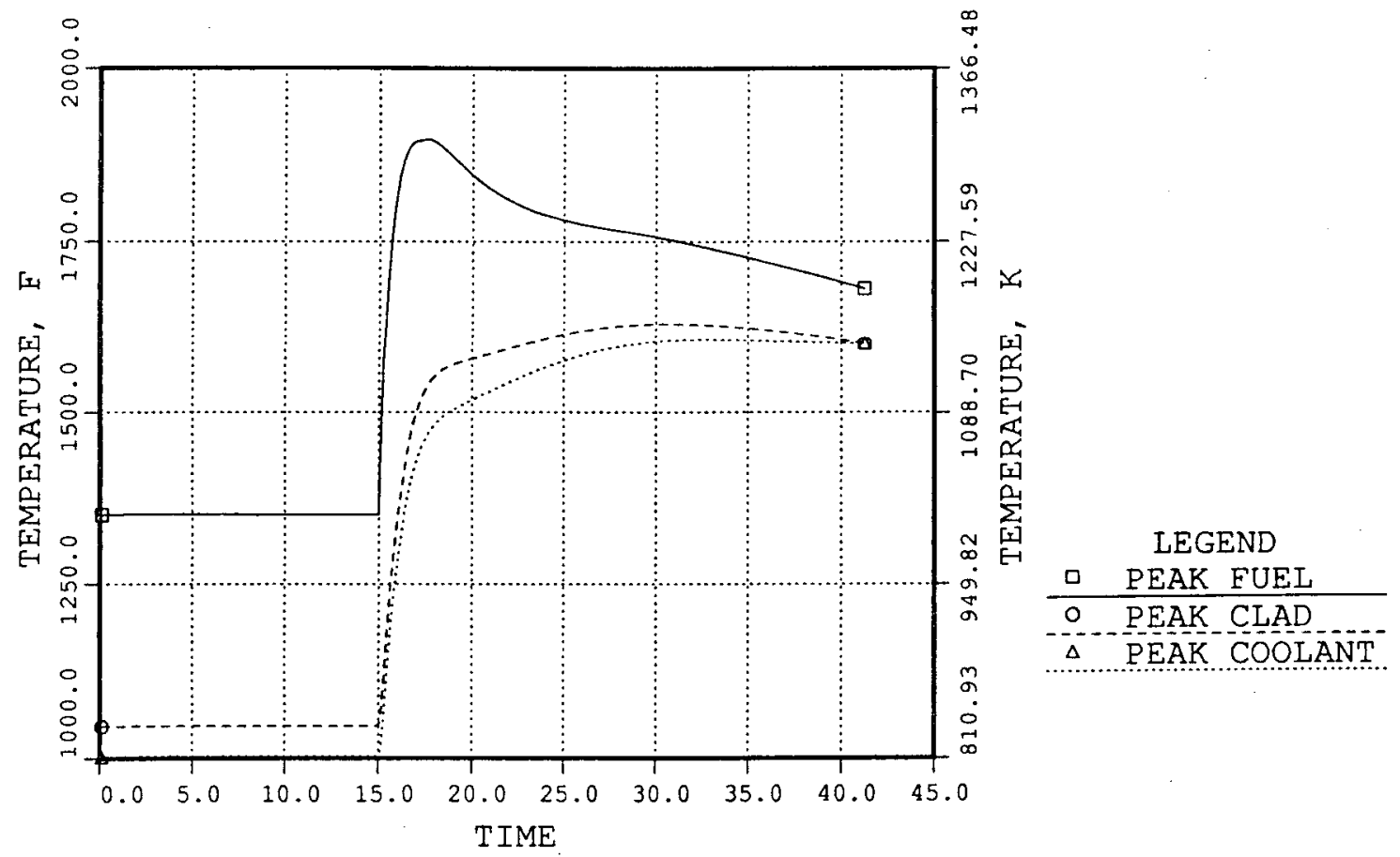

Fig. 5.1-50. No Rod PPS. SSE - Channel 1 Peak Temperatures 


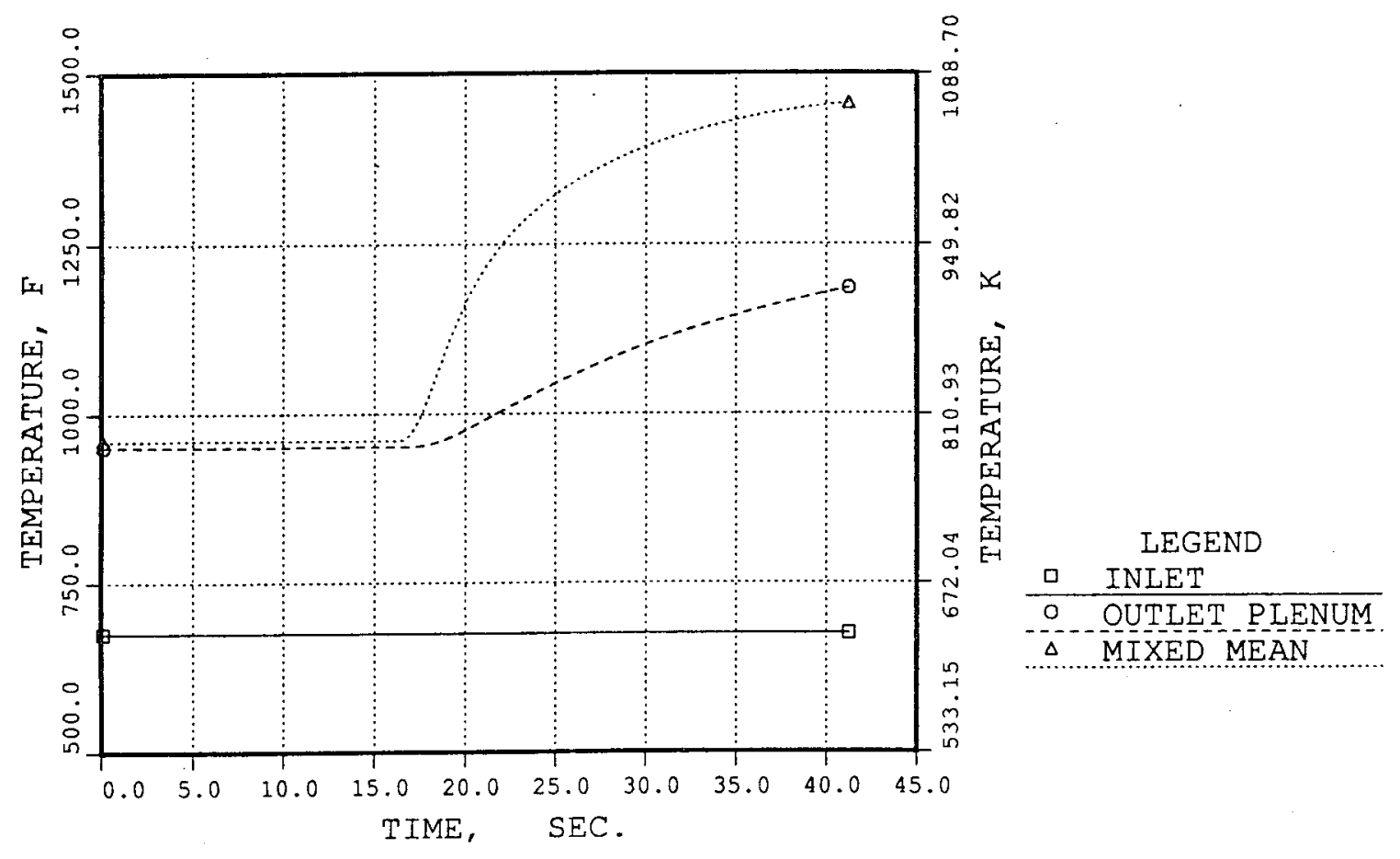

Fig. 5.1-51. No Rod PPS. SSE - Reactor Core Temperatures

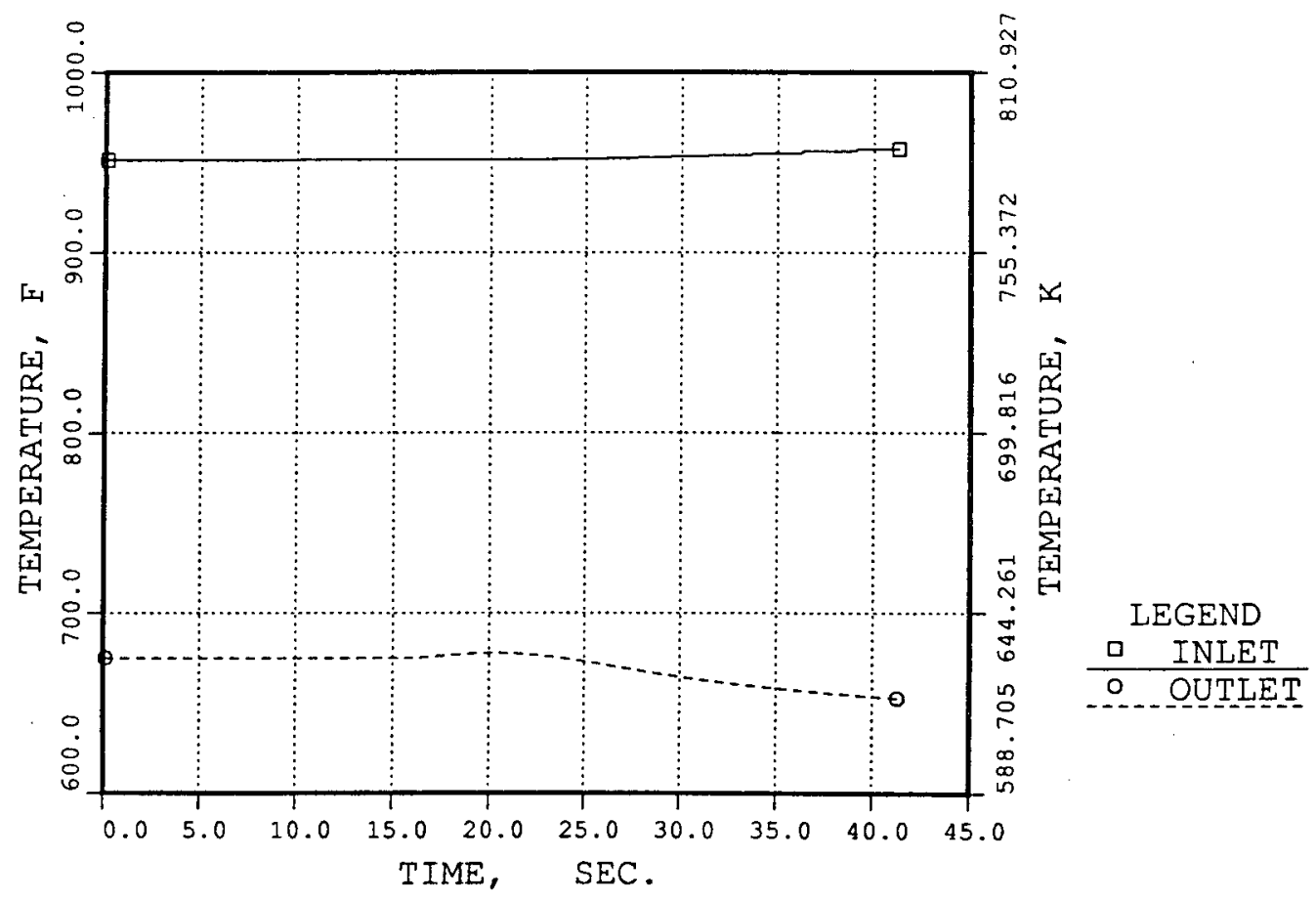

Fig. 5.1-52. No Rod PPS. SSE - IHX Primary Side Temperatures 


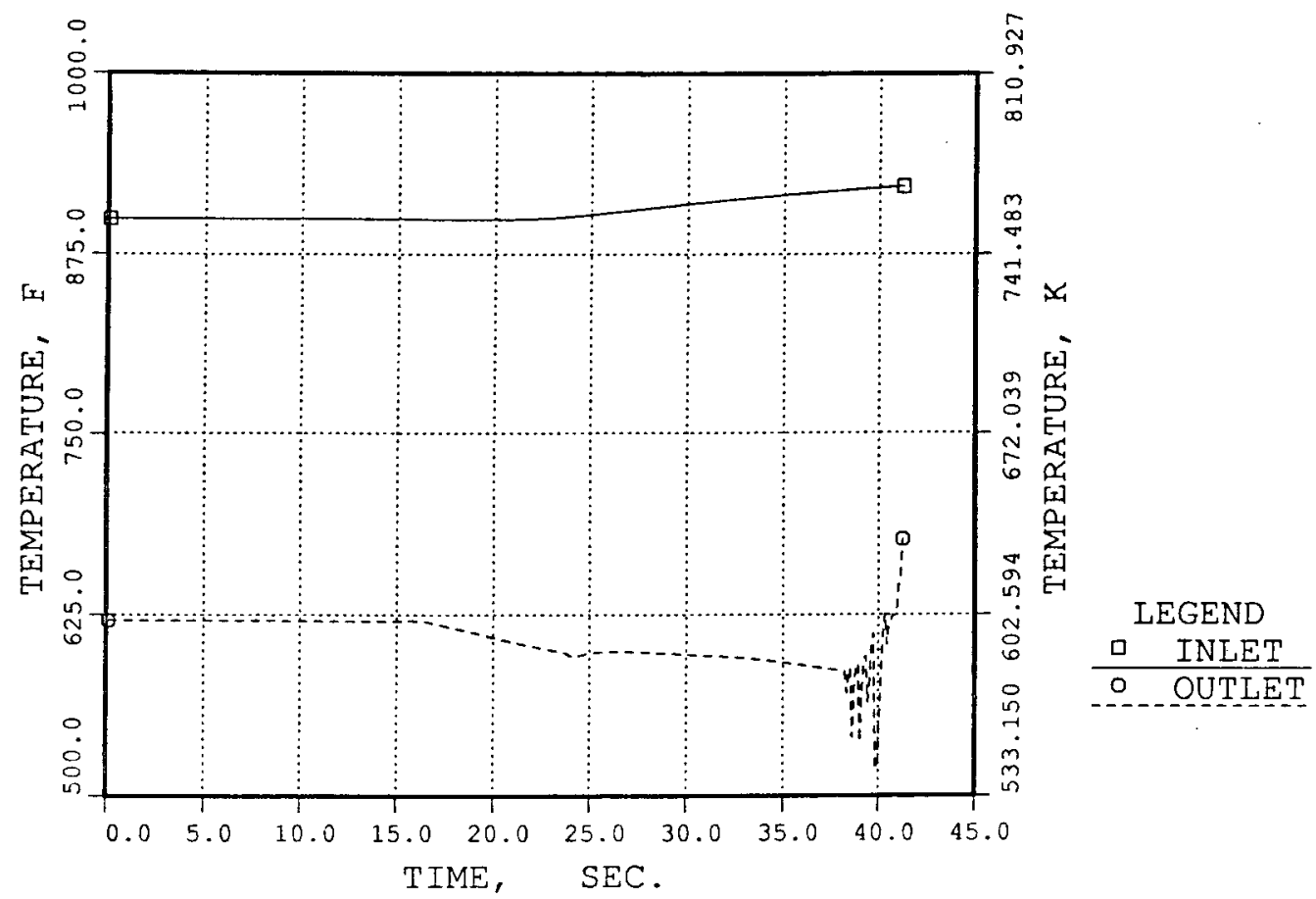

Fig. 5.1-53. No Rod PPS. SSE - SG Sodium Temperatures 


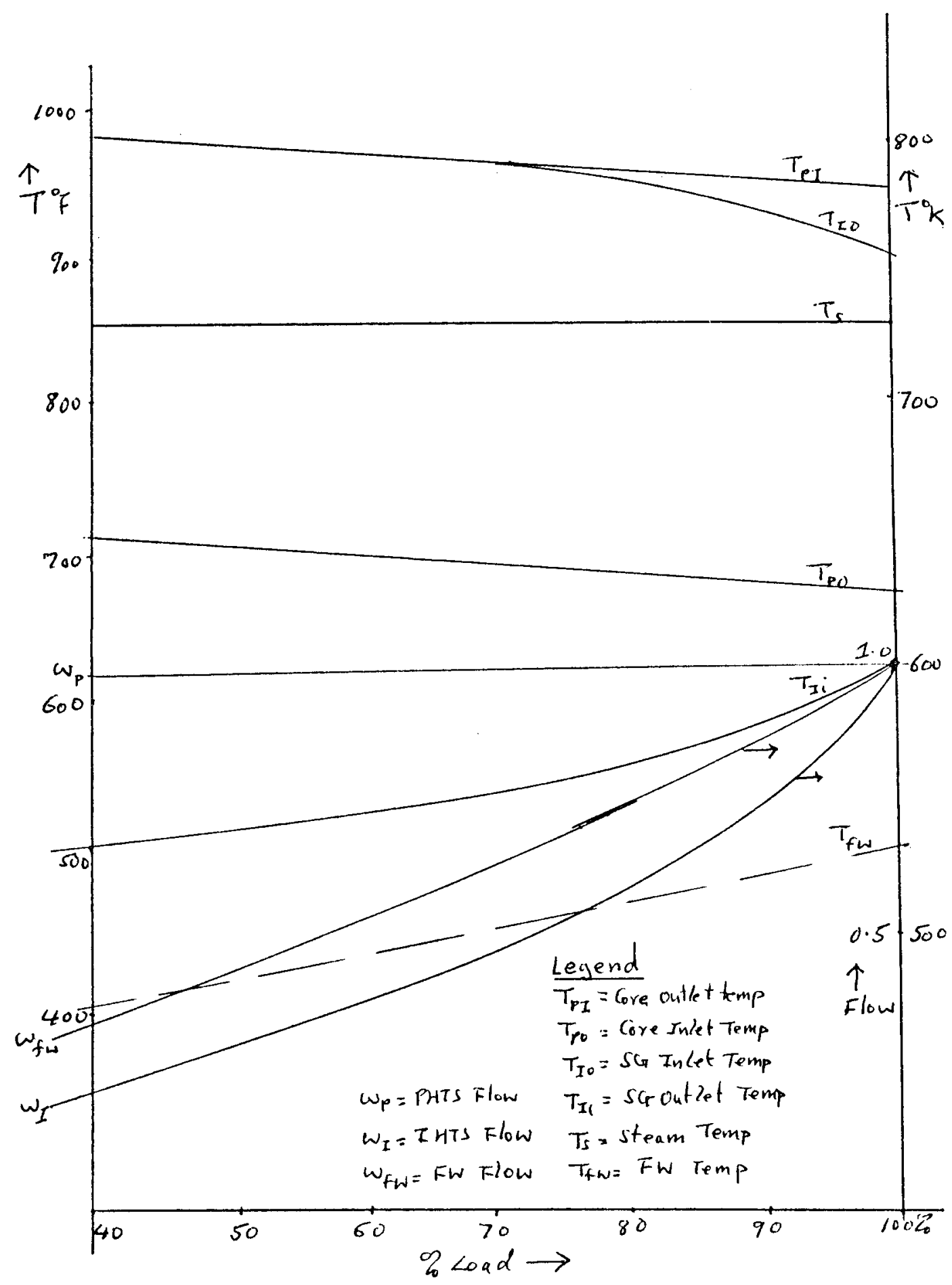

Fig. 6.1-1. Partial Load Balance 


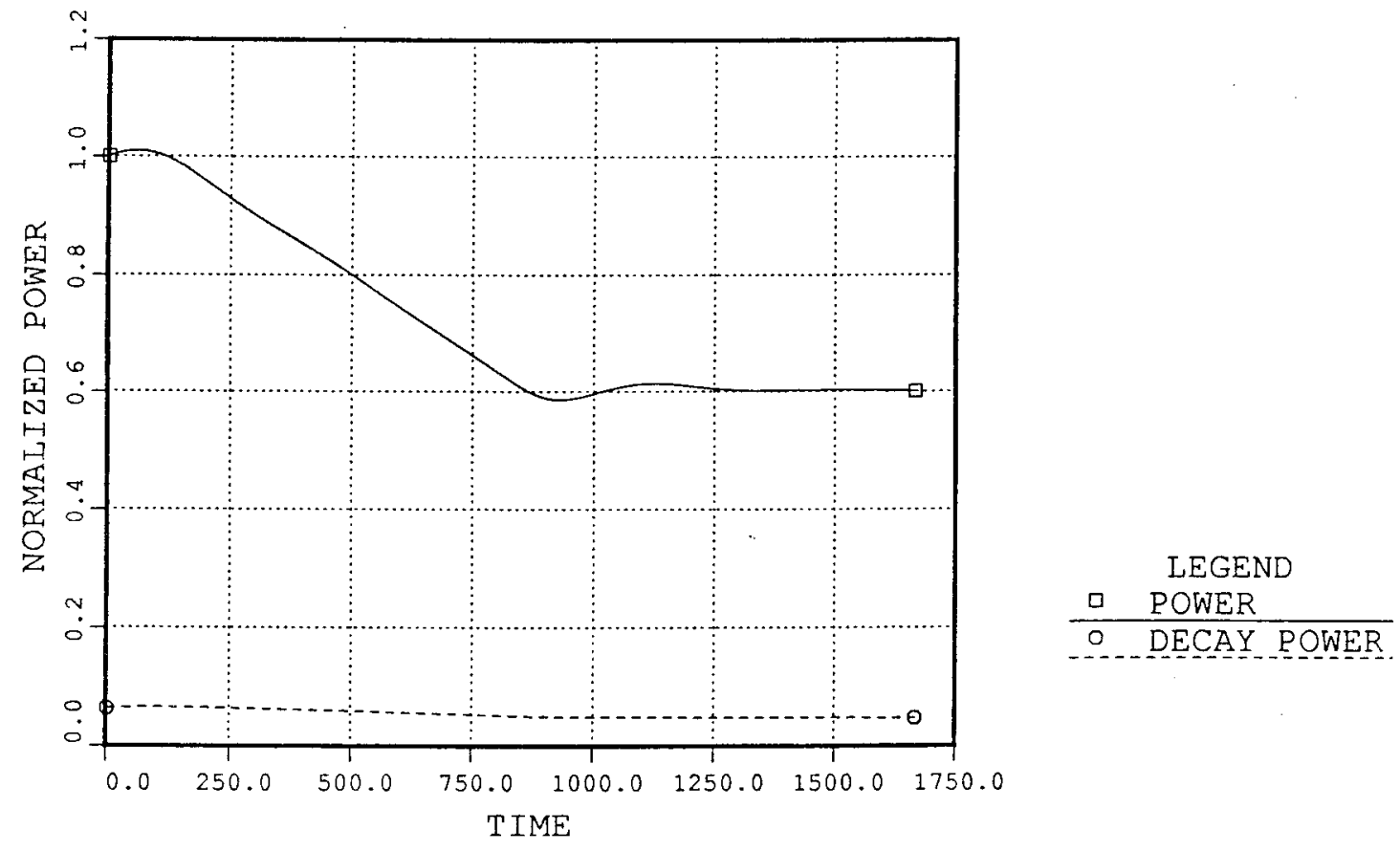

Fig. 6.1-2. No Rod PPS/PCS. Power Ramp 3\%/min. Reactor Power
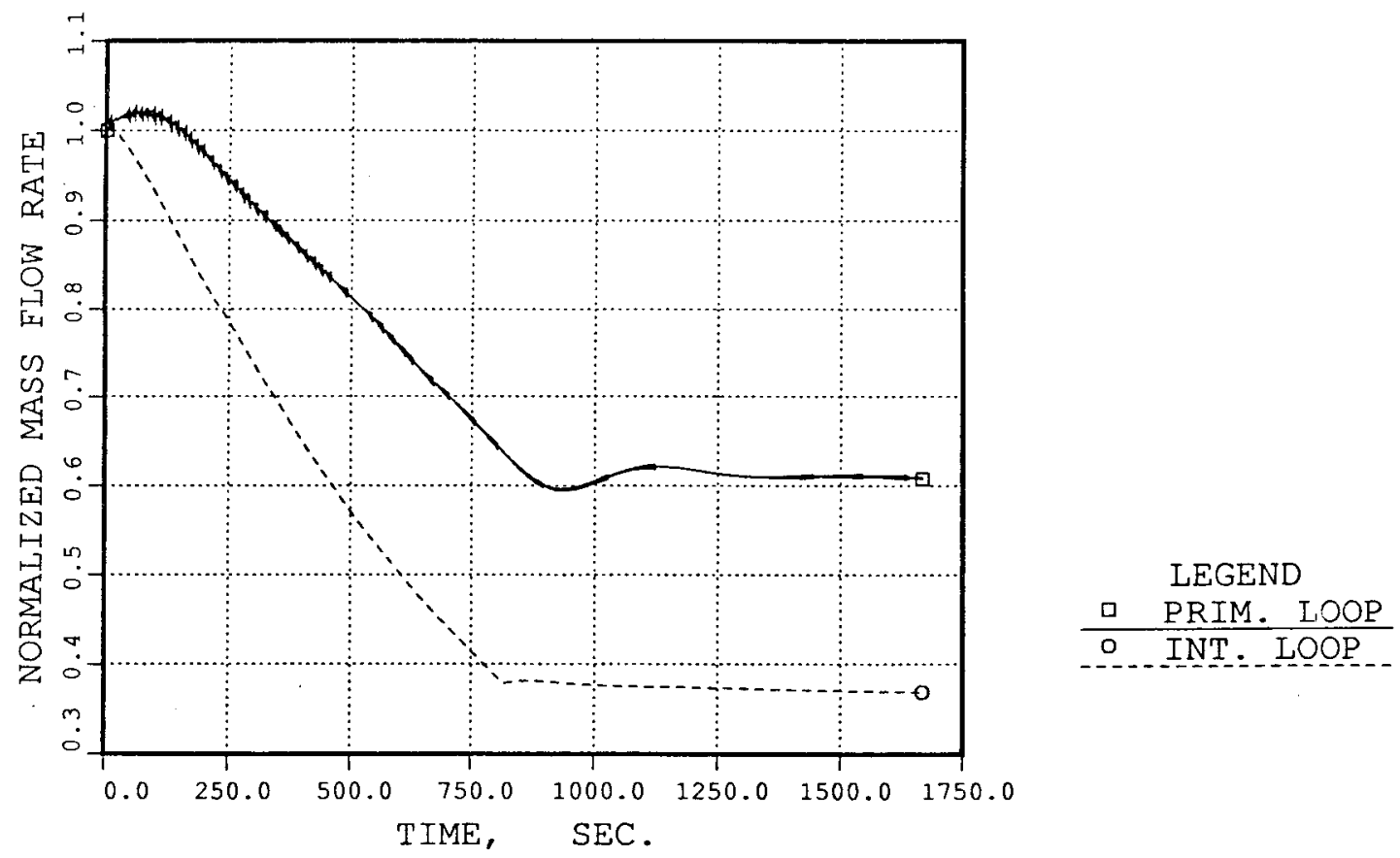

Fig. 6.1-3. No Rod PPj/PCS. Power Ramp 3\%/min. Loop Flows 


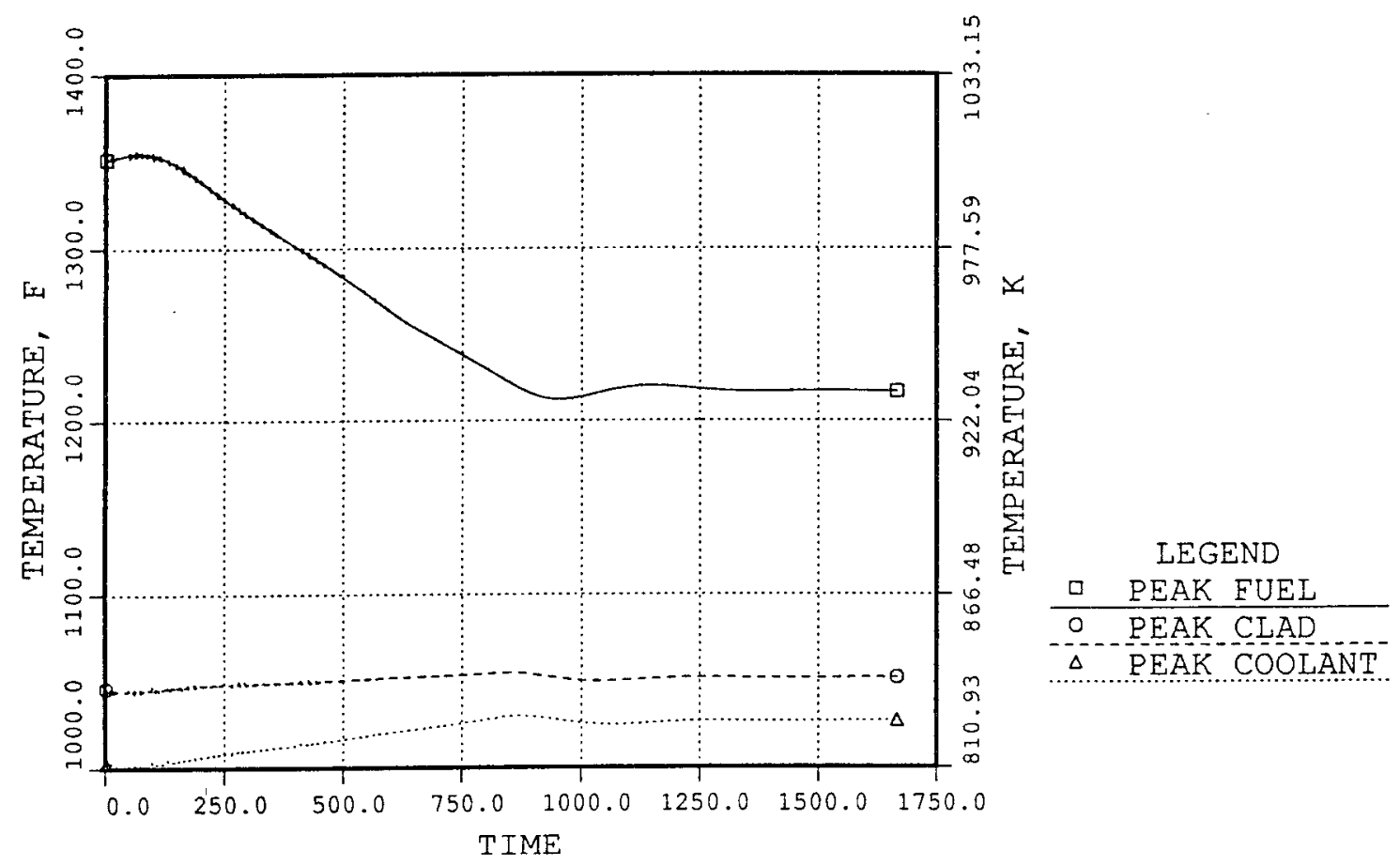

Fig. 6.1-4. No Rod PPS/PCS. Power Ramp 3\%/min. Channel 1 Peak Temperatures

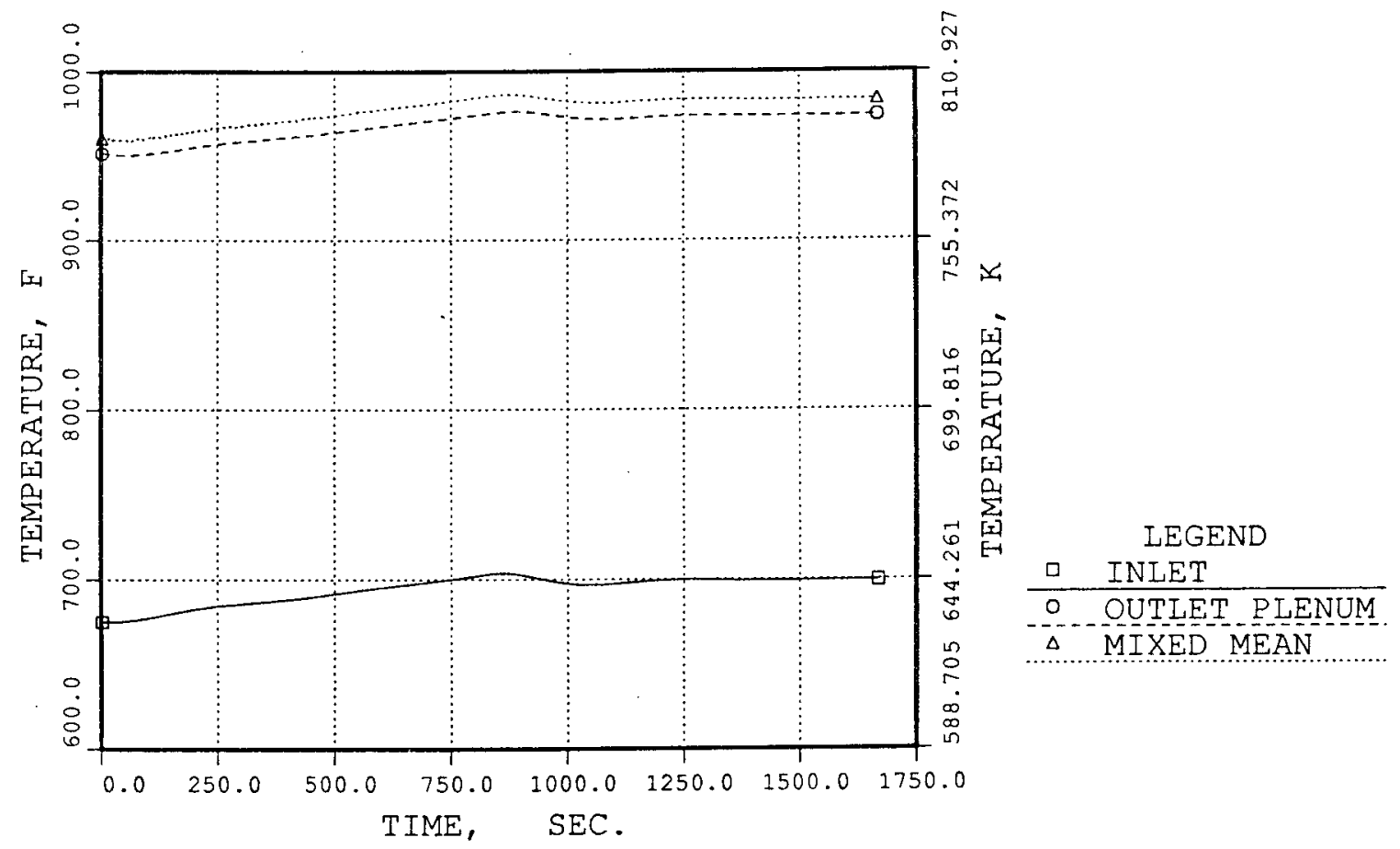

Fig. 6.1-5. No Rod PPS/PCS. Power Ramp 3\%/min. Reactor Core Temperatures 


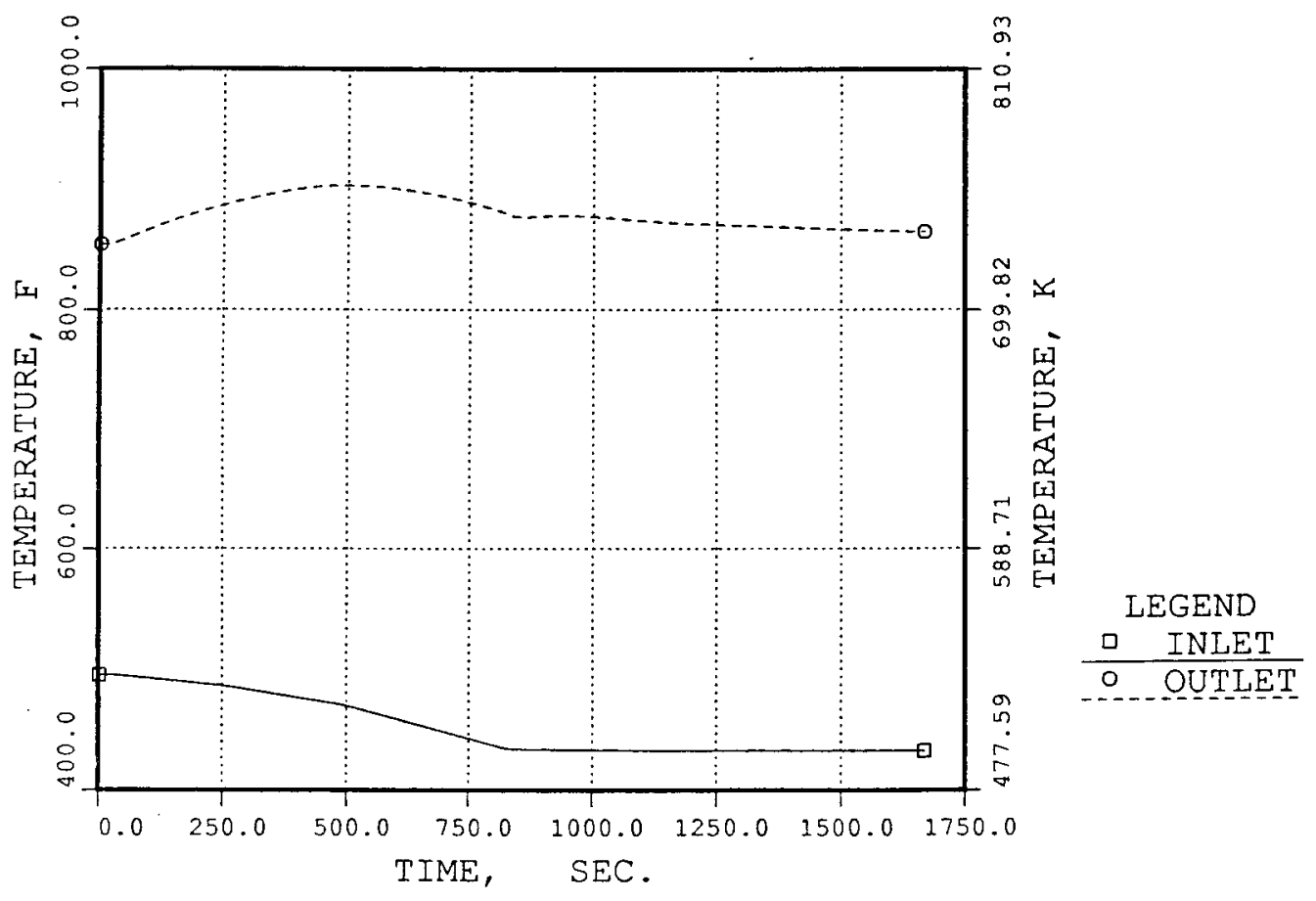

Fig. 6.1-6. No Rod PPS/PCS. Power Ramp 3\%/min. SG Water Temperatures
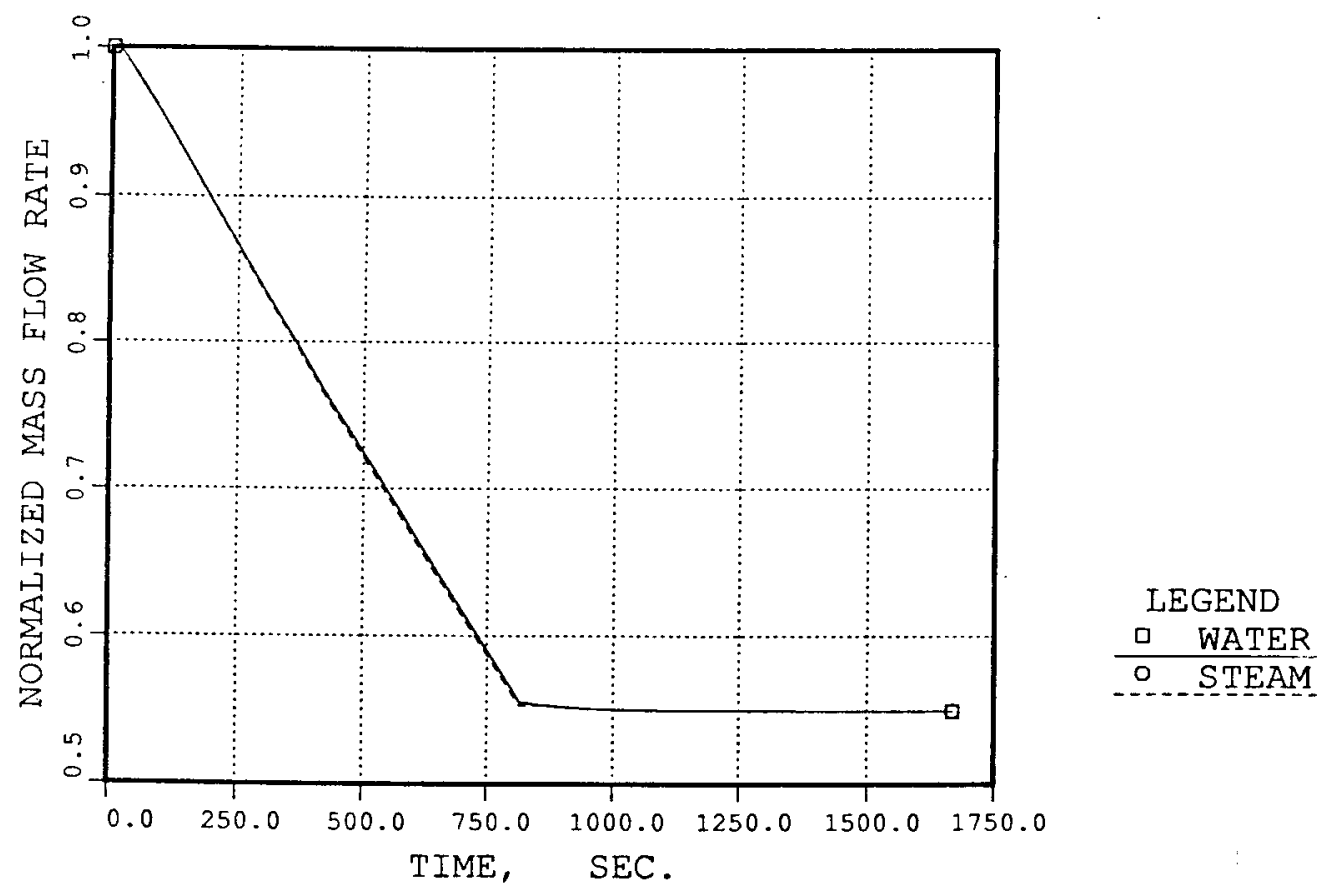

Fig. 6.1-7. No Rod PPś/PCS. Power Ramp 3\%/min. SG Water Flows 

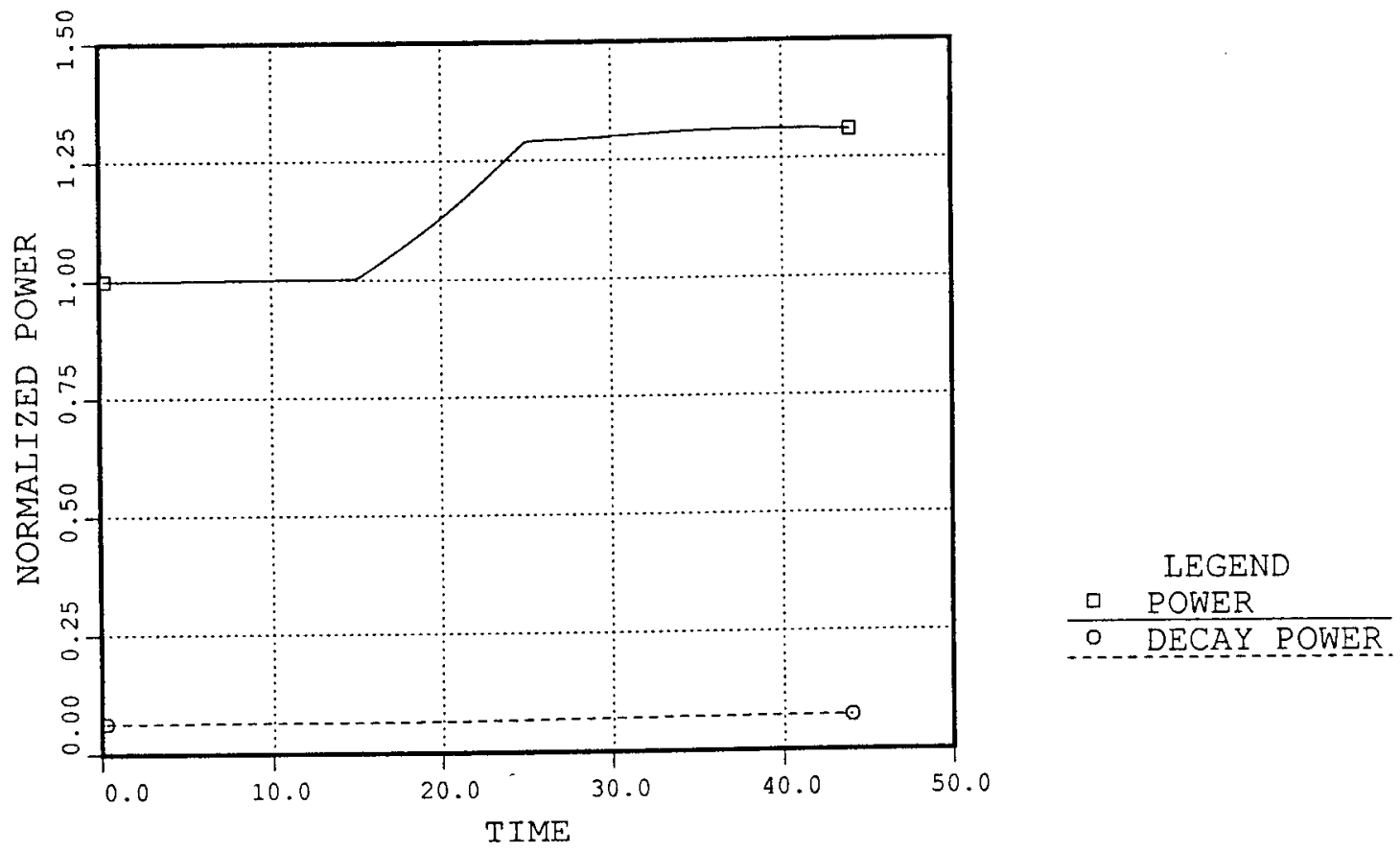

Fig. 6.2-1. No Rod PPS/PCS. 2\$/sec Control Rod Withdrawal Reactor Power
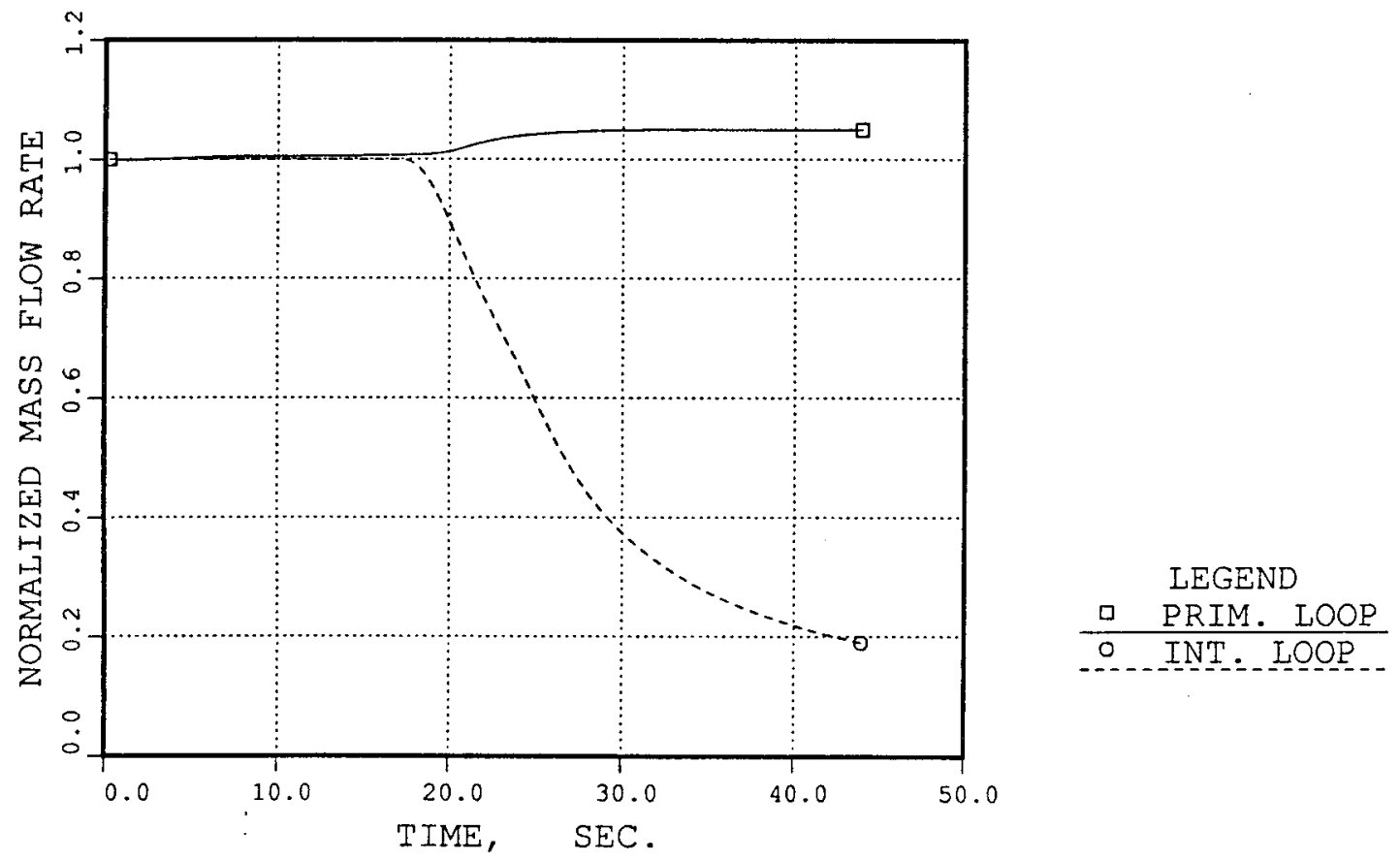

Fig. 6.2-2. No Rod PPS/PCS. 2\$/sec Control Rod Withdrawa Loop Flows 


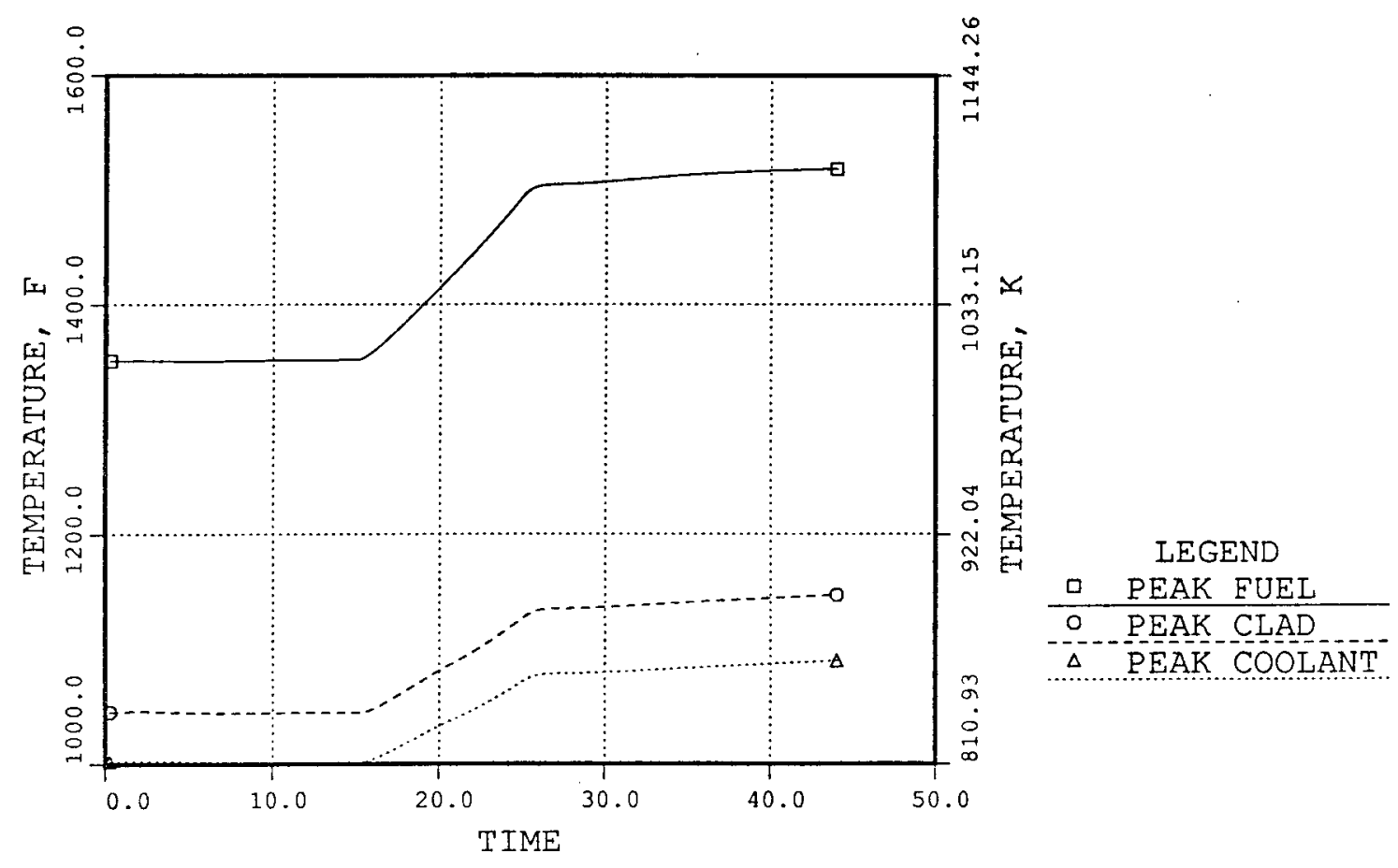

Fig. 6.2-3. No Rod PPS/PCS. 2\$/sec Control Rod Withdrawal Channel 1 Peak Temperatures

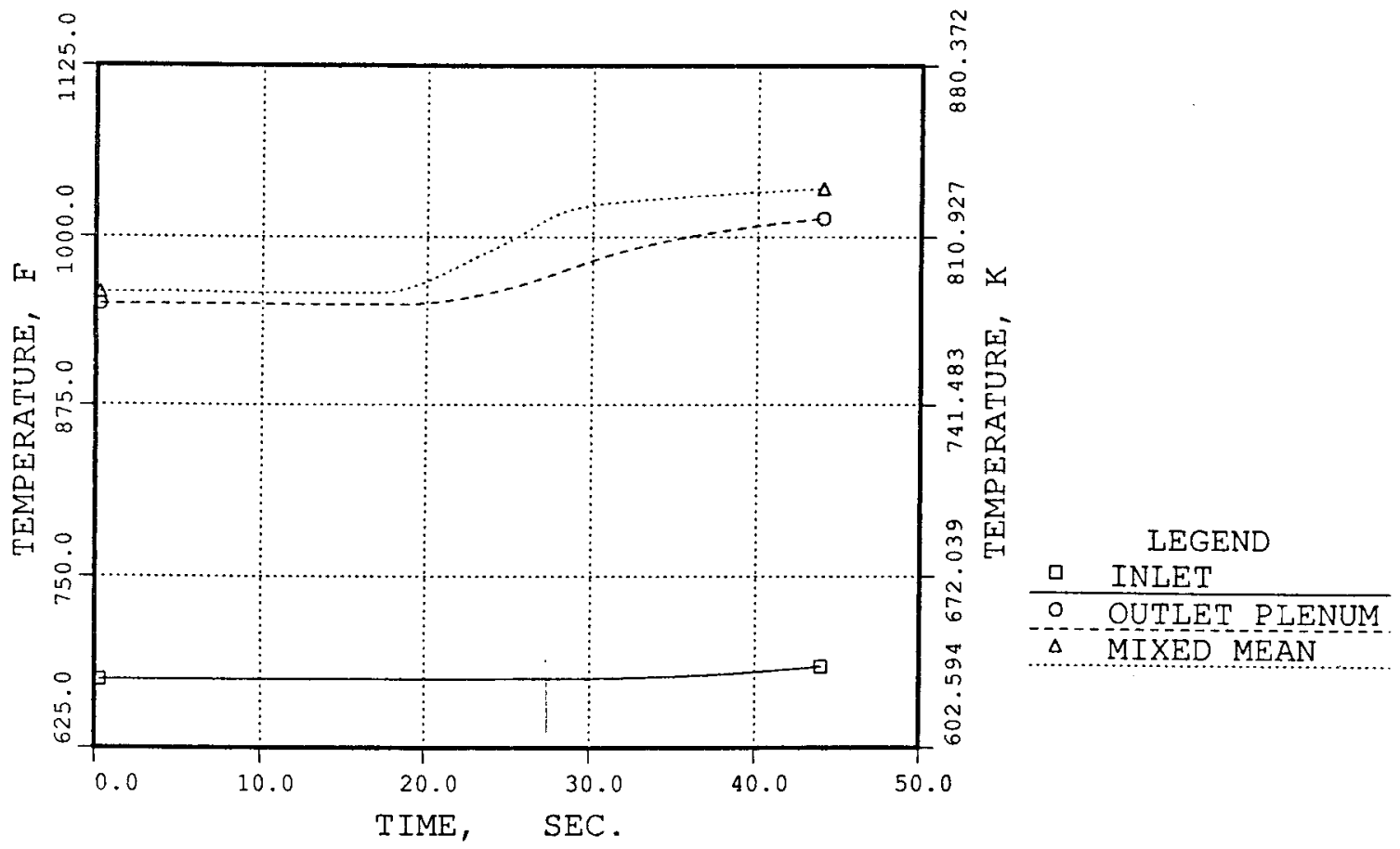

Fig. 6.2-4. No Rod PPS/PCS. 2\$/sec Control Rod Withdrawal Reactor Core Temperatures 


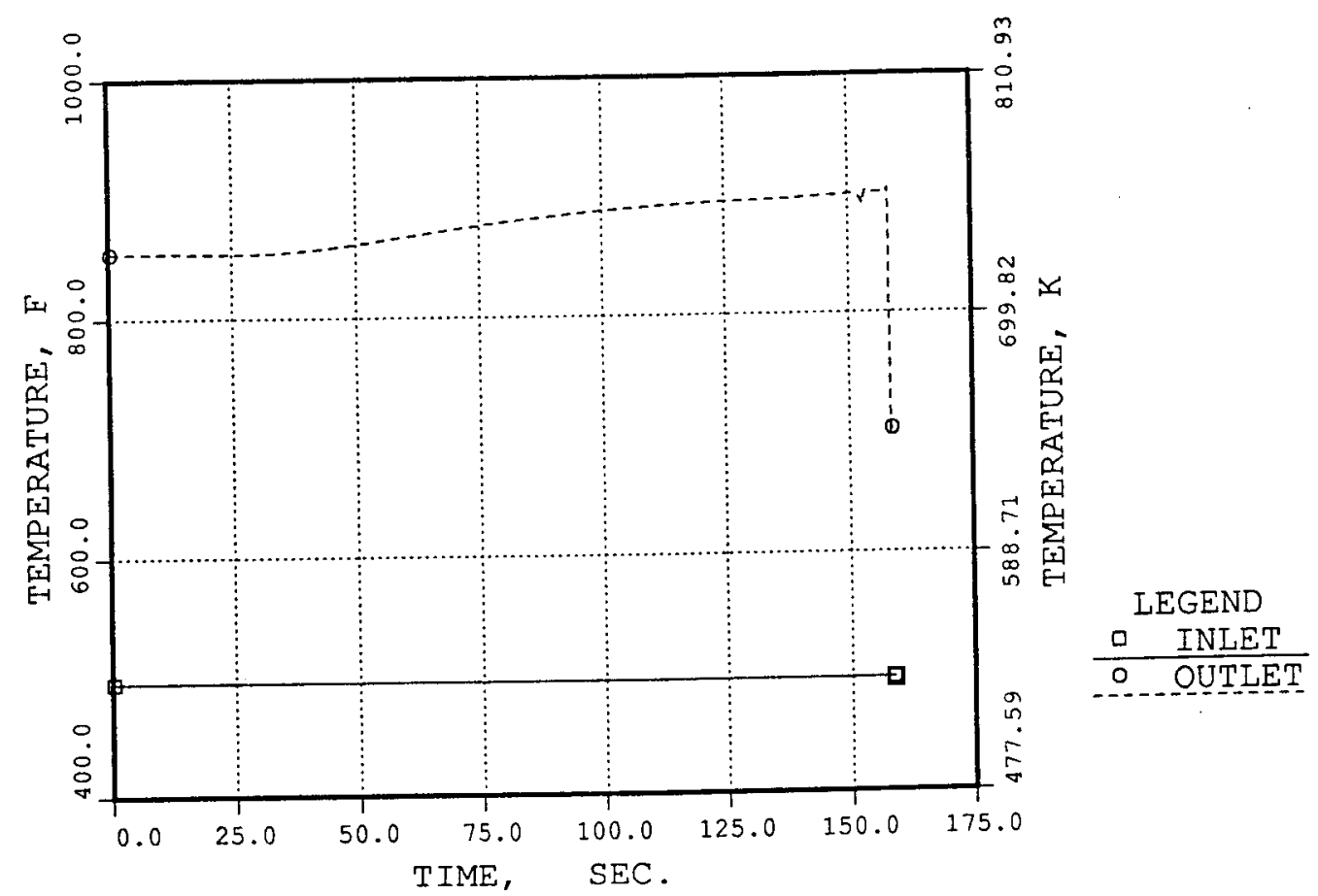

Fig. 6.2-5. No Rod PPS/PCS. 20\$/sec Control Rod Withdrawal/ No Sensor - SG Water Temperatures
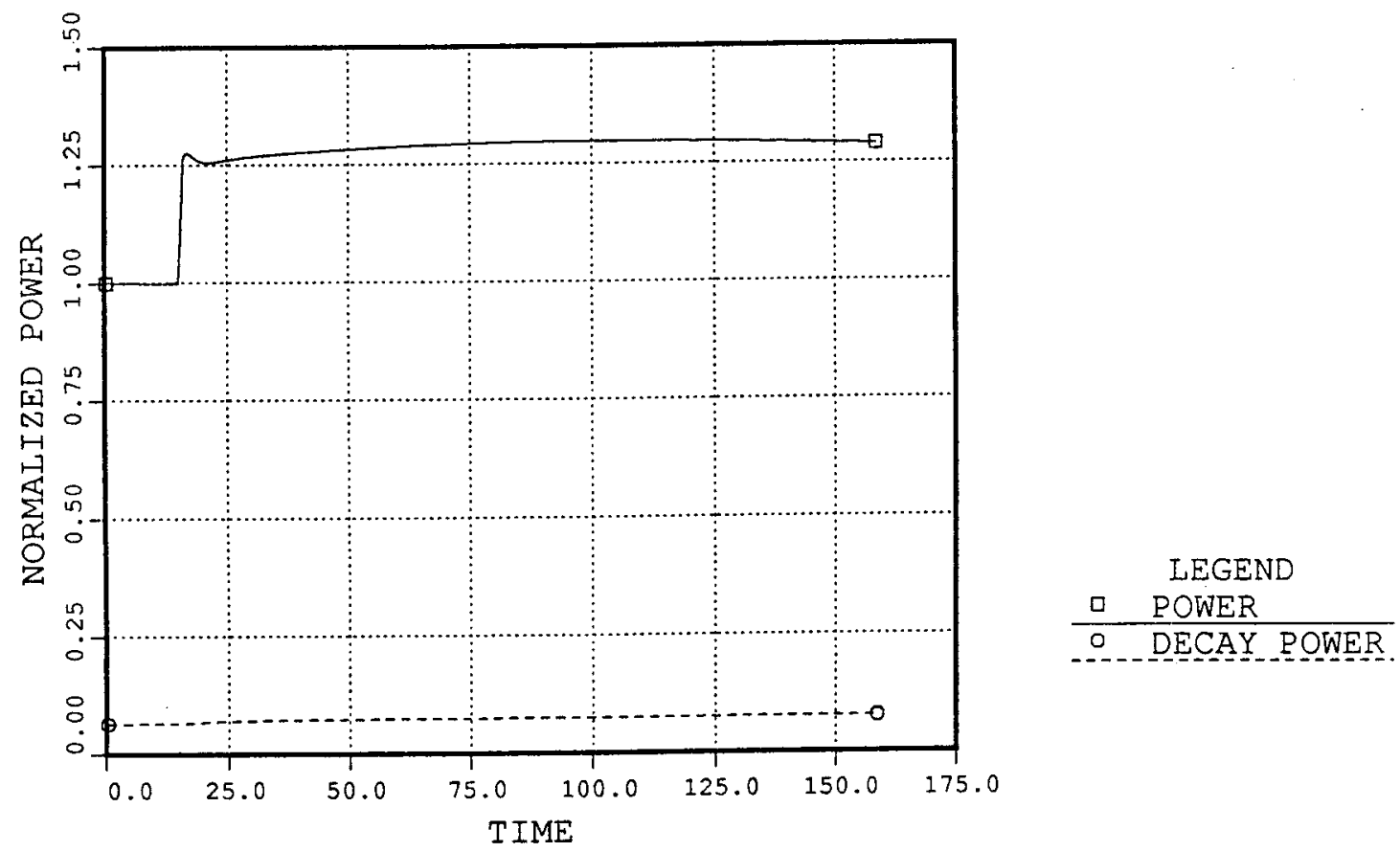

Fig. 6.2-6. No Rod PPS/PCS. 20\$/sec Control Rod Withdrawal/ No Sensor - Reactor Power 


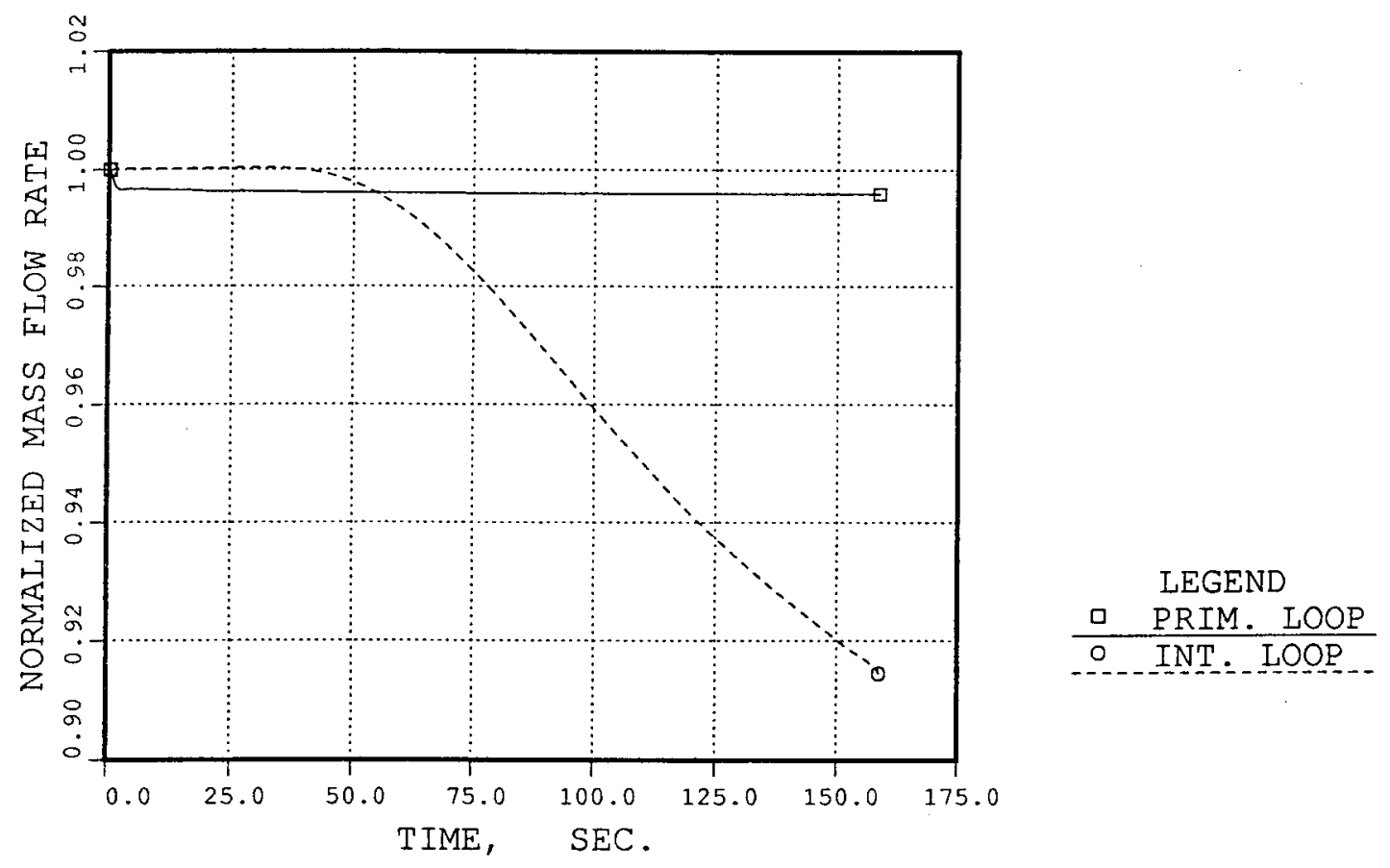

Fig. 6.2-7. No Rod PPS/PCS. 20\$/sec Control Rod Withdrawal/ No Sensor - Loop Flows

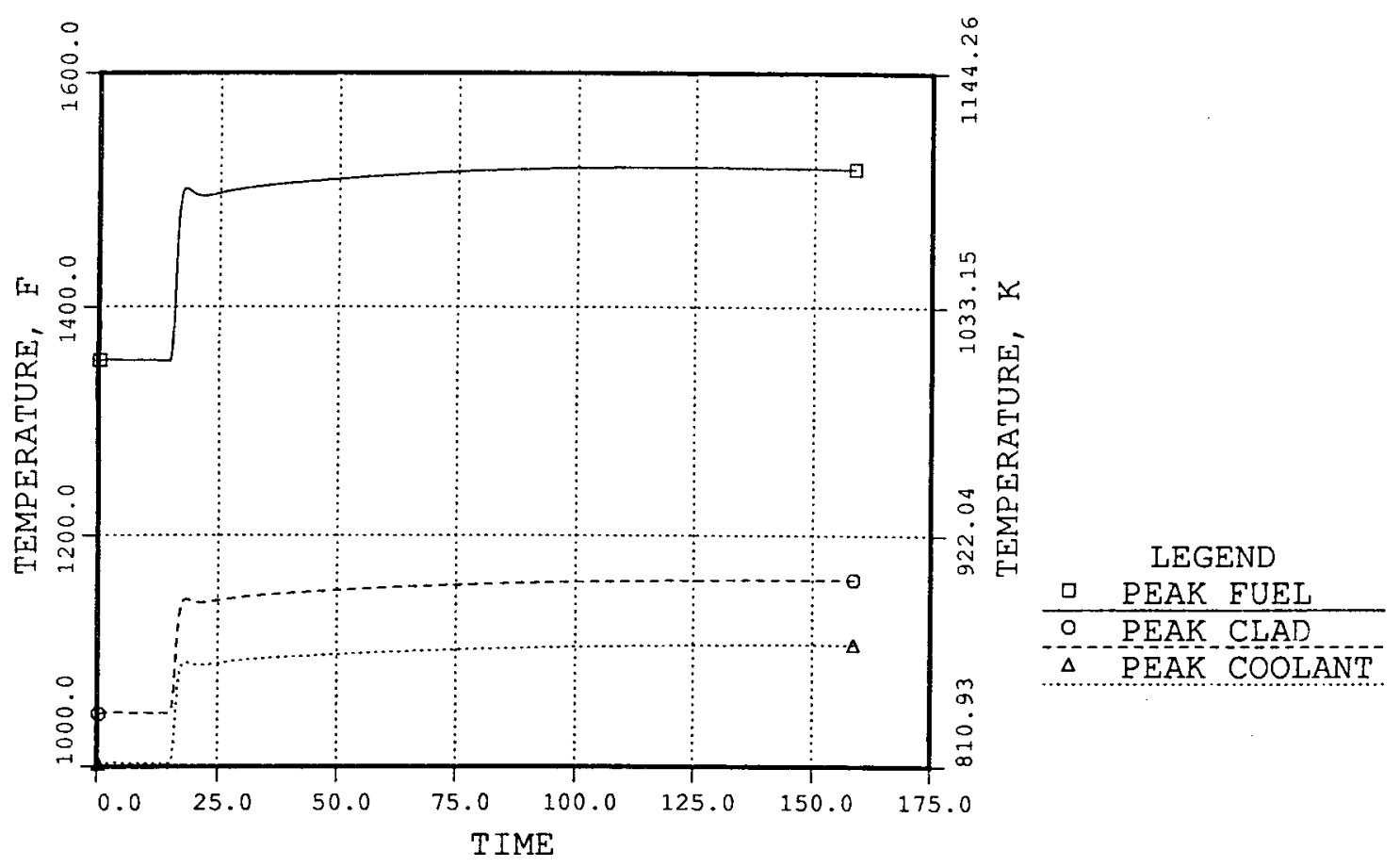

Fig. 6.2-8. No Rod PPS/PCS. 20 $\$ / \mathrm{sec}$ Control Rod Withdrawal/ No Sensor - Channel 1 Peak Temperatures 


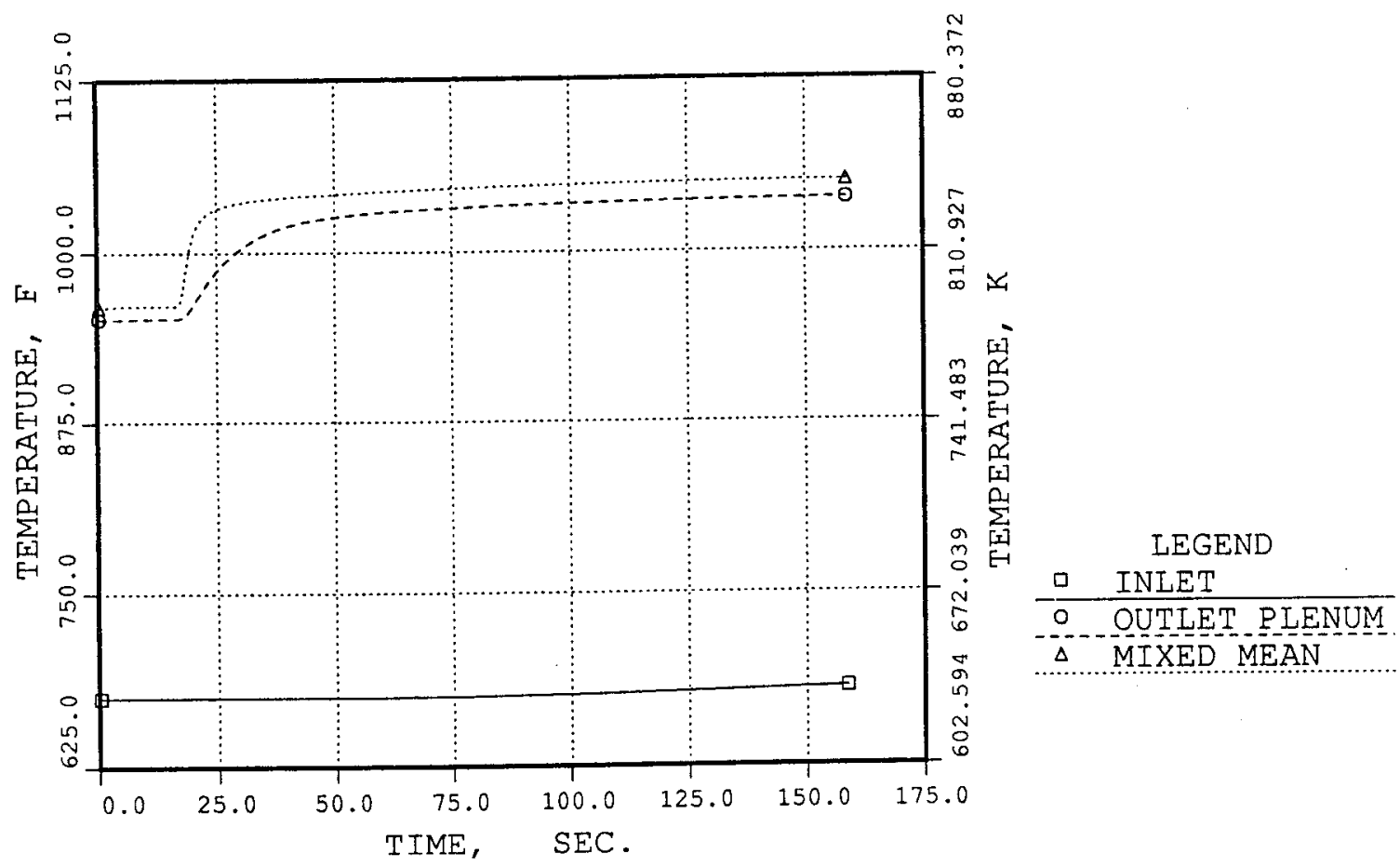

Fig. 6.2-9. No Rod PPS/PCS. 20\$/sec Control Rod Withdrawal/ No Sensor - Reactor Core Temperatures
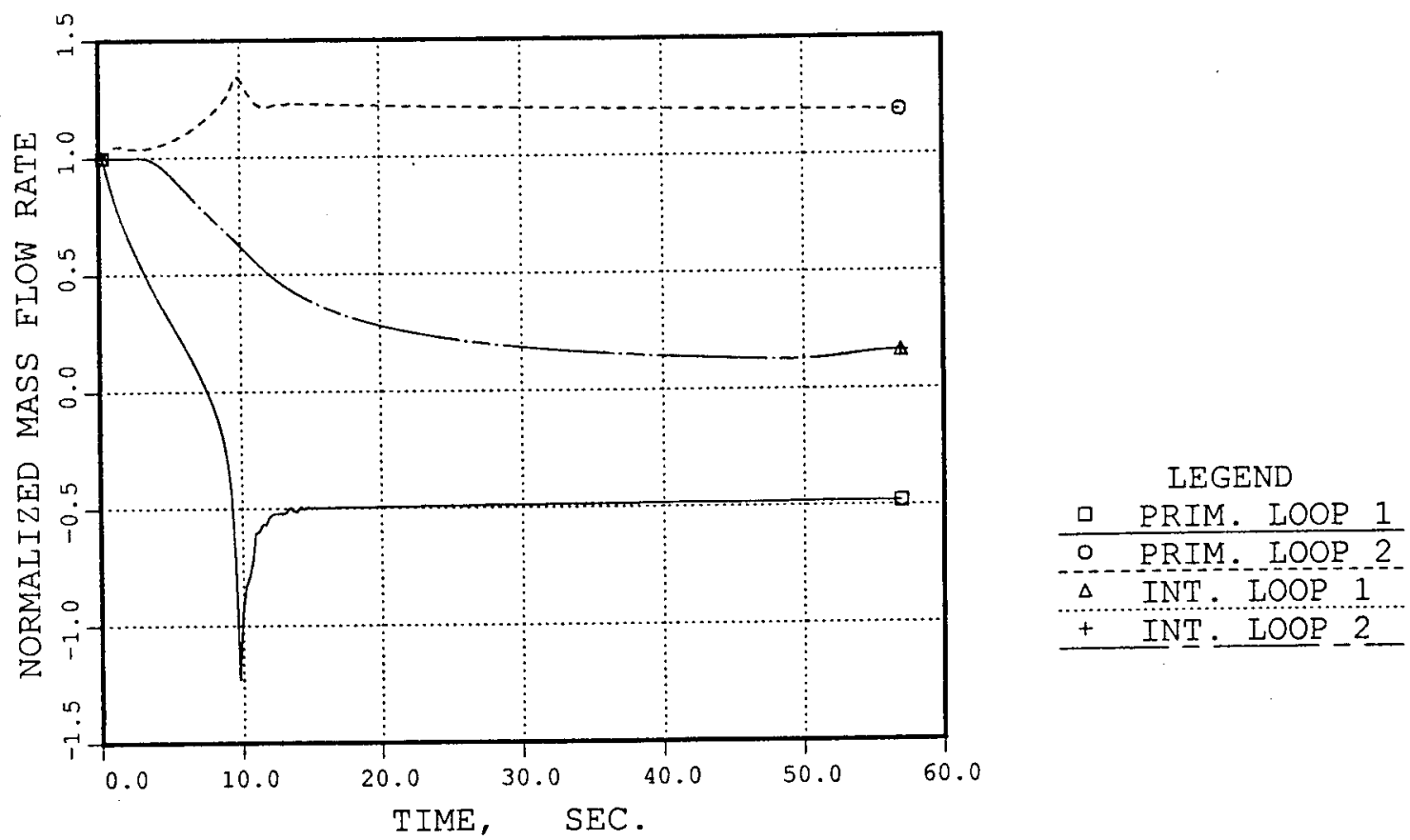

Fig. 6.2-10. No Rod PPS/PCS. 1 PHTS Pump Trip Loop Flows 


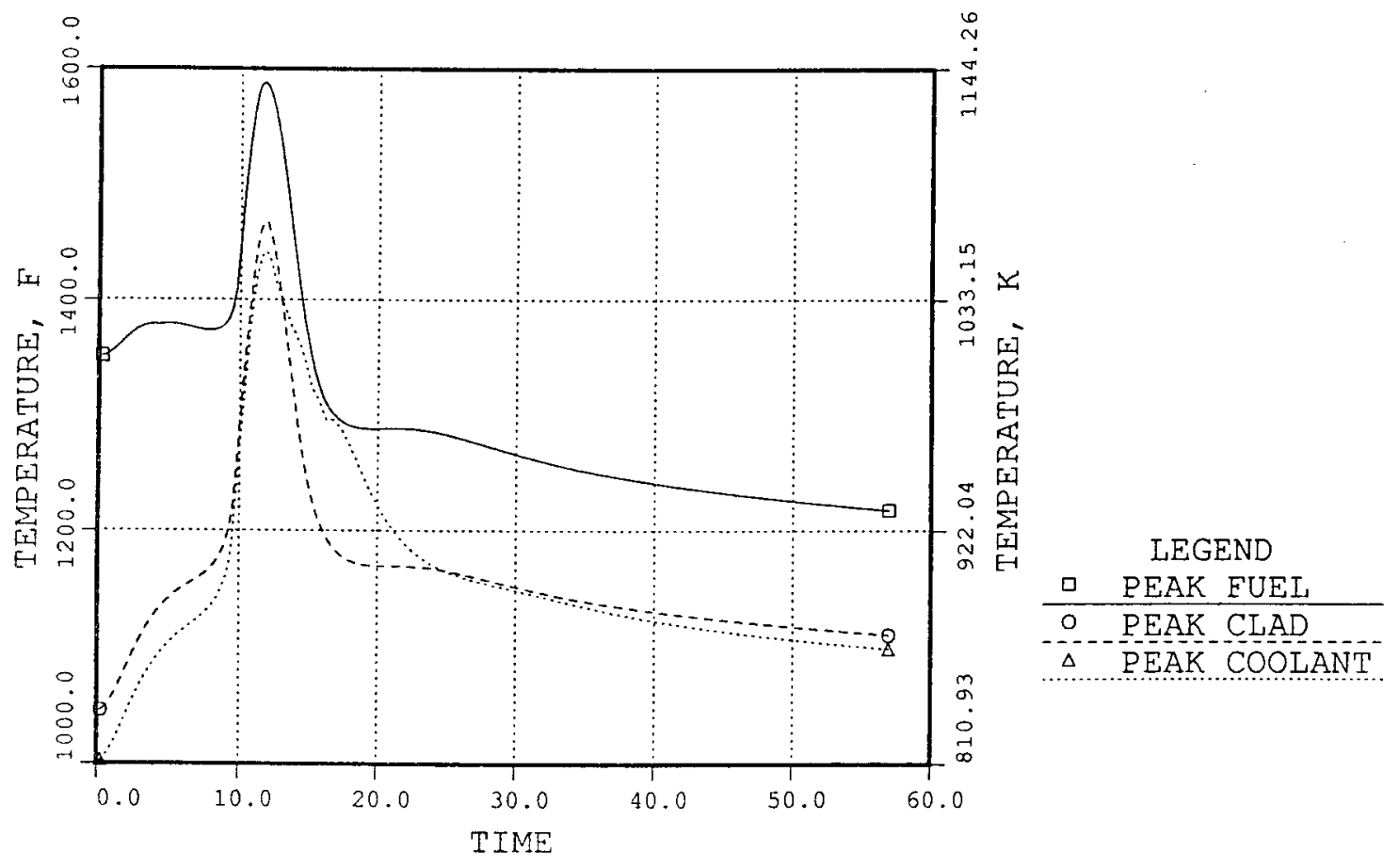

Fig. 6.2-11. No Rod PPS/PCS. 1 PHTS Pump Trip - Channel 1 Peak Temperatures

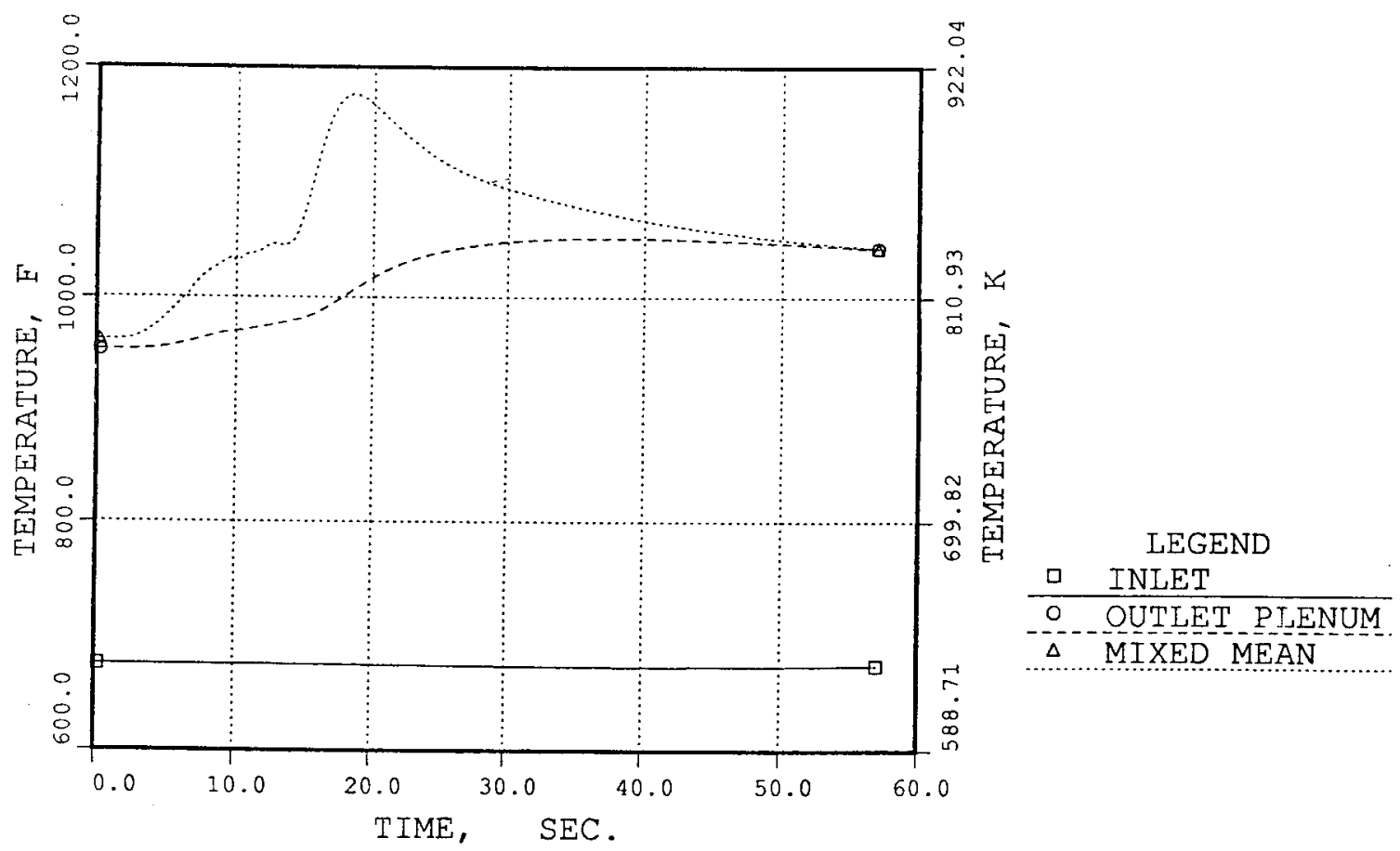

Fig. 6.2-12. No Rod PPS/PCS. 1 PHTS Pump Trip Reactor Core Temperatures 


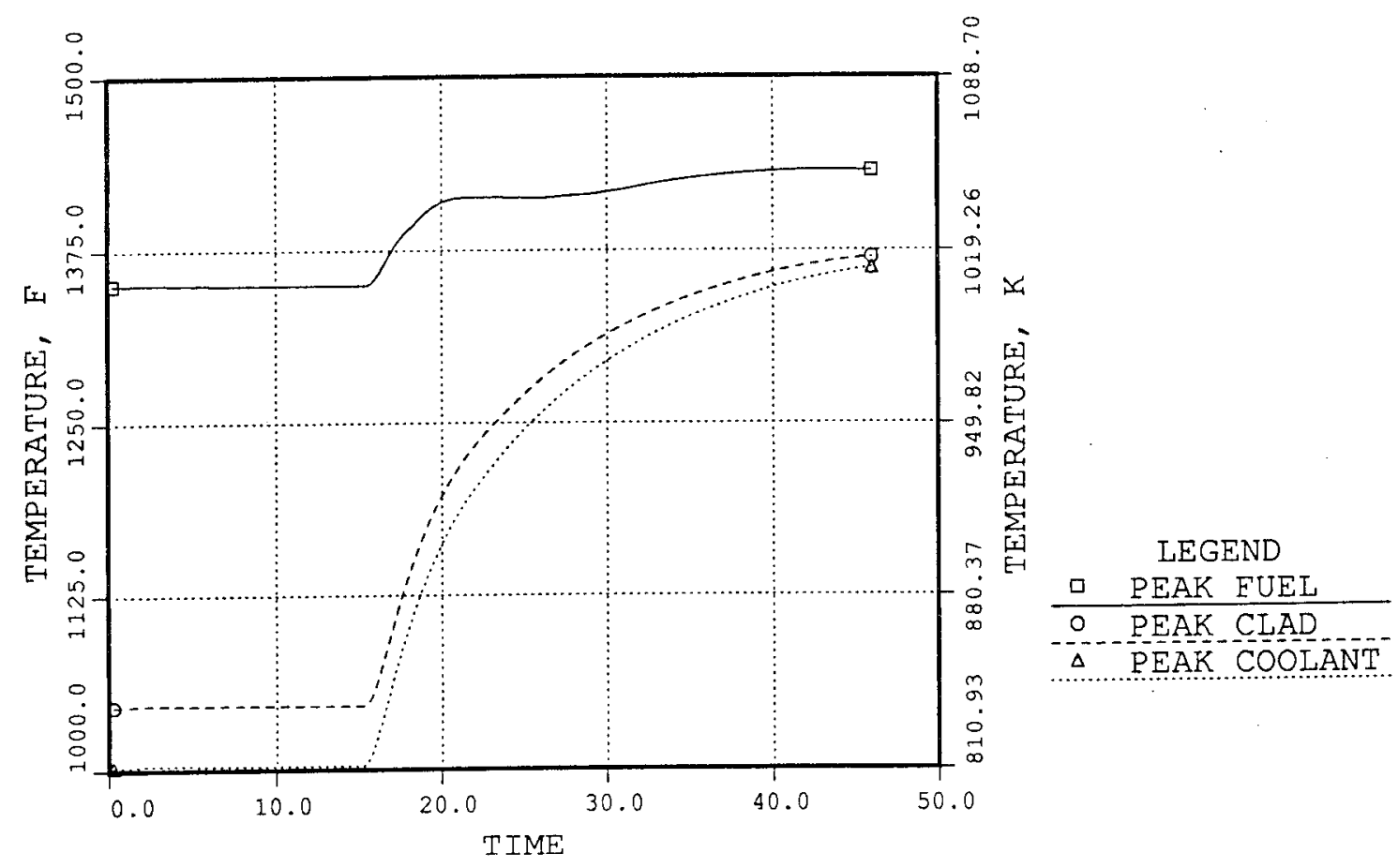

Fig. 6.2-13. No Rod PPS/PCS. 2 PHTS Pump Trip - Channel 1 Peak Temperatures

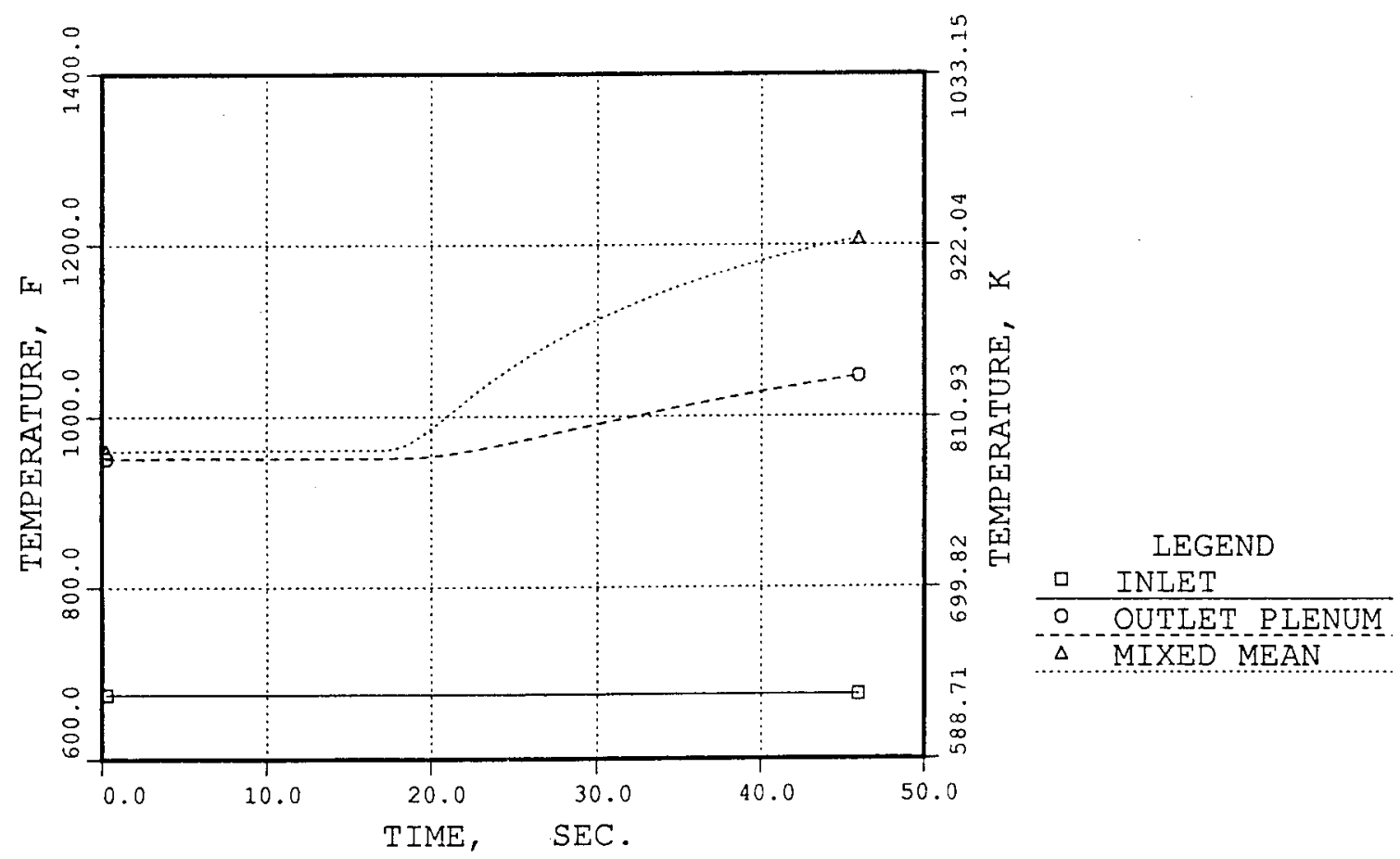

Fig. 6.2-14. No Rod PPS/PCS. 2 PHTS Pump Trip Reactor Core Temperatures 


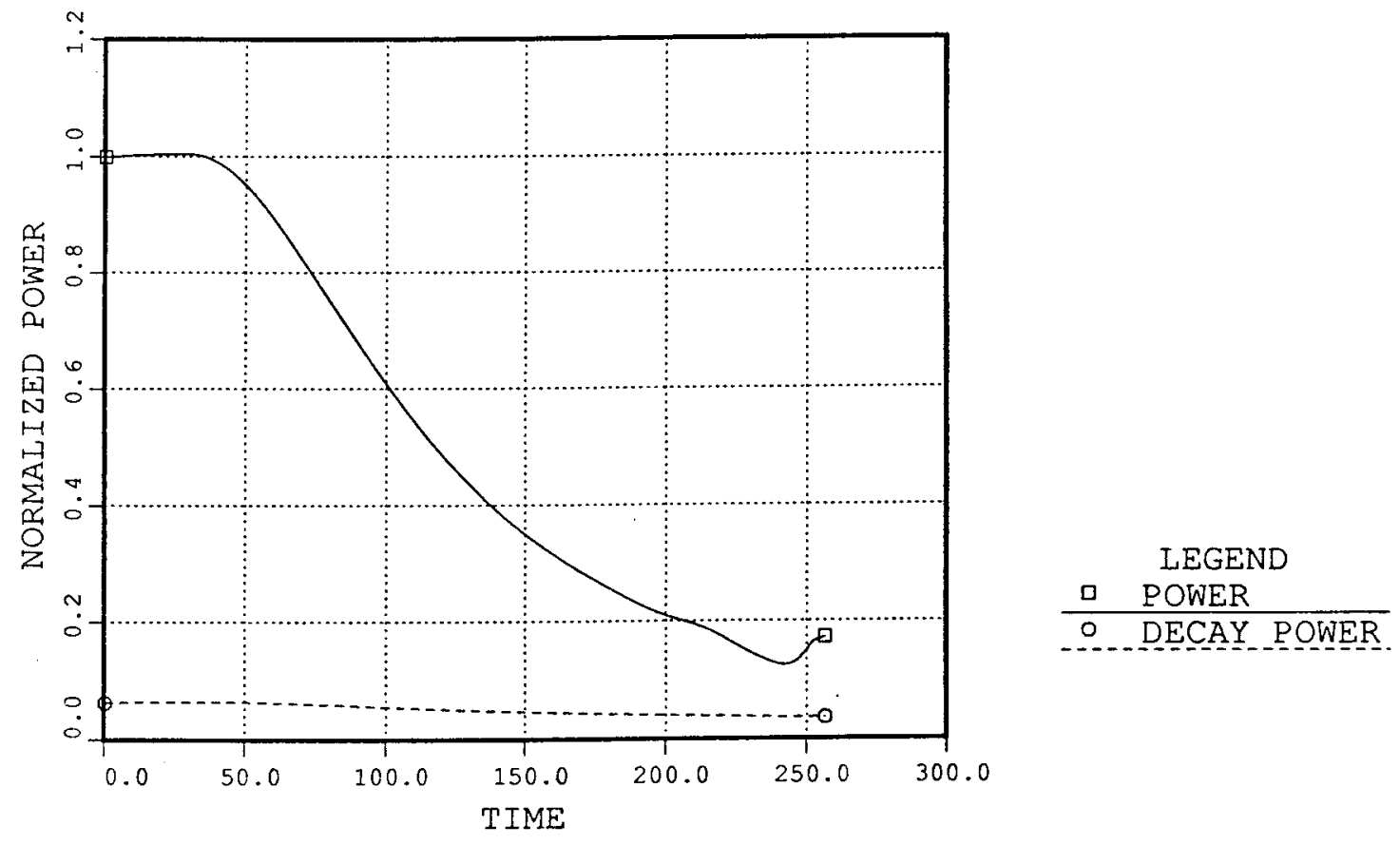

Fig. 6.2-15. No Rod PPS/PCS. 2 IHTS Pump Trip Reactor Power
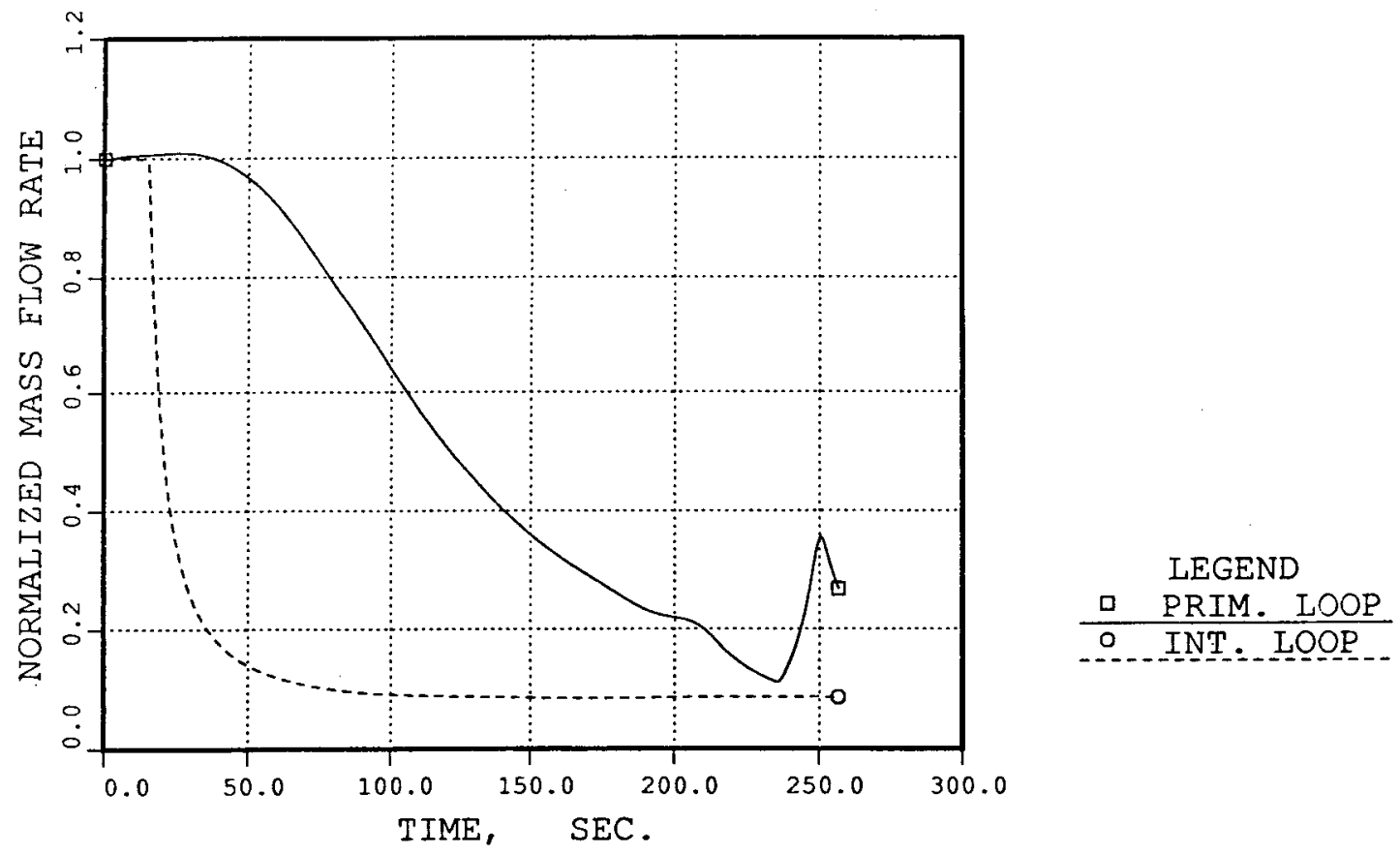

Fig. 6.2-16. No Rod PPS/PCS. 2 IHTS Pump Trip Loop Flows 


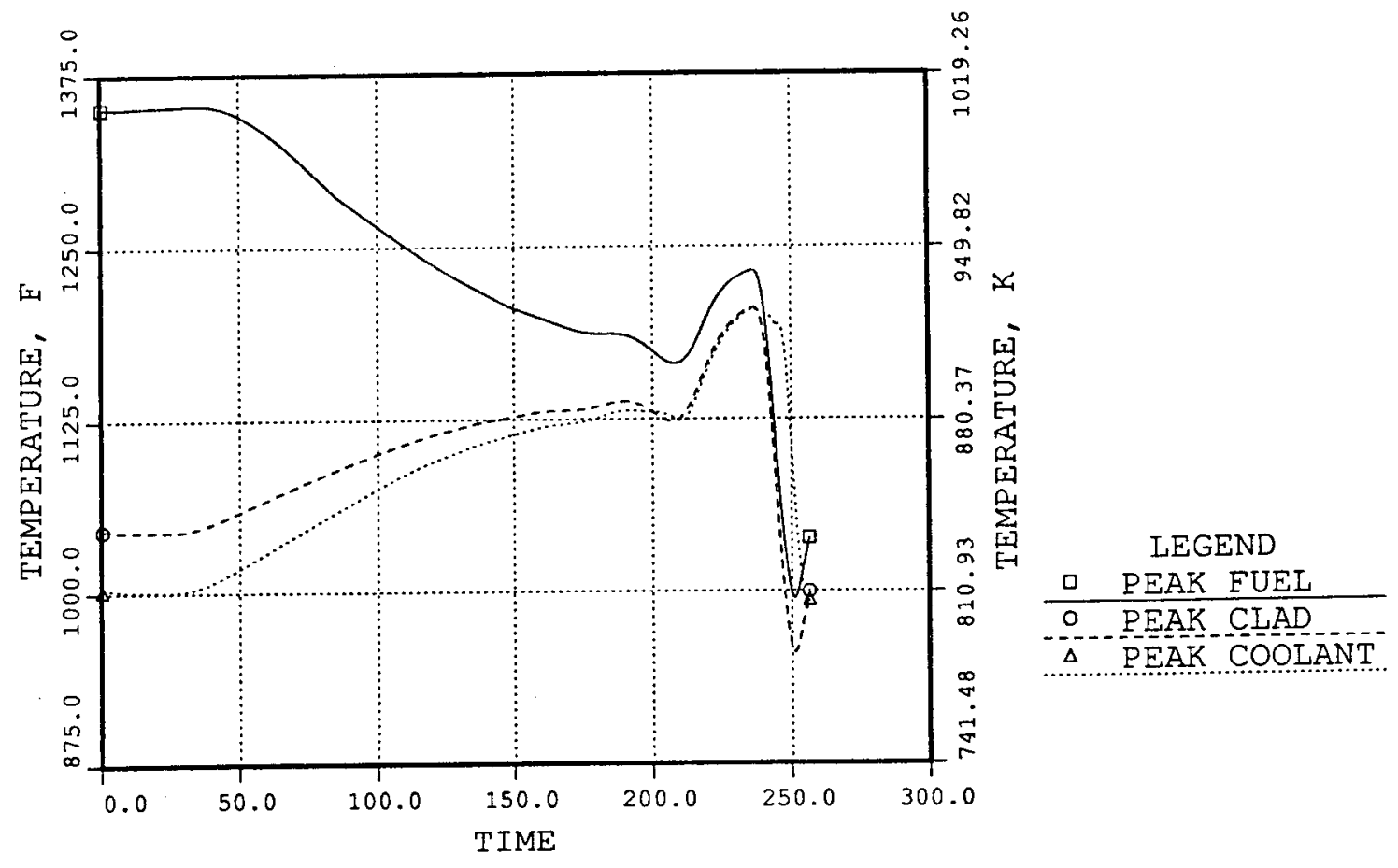

Fig. 6.2-17. No Rod PPS/PCS. 2 IHTS Pump Trip - Channel 1 Peak Temperatures

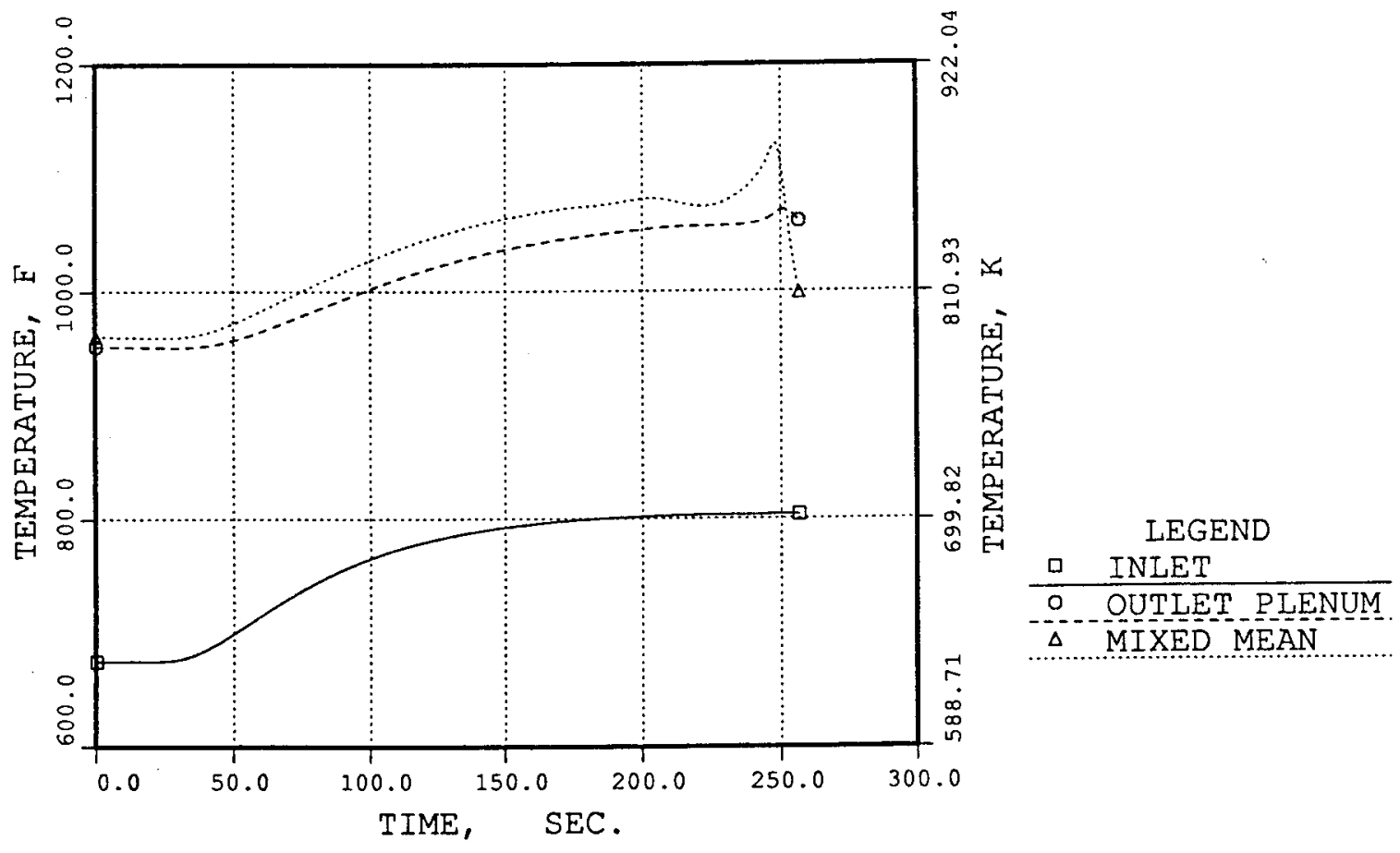

Fig. 6.2-18. No Rod PPS/PCS. 2 IHTS Pump Trip Reactor Core Temperatures 


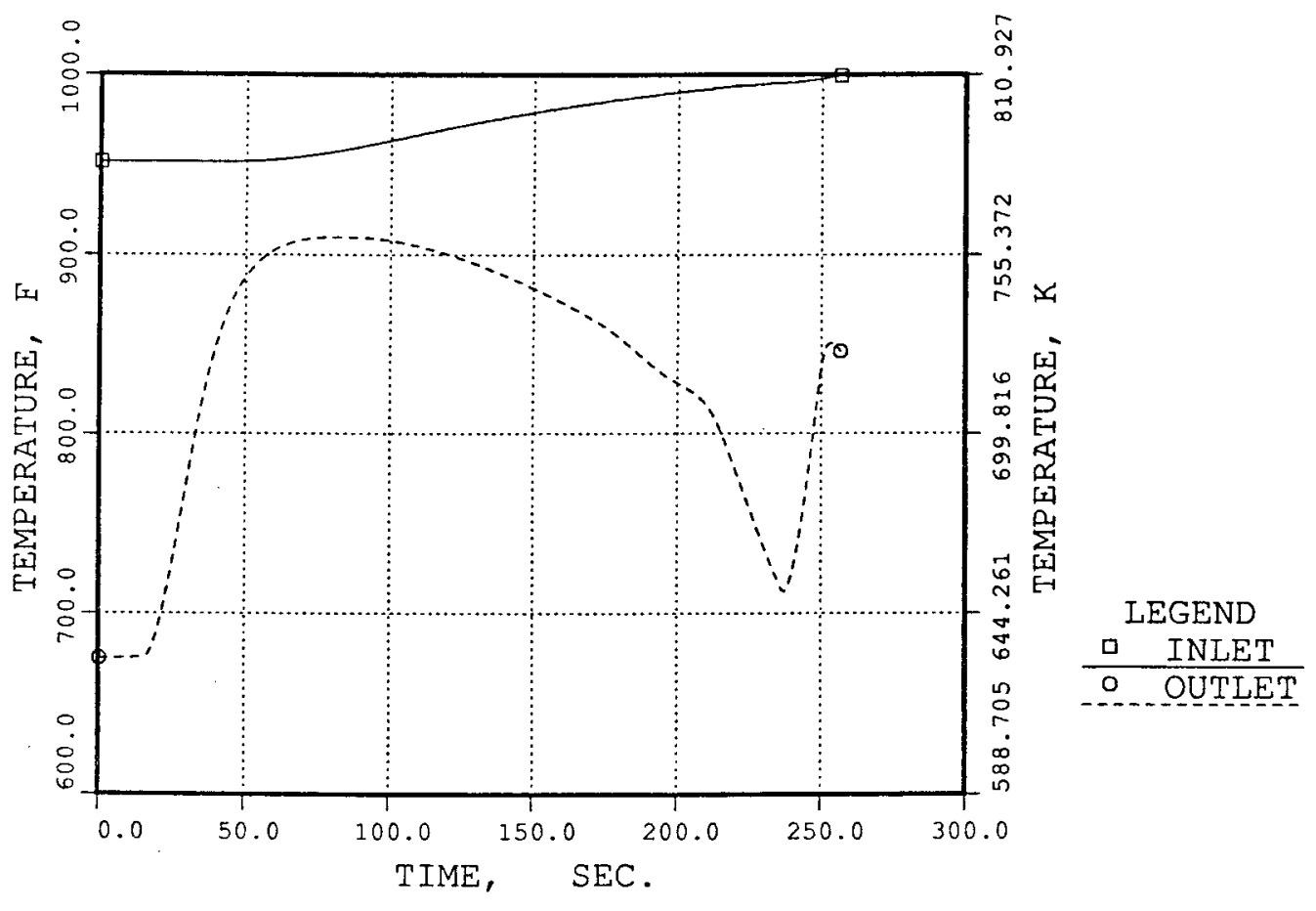

Fig. 6.2-19. No Rod PPS/PCS. 2 IHTS Pump Trip - IHX Primary Side Temperatures

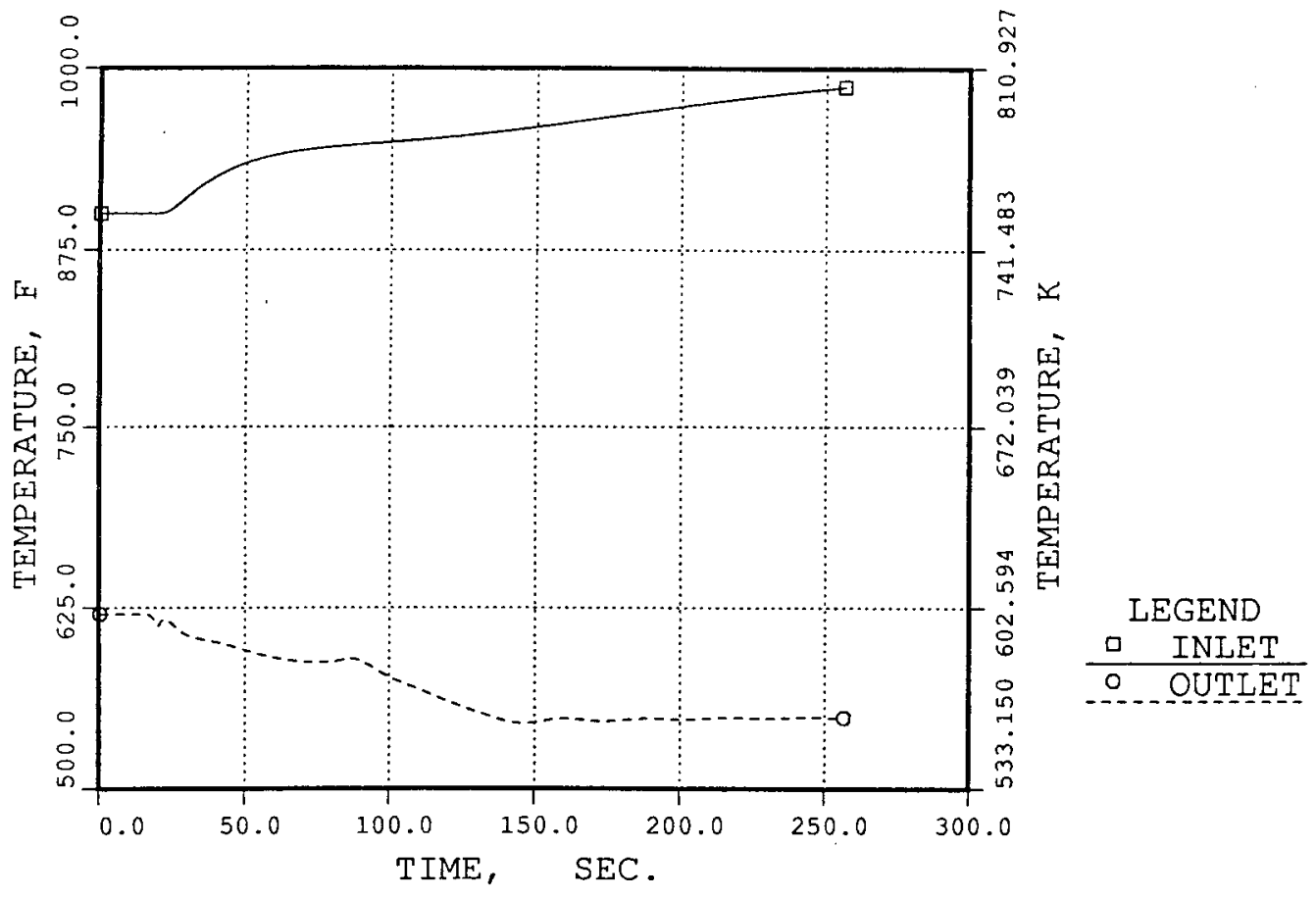

Fig. 6.2-20. No Rod PPS/PCS. 2 IHTS Pump Trip SG Sodium Temperatures 


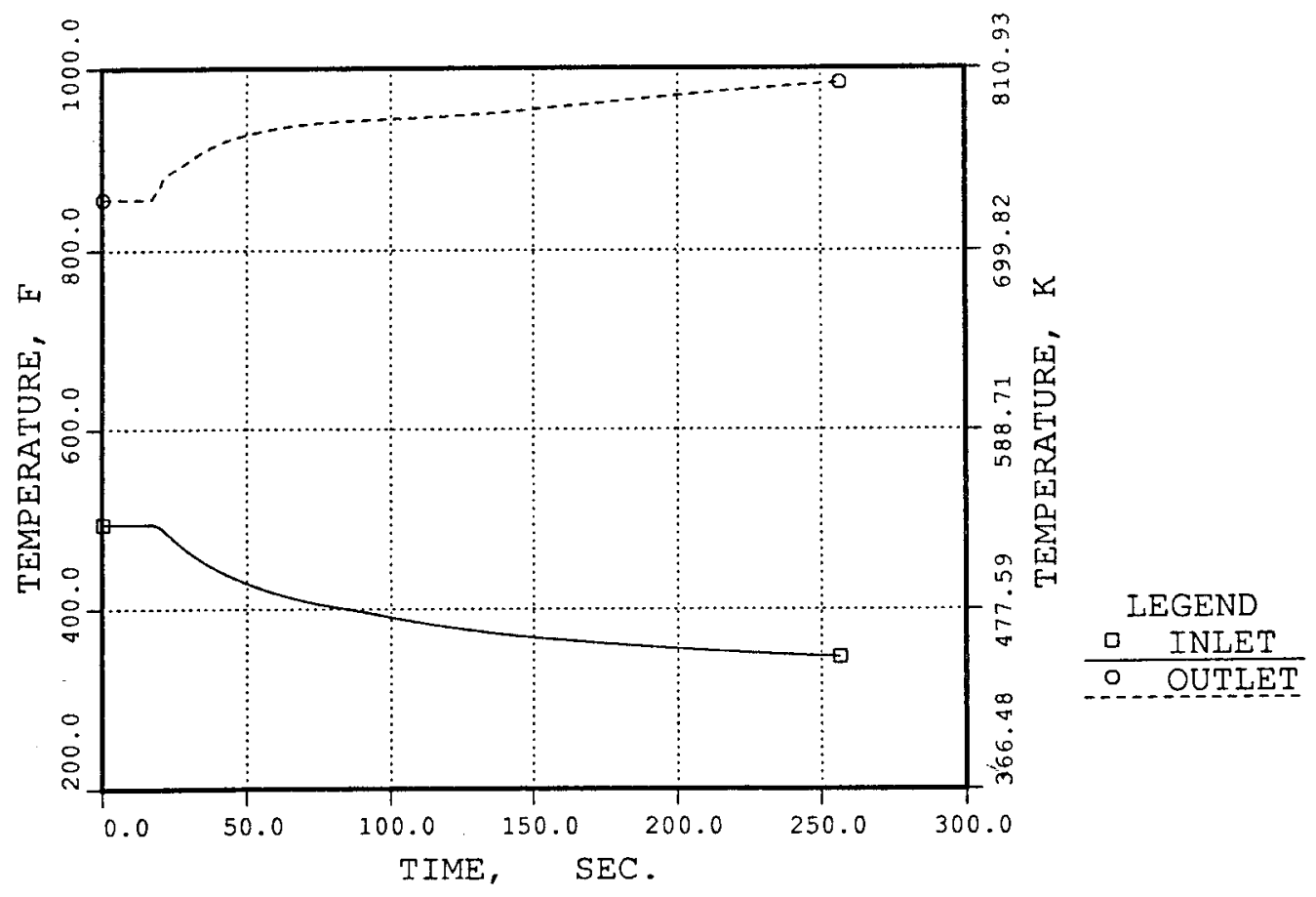

Fig. 6.2-21. No Rod PPS/PCS. 2 IHTS Pump Trip SG Water Temperatures

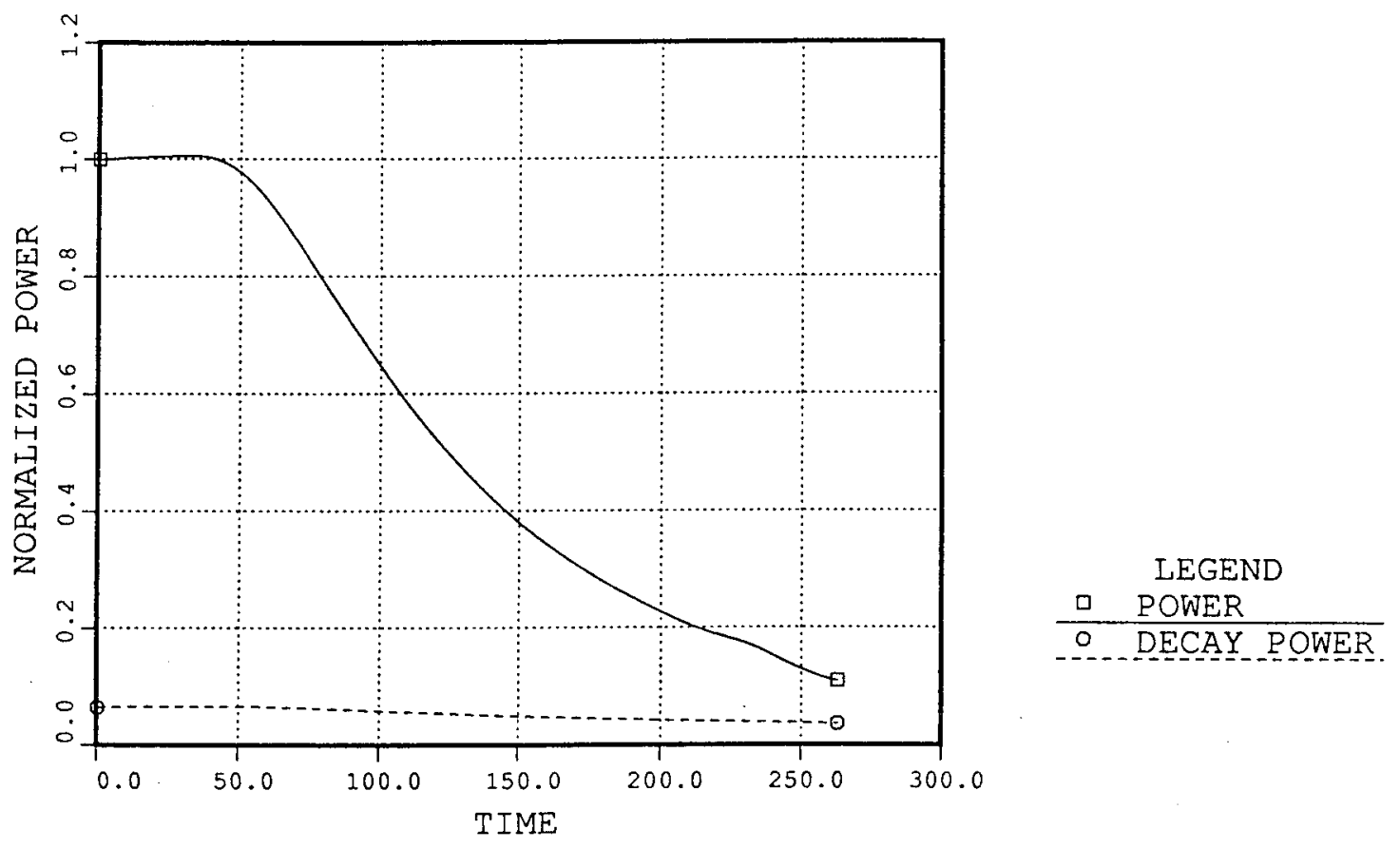

Fig. 6.2-22. No Rod PPS/PCS. 2 SG FW Valve Closure Reactor Power 

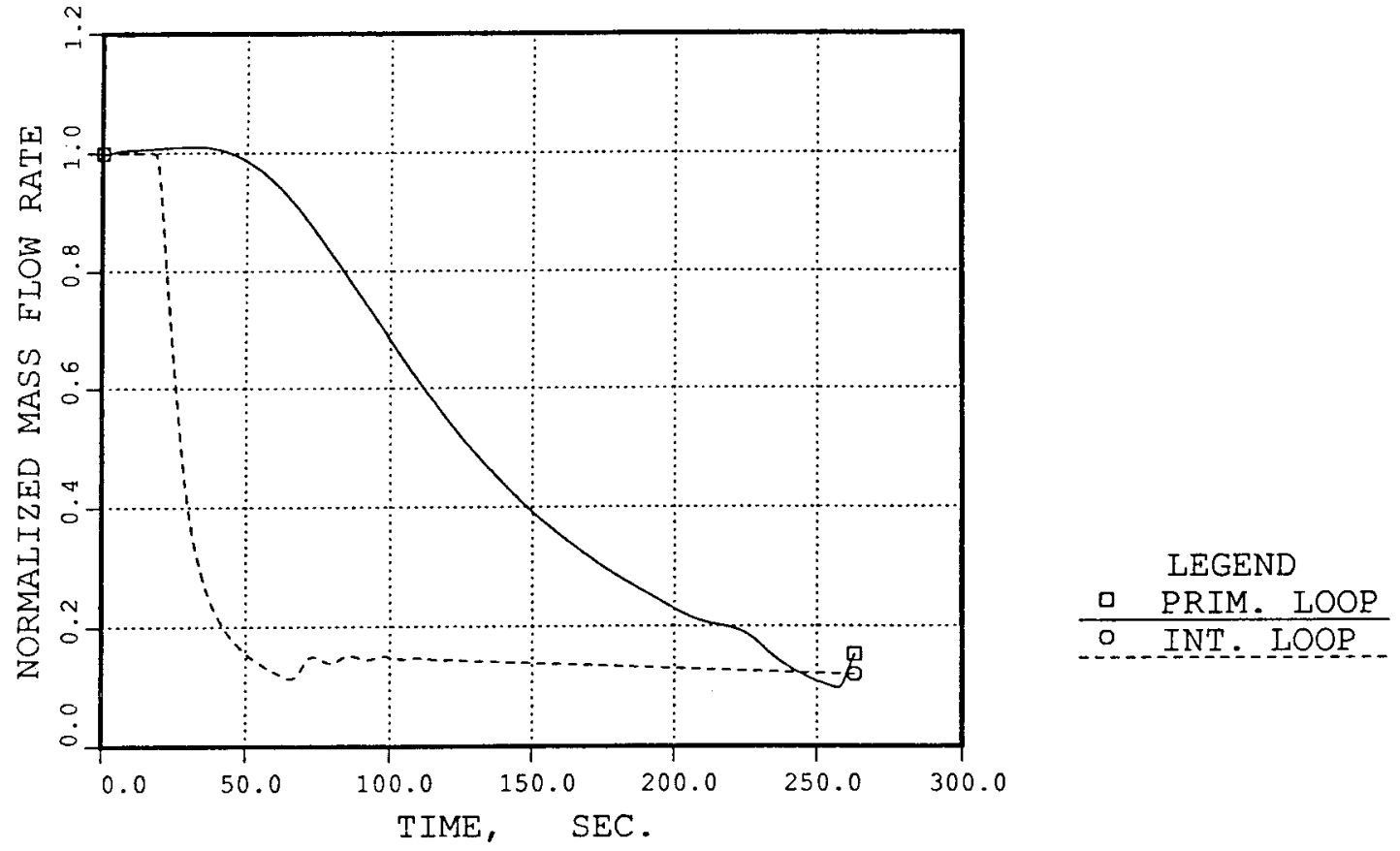

Fig. 6.2-23. No Rod PPS/PCS. 2 SG FW Valve Closure Loop Flows

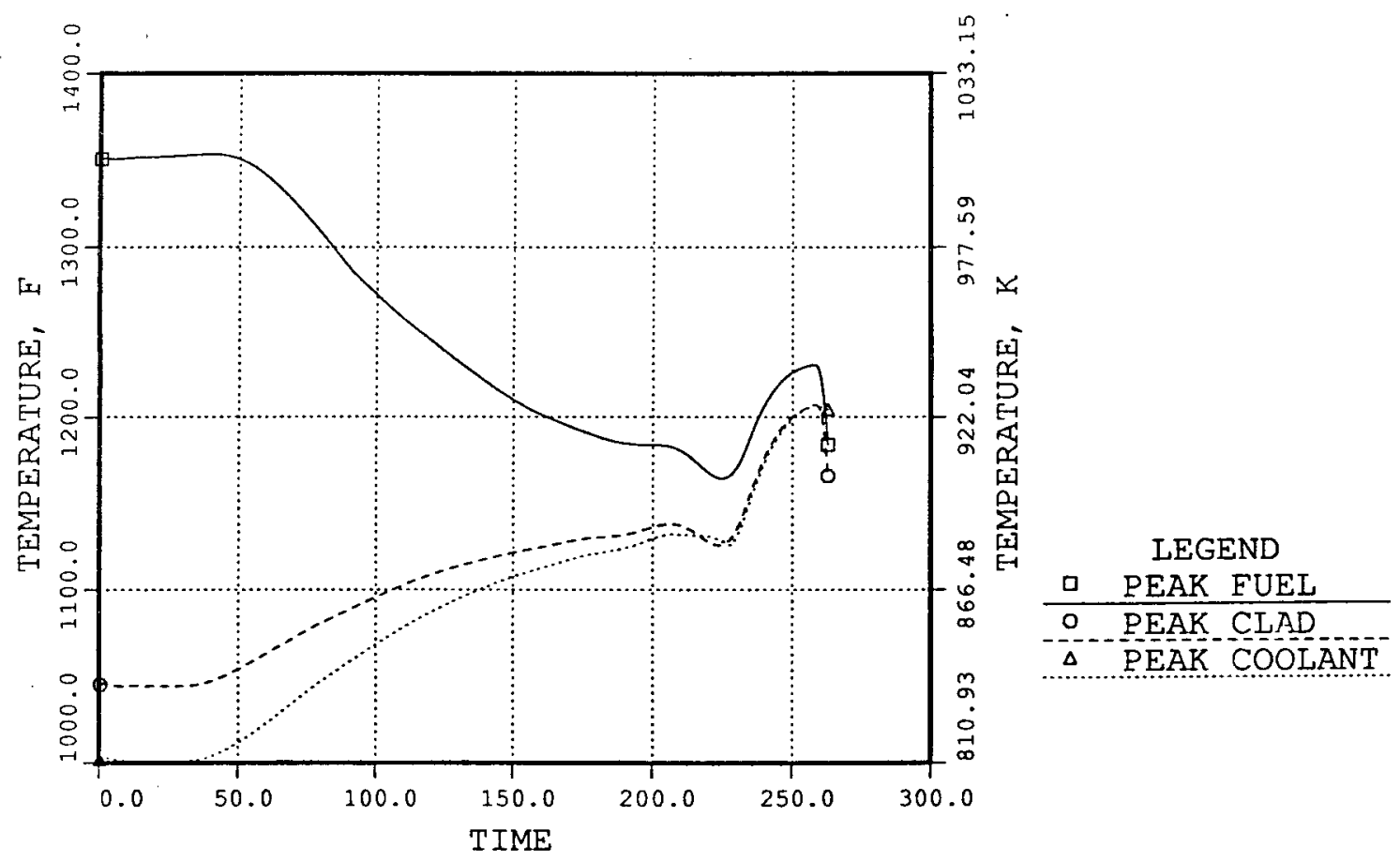

Fig. 6.2-24. No Rod PPS/PCS. 2 SG FW Valve Closure Channe 11 Peak Temperatures 


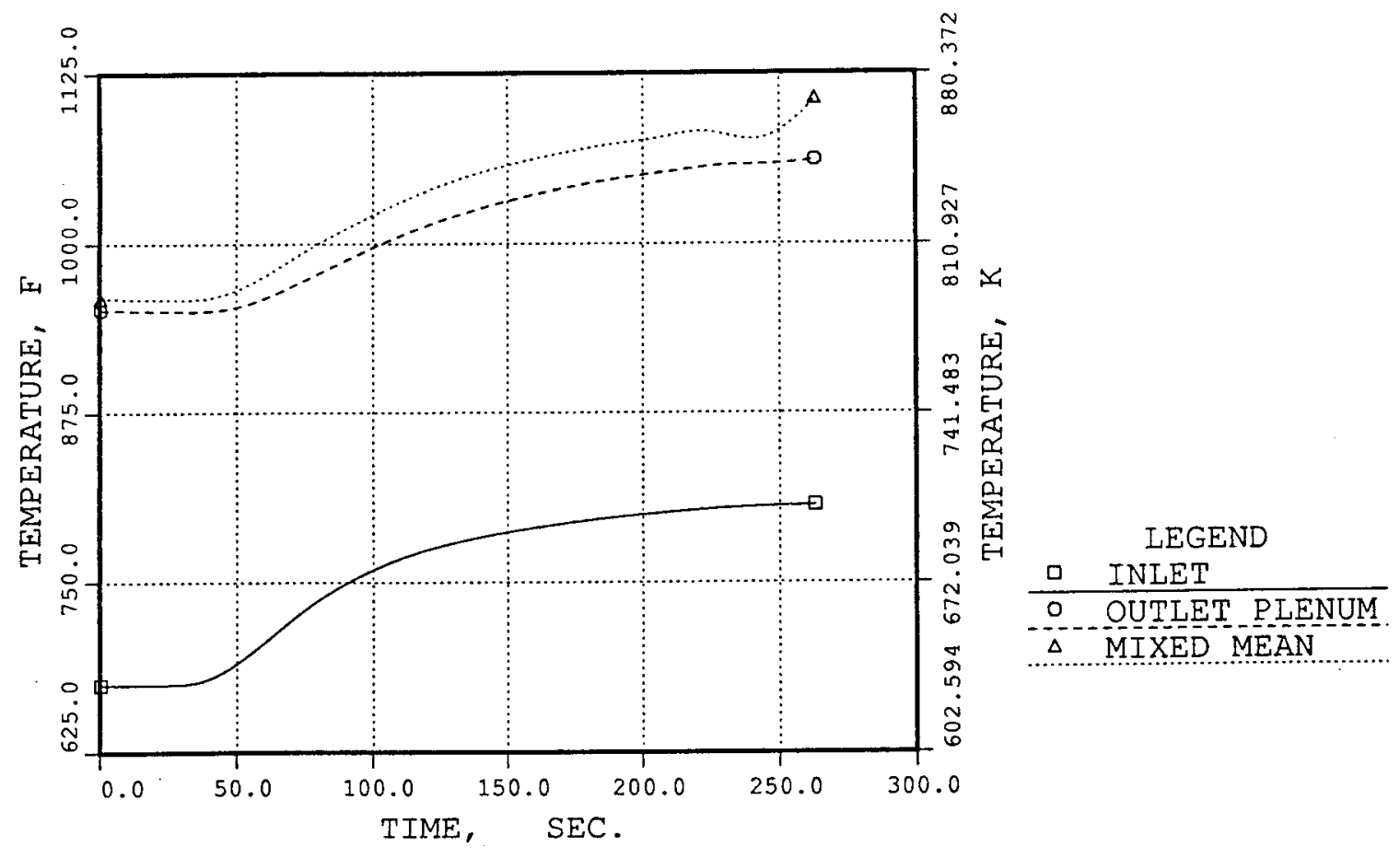

Fig. 6.2-25. No Rod PPS/PCS. 2 SG FW Valve Closure Reactor Core Temperatures

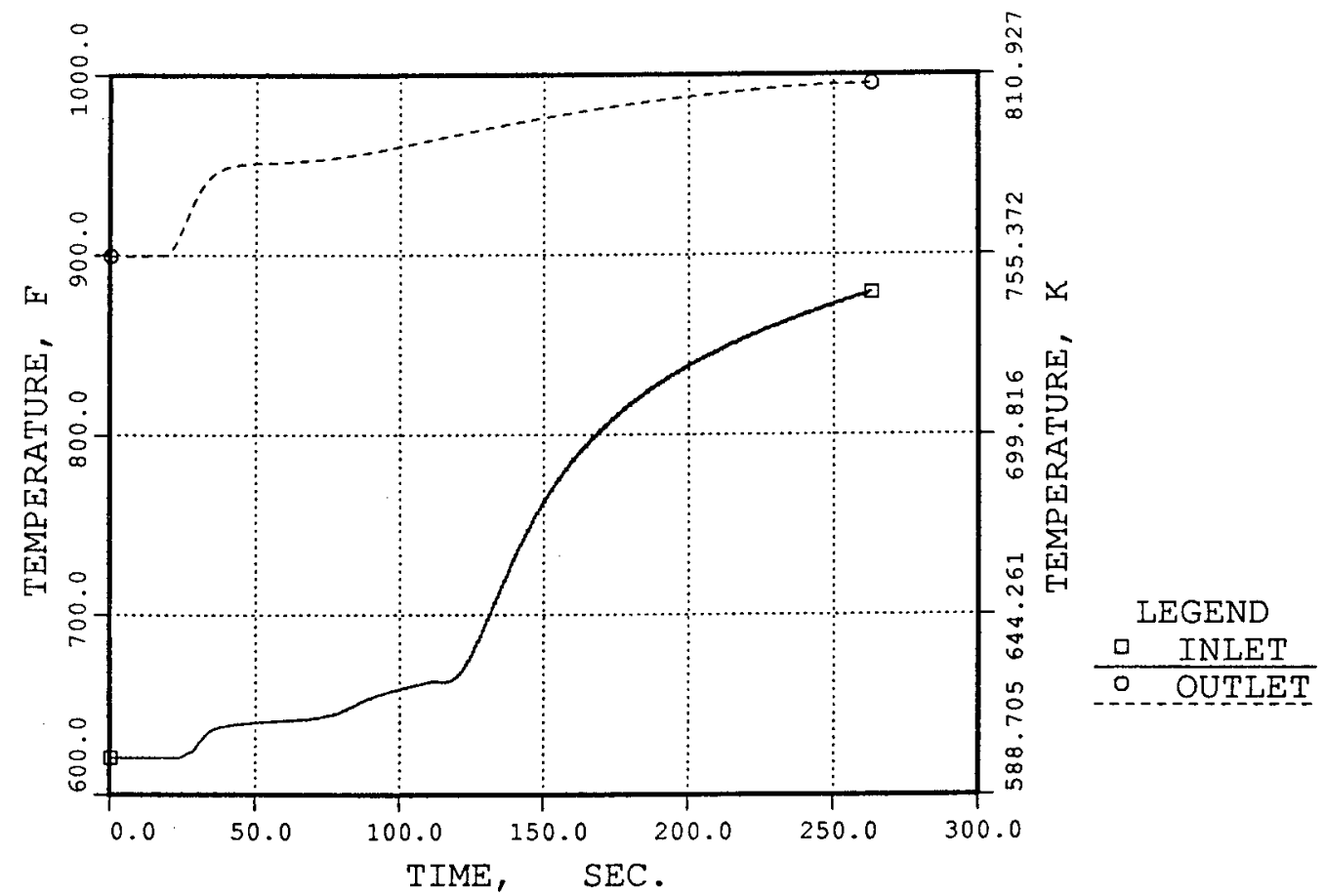

Fig. 6.2-26. No Rod PPS/PCS. 2 SG FW Valve Closure - IHX Intermediate Side Temperatures 


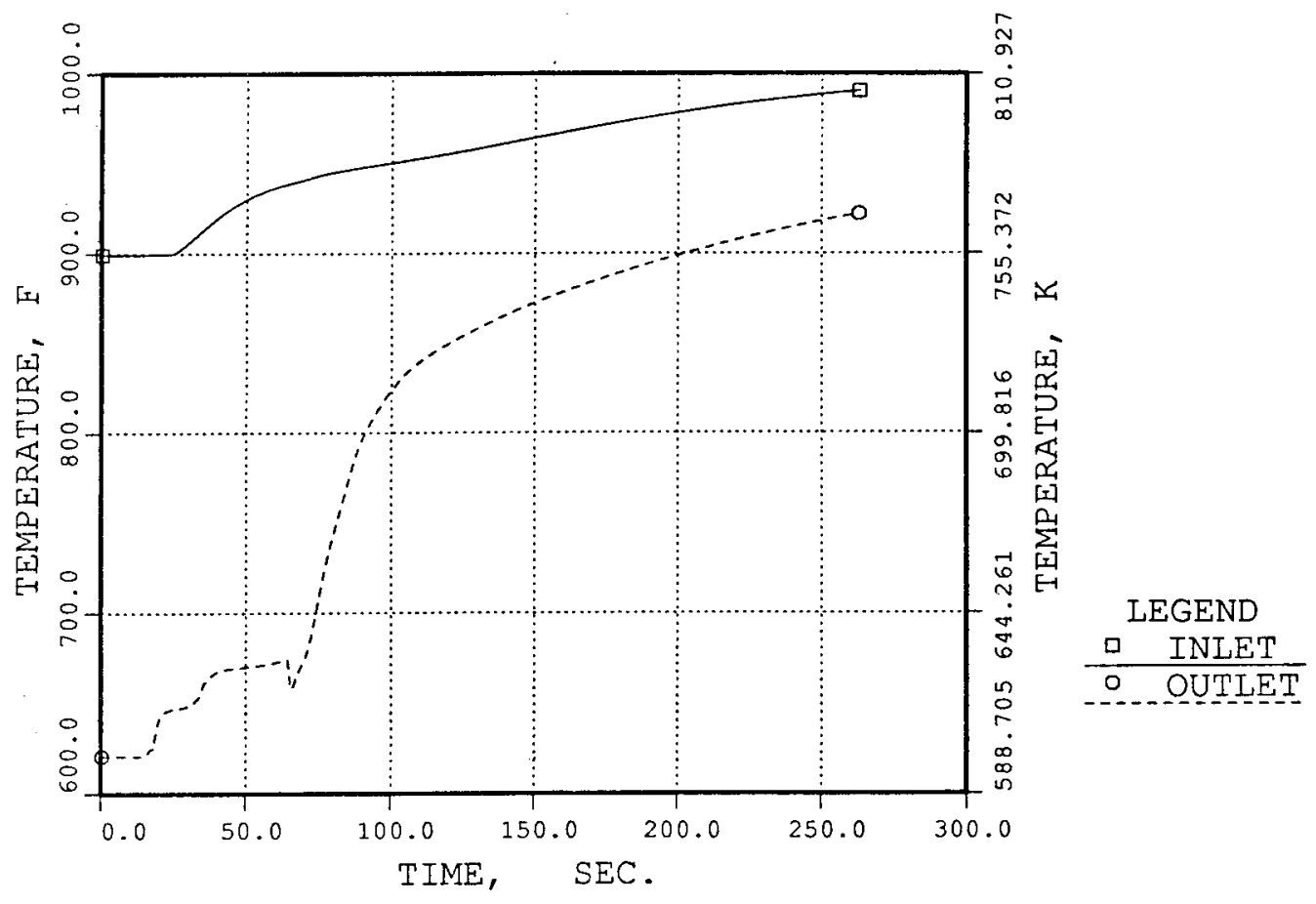

Fig. 6.2-27. No Rod PPS/PCS. 2 SG FW Valve Closure SG Sodium Temperatures

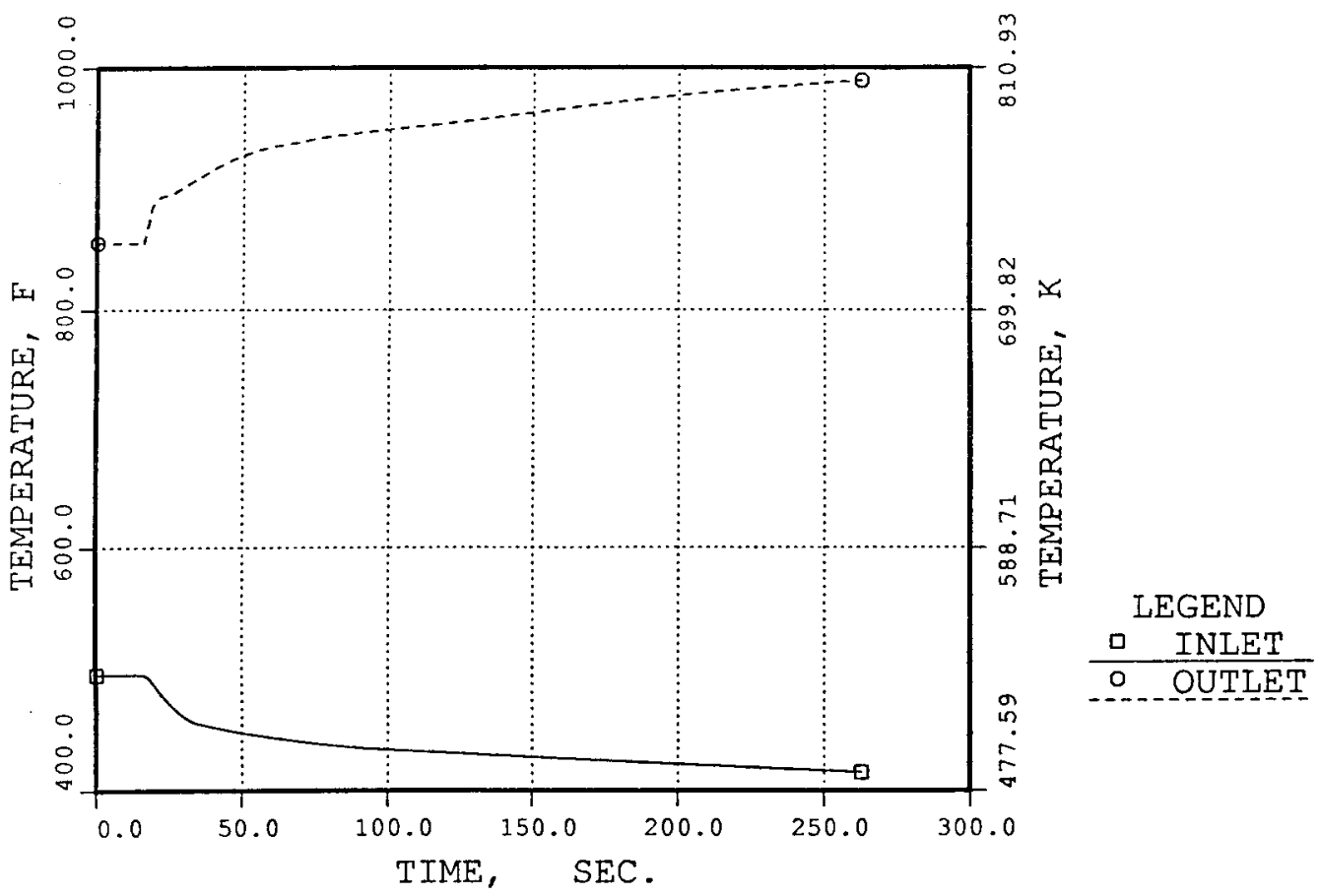

Fig. 6.2-28. No Rod PPS/PCS. 2 SG FW Valve Closure SG Water Temperatures 


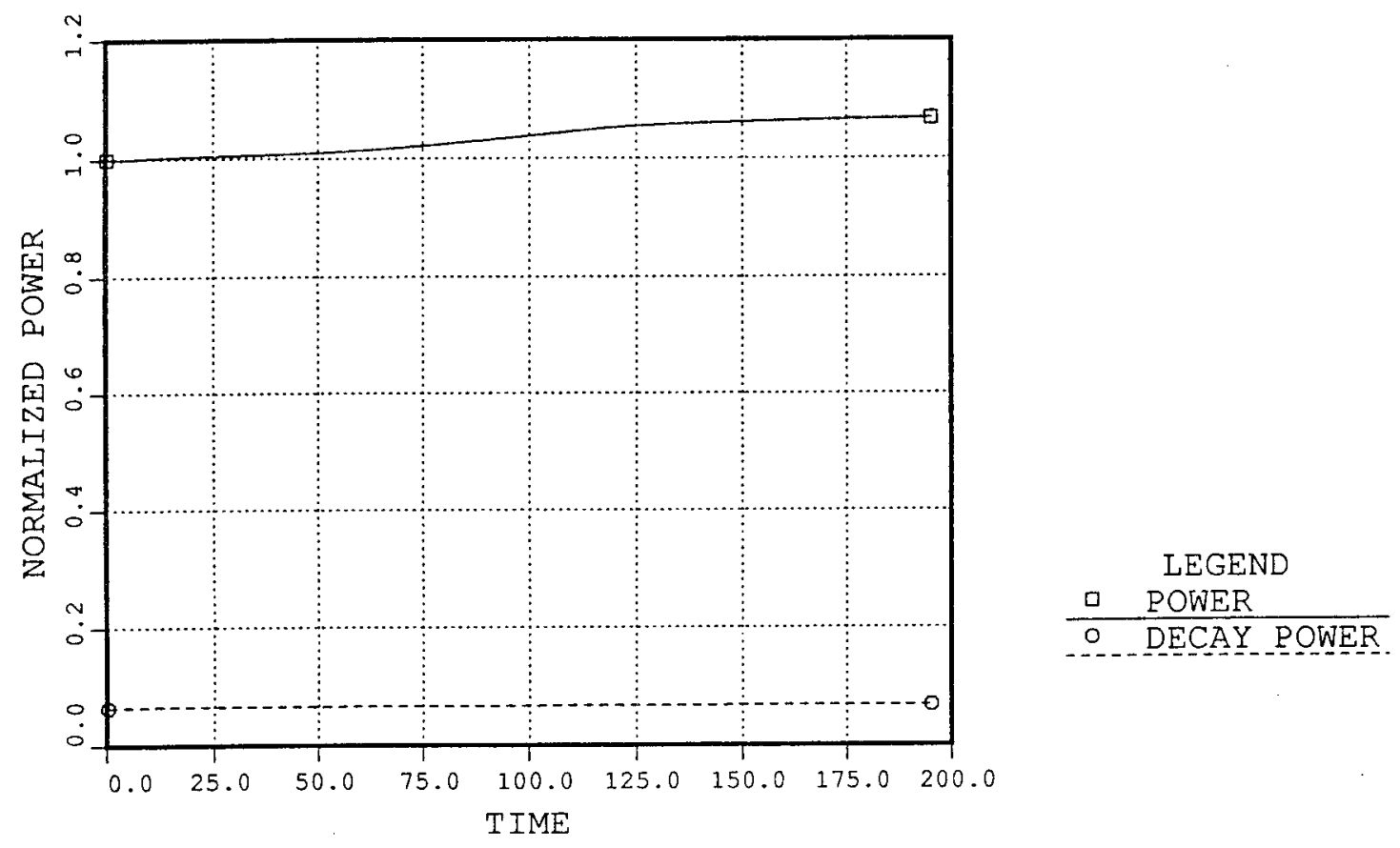

Fig. 6.2-29. No Rod PPS/PCS. 2 SG MFW Overfeed/No Sensor Reactor Power

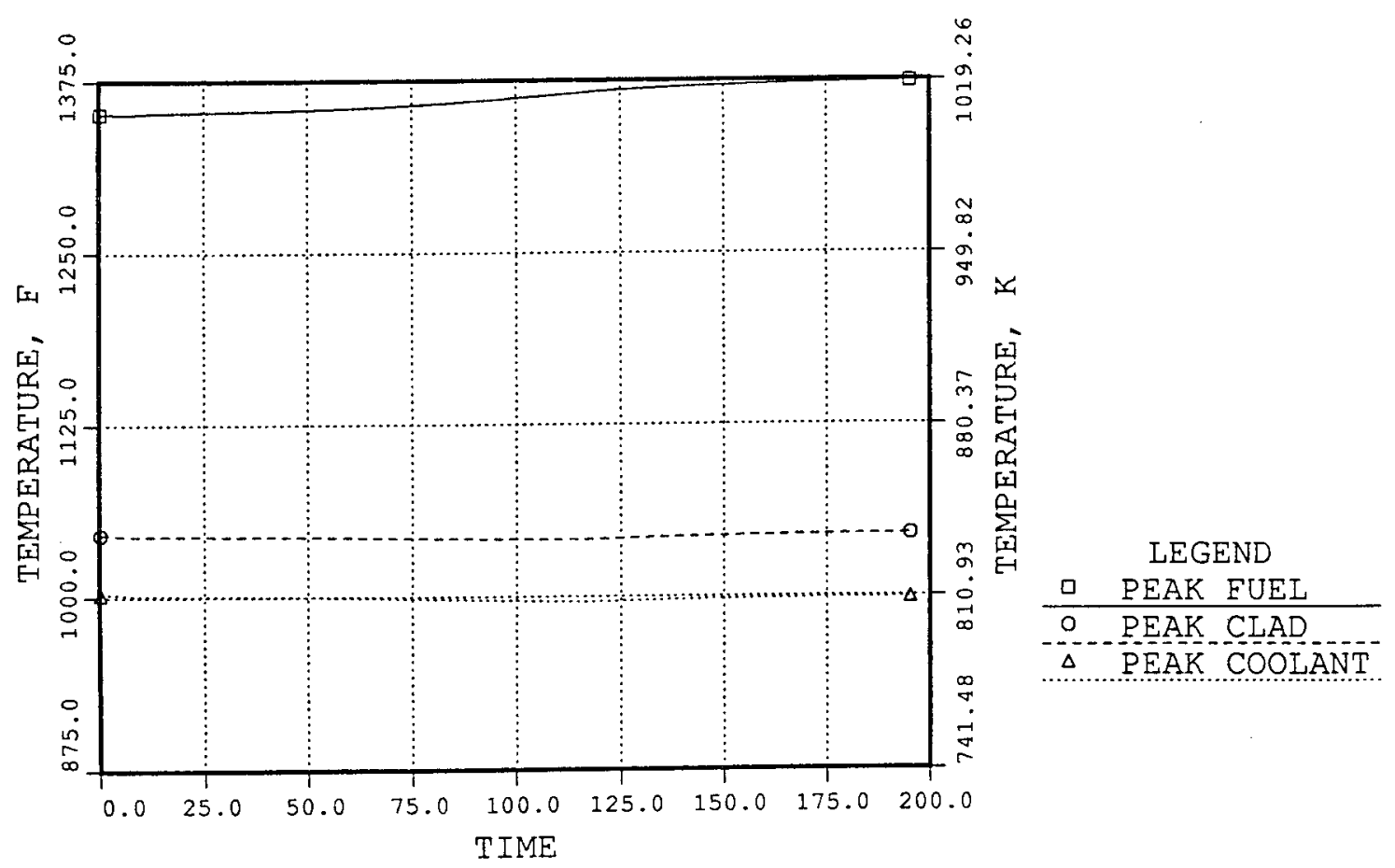

Fig. 6.2-30. No Rod PPS/PCS. 2 SG MFW Overfeed/No Sensor Channe 1 Peak Temperatures 


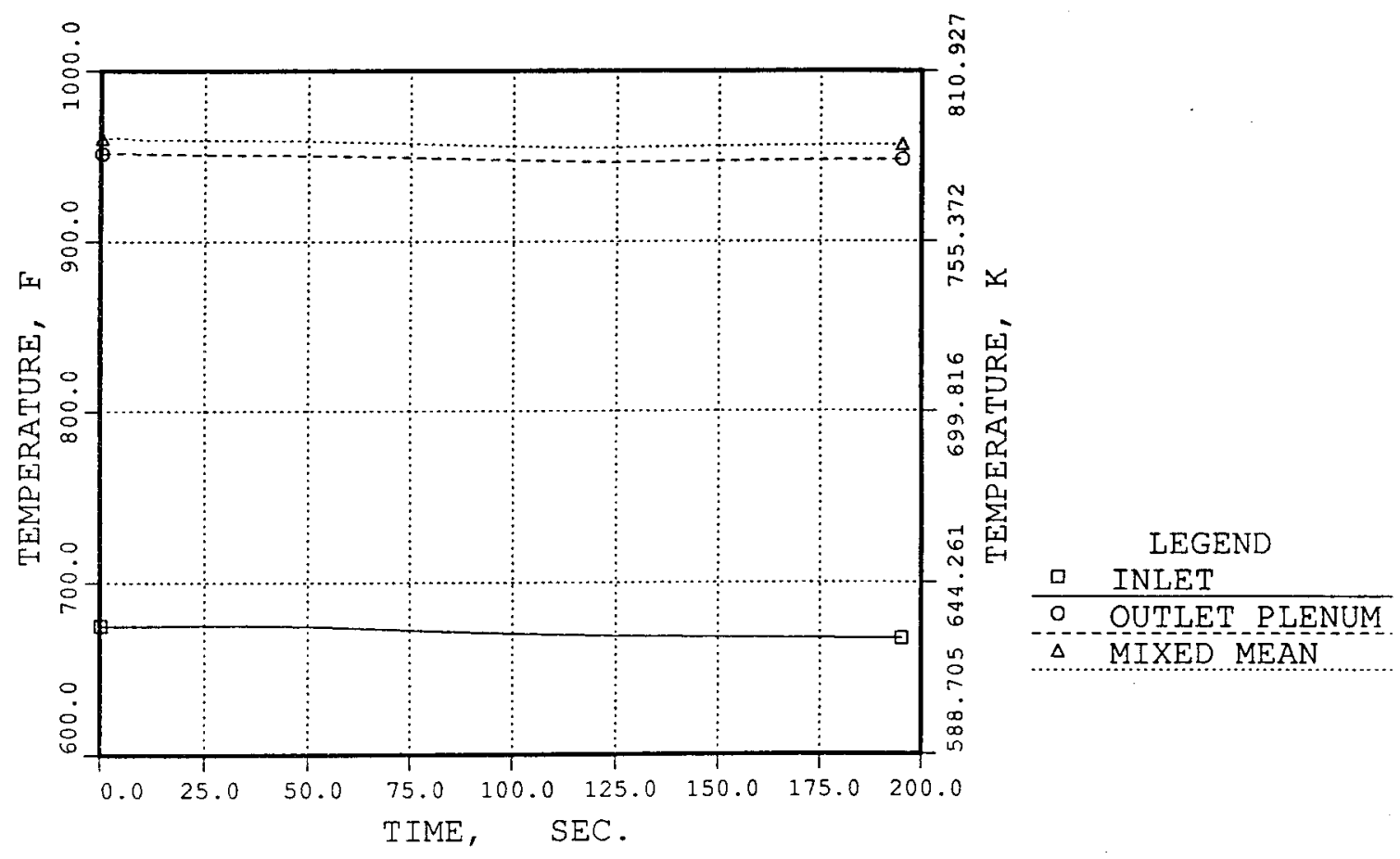

Fig. 6.2-31. No Rod PPS/PCS. 2 SG MFW Overfeed/No Sensor Reactor Core Temperatures

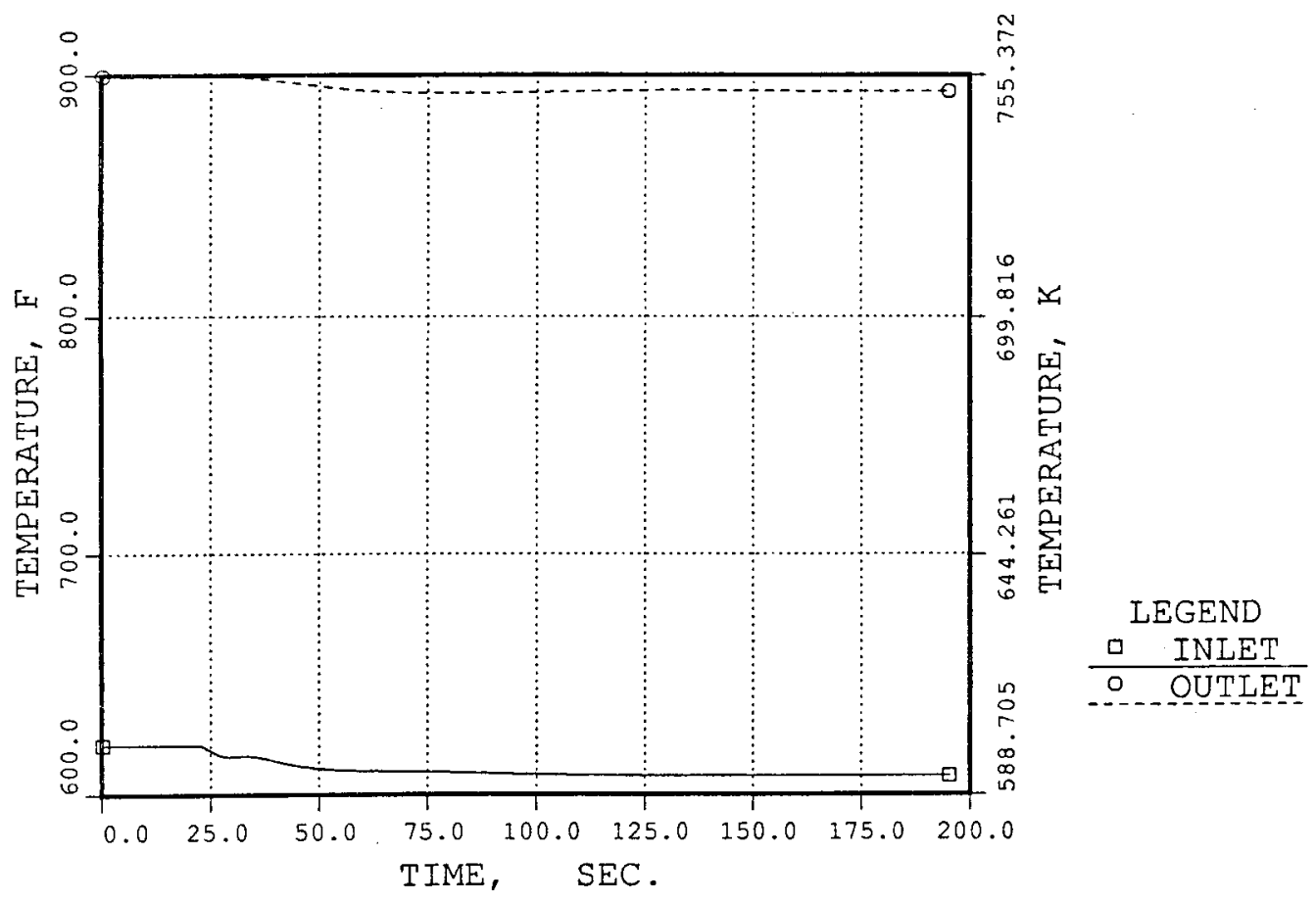

Fig. 6.2-32. No Rod PPS/PCS. 2 SG MFW Overfeed/No Sensor IHX Intermediate Side Temperatures 


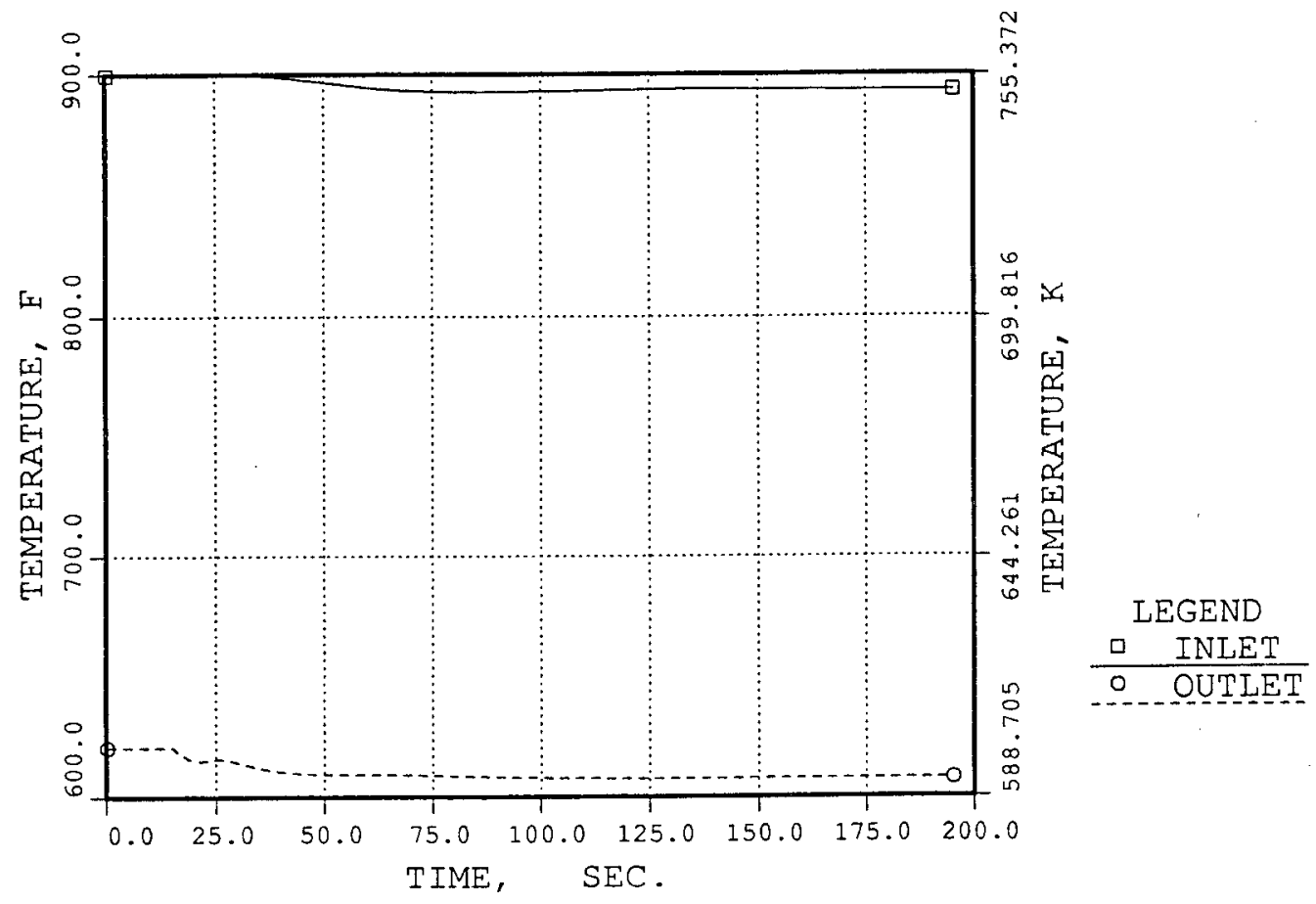

Fig. 6.2-33. No Rod PPS/PCS. 2 SG MFW Overfeed/No Sensor SG Sodium Temperatures

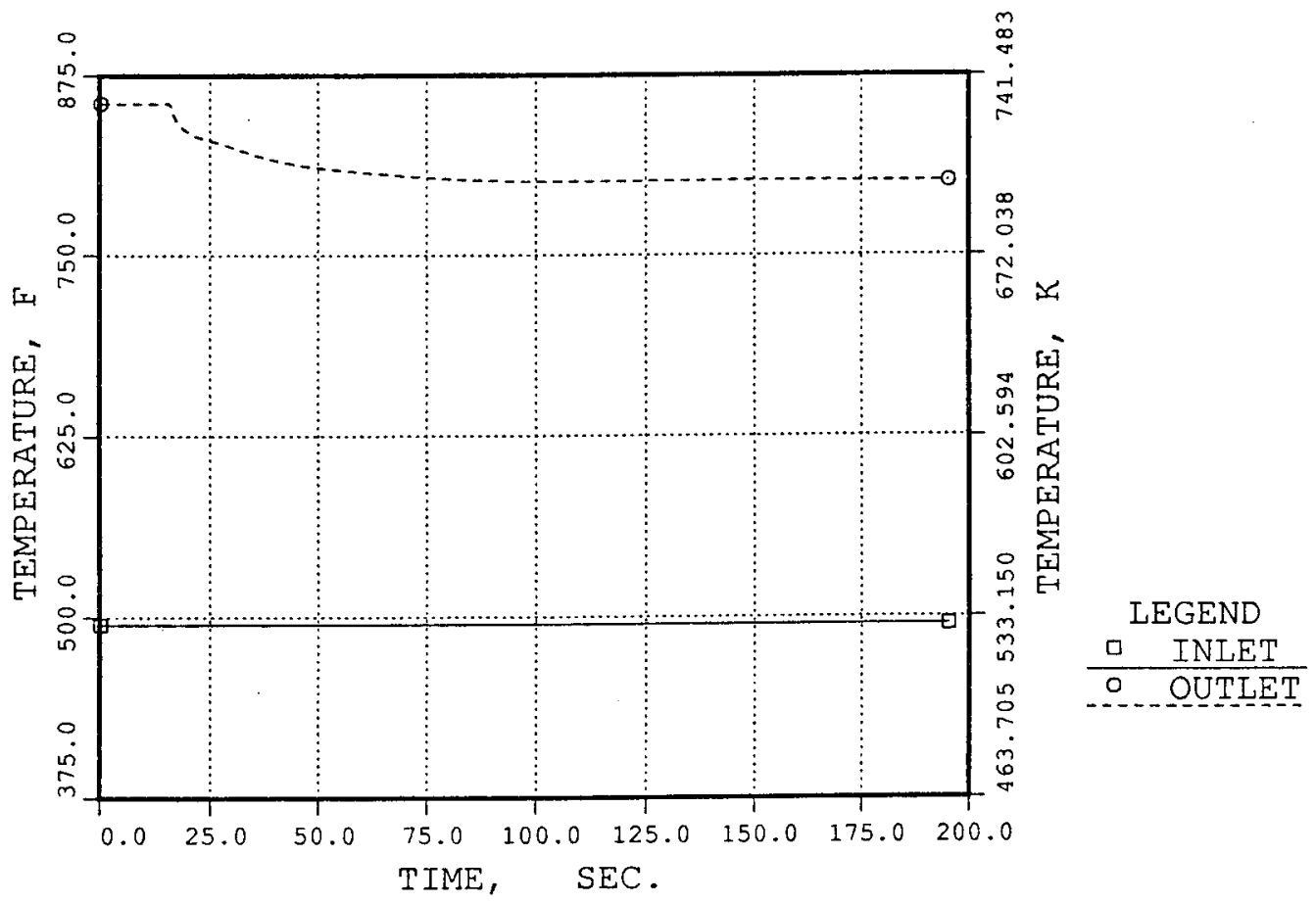

Fig. 6.2-34. No Rod PPS/PCS. 2 SG MFW Overfeed/No Sensor SG Water Temperatures 


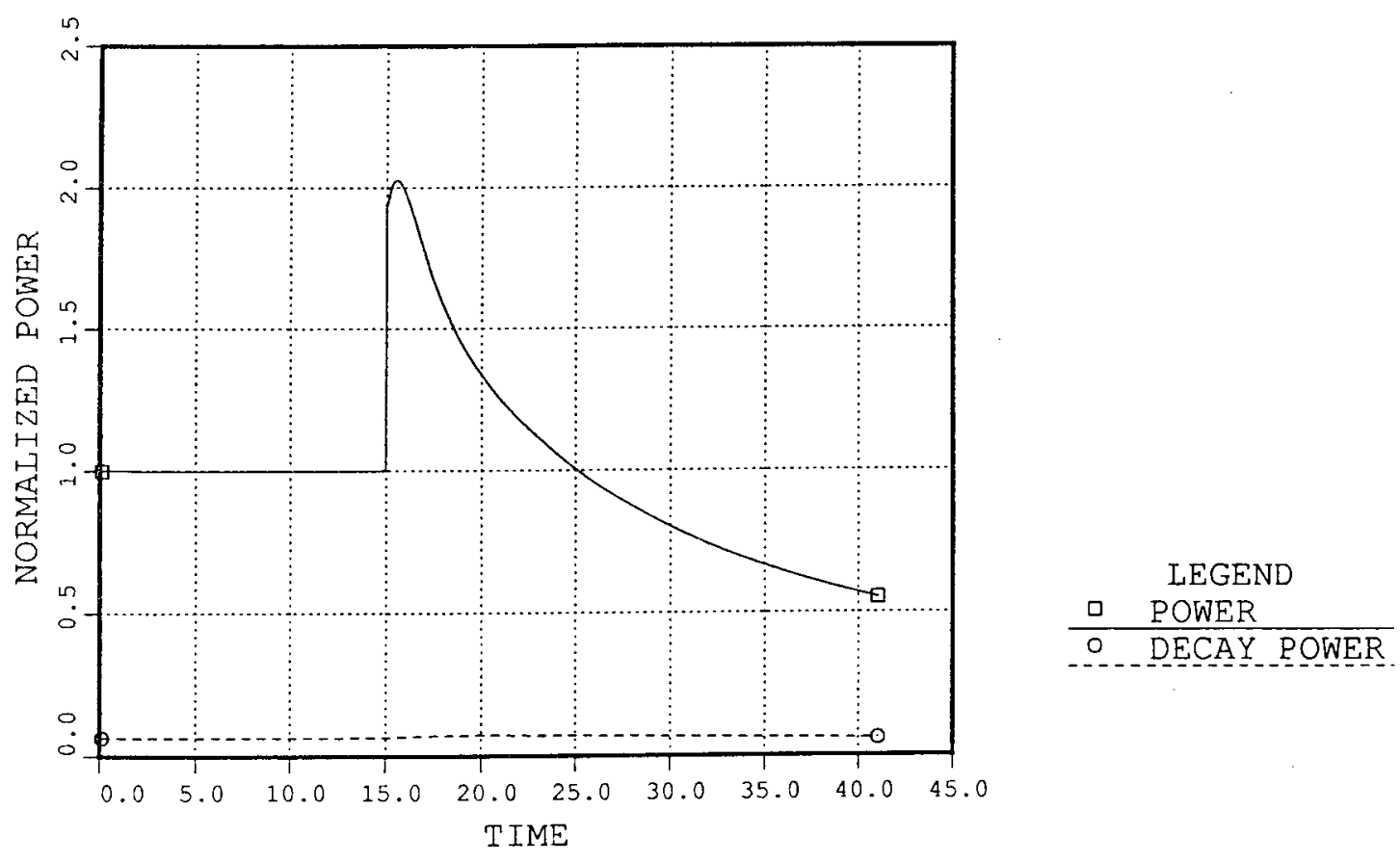

Fig. 6.2-35. No Rod PPS/PCS. SSE - Reactor Power

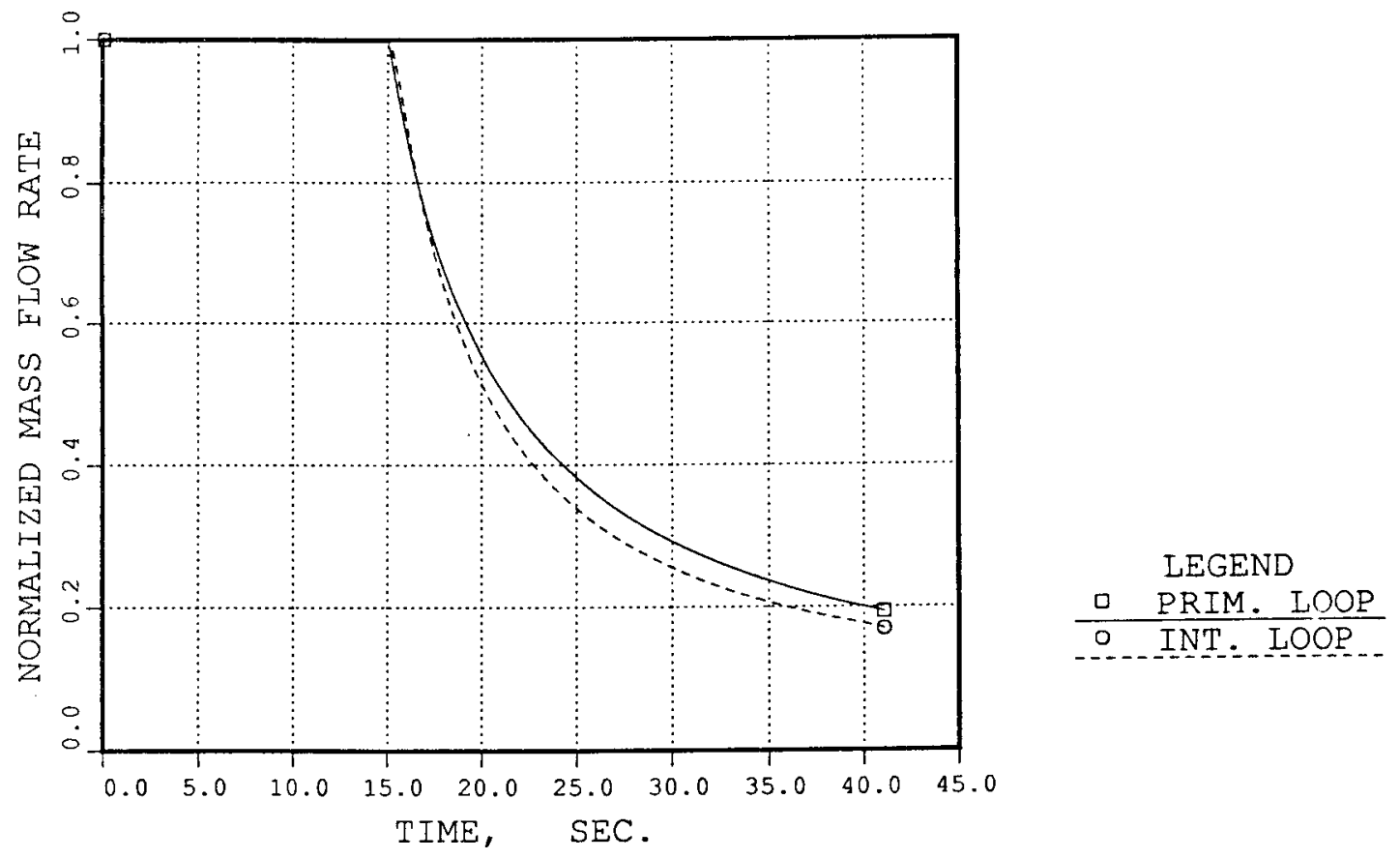

Fig. 6.2-36. No Rod PPS/PCS. SSE - Loop Flows 


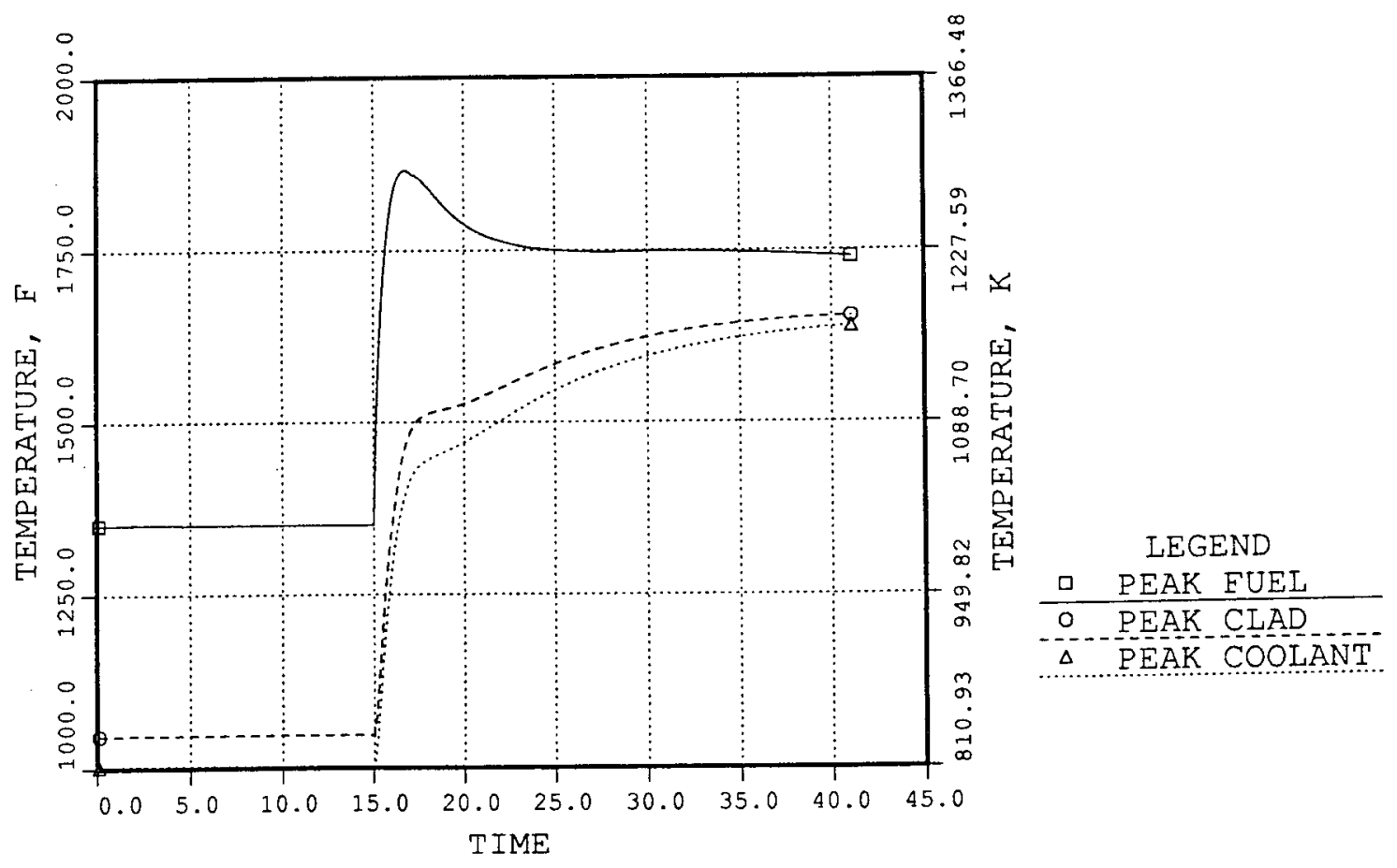

Fig. 6.2-37. No Rod PPS/PCS. SSE - Channel 1 Peak Temperatures

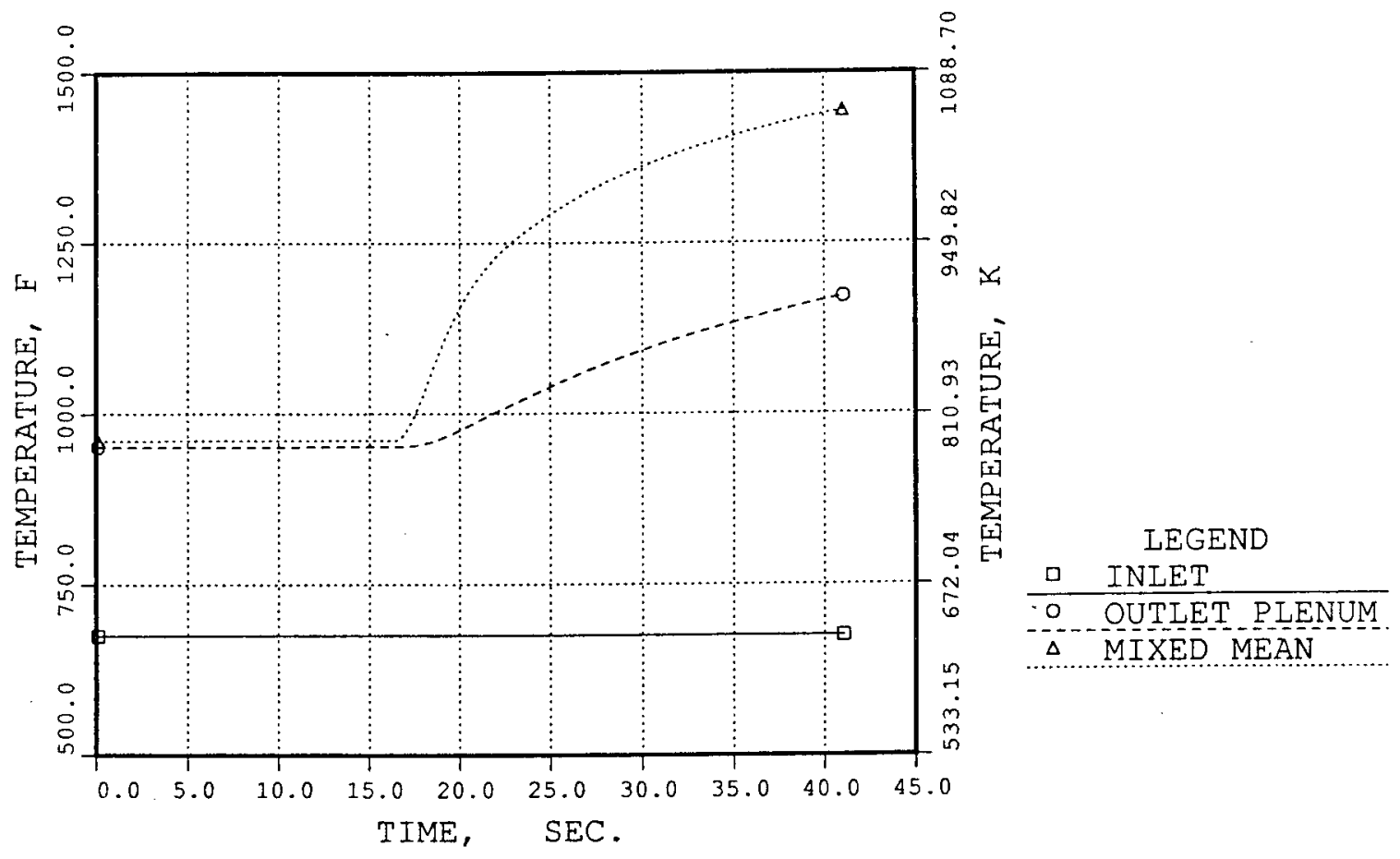

Fig. 6.2-38. No Rod PPS/PCS. SSE - Reactor Core Temperatures 


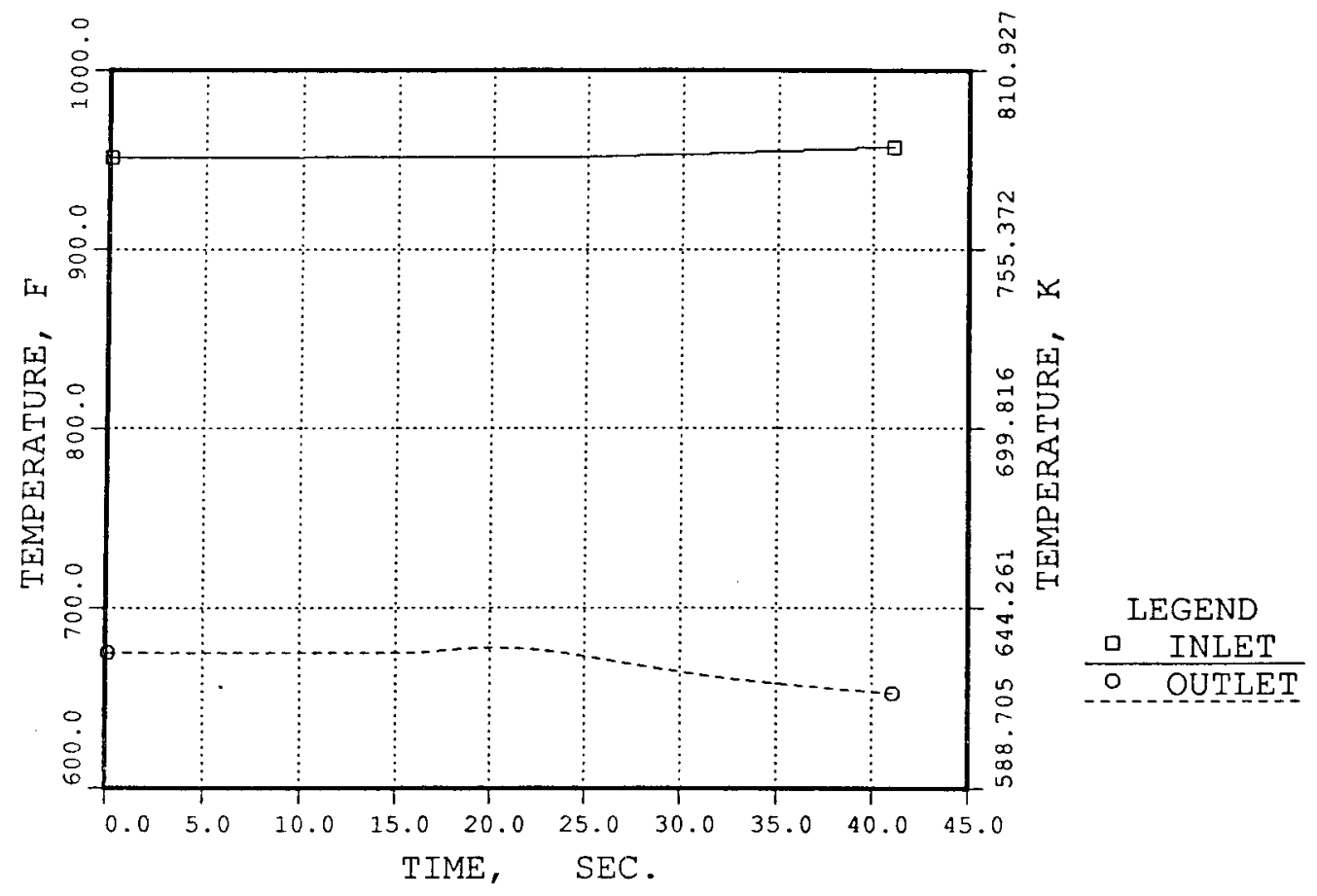

Fig. 6.2-39. No Rod PPS/PCS. SSE - IHX Primary Side Temperatures

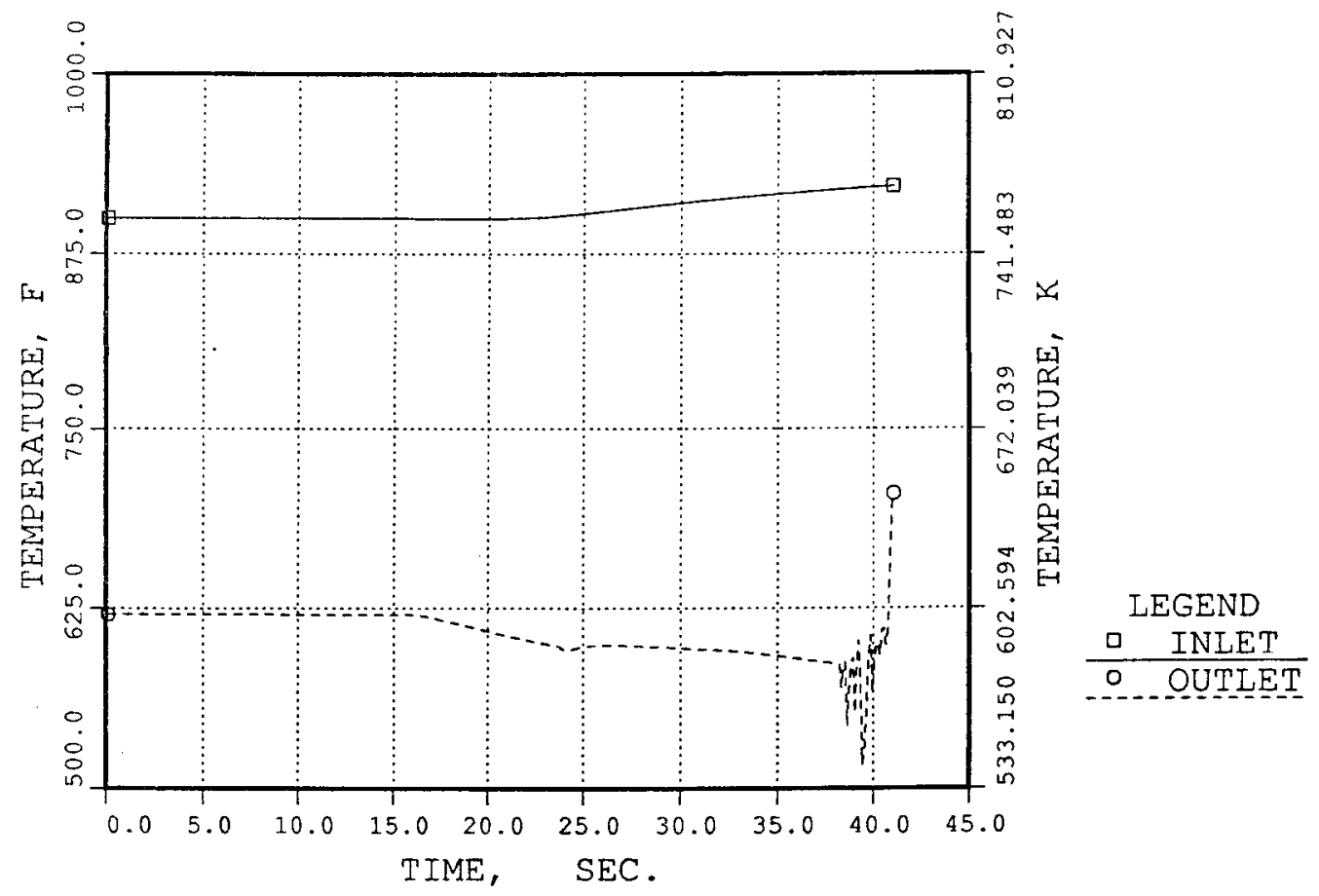

Fig. 6.2-40. No Rod PPS/PCS. SSE - SG Sodium Temperatures 